NISTIR 7198

\title{
Shop Data Model and Interface Specification
}

Charles McLean

Y. Tina Lee

Guodong Shao

Frank Riddick 
NISTIR 7198

\title{
Shop Data Model and Interface Specification
}

\author{
Charles McLean \\ Y. Tina Lee \\ Guodong Shao \\ Frank Riddick \\ Second Author \\ Manufacturing Systems Integration Division \\ Manufacturing Engineering Laboratory
}

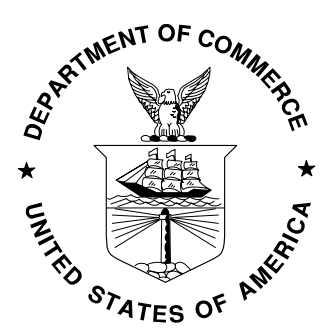

U.S. DEPARTMENT OF COMMERCE

Donald L. Evans, Secretary TECHNOLOGY ADMINISTRATION

Phillip J. Bond, Under Secretary of Commerce for Technology NATIONAL INSTITUTE OF STANDARDS AND TECHNOLOGY

Hratch G. Semerjian, Acting Director 


\section{PREFACE}

The High Performance Computing and Communication (HPCC) program was formally established by the High Performance Computing Act of 1991 (Public Law 102-194). The goal of this program is to accelerate the development of future generations of high performance computers and networks and the use of these resources in the government and throughout the U.S. economy. The National Institute of Standards and Technology's (NIST) System Integration of Manufacturing Applications (SIMA) program is the agency's coordinating focus for its HPCC activities, see [NIST 2003]. SIMA is addressing the information interface needs of the U.S. manufacturing community. The SIMA program focuses on:

- Defining, testing, and promoting standards for interoperability solutions, and

- Facilitating remote access to scientific and engineering data

This document presents an information model that provides neutral data interfaces for integrating machine shop software applications with simulation. The model is presented using the Unified Modeling Language (UML) and the eXtensible Markup Language (XML).

This draft information model is being transferred to the Core Manufacturing Simulation Data (CMSD) Product Development Group (PDG) of the Simulation Interoperability Standards Organization (SISO) [SISO 2005]. The model will be the strawman of the first product of the CMSD PDG. SISO focuses on facilitating simulation interoperability and component reuse across the Department of Defense, other government, and nongovernment applications. SISO originated over ten years ago with a small conference held 1989, called, "Interactive Networked Simulation for Training." One of the outcomes from the workshop of 60 participants was a concern that there was activity occurring in networked simulation, but that it was occurring in isolation. The group believed that if there were a means to exchange information between companies and groups that the technology would advance more rapidly. The group also believed that once the technology begins to stabilize then there would also be a need for standardization. The technology and the consensus of the community would be captured in the standards as networking or simulation technology matured.

The conferences soon developed into the Distributed Interactive Simulation (DIS) Workshops and in late 1996, in light of the development of the High Level Architecture (HLA), the DIS organization transformed itself into a more functional organization called SISO. Subsequently, on 19 November 2003, the IEEE Computer Society Standards Activities Board voted unanimously to grant the SISO Standards Activities Committee (SAC) status as a recognized IEEE Sponsor Committee. The ultimate result is a single body for creating and promoting interoperability standards in the modeling and simulation community. 
Work described in this paper was sponsored by the NIST Systems Integration for Manufacturing Applications (SIMA) and the Software Engineering Institute's (SEI) Technology Insertion, Demonstration, and Evaluation (TIDE) Program. SIMA supports NIST projects applying information technologies and standards-based approaches to manufacturing software integration problems. TIDE is sponsored by the Department of Defense and Software Engineering Institute. No approval or endorsement of any commercial product by the National Institute of Standards and Technology is intended or implied. The work described was funded by the United States Government and is not subject to copyright. 


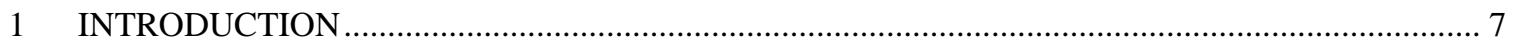

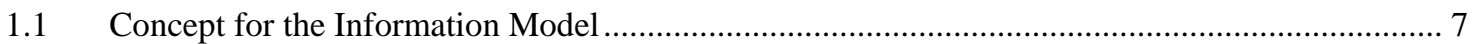

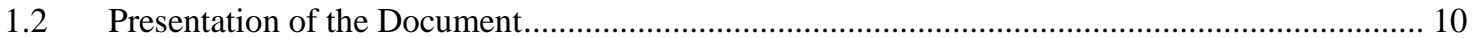

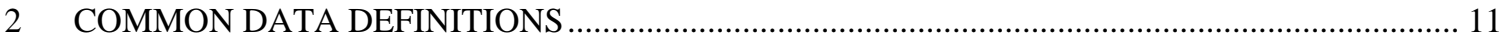

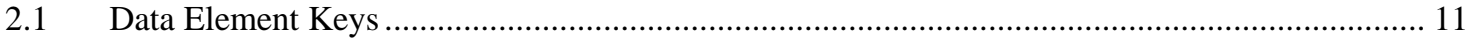

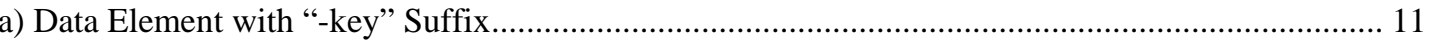

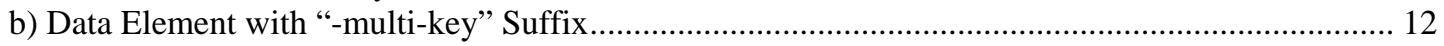

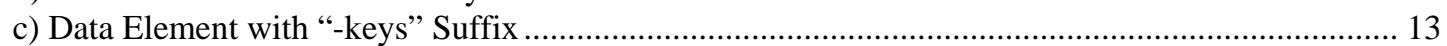

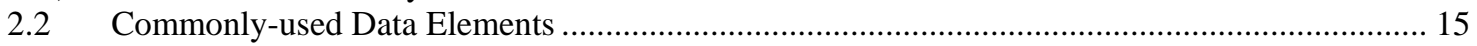

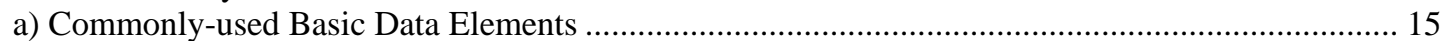

b) Common-used Data Elements with Prefixes/Suffixes....................................................................... 15

2.3 Commonly-Used Complex Data Elements ................................................................................. 16

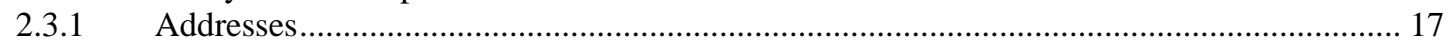

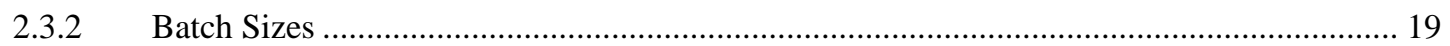

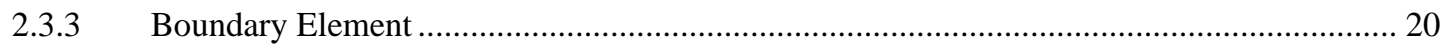

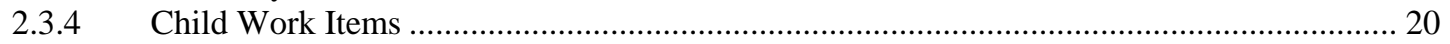

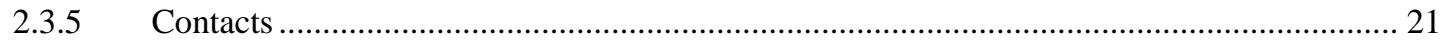

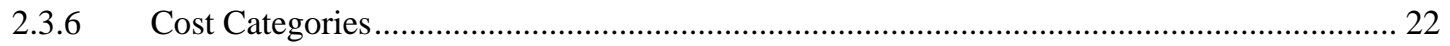

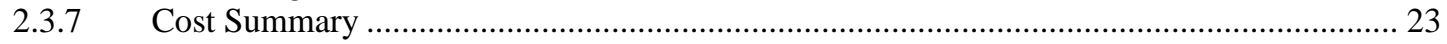

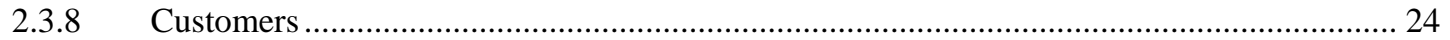

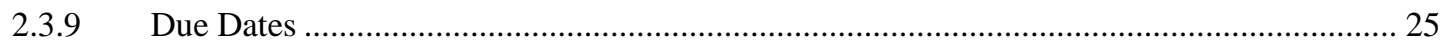

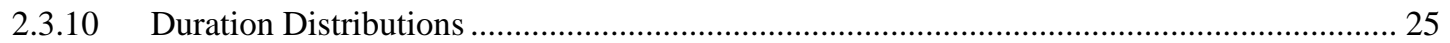

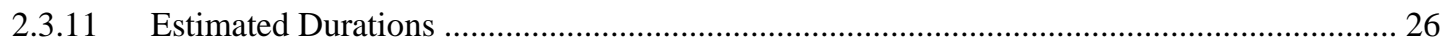

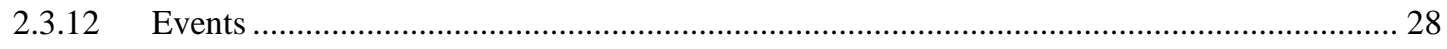

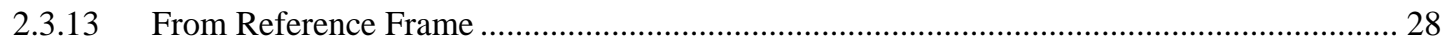

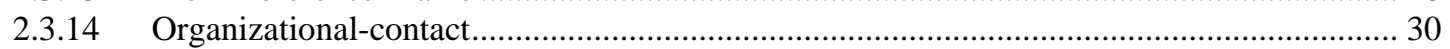

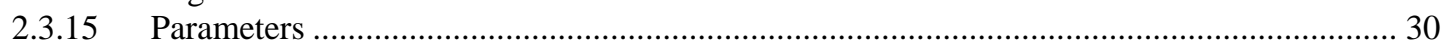

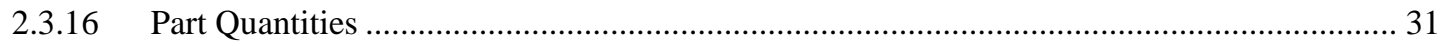

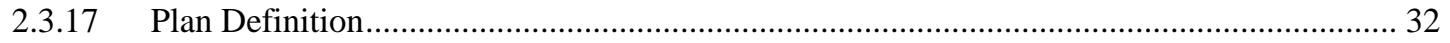

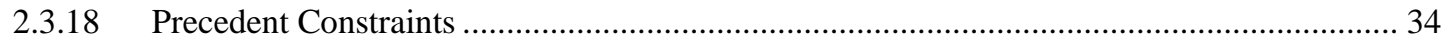

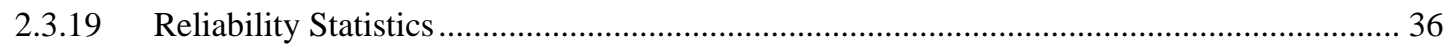

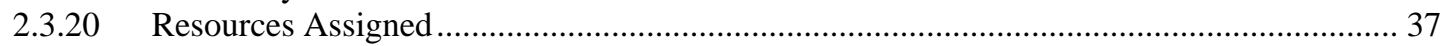

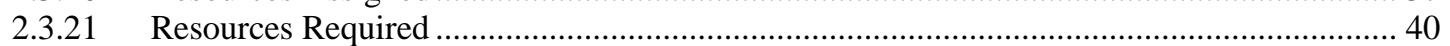

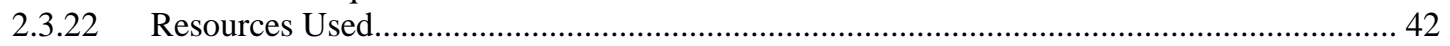

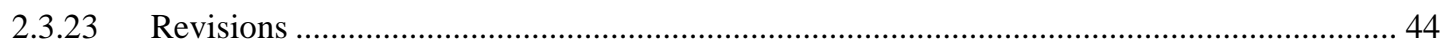

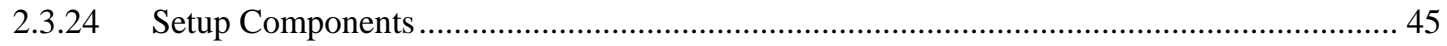

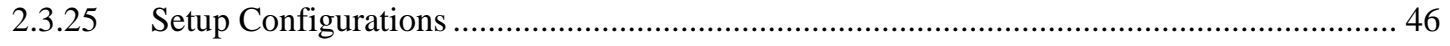

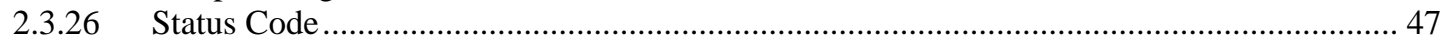

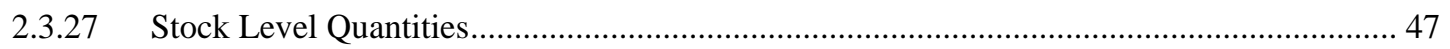

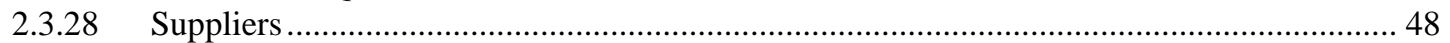

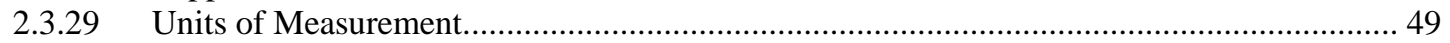

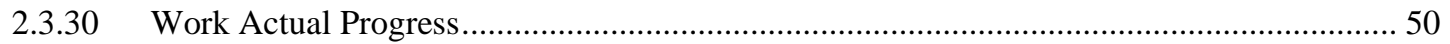

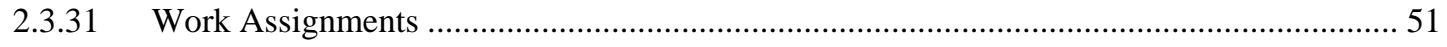

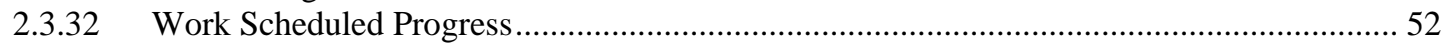

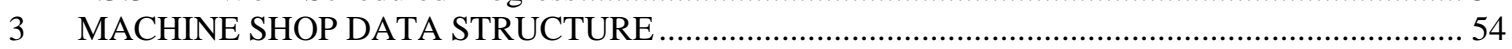

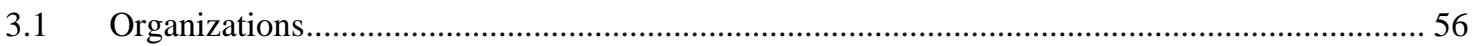

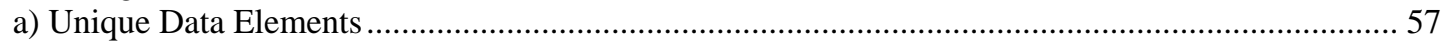

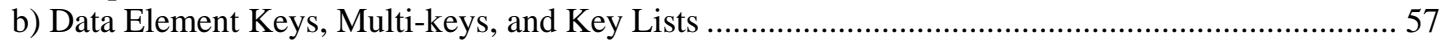

c) Common Data Elements.............................................................................................................. 57

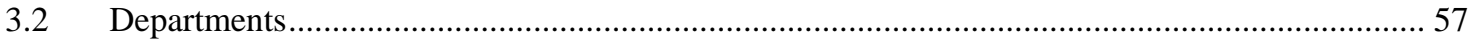

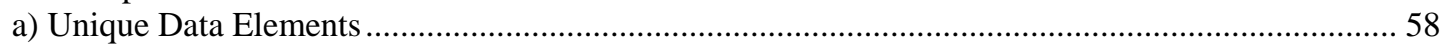

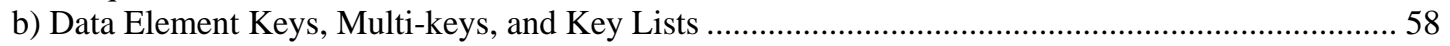

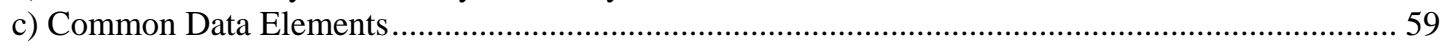

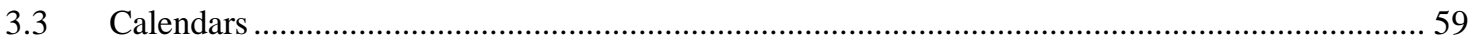

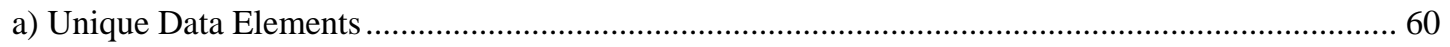




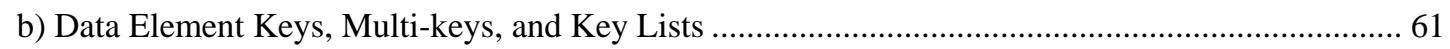

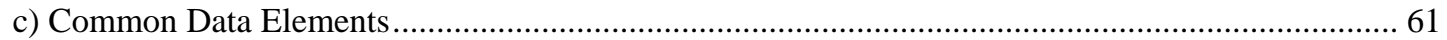

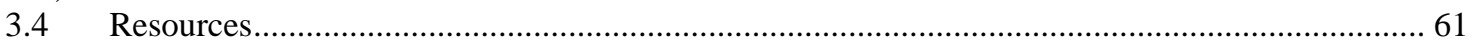

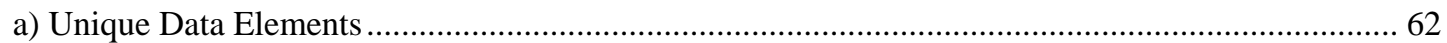

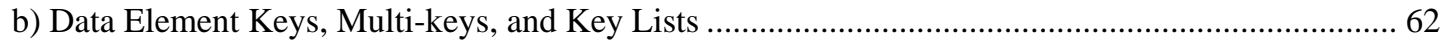

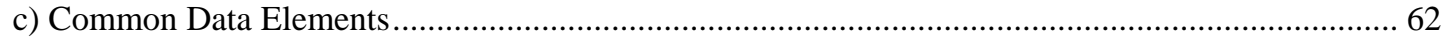

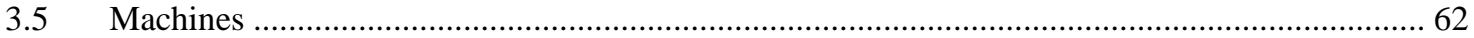

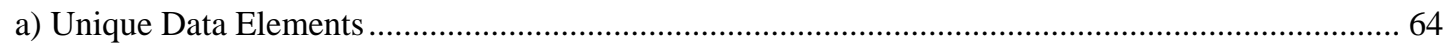

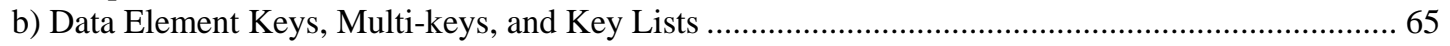

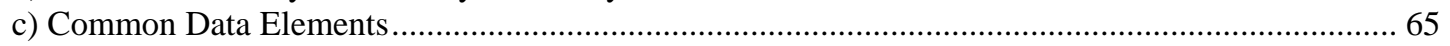

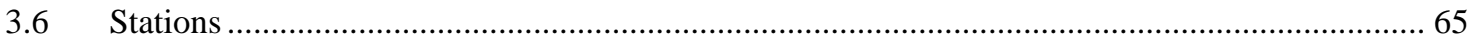

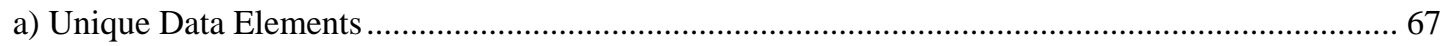

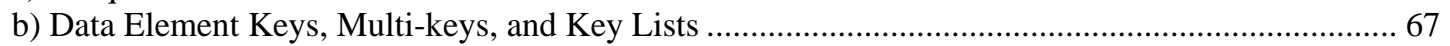

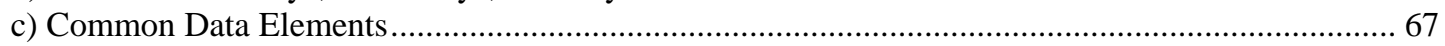

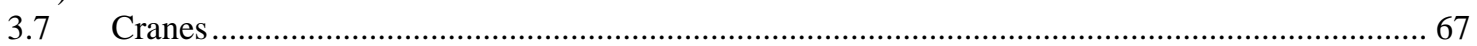

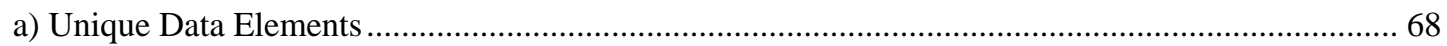

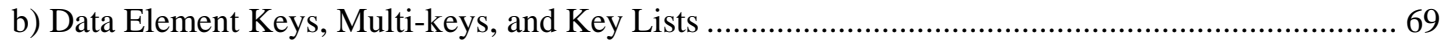

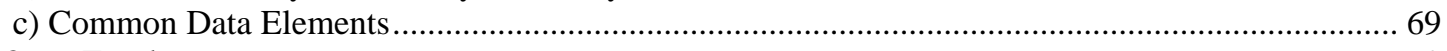

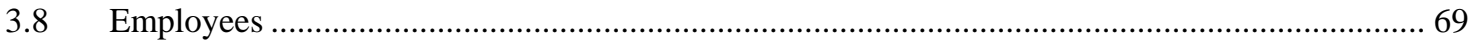

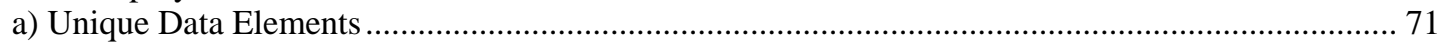

b) Data Element Keys, Multi-keys, and Key Lists ........................................................................ 71

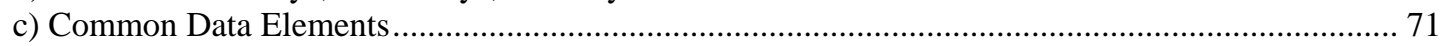

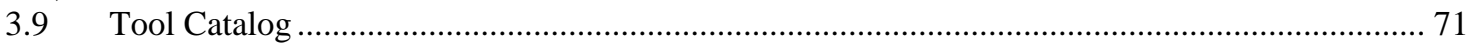

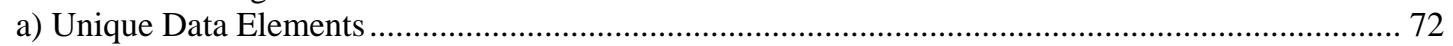

b) Data Element Keys, Multi-keys, and Key Lists ............................................................................... 72

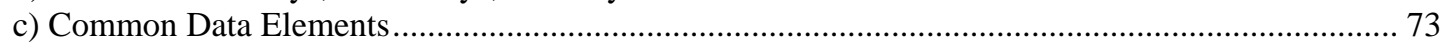

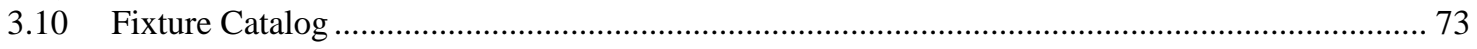

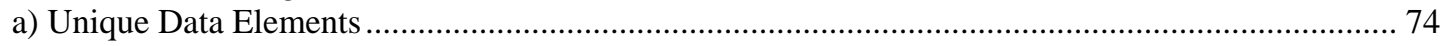

b) Data Element Keys, Multi-keys, and Key Lists .............................................................................. 74

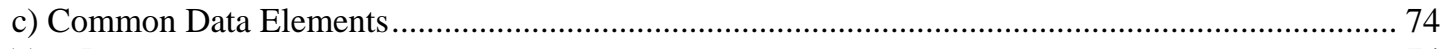

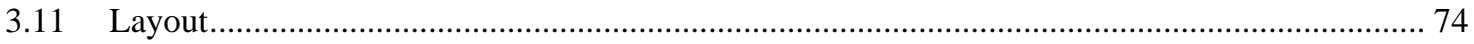

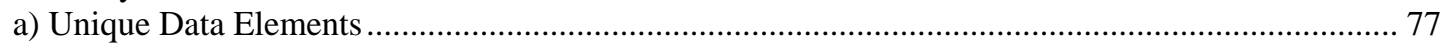

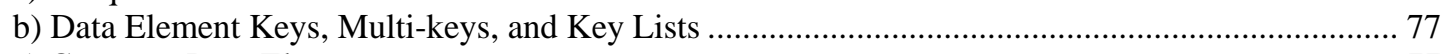

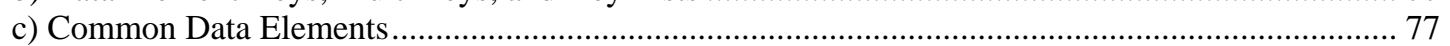

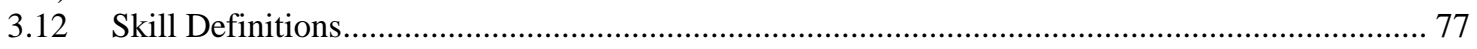

a) Unique Data Elements ......................................................................................................... 78

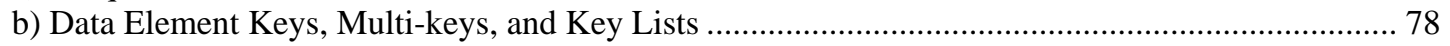

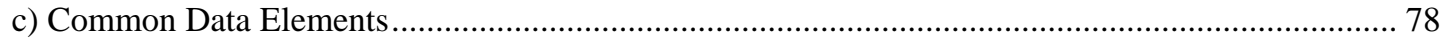

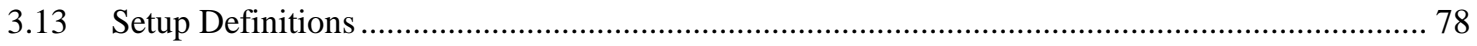

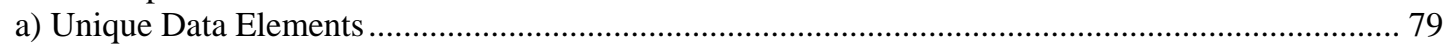

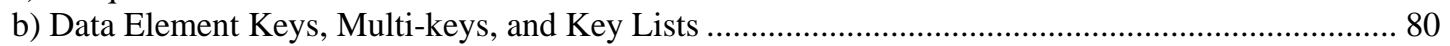

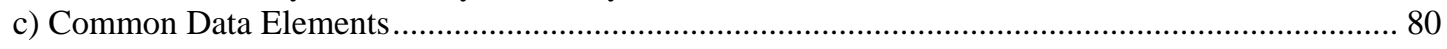

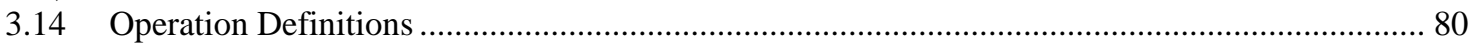

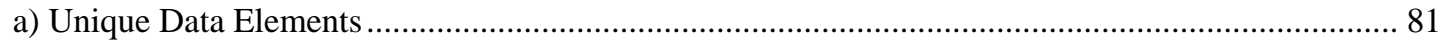

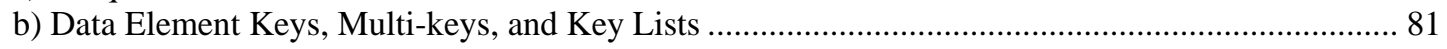

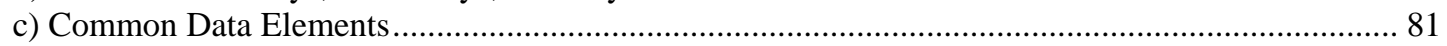

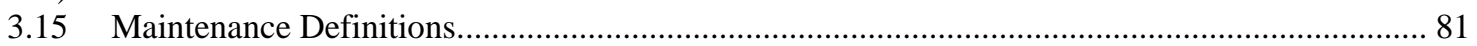

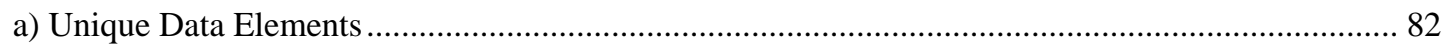

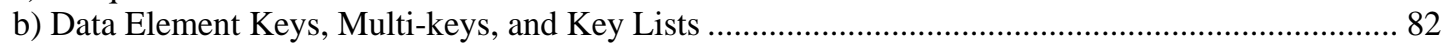

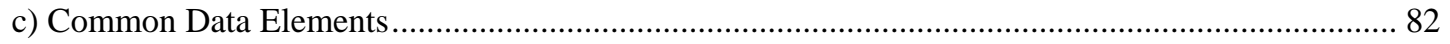

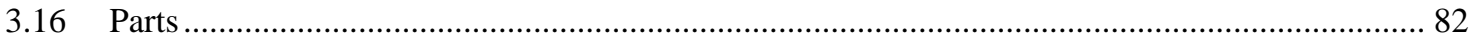

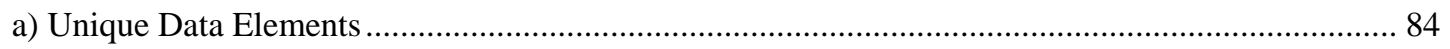

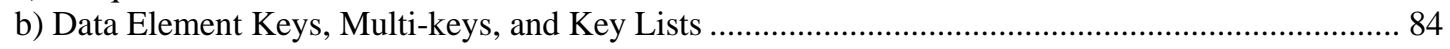

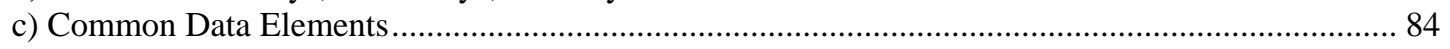

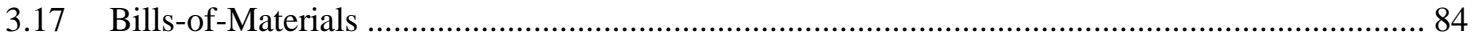

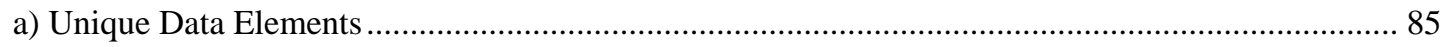




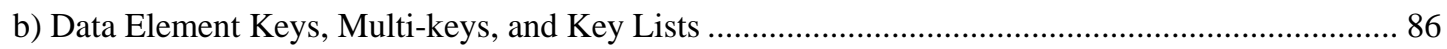

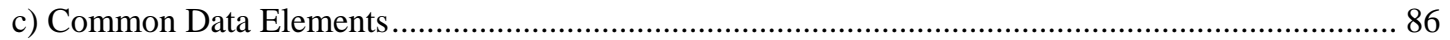

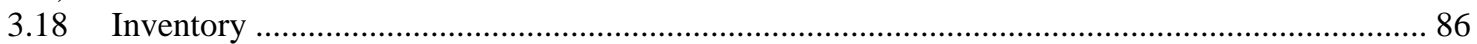

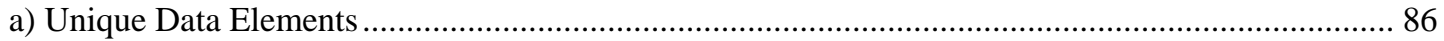

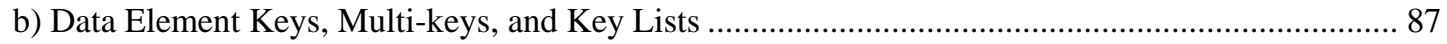

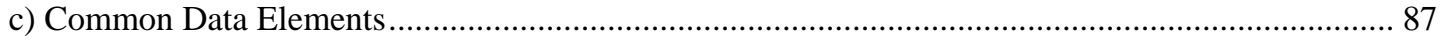

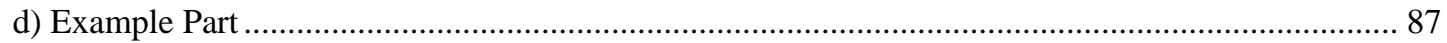

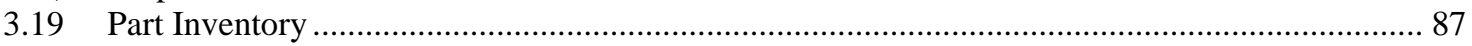

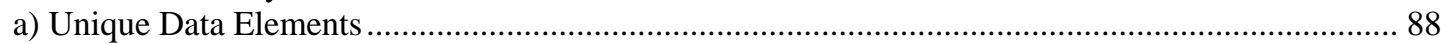

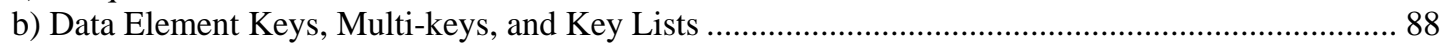

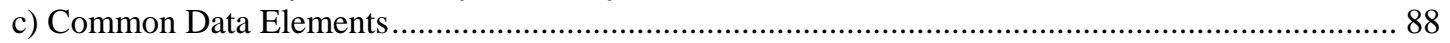

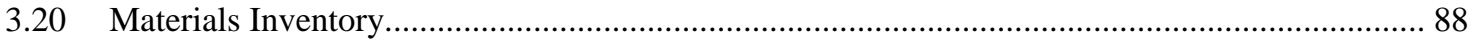

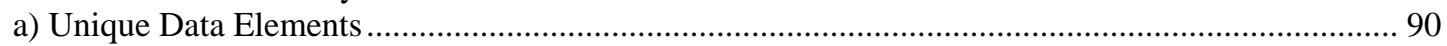

b) Data Element Keys, Multi-keys, and Key Lists ............................................................................... 90

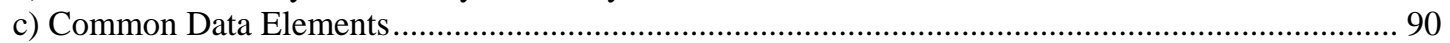

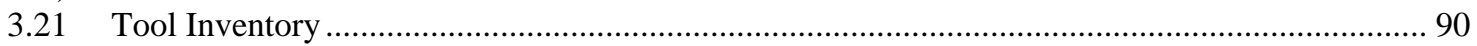

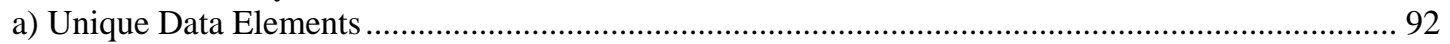

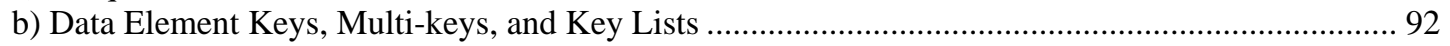

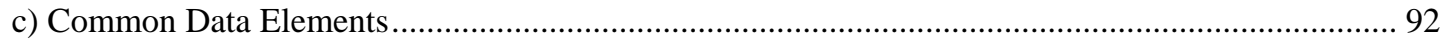

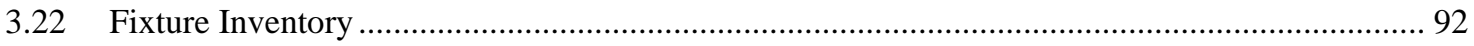

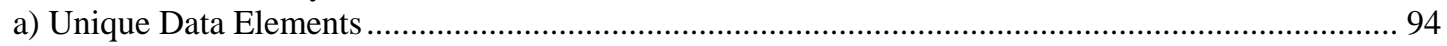

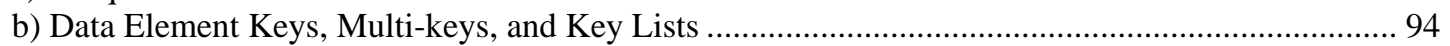

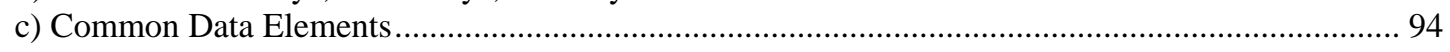

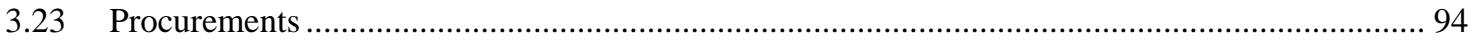

a) Unique Data Elements ............................................................................................................. 96

b) Data Element Keys, Multi-keys, and Key Lists ............................................................................... 96

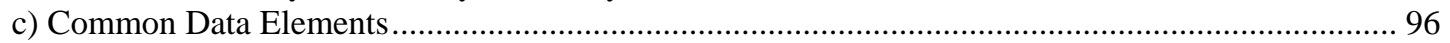

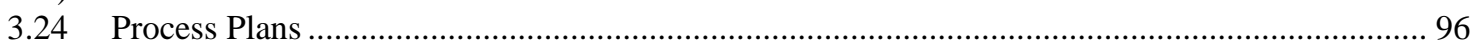

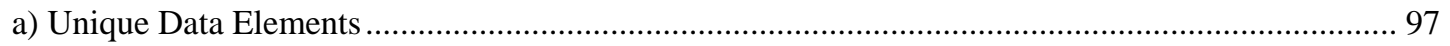

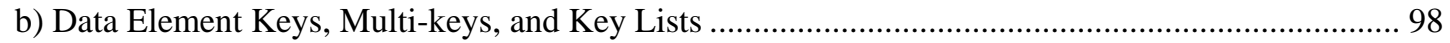

c) Common Data Elements........................................................................................................... 98

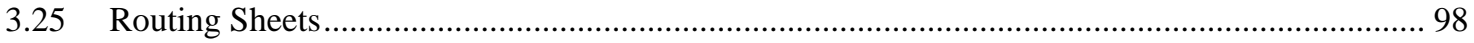

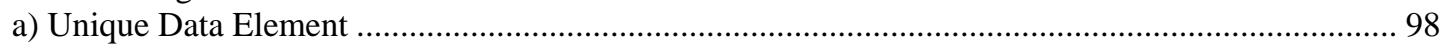

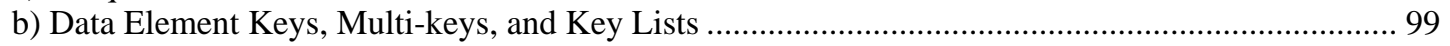

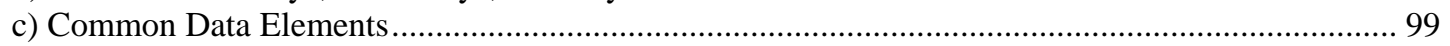

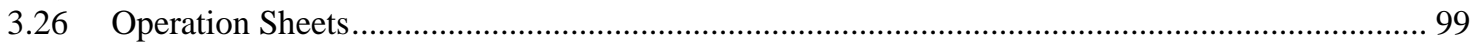

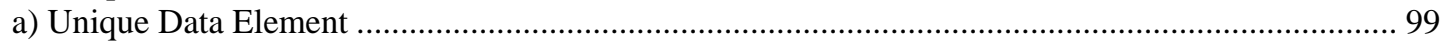

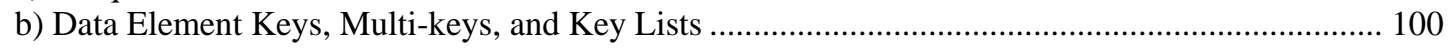

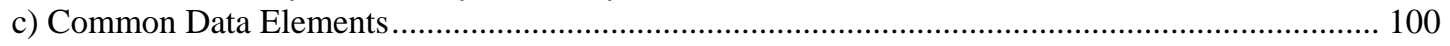

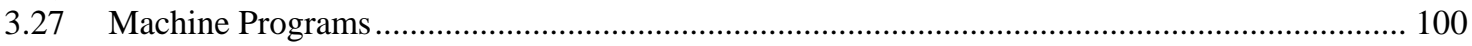

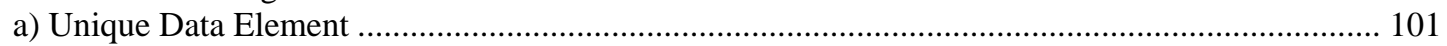

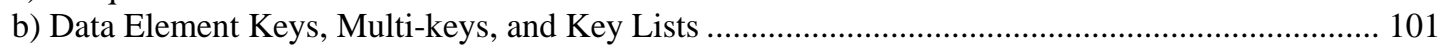

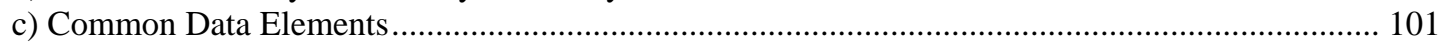

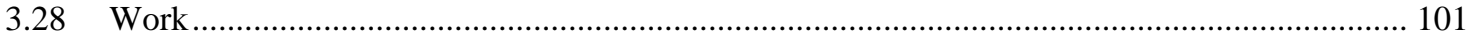

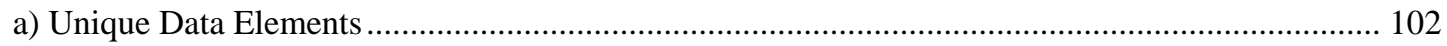

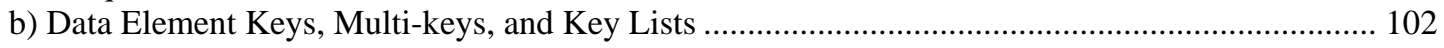

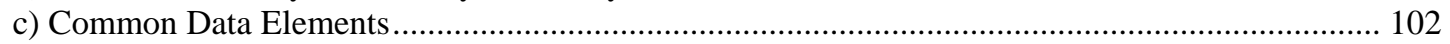

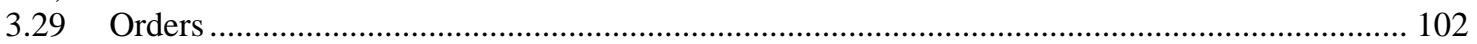

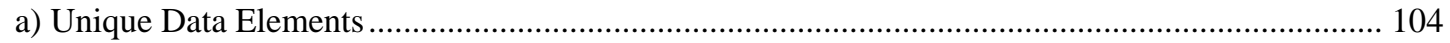

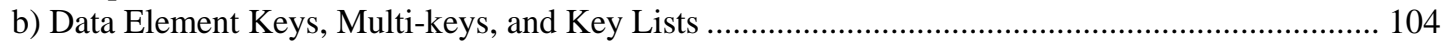

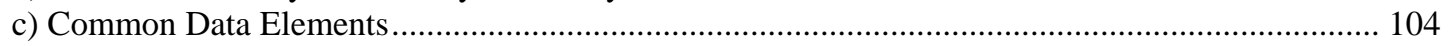

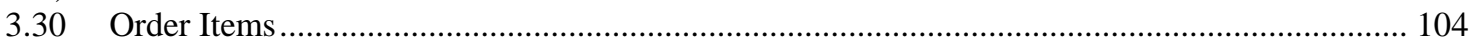

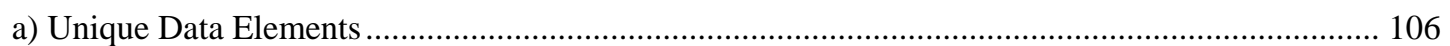

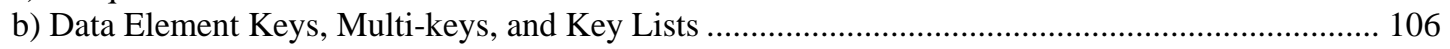

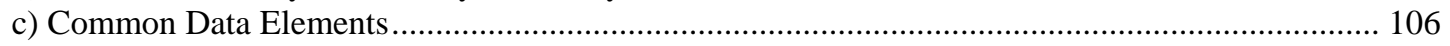

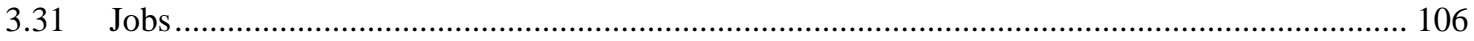




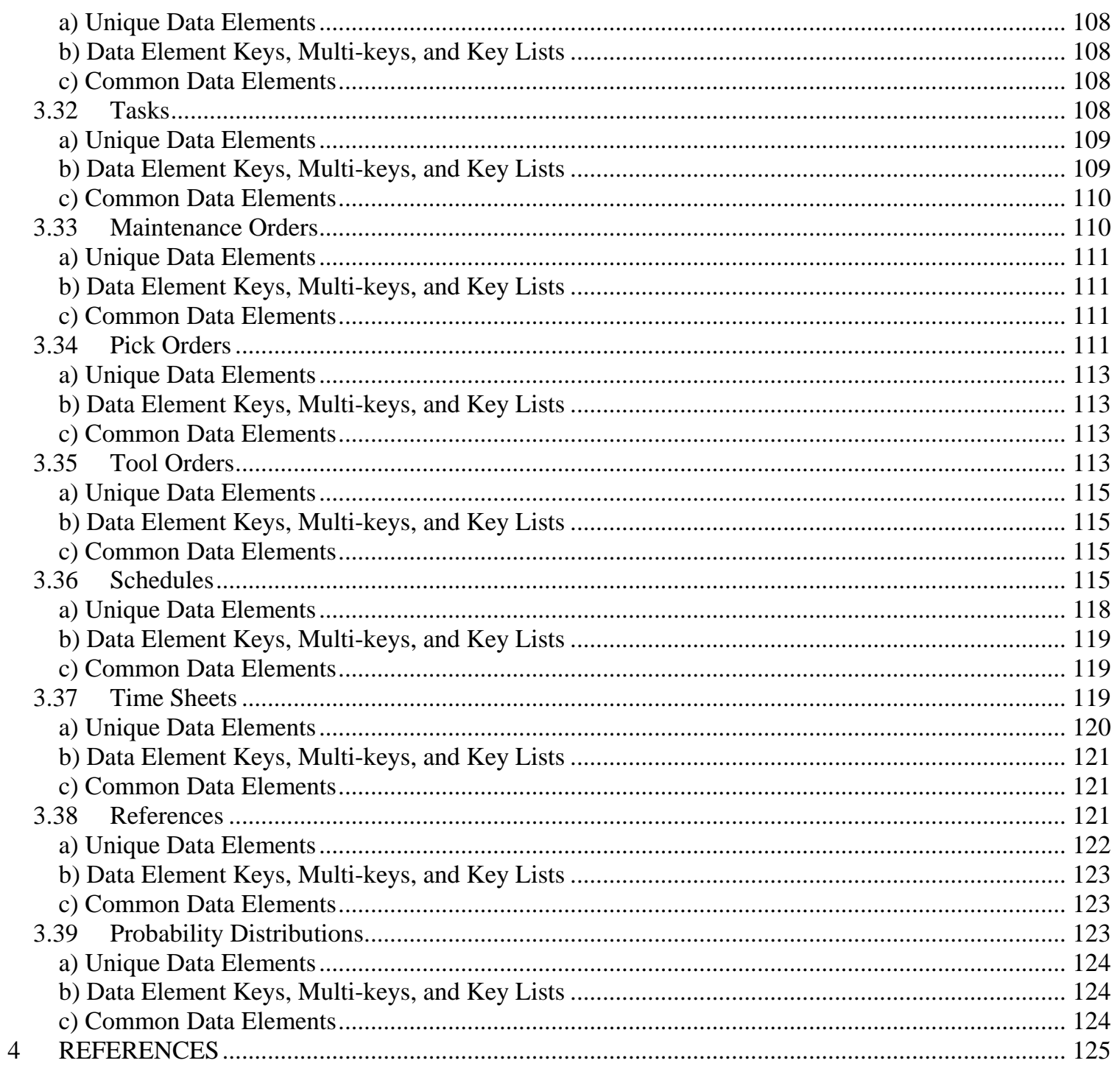


A Machine Shop Information model has been developing at the National Institute of Standards and Technology (NIST) as a part of efforts that support the development of standard data interfaces. This work is being carried out as part of the Software Engineering Institute's Technology, Insertion, Development, and Evaluation (TIDE) Program. The information model is intended to be used for representing and exchanging machine shop data, initially between manufacturing execution, scheduling, and simulation systems. The model is presented in two formats: the Unified Modeling Language (UML) [OMG 2003] and the Extensible Markup Language (XML) [W3C 2000]. The information model, when completed, must satisfy the following needs:

- $\quad$ support data requirements for the entire simulation manufacturing life cycle,

- enable data exchange between simulation and other manufacturing software for machine shops,

- $\quad$ provide for the construction of machine shop simulators, and

- support testing and evaluation of machine shops' manufacturing software.

The Machine Shop Information model contains five major supporting data structures and fifteen major manufacturing data structures. Supporting data structures include:

- time sheets,

- probability distributions,

- revisions,

- references, and

- units of measurement.

Manufacturing data structures include:

- organizations,

- calendars,

- resources (machines, machines, cranes. employees, tool catalog, and fixture catalog),

- skill definitions,

- setup definitions,

- operation definitions,

- maintenance definitions,

- layout,

- parts,

- bills of materials,

- inventory,

- procurements,

- $\quad$ process plans (routing sheets, operation sheets, and machine programs),

- $\quad$ work (orders, order items, jobs, tasks, maintenance orders, pick orders, and tool orders), and

- schedule.

\subsection{Concept for the Information Model}

In this section, the concept of the shop information model from the user perspective is described. The primary objective was to develop a structure for exchanging shop data between various manufacturing software applications, including simulation. The idea was to use the same data structures for managing actual production operations and simulating the machine shop. The rationale was that if one structure can serve both purposes, the need for translation and abstraction of the real data would be minimized when simulations are constructed. The mapping of real world data into simulation abstractions is not, for the most part, addressed in the current information model.

It is also recognized that maintaining data integrity and minimizing the duplication of data were important requirements. For this reason, each unique piece of information appears in only one place in the model. Cross-reference links are used to avoid the creation of redundant copies of data. 
The machine shop information model contains twenty major elements. Each of the major data elements are italicized in the discussion that follows. The data elements are called: organizations, calendars, resources, skill-definitions, setup-definitions, operation-definitions, maintenance-definitions, layout, parts, bills-ofmaterials, inventory, procurements, process-plans, work, schedules, revisions, time-sheets, probabilitydistributions, references, and units-of-measurement. Figure 1 illustrates some of the major elements of the conceptual information model and their relationships to each other.

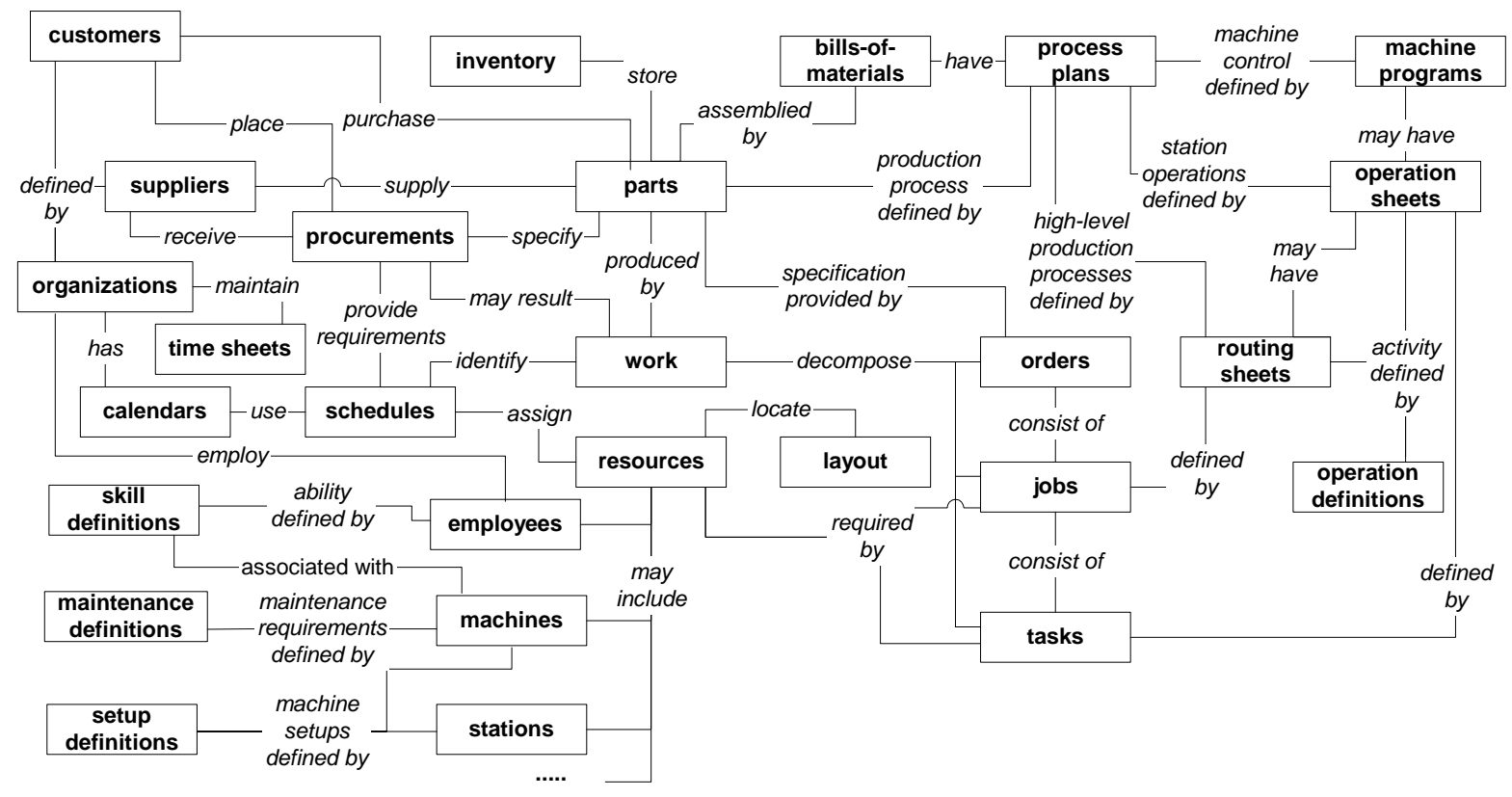

Figure 1. Concept for the Machine Shop Information Model

Perhaps a good place to start the discussion of the information model is with the customer. Machine shops are businesses. They typically produce machined parts for either internal or external customers. Data elements are needed to maintain information on customers. The types of organizational information that is needed about customers is very similar to the data needed about suppliers that provide materials to the shop. The same types of organizational data are also needed about the machine shop itself. For this reason, an organizations element was created to maintain organizational and contact information on the shop, its customers, and its suppliers.

Organizations can be thought of as both a phone book and an organization chart. The element provides sub-elements for identifying departments, their relationships to each other, individuals within departments, and their contact information. Various other types of information needs to be cross-referenced to organizations and contacts within structure, e.g., customer orders, parts, and procurements to suppliers.

The operation of the machine shop revolves around the production of parts, i.e., the fabrication of parts from raw materials such as metal or plastic. The raw materials typically come in the form of blocks, bars, sheets, forgings, or castings. These materials are themselves parts that are procured from suppliers. The parts data element was created to maintain the broad range of information that is needed about each part that is handled by the machine shop. Part data includes an identifying part number, name, description, size, weight, material composition, unit-of-issue, cost, group technology classification codes, and revision (change) data. Cross-reference links are needed to the customers that buy the parts from the shop and/or the suppliers that provide them as raw materials. Links are also needed to other data elements, documents, and files that are related to the production of parts including: part specification documents, geometric models, drawings, bills-of-materials, and process plans. 
The bills-of-materials element is basically a collection of hierarchically-structured parts lists. It is used to define the parts and subassemblies that make up higher-level part assemblies. A bill-of-materials identifies, by a part number reference link, the component or subassembly required at each level of assembly. The quantity required for each part is also indicated. Cross-references links are needed between parts that are assemblies and their associated bill-of-materials.

The parts and bills-of-materials elements establish the basic definition of parts produced or used by the shop. Another element, inventory, is used to identify quantity of part instances at each location within the facility. Inventory data elements are provided for parts, tools, fixtures, and materials. Materials are defined as various types of stock that may be partially consumed in production, e.g., sheets, bars, and rolls.

Structures are provided within inventory to keep track of various stock levels (e.g., reorder point level) and the specific instances of parts that are used in assemblies.

The procurements element identifies the internal and external purchase orders that have been created to satisfy order or part-inventory requirements. Cross-reference links are defined to Parts to identify the specific parts that are being procured and to work to indicate which work items they will be used to satisfy.

The work data element is used to specify a hierarchical collection of work items that define orders, production and support activities within the shop. Support activities include maintenance, inventory picking, and fixture/tool preparation. Work is broken down hierarchically into orders, jobs, and tasks.

Orders may be either customer orders for products or internally-generated orders to satisfy part requirements within the company, e.g., maintenance of inventory levels of stock items sold through a catalog. Orders contain both definition and status information. Definition information specifies whom the order is for (i.e., customer cross-references), its relative priority, critical due dates, what output products are required (a list of order items, i.e., part references and quantities required), special resource requirements, precedence relationships on the processing of order items, and a summary of estimated and actual costs. Order items are also cross-referenced to jobs and tasks that decompose the orders into individual process steps performed at workstations within the shop. Status information includes data about scheduled and actual progress towards completing the order.

Jobs typically define complex production work items that involve activities at multiple stations and ultimately produce parts. Tasks are lower-level work items that are typically performed at a single workstation or area within the shop.

The process-plans element contains the process specifications that describe how production and support work is to be performed in the shop. Major elements contained within process-plans include routing sheets, operation sheets, and equipment programs. Routing and operation sheets are the plans used to define joband task-level work items, respectively, in the work hierarchy. These process plans define the steps, precedence constraints between steps, and resources required to produce parts and perform support activities. Precedence constraints defined in a process plan are used to establish precedence relationships between jobs and tasks. Equipment program elements establish cross reference links to files that contain computer programs that are used to run machine tools and other programmable equipment that process specific parts. Each part in the parts element contains cross-reference links to the process plans that define how to make that part. Jobs and tasks contain links back to the process plans that defined them.

The resources element is used to define production and support resources that may be assigned to jobs or tasks in the shop, their status, and scheduled assignments to specific work items. The resource types available in the machine shop environment include: stations and machines, cranes, employees, tool and tool sets, fixtures and fixture sets.

The skill-definitions, setup-definitions, operations-definitions, maintenance-definitions, and time-sheets elements provide additional supporting information associated with resources. Skill-definitions lists the skills that an employee may possess and the levels of proficiency associated with these skills. Skills are referenced in employee resource requirements contained in process plans. Setup-definitions typically specifies tool or fixture setups on a machine. Tool setups are typically the tools that are required in the tool 
magazine. Fixture setups are work-holding devices mounted on the machine. Setups may also apply to cranes or stations. Operation-definitions specifies the types of operations that may be performed at a particular station or group of stations within the shop. Maintenance-definitions specifies preventive or corrective maintenance to be done on machines or other maintained resources. Time-sheets is used to log individual employee's work hours, leave hours, overtime hours, and so on.

The layout element defines the physical locations of resource objects and part instances within the shop. It also defines reference points, area boundaries, and paths.. It contains references to external files that are used to further define resource and part objects using appropriate graphics standards. Cross-references links are also provided between layout objects and the actual resources that they represent.

Schedules and calendars data elements deal with time. Schedules provides two views of the planned assignment of work and resources. Work items (orders, jobs, and tasks) are mapped to resources, and conversely, resources are mapped to work items. The planned time events associated with those mappings are also identified, e.g., scheduled start times and end times. Calendars identifies scheduled work days for the shop, the shift schedules that are in effect for periods of time, planned breaks, and holiday periods.

The four remaining major data elements are revisions, references, probability-distributions, and units-ofmeasurement. The revisions element is used repeatedly throughout many levels of the information model. It provides a mechanism for identifying versions of subsets of the data, revision dates, and the creator of the data. The references element identifies external digital files and paper documents that support and further define the data elements contained within the shop data structure. It provides a mechanism for linking to outside files that conform to various other format specifications or standards, e.g., STEP (or the International Organization for Standardization 10303, informally known as the STandard for the Exchange of Product model data, STEP) part design files [ISO 1994]. The probability-distributions element defines probability distributions that are used to vary processing times, breakdown and repair times, availability of resources among others. Distributions may be cross-referenced from elsewhere in the model, e.g., equipment resources maintenance data. Units-of-measurement specifies the units used in the file for various quantities such as length, weight, currency, and speed.

\subsection{Presentation of the Document}

The document provides definitions to all data elements presented in the Machine Shop Information Model. Data elements within the model are grouped into three categories: data element keys, commonly-used data elements, and unique manufacturing shop data elements. Section 2 provides definitions to the data elements that are found repeatedly at many levels of the data structures within the information model, in this document these data elements are called data elements keys and commonly-used data elements. Section 3 provides definitions to data elements uniquely specified in the data structures of the information model. Appendix A lists the enumeration items for each enumeration data element. Appendix B presents the data format for each selected data element. 
There are data elements that are found repeatedly at many levels of the data structures within the information model, they are topic of this section. In this section, data elements keys and commonly-used data elements are identified and defined. Data element keys are data elements that serve as individual pointers or a collection of pointers to the information model. The commonly-used data elements are presented according to the elements' data types, including basic data elements, data elements with prefixes/suffixes, and complex data elements. A data element may be a basic data element, which cannot be further subdivided into elements, or a complex data element, which contains more than one basic data elements.

\subsection{Data Element Keys}

This subsection presents a set of data element keys that are used to avoid of redefining the same data elements. The data is grouped into three categories based on each data element's name suffix: “-key”, “multi-key" or "-keys".

\section{a) Data Element with “-key” Suffix}

The data element served as a pointer to the model to avoid of redefining the same data element. The name of this type of data element clearly identifies its source data element. Each source data element can be found at somewhere within the information model. Each of these "-key" suffix data elements is presented with two attributes: identifier and number. Here lists data elements of this type that present in the information model:

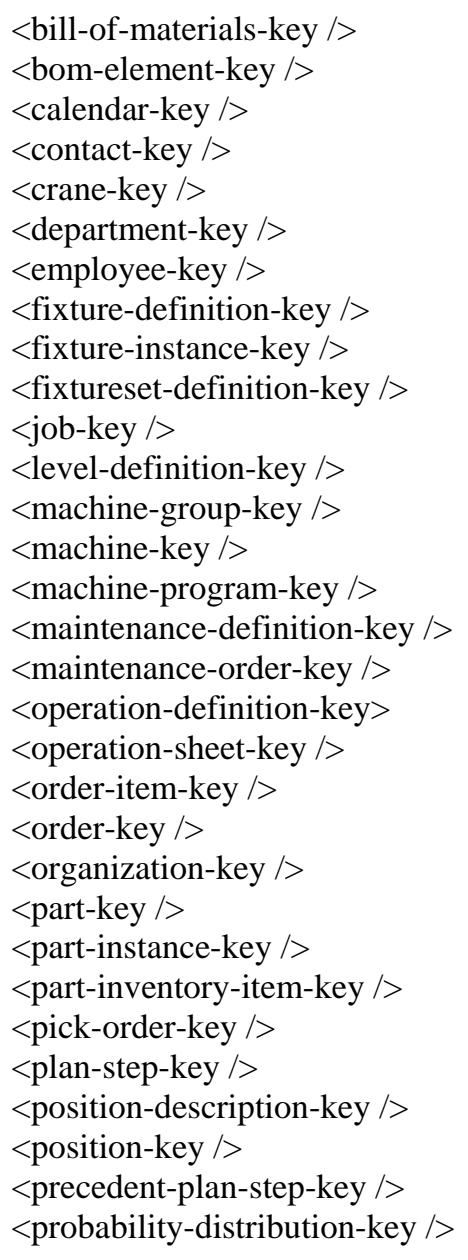




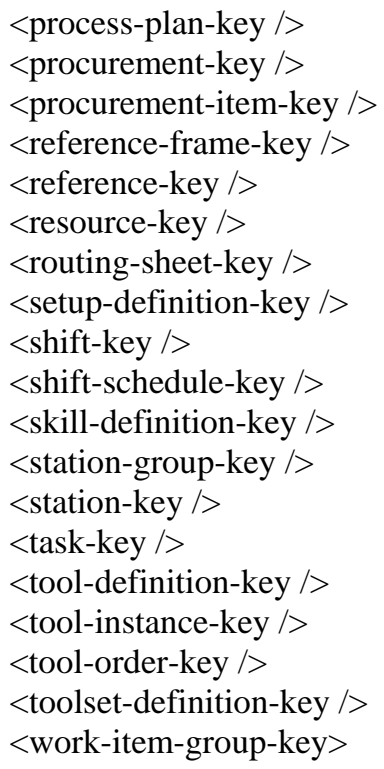

\section{b) Data Element with “-multi-key” Suffix}

Each data element groups two or more "key” suffix data elements to represent a compound data element. Here lists this group's data elements that present in the information model:

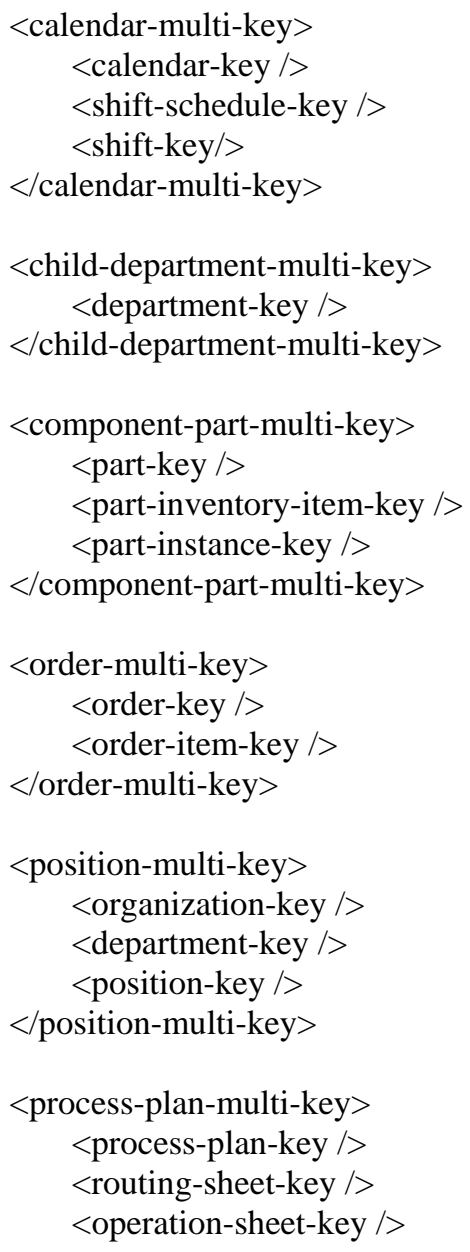




$$
\begin{aligned}
& <\text { machine-program-key / > } \\
& </ \text { process-plan-multi-key }> \\
& <\text { procurement-multi-key }> \\
& <\text { procurement-key /> } \\
& <\text { procurement-item-key /> } \\
& </ \text { procurement-multi-key }> \\
& <\text { skill-multi-key }> \\
& <\text { skill-definition-key /> } \\
& <\text { level-definition-key /> } \\
& </ \text { skill-multi-key }>
\end{aligned}
$$

\section{c) Data Element with “-keys” Suffix}

Each data element is a collection of "key" suffix data elements for convenient purposes. Here lists this group’s data elements that present in the information model:

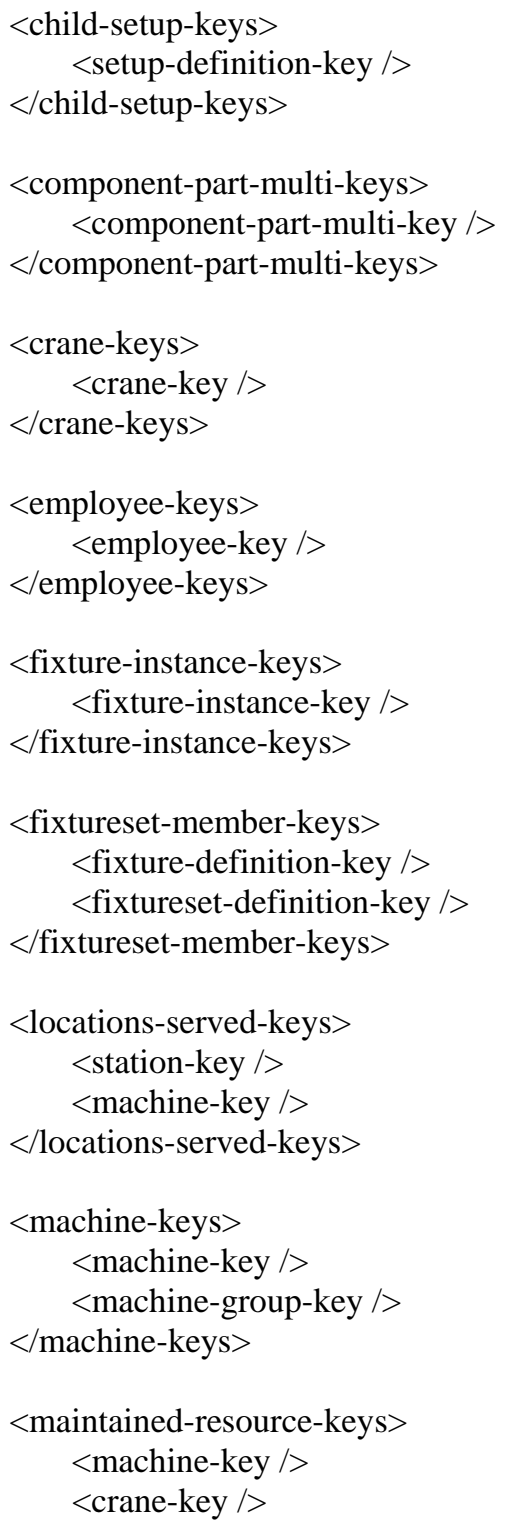


$<$ station-key />

$<$ /maintained-resource-keys $>$

$<$ parent-setup-keys $>$

$<$ setup-definition-key / >

$<$ /parent-setup-keys $>$

$<$ position-multi-keys $>$

$<$ position-multi-key />

$</$ position-multi-keys $>$

<process-plan-multi-keys $>$

$<$ process-plan-multi-key />

$<$ process-plan-multi-keys $>$

$<$ procurement-multi-keys $>$

$<$ procurement-multi-key />

$<$ /procurement-multi-keys $>$

$<$ reference-keys $>$

$<$ reference-key />

$<$ /reference-keys $>$

$<$ setup-definition-keys $>$

$<$ setup-definition-key />

$</$ setup-definition-keys $>$

$<$ setup-resource-keys $>$

$<$ machine-key / $>$

$<$ machine-group-key / $>$

$<$ station-key />

$<$ station-group-key />

$<$ crane-key / >

$<$ /setup-resource-keys $>$

<skill-multi-keys>

$<$ skill-multi-key />

$</$ skill-multi-keys $>$

<station-keys>

$<$ station-key />

$<$ station-group-key />

$</$ station-keys $>$

$<$ tool-instance-keys $>$

$<$ tool-instance-key />

$</$ tool-instance-keys $>$

$<$ toolset-member-keys $>$

$<$ tool-definition-key />

$<$ toolset-definition-key / >

$</$ toolset-member-keys $>$

$<$ work-keys $>$

$<$ order-multi-key />

$<$ job-key / > 


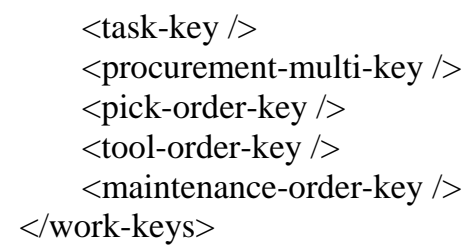

\subsection{Commonly-used Data Elements}

This subsection presents a set of data that is found repeatedly at many levels of the data structure within the model. The data is grouped into three categories: basic data elements, data elements with prefixes/suffixes, and complex data elements. Basic data elements can not be further subdivided into elements in the shop information model. Data elements with prefixes/suffixes use data elements with unique modifiers, either in prefixing or suffixing, for similar but unique purposes; the definitions of these data elements are generally self-explained. Complex data are constructed in a structure form with two or more basic data elements.

\section{a) Commonly-used Basic Data Elements}

Commonly-used basic data elements are listed and defined in this subsection:

comment: a remark or an annotation.

description: text that relates to the nature of the subject.

hourly-rate: a charge or payment calculated by hour.

identifier: a symbol or code number used to uniquely identify the object internally within the system. An identifier is generated automatically by the system when the objects are created.

logical-relationship: a mechanism for representing a logical relationship (i.e., AND, OR) between two objects.

name: a word or group of words used to identify the object by the user or user organization. A name element is provided for readability by the user or user organization.

nominal-duration: a stated duration time as opposed to the real duration time.

number: a symbol or code number used to identify the object to the user or the user organization. It should be a unique key for identifying the object either when taken alone or possibly together with the object type.

priority-rating: a rank value for representing order of urgency or importance associated with the work item initiated by a department, e.g., production jobs.

repetition-count: the number of times the production activities need to be repeated to satisfy the work requirement. For example: if the part quantities required is 50 and the batch size for the routing sheet is 10 , then the repetition count would be 5 .

quantity: a specified number or amount of a particular item.

type: a classification code used to categorize the object.

\section{b) Common-used Data Elements with Prefixes/Suffixes}

Commonly-used data elements with prefixes or suffixes are listed and defined in this subsection: 
code: a system of symbols, letters, or words that representing certain object. Prefixes to code include: color-code, cost-code, function-code, operation-code, shape-code, status-code, weight-code, etc.

coefficient: a numerical factor used with an equation or expression. Prefixes to coefficient include: unit $X$ coefficient, y-coefficient, z-coefficient, y-coefficient, alpha-coefficient, beta-coefficient, gamma-coefficient, etc.

cost: an amount paid or to be paid for a purchase or a service. Prefixes to cost include: unit-cost, materialcost, labor-cost, equipment-usage-cost, total-cost, etc.

date: the date when the activity effective. Prefixes to date include: dates, start-date, end-date, effectivestart-date, effective-end-date, release-date, request-earliest-ship-date, request-latest-ship-date, materialavailability-date, etc. The format for date is yyyy-mm- $d d$ where yyyy is for representing year, $\mathrm{mm}$ for month, and $d d$ for the day of the month.

duration: the period of time during which some activity performs or lasts. Prefixes to duration include: estimated-duration, nominal-duration, etc.

location: a place where something is or might be located. Prefixes to location include current-location, etc.

maximum: the maximum required number of a particular object. Suffixes to maximum include: maximumstations, maximum-machines, maximum-employees, etc.

minimum: the minimum required number of a particular object. Suffixes to minimum include: minimumstations, minimum-machines, minimum-employees, etc.

number: a system of symbols, letters, or words that representing certain object. Prefixes to number include: day-number, maximum-level-number, minimum-level-number, model-number, serial-number, etc.

number-of: a total number of a particular object. Suffixes to number-of include: number-of-stations, number-of-machines, number-of-employees, number-of-cranes, etc.

rate: a quantity measured in terms of another measured quantity. Prefixes to rate include: hourly-rate, overtime-rate, annual-absentee-rate, etc.

state: a stage or condition of development. Prefixes to state include: operational-state, maintenance-state, etc.

time: the time of the date when the activity effective. Prefixes to time include: start-time, end-time, etc. The format for time is hh:mm:ss where $h h$ is for representing hour ranging between 0 and $24, \mathrm{~mm}$ is for representing minute ranging between 0 and 60 , and ss is operational and is for representing minute ranging between 0 and 60 .

type: a classification code used to categorize the object. Prefixes to type include: controller-type, operationtype, operation-subtype, material-type, salary-type, etc.

units describes the units for a particular measurement. Prefixes to units include: angular-units, currencyunits, distance-units, length-units, mass-units, speed-units, time-duration-units, and volume-units.

value: a numerical measure of the subject. Prefixes to value include: value1, value2, value3, etc. value1, value2, value 3 are used to specify coefficients for a probability distribution.

\subsection{Commonly-Used Complex Data Elements}

Commonly-used complex data elements are defined in the following subsections: 
2.3.1 addresses

2.3.2 batch-sizes

2.3.3 boundary-elements

2.3.4 child-work-items

2.3.5 contacts

2.3.6 cost-categories

2.3.7 cost-summary

2.3.8 customers

2.3.9 due-dates

2.3.10 duration-distributions

2.3.11 estimated-durations

2.3.12 events

2.3.13 from-reference-frame

2.3.144 organizational-contact

2.3.155 parameters

2.3.16 part-quantities

2.3.17_plan-definition

2.3.18 precedent-constraints

2.3.19 reliability-statistics

2.3.20 resources-assigned

2.3.21 resources-required

2.3.22 resources-used

2.3.23 revisions

2.3.24 setup-components

2.3.25 setup-configurations

2.3.26 status-code

2.3.27 stock-level-quantities

2.3.28 suppliers

2.3.29 units-of-measurement

2.3.30 work-actual-progress

2.3.31 work-assignments

2.3.32 work-scheduled-progress

\subsubsection{Addresses}

addresses specifies contact information of an organization, an organization unit, or an individual. It is represented by a set of address data elements.

The UML model for the addresses element is shown below: 


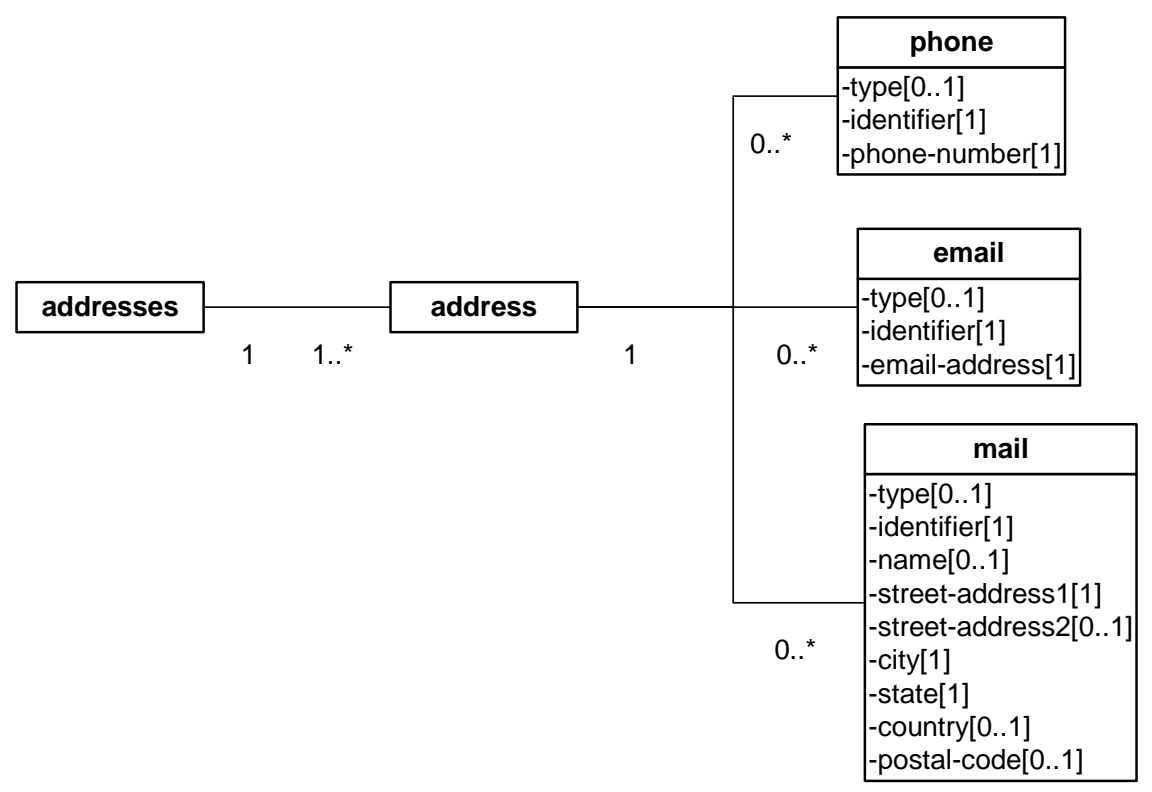

The XML structure for the addresses element is shown below:

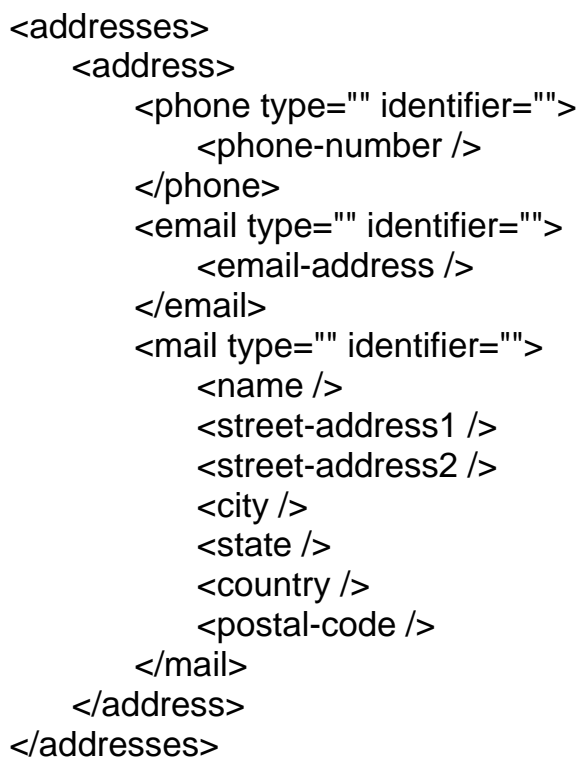

The unique data elements, data element keys, and common data elements introduced in this element are described below.

\section{a) Unique Data Elements}

address: information about phone number, email addresses and mailing addresses. It is represented by the following data elements: phone, email, and mail.

addresses: a collection of individual addresses.

city: the city the address belongs. 
country: the country the address belongs.

email: information about the email address. It is represented by the following data elements: type, identifier, and email-address.

mail: information about the mailing address. It is represented by the following data elements: type, identifier, name, street-address1, street-address2, city, state, country, and postal-code.

phone: information about the phone number. It is represented by the following data elements: type, identifier, and number.

state: the state the address belongs.

street-address1: the first part of the street address of the mailing address.

street-address2: the second part of the street address of the mailing address.

\section{b) Data Element Keys, Multi-keys, and Key Lists}

No keys are used in this element.

\section{c) Common Data Elements}

See Section 2.2 for commonly-used basic data definitions that define these common data attribute(s) and/or element(s): identifier, name, number, postal-code, and type.

\subsubsection{Batch Sizes}

batch-sizes identifies the type and total quantity of each part. It is represented by a set of batch-size data elements.

The UML model for the batch-sizes element is shown below:

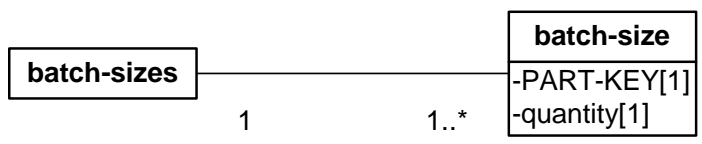

The XML structure for the batch-sizes element is shown below:

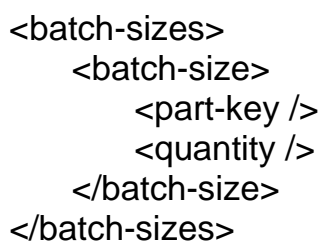

The unique data elements, data element keys, and common data elements introduced in this element are described below.

\section{a) Unique Data Elements}


batch-size: the type and quantity of a particular part. It is represented by the following data elements: partkey and quantity.

batch-sizes: a collection of individual batch-sizes.

\section{b) Data Element Keys, Multi-keys, and Key Lists}

part-key is used in this element.

\section{c) Common Data Elements}

See Section 2.2 for commonly-used basic data definitions that define these common data attribute(s) and/or element(s): quantity.

\subsubsection{Boundary Element}

boundary-element specifies information about a boundary reference point. It is used to define areaboundary, path-route, object-boundary, and object-boundary.

The UML model for the boundary-element element is shown below:

\begin{tabular}{|l|}
\hline boundary-element \\
\hline -type[0..1] \\
-identifier[1] \\
-number[1] \\
-name[0..1] \\
\hline
\end{tabular}

The XML structure for the batch-sizes element is shown below:

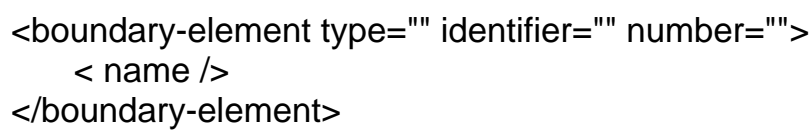

The unique data elements, data element keys, and common data elements introduced in this element are described below.

\section{a) Unique Data Elements}

boundary-element: information about a reference point of an area, a path, or an object.

\section{b) Data Element Keys, Multi-keys, and Key Lists}

No keys are used in this element.

\section{c) Common Data Elements}

See Section 2.2 for commonly-used basic data definitions that define these common data attribute(s) and/or element(s): identifier, name, number, and type.

\subsubsection{Child Work Items}


child-work-items specifies a collection of subordinate (up to one level down) work items. A sample of a subordinate work item is that a task can be a child work item of a job. child-work-items is represented by the following data elements: work-keys and work-item-group.

The UML model for the child-work-items element is shown below:

\begin{tabular}{|c|c|c|c|}
\hline & & & work-item-group \\
\hline child-work-items & & & $\begin{array}{l}\text {-type[0..1] } \\
\text {-identifier[1] } \\
\text {-number[1] }\end{array}$ \\
\hline -WORK-KEYS[1] & 1 & 1..* & $\begin{array}{l}\text {-name[0..1] } \\
\text {-logical-relationship[1] } \\
\text {-WORK-KEYS[0..1] } \\
\text {-WORK-ITEM-GROUP-KEY[0..1] }\end{array}$ \\
\hline
\end{tabular}

The XML structure for the child-work-items element is shown below:

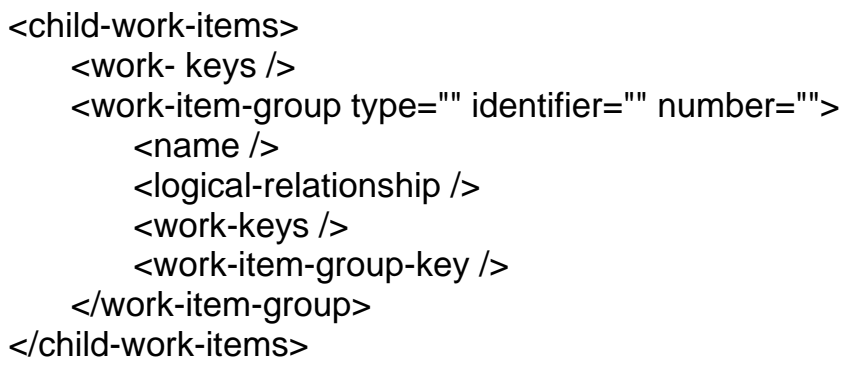

The unique data elements, data element keys, and common data elements introduced in this element are described below.

\section{a) Unique Data Elements}

child-work-items: a collection of subordinate (up to one level down) work items.

work-item-group: information that represents a set of work items and the logical relationships among these work items. It is represented by the following data elements: type, identifier, number, name, logicalrelationship, work- keys and work-item-group-key.

\section{b) Data Element Keys, Multi-keys, and Key Lists}

work-item-group-key and work-keys are used in this element.

\section{c) Common Data Elements}

See Section 2.2 for commonly-used basic data definitions that define these common data attribute(s) and/or element(s): type, identifier, logical-relationship, name, number, and work-keys.

\subsubsection{Contacts}

contacts is a collection of contact information, including phone numbers, email addresses, and mailing addresses, of an organization or an organization unit. It is represented by a set of contact data elements.

The UML model for the contacts element is shown below: 


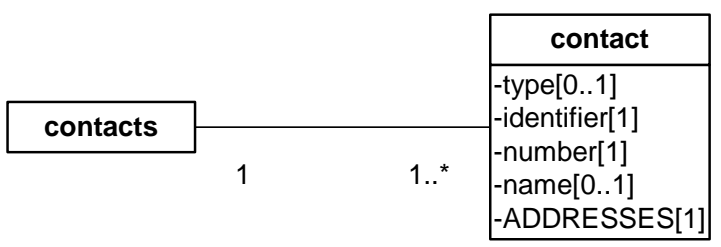

The XML structure for the contacts element is shown below:

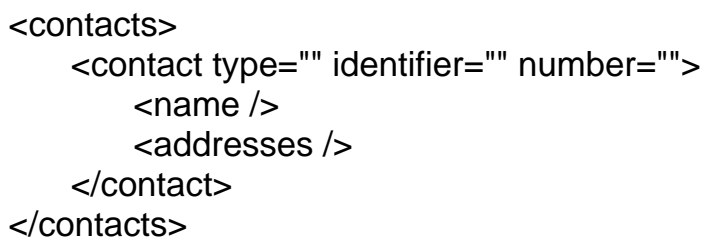

The unique data elements, data element keys, and common data elements introduced in this element are described below.

\section{a) Unique Data Elements}

contact: contact information of an organization or an organization unit. The information includes phone numbers, email addresses, and mailing addresses. It is represented by the following data elements: type, identifier, number, name, and addresses.

\section{b) Data Element Keys, Multi-keys, and Key Lists}

No keys are used in this element.

\section{c) Common Data Elements}

See Section 2.2 for commonly-used basic data definitions that define these common data attribute(s) and/or element(s): addresses, identifier, name, number, and type.

\subsubsection{Cost Categories}

cost-categories specifies the cost figures in the following categories: materials, labor, equipment usage, equipment depreciation cost, and total. It is represented by the following data elements: materials-cost, labor-cost, equipment-usage-cost, and total-cost.

The UML model for the cost-categories element is shown below:

\begin{tabular}{|l|}
\multicolumn{1}{|c|}{ cost-categories } \\
\hline -materials-cost[0..1] \\
-labor-cost[0..1] \\
-equipment-usage-cost[0..1] \\
-equipment-depreciation-cost[0..1] \\
-total-cost[0..1] \\
\hline
\end{tabular}

The XML structure for the cost-categories element is shown below:

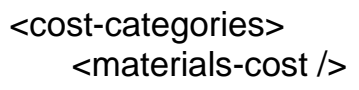




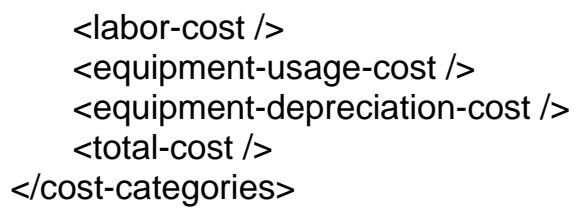

The unique data elements, data element keys, and common data elements introduced in this element are described below.

\section{a) Unique Data Elements}

cost-categories: information about costs in the categories of materials, labor, equipment usage, equipment depreciation, and total.

\section{b) Data Element Keys, Multi-keys, and Key Lists}

No keys are used in this element.

\section{c) Common Data Elements}

See Section 2.2 for commonly-used basic data definitions that define these common data attribute(s) and/or element(s): equipment-usage-cost, labor-cost, materials-cost, and total-cost.

\subsubsection{Cost Summary}

cost-summary specifies a summary of costs at different manufacturing stages: estimation, planning and actual expenses. It is represented by the following data elements: estimated-costs, planned-costs, and actual-costs.

The UML model for the cost-summary element is shown below:

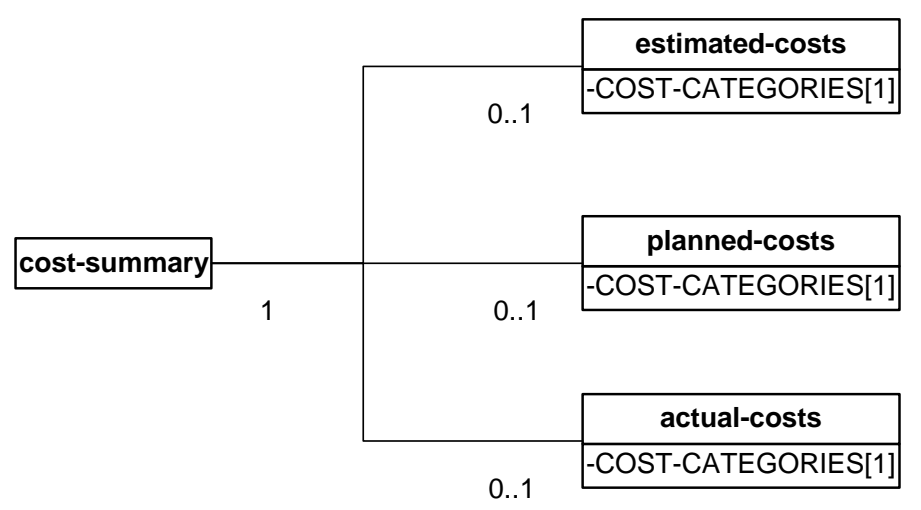

The XML structure for the cost-summary element is shown below:

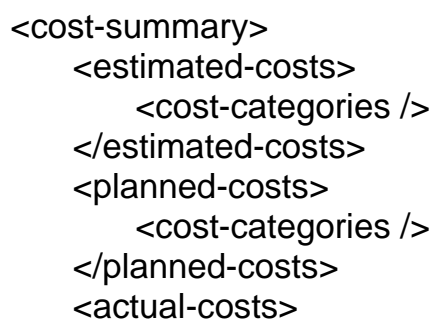




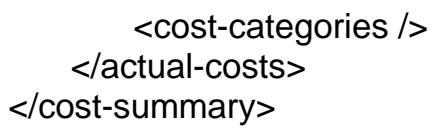

The unique data elements, data element keys, and common data elements introduced in this element are described below.

\section{a) Unique Data Elements}

actual-costs: information about actual expenses, in several spending categories, such as materials, labor, etc. It is represented by the cost-categories data element.

cost-summary: information about costs at different manufacturing stages including estimation, planning and final stages.

estimated-costs: information about the costs, in several categories, that are calculated by estimation. It is represented by the cost-categories data element.

planned-costs: information about costs, in several categories, that are calculated when a planning is performed. It is represented by the cost-categories data element.

\section{b) Data Element Keys, Multi-keys, and Key Lists}

No keys are used in this element.

\section{c) Common Data Elements}

See Section 2.2 for commonly-used basic data definitions that define these common data attribute(s) and/or element(s): cost-categories.

\subsubsection{Customers}

customers specifies contact information about an organization's customers. It is represented by a set of organizational-contact data elements.

The UML model for the customers element is shown below:

\begin{tabular}{|c|}
\hline customers \\
\hline -ORGANIZATIONAL-CONTACT[1..*] \\
\hline
\end{tabular}

The XML structure for the customers element is shown below:

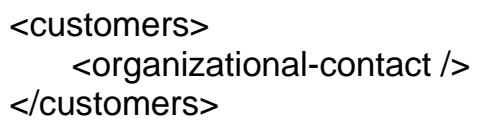

The unique data elements, data element keys, and common data elements introduced in this element are described below. 


\section{a) Unique Data Elements}

customers: a collection of individual customers.

\section{b) Data Element Keys, Multi-keys, and Key Lists}

No keys are used in this element.

\section{c) Common Data Elements}

See Section 2.2 for commonly-used basic data definitions that define these common data attribute(s) and/or element(s): organizational-contact.

\subsubsection{Due Dates}

due-dates specifies a set of dates that are requested or estimated. These dates are normally associated with a work item. It is represented by the following data elements: release-date, requested-earliest-ship-date, and requested-latest-ship-date.

The UML model for the due-dates element is shown below:

\begin{tabular}{|l|}
\hline \multicolumn{1}{|c|}{ due-dates } \\
\hline -release-date[0..1] \\
-requested-earliest-ship-date[0..1] \\
-requested-latest-ship-date[0..1] \\
\hline
\end{tabular}

The XML structure for the due-dates element is shown below:

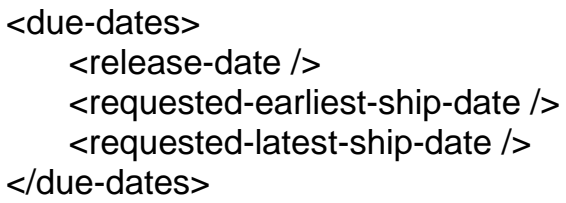

The unique data elements, data element keys, and common data elements introduced in this element are described below.

\section{a) Unique Data Elements}

due-dates: a collection of different types of due dates including release due date, requested earliest shipping date, and requested latest shipping date.

\section{b) Data Element Keys, Multi-keys, and Key Lists}

No keys are used in this element.

\section{c) Common Data Elements}

See Section 2.2 for commonly-used basic data definitions that define these common data attribute(s) and/or element(s): release-date, requested-earliest-ship-date, and requested-latest-ship-date.

\subsubsection{Duration Distributions}


duration-distributions specifies distributions that are used to vary time duration, such as processing times, breakdown and repair times, etc. It is represented by the following data elements: probability-distributionkey and probability-distribution.

The UML model for the duration-distributions element is shown below:

\begin{tabular}{|c|c|c|c|}
\hline & & & probability-distribution \\
\hline & & & \multirow{3}{*}{$\begin{array}{l}\text {-type[0..1] } \\
\text {-identifier[1] } \\
\text {-number[1] } \\
\text {-name[0..1] } \\
\text {-description[0..1] } \\
\text {-value1[1] } \\
\text {-value2[1] } \\
\text {-value3[1] }\end{array}$} \\
\hline duration-distributions & & & \\
\hline -PROBABILITY-DISTRIBUTION-KEY[0..*] & 1 & $0 . .^{*}$ & \\
\hline
\end{tabular}

The XML structure for the duration-distributions element is shown below:

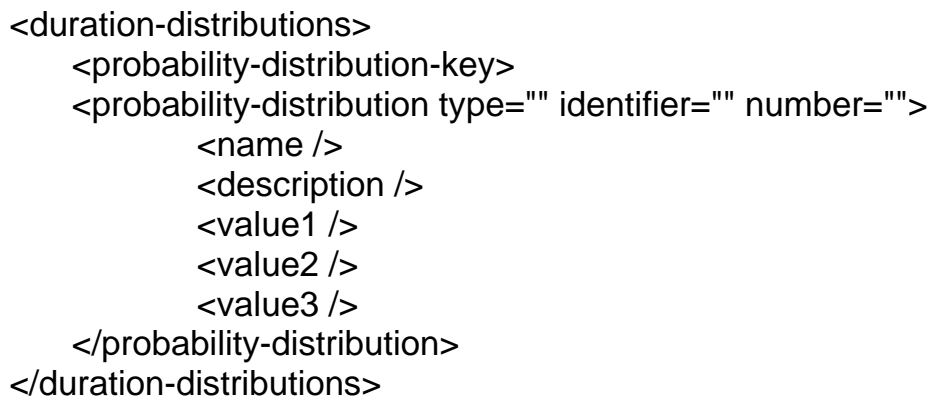

The unique data elements, data element keys, and common data elements introduced in this element are described below.

\section{a) Unique Data Elements}

duration-distributions: a collections of various probability distributions.

probability-distribution: a distribution that is used to vary processing times, breakdown and repair times, etc. It is represented by the following data elements: type, identifier, number, name, description, value1, value2, and value 3 where value1, value 2 and value 3 are distribution coefficients.

\section{b) Data Element Keys, Multi-keys, and Key Lists}

probability-distribution-key is used in this element.

\section{c) Common Data Elements}

See Section 2.2 for commonly-used basic data definitions that define these common data attribute(s) and/or element(s): description, identifier, name, number, type, value1, value2, and value3.

\subsubsection{Estimated Durations}

estimated-durations specifies distributions that are used to vary time duration for setup, unit operation, and total operations during a plan step. It is represented by the following data elements: setup-duration, unitoperation-duration, and total-operations-durations. 
The UML model for the estimated-durations element is shown below:

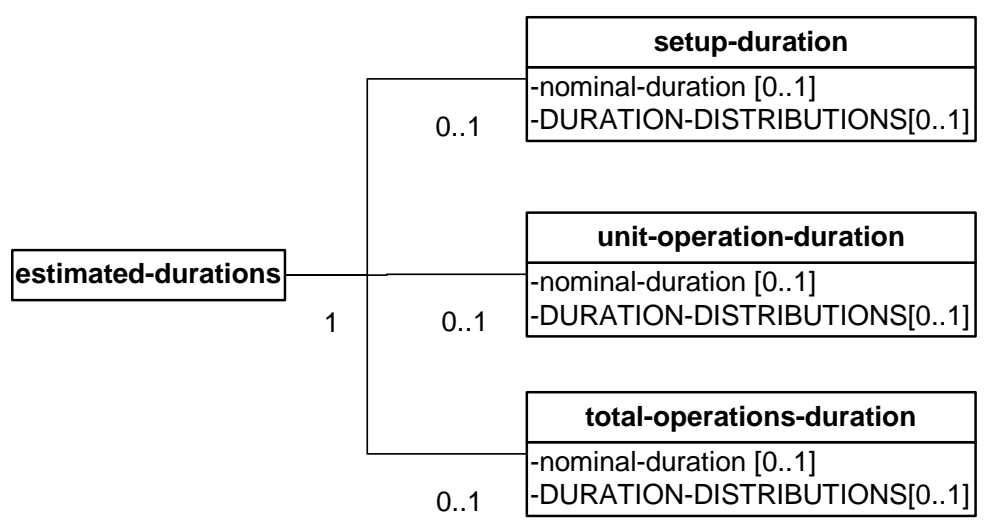

The XML structure for the estimated-duration element is shown below:

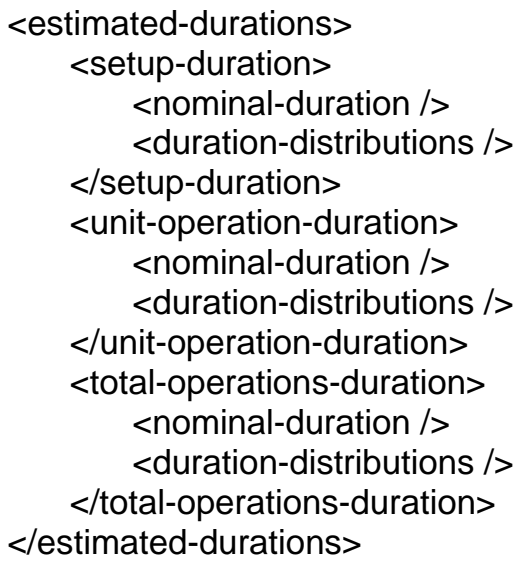

The unique data elements, data element keys, and common data elements introduced in this element are described below.

\section{a) Unique Data Elements}

estimated-durations: a collection of time duration estimations for setup duration, unit operation duration, and total operations.

setup-duration: an estimated time required to perform machine setups. It is represented by the following data elements: nominal-duration and duration-distributions.

total-operations-duration: an estimated time required to perform a complete set of operations. It is represented by the following data elements: nominal-duration and duration-distributions.

unit-operation-duration: an estimated time required to perform an unit of a particular operation. It is represented by the following data elements: nominal-duration and duration-distributions.

\section{b) Data Element Keys, Multi-keys, and Key Lists}

No data element keys are used in this element. 


\section{c) Common Data Elements}

See Section 2.2 for commonly-used basic data definitions that define these common data attribute(s) and/or element(s): duration-distributions and nominal-duration.

\subsubsection{Events}

events specifies a set of time tags. events is represented by a set of event data elements.

The UML model for the events element is shown below:

\begin{tabular}{|c|c|c|c|}
\hline & & & \multirow{3}{*}{\begin{tabular}{|l|}
\multicolumn{1}{|c|}{ event } \\
-type[0..1] \\
-identifier[1] \\
-number[1] \\
-name[0..1] \\
-date[1] \\
-time[0..1]
\end{tabular}} \\
\hline & & & \\
\hline events & 1 & 1...* & \\
\hline
\end{tabular}

The XML structure for the events element is shown below:

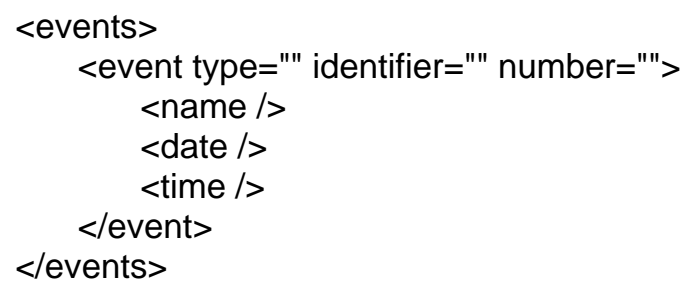

The unique data elements, data element keys, and common data elements introduced in this element are described below.

\section{a) Unique Data Elements}

event: information about a time tag. It is presented by the following data elements: type, identifier, number, name, date, and time.

events: a collection of individual events.

\section{b) Data Element Keys, Multi-keys, and Key Lists}

No keys are used in this element.

\section{c) Common Data Elements}

See Section 2.2 for commonly-used basic data definitions that define these common data attribute(s) and/or element(s): date, identifier, name, number, time and type.

\subsubsection{From Reference Frame}

from-reference-frame specifies information about coordinate transformations, including translation, scaling, and rotation, from a reference frame. It is represented by the following data elements: reference-frame-key, translation, scaling, and rotation. 
The UML model for the from-reference-frame element is shown below:

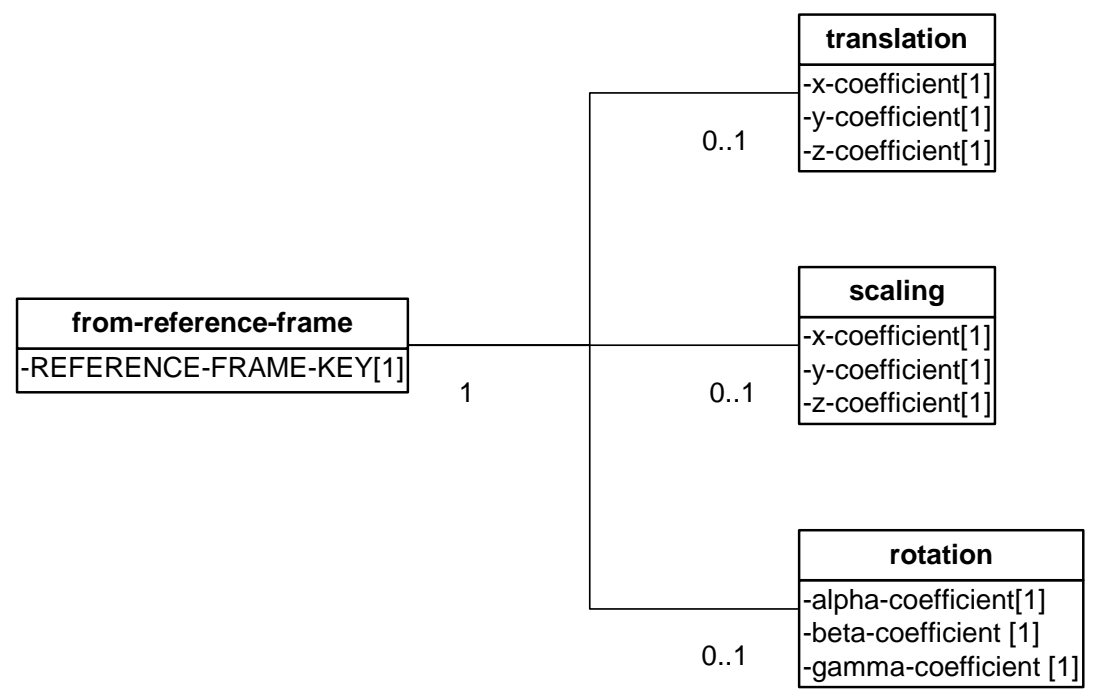

The XML structure for the from-reference-frame element is shown below:

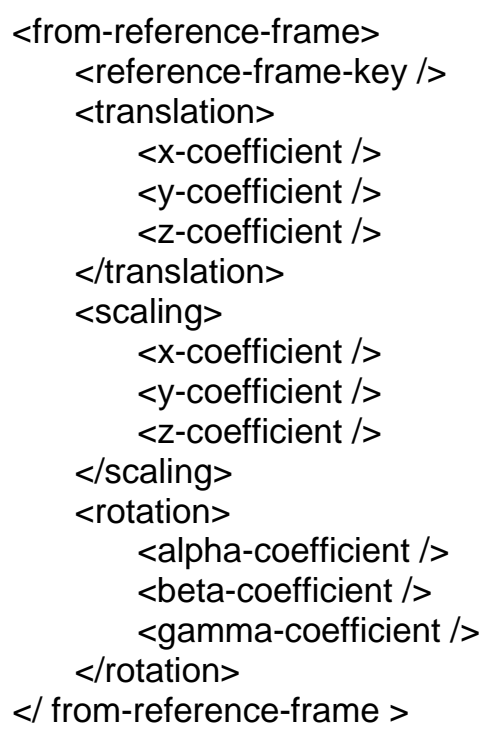

The unique data elements, data element keys, and common data elements introduced in this element are described below.

\section{a) Unique Data Elements}

from-reference-frame: information about a coordinate transformation related to rotation, scaling, or translation.

rotation: information about a rotation transformation performed onto a coordinate system. It is represented by the following data elements: $x$-coefficient, $y$-coefficient, and $z$-coefficient. 
scaling: information about a scaling transformation performed onto a coordinate system. It is represented by the following data elements: $x$-coefficient, $y$-coefficient, and $z$-coefficient.

translation: information about a translation transformation performed onto a coordinate system. It is represented by the following data elements: $x$-coefficient, $y$-coefficient, and $z$-coefficient.

\section{b) Data Element Keys, Multi-keys, and Key Lists}

reference-frame-key is used in this element.

\section{c) Common Data Elements}

See Section 2.2 for commonly-used basic data definitions that define these common data attribute(s) and/or element(s): alpha-coefficient, beta-coefficient, gamma-coefficient, $x$-coefficient, $y$-coefficient, and $z$ coefficient.

\subsubsection{Organizational-contact}

organizational-contact specifies the contact information of a particular organization and/or department. The contact information includes phone numbers, email addresses, and mailing addresses. It is represented by the following data elements: organization-key, department-key, and contact-key.

The UML model for the organizational-contact element is shown below:

\begin{tabular}{|l|}
\hline organizational-contact \\
\hline -ORGANIZATION-KEY[1] \\
-DEPARTMENT-KEY[0..1] \\
-CONTACT-KEY[O..1] \\
\hline
\end{tabular}

The XML structure for the organizational-contact element is shown below:

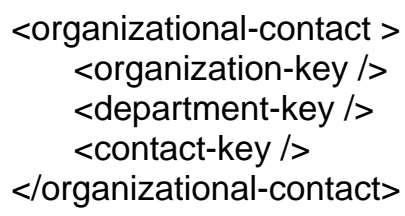

The unique data elements, data element keys, and common data elements introduced in this element are described below.

\section{a) Unique Data Elements}

organizational-contact: contact information of a particular organization and/or department.

\section{b) Data Element Keys, Multi-keys, and Key Lists}

contact-key, department-key, and organization-key are used in this element.

\section{c) Common Data Elements}

No common data elements are used in this element.

\subsubsection{Parameters}


parameters specifies a set of variables that appearing in a mathematical expression. The data associated with parameters are type, identifier, number, name, value, and default. value is a given value for the parameter, and default is a pre-assigned value for the parameter.

The UML model for the parameters element is shown below:

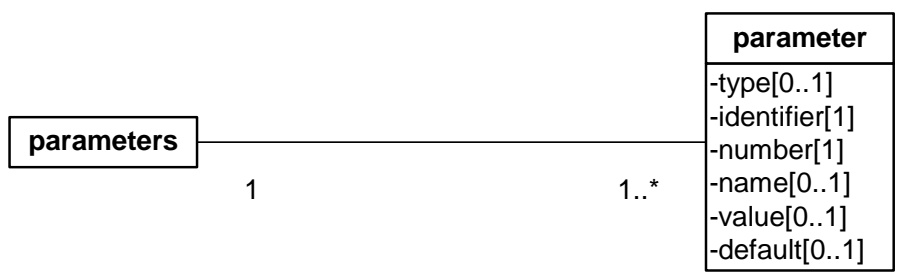

The XML structure for the parameters element is shown below:

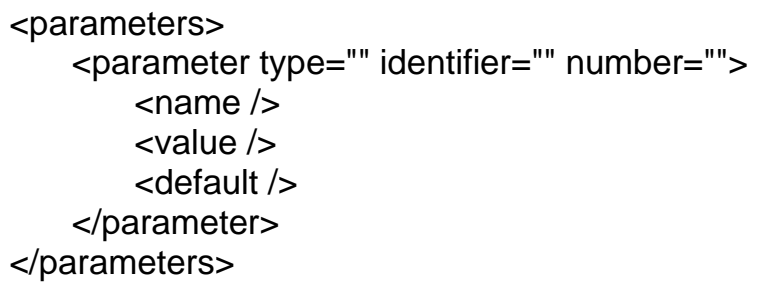

The unique data elements, data element keys, and common data elements introduced in this element are described below.

\section{a) Unique Data Elements}

default: a pre-assigned value that is used when the parameter value is not specified.

parameters: a collection of individual parameters.

\section{b) Date Element Keys and Multi-keys}

No keys are used in this element.

\section{c) Common Data Elements}

See Section 2.2 for commonly-used basic data definitions that define these common data attribute(s) and/or element(s): identifier, name, number, type, and value.

\subsubsection{Part Quantities}

part-quantities specifies the type and quantity of each part. It is represented by a set of part-quantity data elements.

The UML model for the part-quantities element is shown below:

\begin{tabular}{|c|c|c|c|}
\hline & & & part-quantity \\
\hline part-quantities & & & -PART-KEY[1] \\
\hline
\end{tabular}


The XML structure for the part-quantities element is shown below:

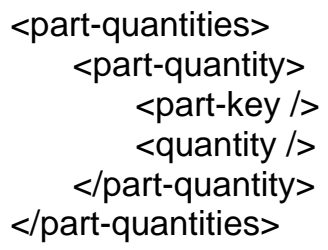

The unique data elements, data element keys, and common data elements introduced in this element are described below.

\section{a) Unique Data Elements}

part-quantity: the type and quantity number of a particular part. It is represented by the following data elements: part-key, and quantity.

\section{b) Data Element Keys, Multi-keys, and Key Lists}

part-key is used in this element.

\section{c) Common Data Elements}

See Section 2.2 for commonly-used basic data definitions that define these common data attribute(s) and/or element(s): quantity.

\subsubsection{Plan Definition}

plan-definition specifies information about a particular operation defined within an operation sheet or a routing sheet that supports a particular process plan. The information contains all required resources, operation steps, and each operation step's precedent constraints. It is represented by the following data elements: parameters, resources-required, plan-steps, and step-precedent-constraints.

The UML model for the plan-definition element is shown below: 


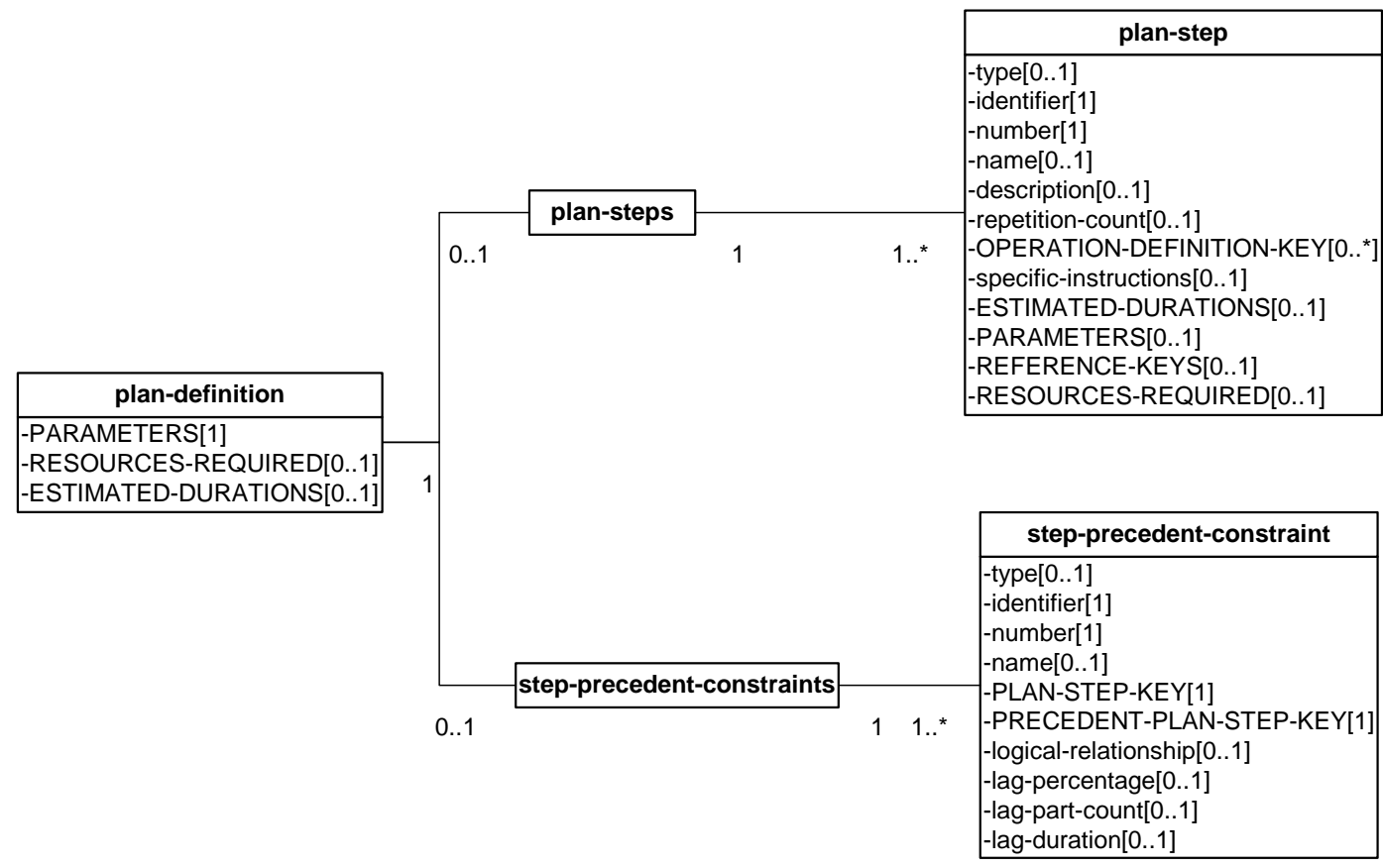

The XML structure for the plan-definition element is shown below:

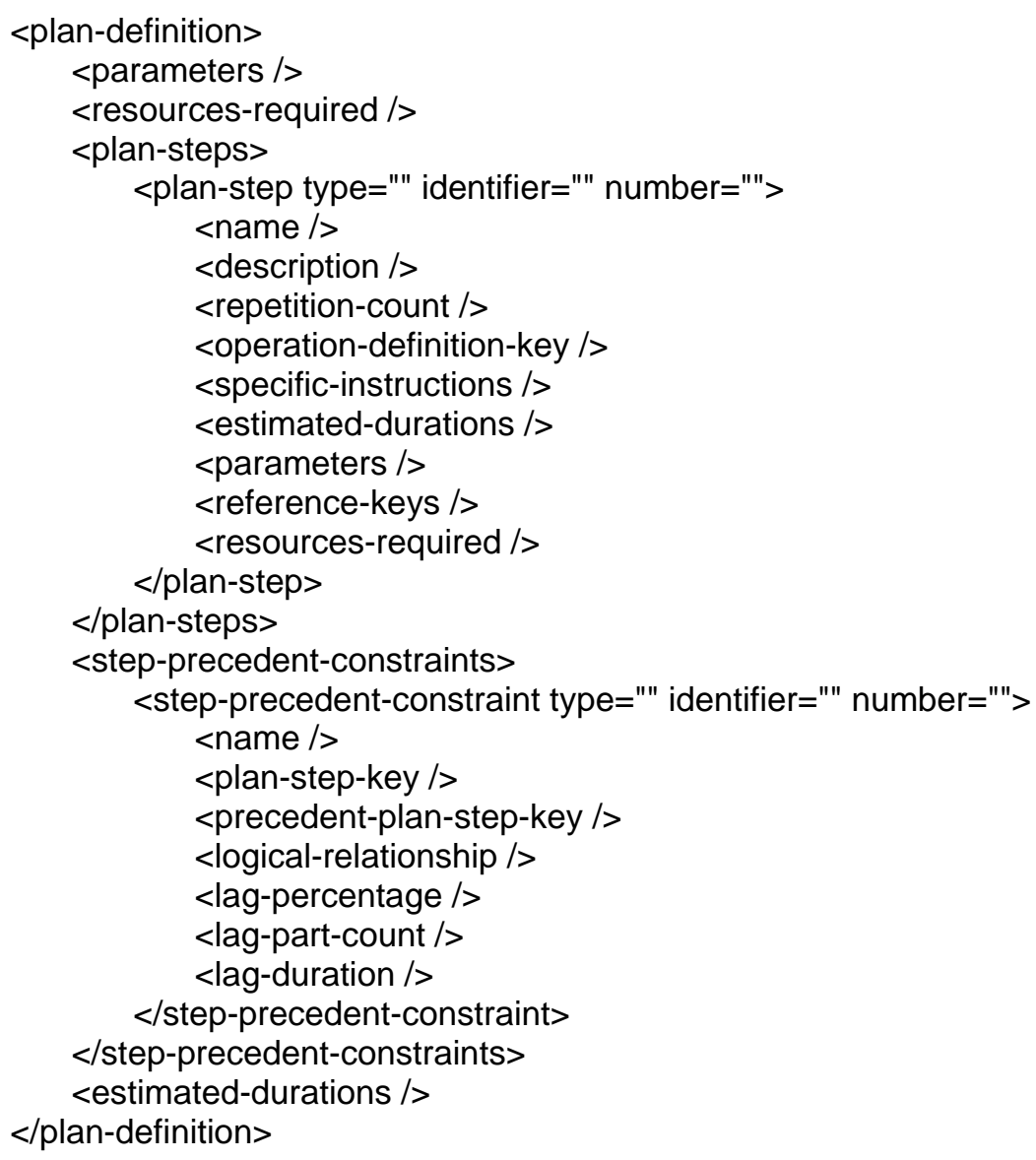


The unique data elements, data element keys, and common data elements introduced in this element are described below.

\section{a) Unique Data Elements}

lag-duration: the amount of time that must elapse after a constraining work-item starts (SS or SF) or finishes (FS or FF) and before a constrained job may start (SS or FS) or finish (SF or FF), where FS indicates the constraining work-item must finish before the constrained work-item may start, FF indicates the constraining work-item must finish before the constrained work-item may finish, SS indicates the constraining work-item must start before the constrained work-item may start, and SF indicates the constraining work-item must start before the constrained work-item may finish.

lag-part-count: the number of parts that must be completed after a constraining work-item starts (SS or SF) or finishes (FS or FF) and before a constrained job may start (SS or FS) or finish (SF or FF).

lag-percentage: the percentage of the estimated work-item completion time that must elapse after a constraining work-item starts (SS or SF) or finishes (FS or FF) and before a constrained job may start (SS or FS) or finish (SF or FF).

logical-relationship: the relationship between when a constraining work-item starts or finishes (always stated first) and when a constrained work-item starts or finishes (always stated last). The relationship is stated as one of "FS", "FF", "SS", or "SF".

plan-definition: information about a particular operation defined within an operation sheet or a routing sheet that supports a particular process plan.

plan-step: information about an operation step that supports a manufacturing operation defined in the process plan. The information includes the identification, time requirements, resource requirements, and references about the operation step. It is represented by the following data elements: type, identifier, number, name, description, repetition-count, operation-definition-key, specific-instructions, plan-durations, parameters, reference-keys, step-durations, and resources-required.

plan-steps: a collection of operation steps. It is represented by a set of plan-step data elements.

specific-instructions: statements related to a particular operation.

step-precedent-constraint: a set of precedent constraints applied to a particular operation step specified in the process plan. It is represented by the following data elements: type, identifier, number, name, planstep-key, precedent-plan-step-key, logical-relationship, lag-percentage, lag-part-count and lag-duration.

step-precedent-constraints: a collection of precedent constraints for a particular manufacturing operation. It is represented by a set of step-precedent-constraint data elements.

\section{b) Data Element Keys, Multi-keys, and Key Lists}

operation-definition-key, plan-step-key, reference-keys, and precedent-plan-step-key are used in this element.

\section{c) Common Data Elements}

See Section 2.2 for commonly-used basic data definitions that define these common data attribute(s) and/or element(s): description, estimated-durations, identifier, logical-relationship, name, number, parameters, plan-durations, repetition-count, resources-required, and type.

\subsubsection{Precedent Constraints}


precedent-constraints describes all precedent constraints for a particular work item and its children work items. A precedent constraint is a prerequisite for starting the performance of the work item, such prerequisite is based on the completion of a particular work item or a set of work items. A precedent constraint may be about procurement order, production item, pick up order, or maintenance order. It is represented by a set of precedent-constraint data elements.

The UML model for the precedent-constraints element is shown below:

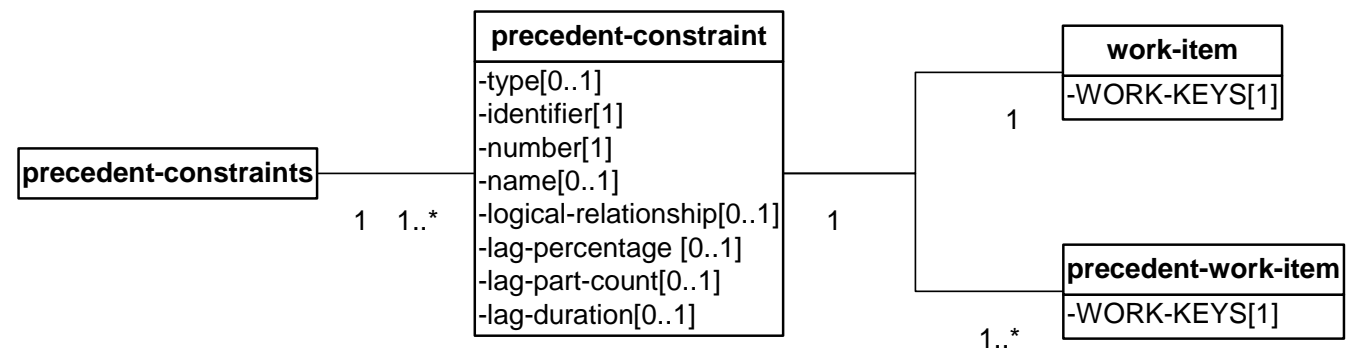

The XML structure for the precedent-constraints element is shown below:

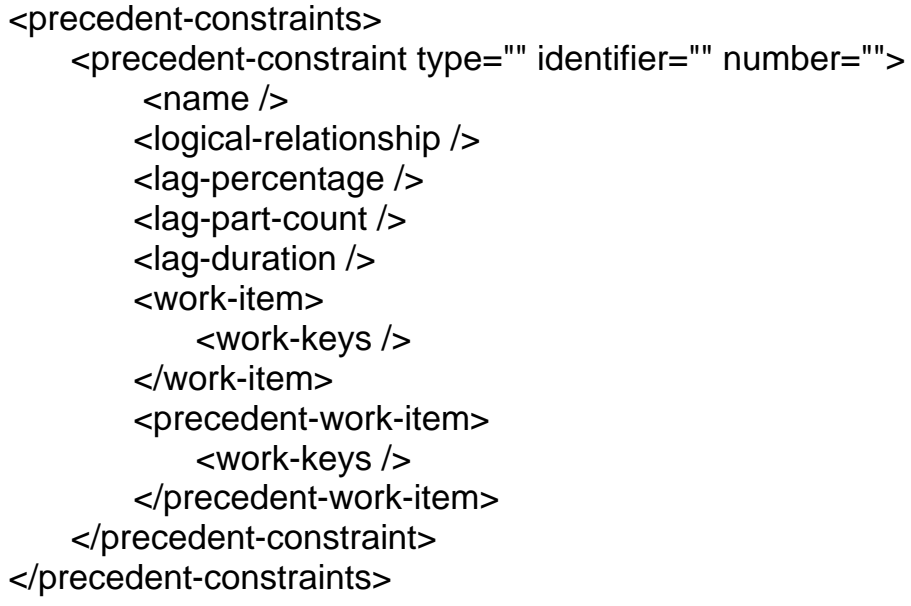

The unique data elements, data element keys, and common data elements introduced in this element are described below.

\section{a) Unique Data Elements}

lag-duration: (refer to Section 2.3.17).

lag-part-count: (refer to Section 2.3.17).

lag-percentage: (refer to Section 2.3.17).

logical-relationship: (refer to Section 2.3.17).

precedent-constraint: a precedent constraint is a prerequisite for starting the performance of a particular work item, such prerequisite is based on the completion of a particular work item or a set of work items. A precedent constraint may be about procurement order, production item, pick up order, or maintenance 
order. It is represented by the following data elements: type, identifier, number, name, logical-relationship, lag-percentage, lag-duration, part-lag-count, precedent-work-item, and work-item,

precedent-constraints: a collection of individual precedent constraints.

precedent-work-item: a collection of precedent work items to a particular work item.

work-item: a particular work item with whom the precedent work items are associated.

\section{b) Data Element Keys, Multi-keys, and Key Lists}

No keys are used in this element.

\section{c) Common Data Elements}

See Section 2.2 for commonly-used basic data definitions that define these common data attribute(s) and/or element(s): identifier, logical-relationship, name, number, type, and work-keys.

\subsubsection{Reliability Statistics}

reliability-statistics specifies statistics data about a particular machine's mean time between failures and mean time to repair. It is represented by the following data elements: mean-time-between-failure and mean-time-to-repair.

The UML model for the reliability-statistics element is shown below:

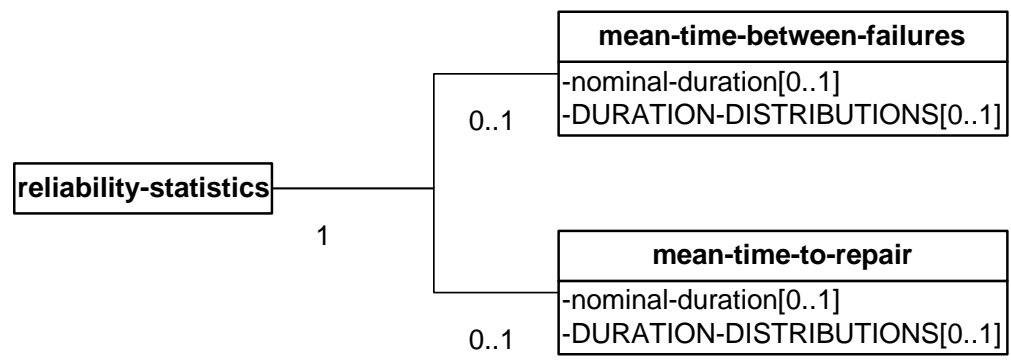

The XML structure for the reliability-statistics element is shown below:

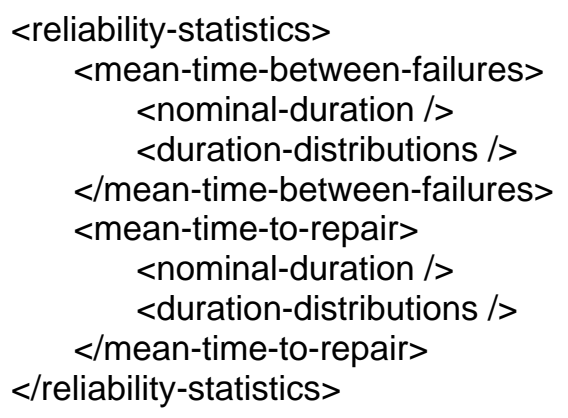

The unique data elements, data element keys, and common data elements introduced in this element are described below. 


\section{a) Unique Data Elements}

mean-time-between-failure: an average statistic value about time duration between two failures of a particular machine.

mean-time-to-repair: an average statistic value about time used to repair a particular machine.

reliability-statistics: statistics data about a particular machine's mean time between failures and mean time between repair.

\section{b) Data Element Keys, Multi-keys, and Key Lists}

No keys are used in this element.

\section{c) Common Data Elements}

See Section 2.2 for commonly-used basic data definitions that define these common data attribute(s) and/or element(s): duration-distributions and nominal-duration.

\subsubsection{Resources Assigned}

resources-assigned specifies the resources that assigned to a particular work item. The resources may include stations, machines, employees, cranes, and parts. It is represented by the following data elements: stations-assigned, machines-assigned, employees-assigned, cranes-assigned, and parts-assigned.

The UML model for the resources-assigned element is shown below: 


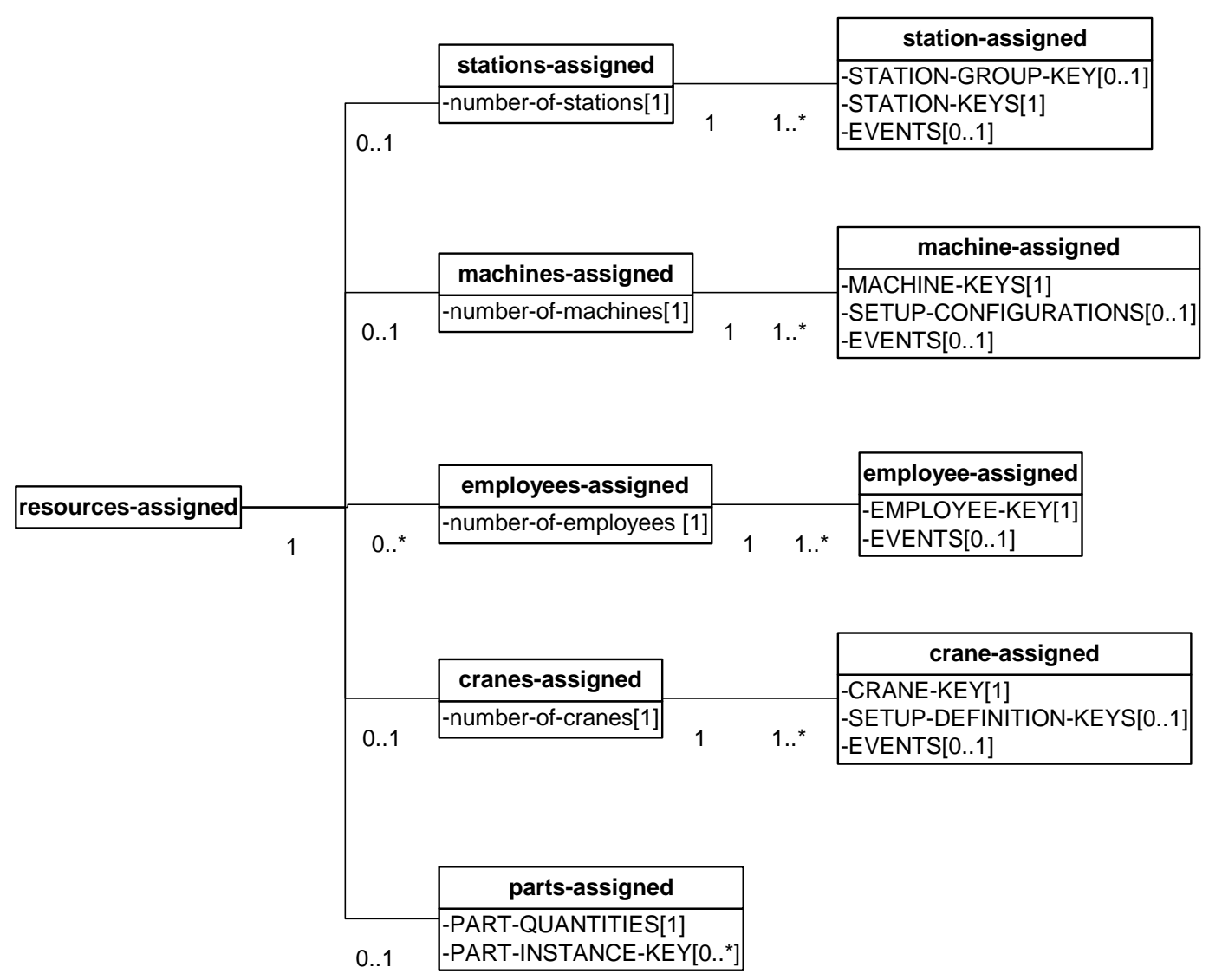

The XML structure for the resources-assigned element is shown below:

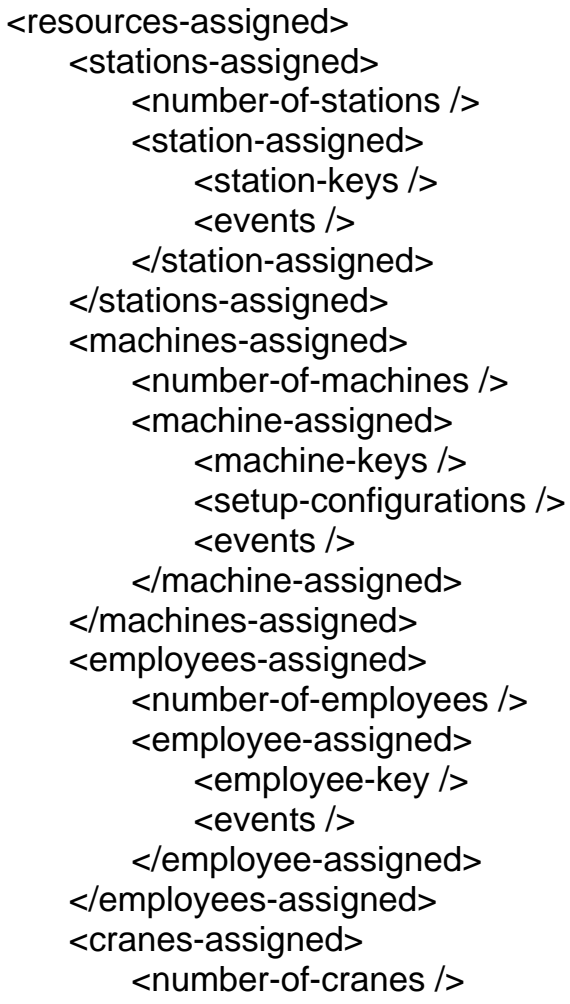




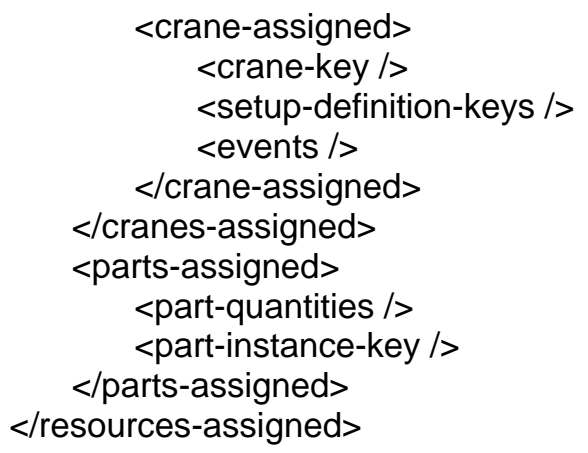

The unique data elements, data element keys, and common data elements introduced in this element are described below.

\section{a) Unique Data Elements}

crane-assigned: the crane that is assigned to a particular work item. It is represented by the following data elements: crane-key, setup-definition-keys, and events.

cranes-assigned: the cranes that are assigned to a particular work item. It is represented by the following data elements: number-of-cranes and crane-assigned.

employee-assigned: the employee that is assigned to a particular work item. It is represented by the following data elements: employee-key and events.

employees-assigned: the employees that are assigned to a particular work item. It is represented by the following data elements: number-of-employees and employee-assigned.

machine-assigned: the machine that is assigned to a particular work item. It is represented by the following data elements: machine-keys, setup-configurations, and events.

machines-assigned: the machines that are assigned to a particular work item. It is represented by the following data elements: number-of-machines and machine-assigned.

parts-assigned: parts that are assigned to a particular work item. It is represented by the following data elements: part-quantities and part-instance-key.

resources-assigned: information about the resources that are assigned to a particular work item.

station-assigned: the station that is assigned to a particular work item. It is represented by the following data elements: station-group-key, station-key, and events.

stations-assigned: the stations that are assigned to a particular work item. It is represented by the following data elements: number-of-stations and station-assigned.

\section{b) Data Element Keys, Multi-keys, and Key Lists}

crane-key, employee-key, machine-keys, part-instance-key, setup-definition-keys, and station-keys are used in this element.

\section{c) Common Data Elements}

See Section 2.2 for commonly-used basic data definitions that define these common data attribute(s) and/or element(s): events, number-of-cranes, number-of-employees, number-of-machines, number-of-stations, part-quantities, and setup-configurations. 


\subsubsection{Resources Required}

resources-required specifies the resources required to perform a particular work item. The resources may include stations, machines, employees, cranes, and parts. It is represented by the following data elements: stations-required, machines-required, employees-required, cranes-required, and parts-required.

The UML model for the resources-required element is shown below:

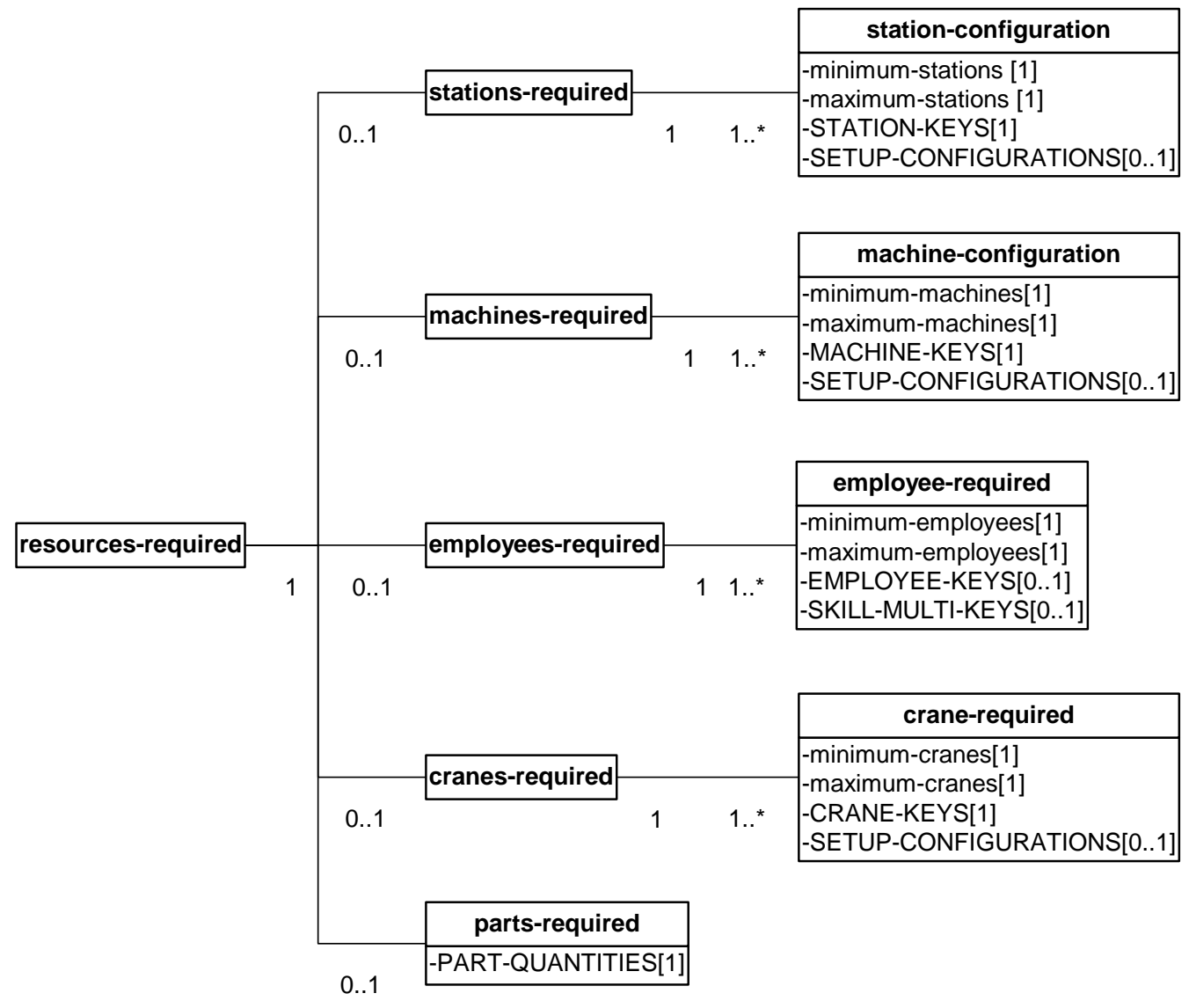

The XML structure for the resources-required element is shown below:

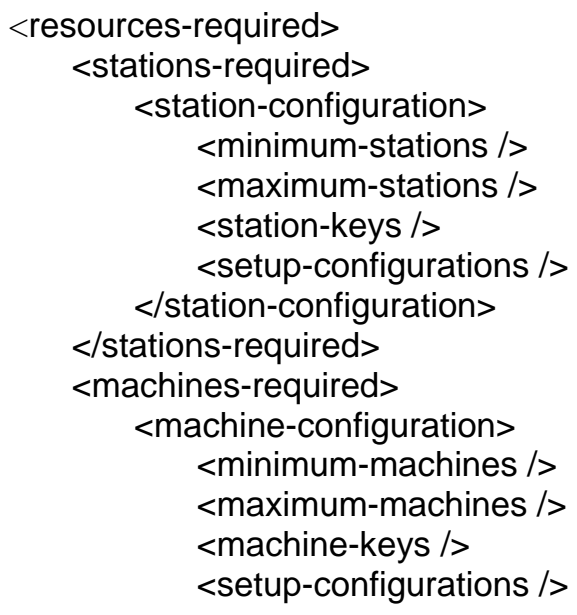




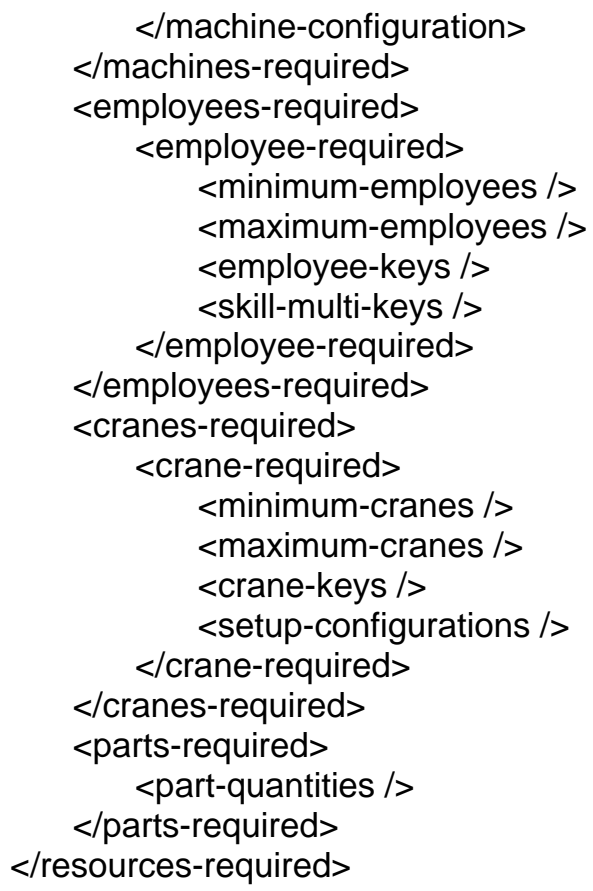

The unique data elements, data element keys, and common data elements introduced in this element are described below.

\section{a) Unique Data Elements}

crane-required: the crane that is required to a particular work item. It is represented by the following data elements: crane-key and setup-definition-keys.

cranes-required: the cranes that are required to a particular work item. It is represented by a set of cranerequired data elements.

employee-required: the employee that is required to a particular work item. It is represented by the following data elements: minimum-employees, maximum-employees, employee-keys, and skill-multi-keys.

employees-required: the employees that are required to a particular work item. It is represented by a set of employee-required data elements.

machine-configuration: the required machines and their setups. It is represented by the following data elements: minimum-machines, maximum-machines, machine-keys, and setup-configurations.

machines-required: the machines that are required to a particular work item. It is represented by the following data elements: minimum-machines, maximum-machines, and machine-configuration.

parts-required: parts that are required to a particular work item. It is represented by the following data elements: part-quantities and part-instance-key.

resources-required: information about the resources that are required to perform a particular work item.

stations-required: the stations that are required to a particular work item. It is represented by the following data elements: minimum-stations, maximum-stations, station-group-key, and station-key.

station-configuration: the required stations and their setups. It is represented by the following data elements: minimum-stations, maximum-stations, station-key, and setup-configurations. 


\section{b) Data Element Keys, Multi-keys, and Key Lists}

crane-keys, employee-keys, machine-keys, skill-multi-keys, and station-keys are used in this element.

\section{c) Common Data Elements}

See Section 2.2 for commonly-used basic data definitions that define these common data attribute(s) and/or element(s): maximum-employees, maximum-machines, maximum-stations, minimum-employees, minimummachines, minimum-station, part-quantities, and setup-configurations.

\subsubsection{Resources Used}

resources-used specifies the resources used by a particular work item. The resources may include stations, machines, employees, cranes, and parts. It is represented by the following data elements: stations-used, machines-used, employees-used, cranes-used, and parts-used.

The UML model for the resources-used element is shown below:

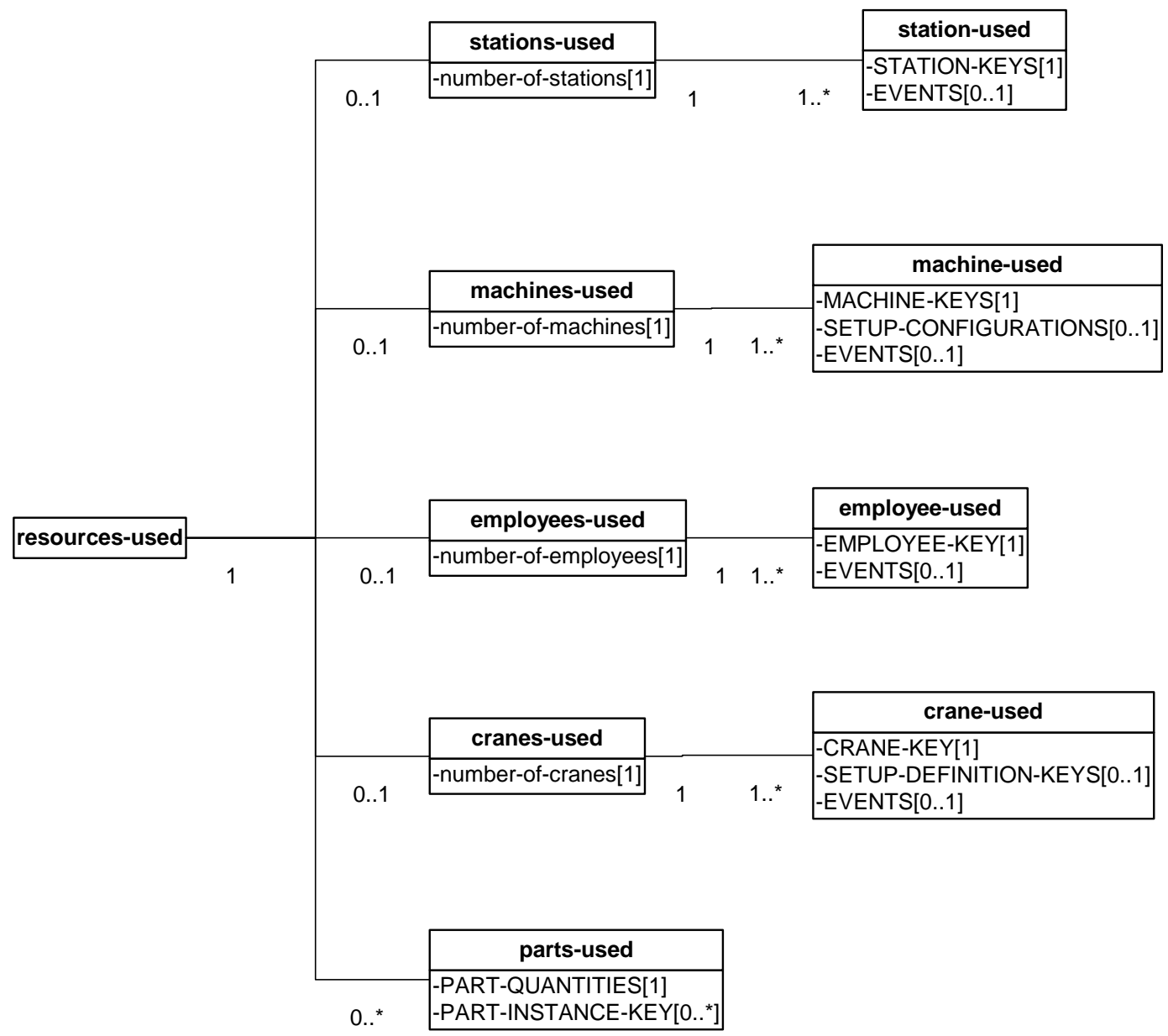

The XML structure for the resources-used element is shown below:

$$
<\text { resources-used }>
$$

$<$ stations-used $>$ 


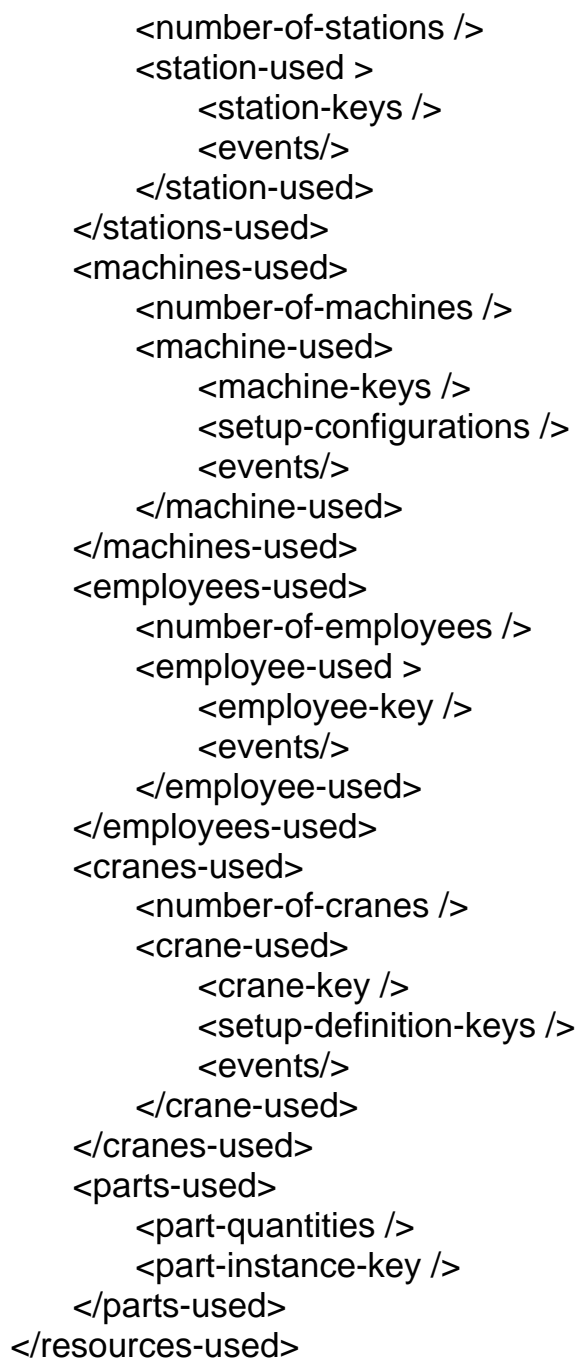

The unique data elements, data element keys, and common data elements introduced in this element are described below.

\section{a) Unique Data Elements}

crane-used: the crane that is used to a particular work item. It is represented by the following data elements: crane-key, setup-definition-keys, and events.

cranes-used: the cranes that are used to a particular work item. It is represented by the following data elements: number-of-cranes and crane-used.

employee-used: the employee that is used to a particular work item. It is represented by the following data elements: number-of-employees, employee-key, and events.

employees-used: the employees that are used to a particular work item. It is represented by the following data elements: number-of-employees and employee-used.

machine-used: the machine that is used to a particular work item. It is represented by the following data elements: machine-keys, setup-configurations, and events. 
machines-used: the machines that are used to a particular work item. It is represented by the following data elements: number-of-machines and machine-used.

parts-used: parts that are used to a particular work item. It is represented by the following data elements: part-quantities and part-instance-key.

resources-used: information about the resources that are used by a particular work item.

station-used: the station that is used to a particular work item. It is represented by the following data elements: station-keys, and events.

stations-used: the stations that is used to a particular work item. It is represented by the following data elements: number-of-stations and station-used.

\section{b) Data Element Keys, Multi-keys, and Key Lists}

crane-key, employee-key, machine-keys, machine-group-key, part-instance-key, setup-definition-keys, station-group-key, and station-keys are used in this element.

\section{c) Common Data Elements}

See Section 2.2 for commonly-used basic data definitions that define these common data attribute(s) and/or element(s): events, number-of-cranes, number-of-employees, number-of-machines, number-of-stations, part-quantities, and setup-configurations.

\subsubsection{Revisions}

revisions specifies information about a set of revisions of the subjects. Information included in the element are each revision's identification, description, date, creators, etc.

The UML model for the revisions element is shown below:

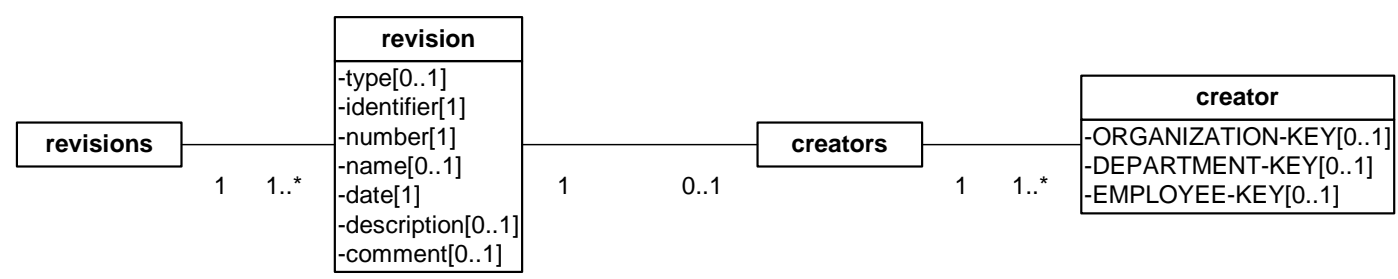

The XML structure for the revisions element is shown below:

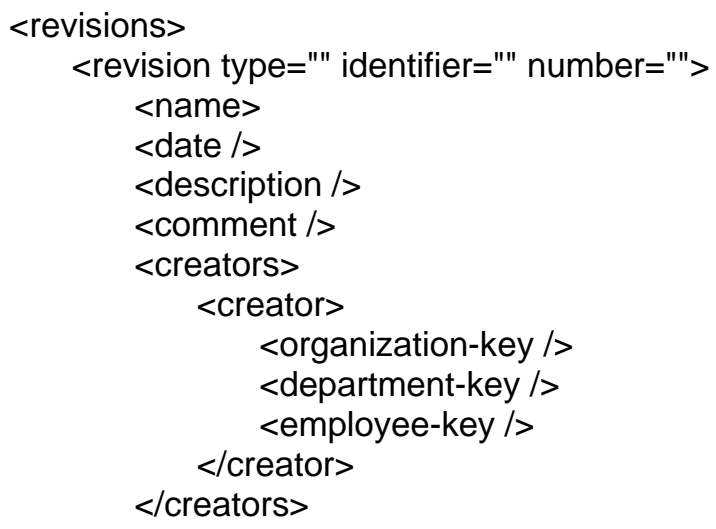




$$
\begin{gathered}
\quad \text { /revision> } \\
\text { </revisions }>
\end{gathered}
$$

The unique data elements, data element keys, and common data elements introduced in this element are described below.

\section{a) Unique Data Elements}

creator: the person/system who drafts the version. It is represented by the following data elements: organization-key, department-key, and employee-key.

creators: the persons/systems who draft the version. It is represented by a set of creator data elements.

revision: information about a particular subject's revision. It is represented by the following data elements: type, identifier, number, name, date, description, comment, and creators.

revisions: a collection of individual revisions.

\section{b) Data Element Keys, Multi-keys, and Key Lists}

department-key, employee-key, and organization-key are used in this element.

\section{c) Common Data Elements}

See Section 2.2 for commonly-used basic data definitions that define these common data attribute(s) and/or element(s): comment, date, description, identifier, name, number, and type.

\subsubsection{Setup Components}

setup-components specifies the components items that are required to support a particular machine setup. The components items may include particular fixture(s), fixtureset(s), too(s), and toolset(s). It is represented by the following data elements: fixture-definition-key, fixtureset-definition-key, tool-definitionkey, toolset-definition-key, and logical-structure.

The UML model for the setup-components element is shown below:

\begin{tabular}{|l|}
\hline \multicolumn{1}{|c|}{ setup-components } \\
\hline -FIXTURE-DEFINITION-KEY[0..*] \\
-FIXTURESET-DEFINITION-KEY[0..*] \\
-TOOL-DEFINITION-KEY[O..*] \\
-TOOLSET-DEFINITION-KEY[0..*] \\
\hline
\end{tabular}

The XML structure for the setup-components element is shown below:

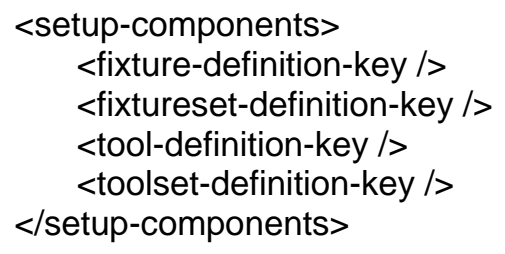

The unique data elements, data element keys, and common data elements introduced in this element are described below. 


\section{a) Unique Data Elements}

setup-components: information about the components items that required to support a particular machine setup.

\section{b) Data Element Keys, Multi-keys, and Key Lists}

fixture-definition-key, fixtureset-definition-key, tool-definition-key, and toolset-definition-key are used in this element.

\section{c) Common Data Elements}

None.

\subsubsection{Setup Configurations}

setup-configurations specifies a collection of configurations that are used to support particular machines' setups. It identifies each machine setup's source definition and the tools/fixtures/toolsets/fixtursets that are required for this machine setup. It is represented by a set of setup-configuration data elements.

The UML model for the setup-configurations element is shown below:

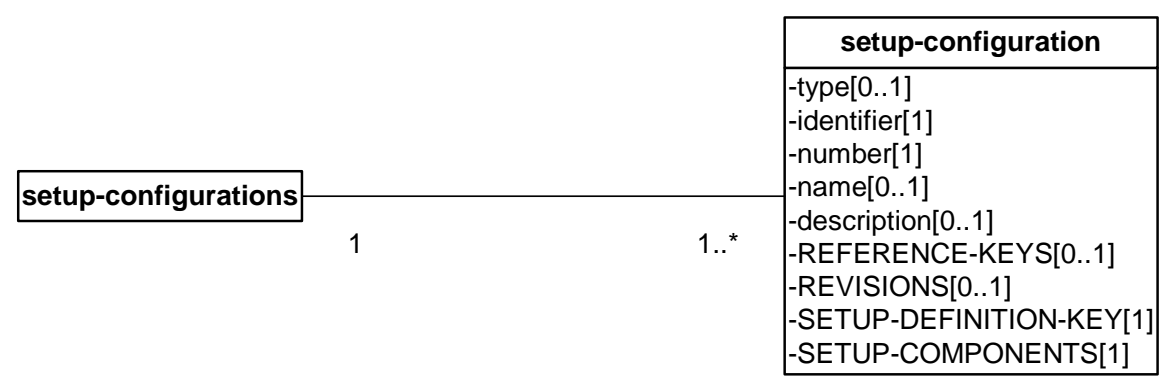

The XML element for the setup-configurations element is shown below:

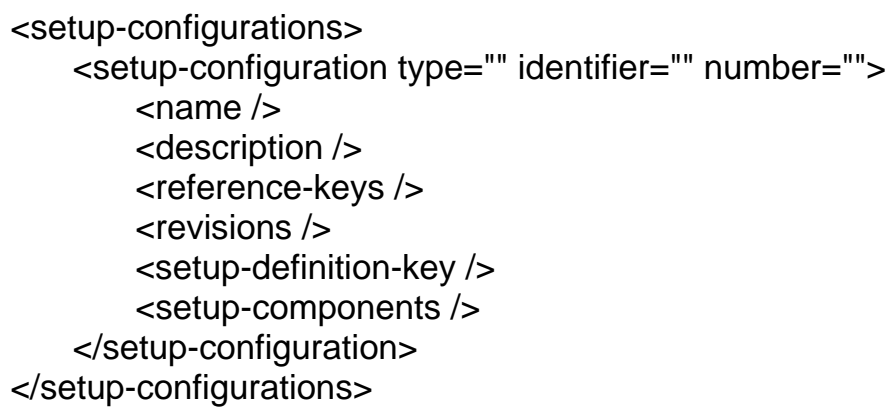

The unique data elements, data element keys, and common data elements introduced in this element are described below.

\section{a) Unique Data Elements}

setup-configuration: a configuration about a particular machine setup. The configuration describes the type of setup and changeover, and the component items required to do the setup. setup-configuration is represented by the following data elements: type, identifier, number, name, description, reference-keys, revisions, setup-definition-key, and setup-components. 
setup-configurations: a collection of individual setup configurations.

\section{b) Data Element Keys, Multi-keys, and Key Lists}

reference-keys and setup-definition-key are used in this element.

\section{c) Common Data Elements}

See Section 2.2 for commonly-used basic data definitions that define these common data attribute(s) and/or element(s): description, identifier, name, number, revisions, setup-components, and type.

\subsubsection{Status Code}

status-code specifies the state of a particular action/function. It is represented by the following data elements: type, identifier, number, name, value, and default.

The UML model for the status-code element is shown below:

\begin{tabular}{|l|}
\hline status-code \\
\hline -type[0..1] \\
-identifier[1] \\
-number[1] \\
-name[0..1] \\
-value[0..1] \\
-default[0..1] \\
\hline
\end{tabular}

The XML structure for the status-code element is shown below:

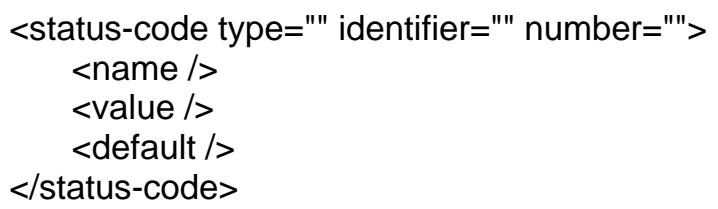

The unique data elements, data element keys, and common data elements introduced in this element are described below.

\section{a) Unique Data Elements}

default: a pre-assigned value that is used when the value of the status code is not specified. status-code: information about the state of a particular action/function.

\section{b) Data Element Keys, Multi-keys, and Key Lists}

No keys are used in this element.

\section{c) Common Data Elements}

See either Section 2.2 for commonly-used basic data definitions or the list at the beginning of Section 0 for the sections that define these common data attribute(s) and/or element(s): identifier, name, number, type, and value.

\subsubsection{Stock Level Quantities}


stock-level-quantities specifies the quantities of tools, fixtures, materials, or parts for various purposes. It is represented by the following data elements: allocated-quantity, back-order-quantity, onhand-quantity, on-order-quantity, required-quantity, safety-stock-quantity, replenishment-volume-quantity, and work-in-progress-quantity.

The UML model for the stock-level-quantities element is shown below:

\begin{tabular}{|l|}
\hline \multicolumn{1}{|c|}{ stock-level-quantities } \\
\hline -on-hand-quantity[1] \\
-allocated-quantity[0..1] \\
-safety-stock-quantity[0..1] \\
-replenishment-volume-quantity[0..1] \\
-required-quantity[0..1] \\
-on-order-quantity[0..1] \\
-back-order-quantity[0..1] \\
-work-in-process-quantity[0..1] \\
\hline
\end{tabular}

The XML structure for the stock-level-quantities element is shown below:

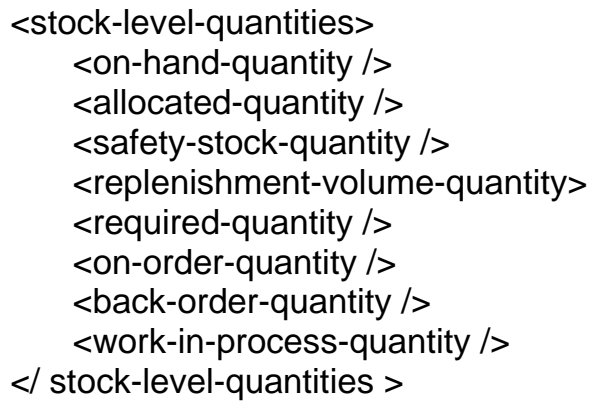

The unique data elements, data element keys, and common data elements introduced in this element are described below.

\section{a) Unique Data Elements}

stock-level-quantities: information about the quantities of tools, fixtures, materials, or parts for various purposes.

\section{b) Data Element Keys, Multi-keys, and Key Lists}

No keys are used in this element.

\section{c) Common Data Elements}

See Section 2.2 for commonly-used basic data definitions that define these common data attribute(s) and/or element(s): allocated-quantity, back-order-quantity, on-hand-quantity, on-order-quantity, replenishmentvolume-quantity, required-quantity, safety-stock-quantity, and work-in-progress-quantity.

\subsubsection{Suppliers}

suppliers specifies contact information about an organization's suppliers. It is represented by a set of organizational-contact data elements.

The UML model for the suppliers element is shown below: 
The XML structure for the suppliers element is shown below:

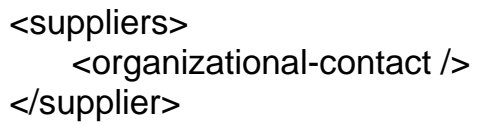

The unique data elements, data element keys, and common data elements introduced in this element are described below.

\section{a) Unique Data Elements}

suppliers: contact information about an organization's suppliers.

\section{b) Data Element Keys, Multi-keys, and Key Lists}

No keys are used in this element.

\section{c) Common Data Elements}

See Section 2.2 for commonly-used basic data definitions that define these common data attribute(s) and/or element(s): organizational-contact.

\subsubsection{Units of Measurement}

units-of-measurement describes various measurement units used in the file, for example, the measurement may be for distance, speed, mass, time duration, or currency. The data associated with units-ofmeasurements are the following: type, identifier, number, name, description, reference-keys, angular-units, currency-units, distance-units, length-units, mass-units, speed-units, time-duration-units, and volume-units.

The UML model for the units-of-measurement element is shown below:

\begin{tabular}{|l|}
\hline \multicolumn{1}{|c|}{ units-of-measurement } \\
\hline -type[0..1] \\
-identifier[1] \\
-number[1] \\
-name[0..1] \\
-description[0..1] \\
-REFERENCE-KEYS[0..1] \\
-angular-units[0..1] \\
-currency-units[0..1] \\
-distance-units[0.1] \\
-length-units[0..1] \\
-mass-units[0..1] \\
-speed-units[0..1] \\
-time-duration-units[0..1] \\
-volume-units[0..1] \\
\hline
\end{tabular}

The XML structure for the units-of-measurement element is shown below: 


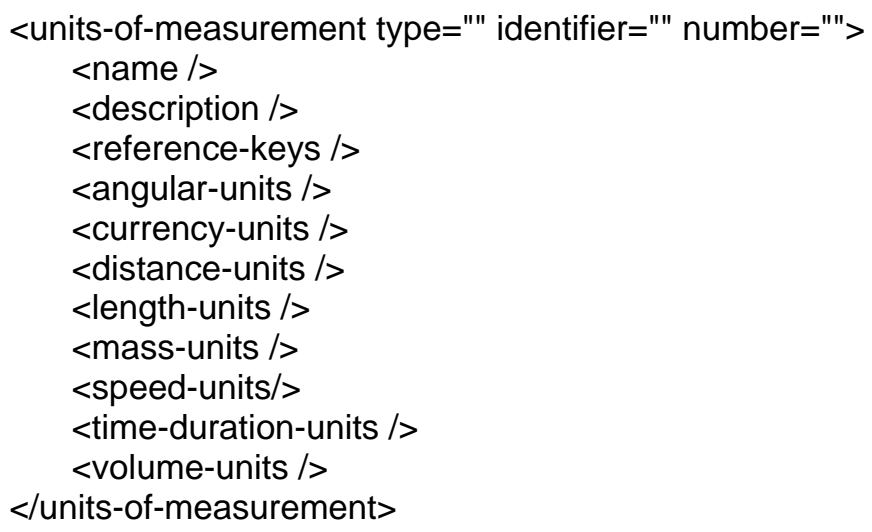

The unique data elements, data element keys, and common data elements introduced in this element are described below.

\section{a) Unique Data Elements}

units-of-measurement: information about various measurements units used in the file.

\section{b) Data Element Keys, Multi-keys, and Key Lists}

No keys are used in this element.

\section{c) Common Data Elements}

See Section 2.2 for commonly-used basic data definitions that define these common data attribute(s) and/or element(s): angular-units, currency-units, description, distance-units, identifier, length-units, mass-units, name, number, reference-keys, speed-units, time-duration-units, type, and volume-units.

\subsubsection{Work Actual Progress}

work-actual-progress specifies a particular work item's actual working progress, including the date of material availability, a code of work status, all resources used, all events took placed, total setup time used, total operation time used, work completion percentage, number of part(s) completed, and a cost summary. It is represented by the following data elements: material-availability-date, status-code, resources-used, events, setup-time-applied, operation-time-applied, percent-completion, parts-completed, and costsummary.

The UML model for the work-actual-progress element is shown below:

\begin{tabular}{|c|c|c|c|}
\hline work-actual-progress & & & \\
\hline $\begin{array}{l}\text {-material-availability-date[0..1] } \\
\text {-STATUS-CODE[0..1] }\end{array}$ & & & \\
\hline -RESOURCES-USED[0..1] & & & parts-completed \\
\hline $\begin{array}{l}\text {-EVENTS[0..1] } \\
\text {-setup-time-applied[0..1] } \\
\text {-operation-time-applied[0..1] } \\
\text {-percent-completion[0..1] } \\
\text {-COST-SUMMARY[0..1] }\end{array}$ & 1 & $0 . .1$ & -PART-QUANTITIES[1] \\
\hline
\end{tabular}

The XML structure for the work-actual-progress element is shown below:

$<$ work-actual-progress $>$ 


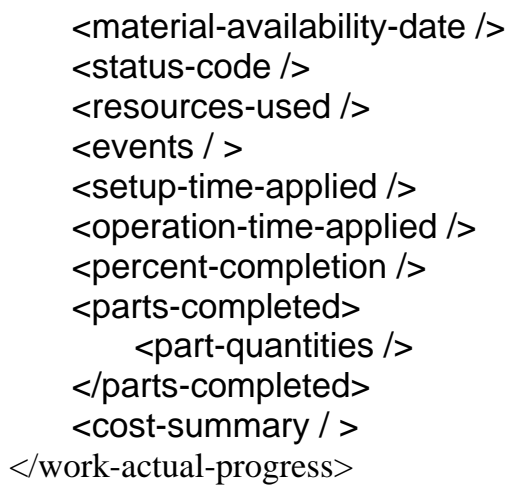

The unique data elements, data element keys, and common data elements introduced in this element are described below.

\section{a) Unique Data Elements}

operation-time-applied: time spent on performing operation.

parts-completed: the part type and quantity of each part that resulted from the work item. It is represented by a collection of part-quantities data elements.

percent-completion: a completion percentage of the part(s).

setup-time-applied: time spent on setting up machine(s).

work-actual-progress: information about a particular work item’s actual working progress.

\section{b) Data Element Keys, Multi-keys, and Key Lists}

No keys are used in this element.

\section{c) Common Data Elements}

See Section 2.2 for commonly-used basic data definitions that define these common data attribute(s) and/or element(s): cost-summary, events, material-availability-date, part-quantity, resources-used, and statuscode.

\subsubsection{Work Assignments}

work-assignments specifies information about a particular resource’s work assignments. It includes work items, required setup, and all events resulted from each assignment. It is represented by a set of workassignment data elements.

The UML model for the work-assignments element is shown below:

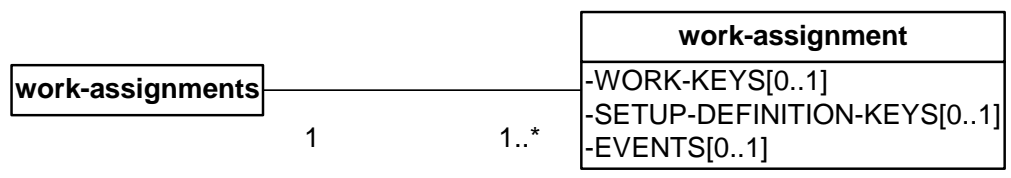

The XML structure for the work-assignments element is shown below: 


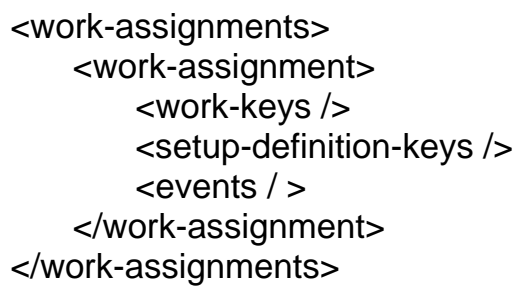

The unique data elements, data element keys, and common data elements introduced in this element are described below.

\section{a) Unique Data Elements}

work-assignment: information about a particular resource's work assignment. It is represented by the following data elements: work-keys, setup-definition-keys, and events.

work-assignments: a collection of individual work assignments.

\section{b) Data Element Keys, Multi-keys, and Key Lists}

No keys are used in this element.

\section{c) Common Data Elements}

See Section 2.2 for commonly-used basic data definitions that define these common data attribute(s) and/or element(s): events.

\subsubsection{Work Scheduled Progress}

work-scheduled-progress specifies a particular work item's scheduled progress, including the date of material availability, a code of work status, all resources assigned, and all events took place. It is represented by the following data elements: material-availability-date, status-code, and events.

The UML model for the work-scheduled-progress element is shown below:

\begin{tabular}{|l|}
\hline \multicolumn{1}{|c|}{ work-scheduled-progress } \\
\hline -material-availability-date[0..1] \\
-STATUS-CODE[0..1] \\
-RESOURCES-ASSIGNED[0..1] \\
-EVENTS[0..1] \\
-COST-SUMMARY[0..1] \\
\hline
\end{tabular}

The XML structure for the work-scheduled-progress element is shown below:

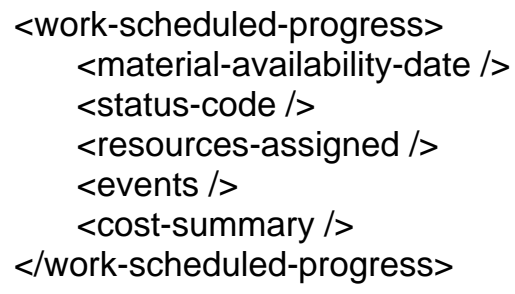


The unique data elements, data element keys, and common data elements introduced in this element are described below.

\section{a) Unique Data Elements}

work-scheduled-progress: information about a particular work item’s scheduled progress.

\section{b) Data Element Keys, Multi-keys, and Key Lists}

No keys are used in this element.

\section{c) Common Data Element}

See Section 2.2 for commonly-used basic data definitions that define these common data attribute(s) and/or element(s): cost-summary, events, material-availability-date, resource-assigned, and status-code. 


\section{MACHINE SHOP DATA STRUCTURE}

The manufacturing shop data elements are presented in the following format:

- $\quad$ summary description of the element

- a Unified Modeling Language (UML) information model for the element

- an eXtensible Markup Language (XML) template for coding the data of the element

- unique data elements: data elements that are uniquely defined within this particular element

- data element keys, multi-keys, and key lists: key or pointer elements that are used to reference objects defined elsewhere in the model (refer to Section 2.1).

- common data elements: data elements that are used repeatedly by other elements within the information model (refer to Section 2.2 and 2.3)

This section presents major elements of machine shop data structure. The elements are further defined in the following subsections:

\section{1_organizations}

3.2 departments

3.3 calendars

3.4 resources

3.5_machines

3.6 stations

3.7 cranes

3.8 employees

3.9 tool-catalog

3.10 fixture-catalog

3.11 layout

3.12 skill-definitions

3.13 setup-definitions

3.14 operation-definitions

3.15 maintenance-definitions

3.16_parts

3.17 bills-of-materials

3.18 inventory

3.19_part-inventory

3.20 materials-inventory

3.21 tool-inventory

3.22 fixture-inventory

3.23 procurements

3.24 process-plans

3.25 routing-sheets

3.26 operation-sheets

3.27 machine-programs

3.28 work

3.29 orders

3.30 order-items

3.31_jobs

3.32 tasks

3.33 maintenance-orders

3.34 pick-orders

3.35 tool-orders

3.36_ schedules

3.37 time-sheets

3.38 references

3.39_probability-distributions 
The UML information model for the overall shop-data element is shown below:
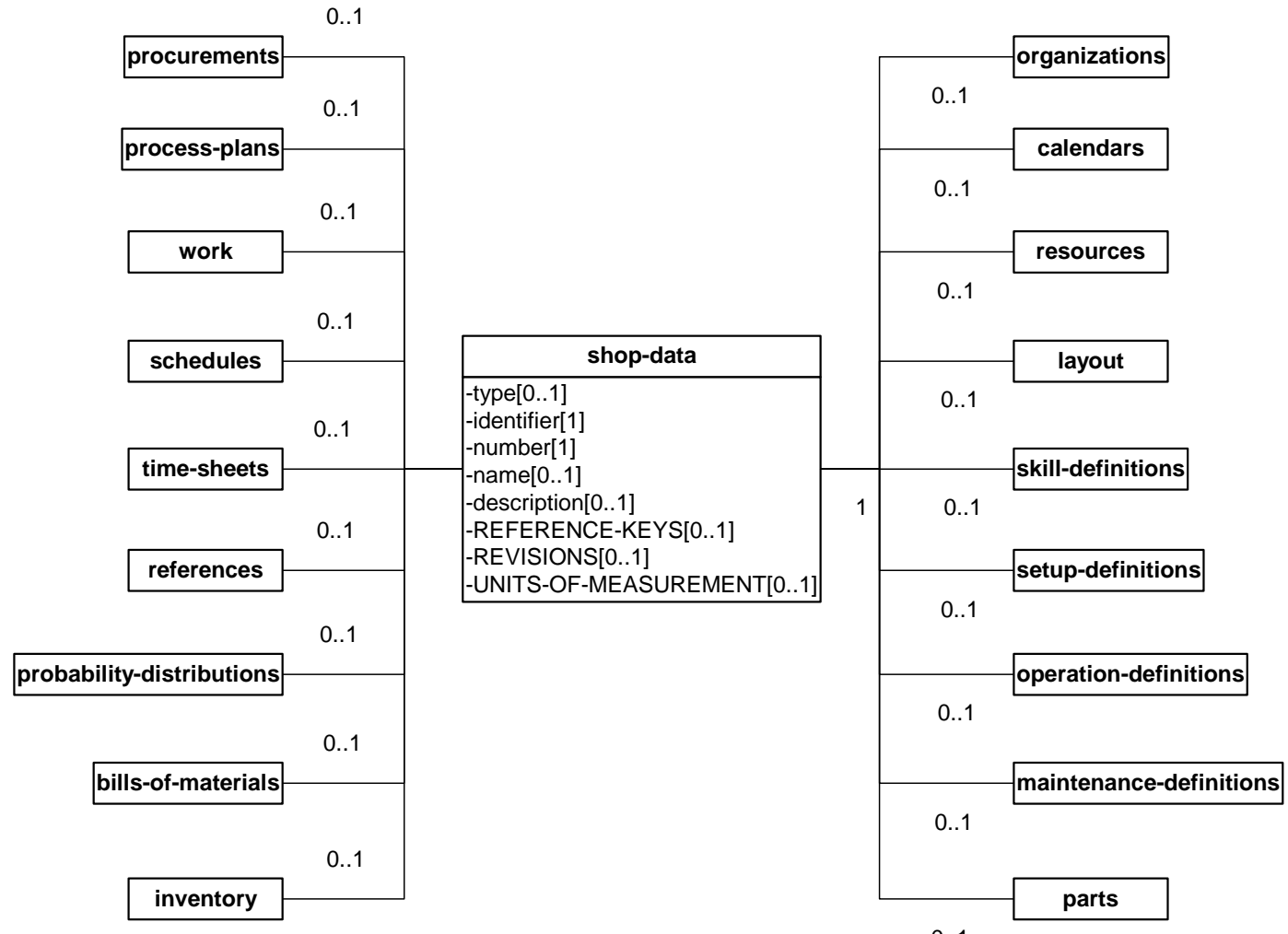

The overall XML structure for the shop-data element is shown below:

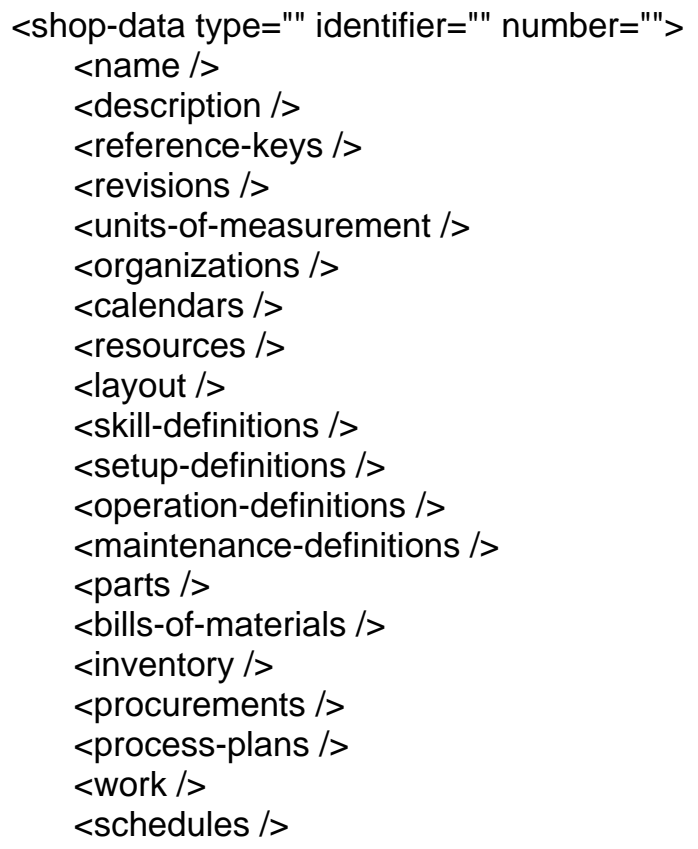




\section{$<$ time-sheets $/>$ $<$ references $/>$ \\ $<$ probability-distributions / $>$ $</$ shop-data $>$}

\subsection{Organizations}

organizations is used to maintain organizational structure, contacts and addresses information for the manufacturing organization, its customers and suppliers. The departmental structure of an organization may be defined using the departments element, see section 3.2. The position-descriptions element may be used to specify a position-description for each position in the organization. The organizations element is illustrated below:

The UML information model for the organizations element is shown below:

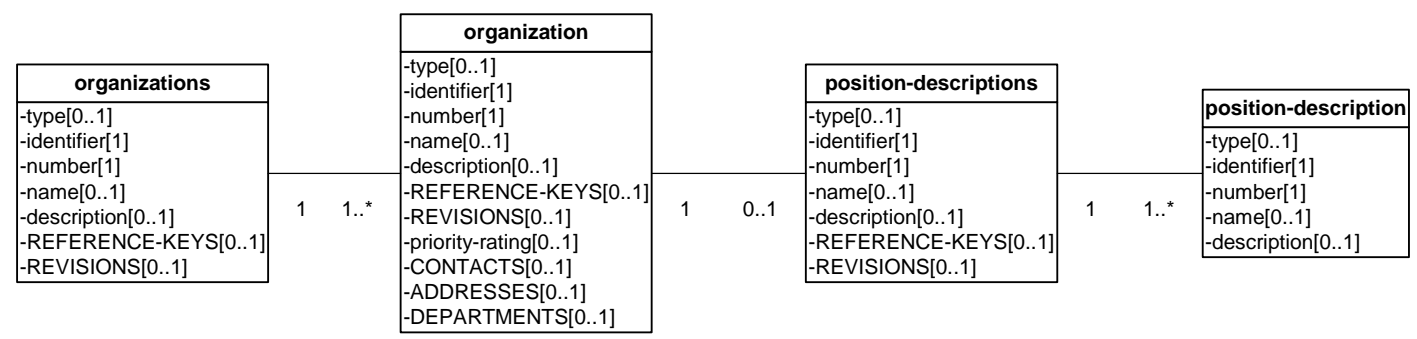

The XML structure for the organizations element is shown below:

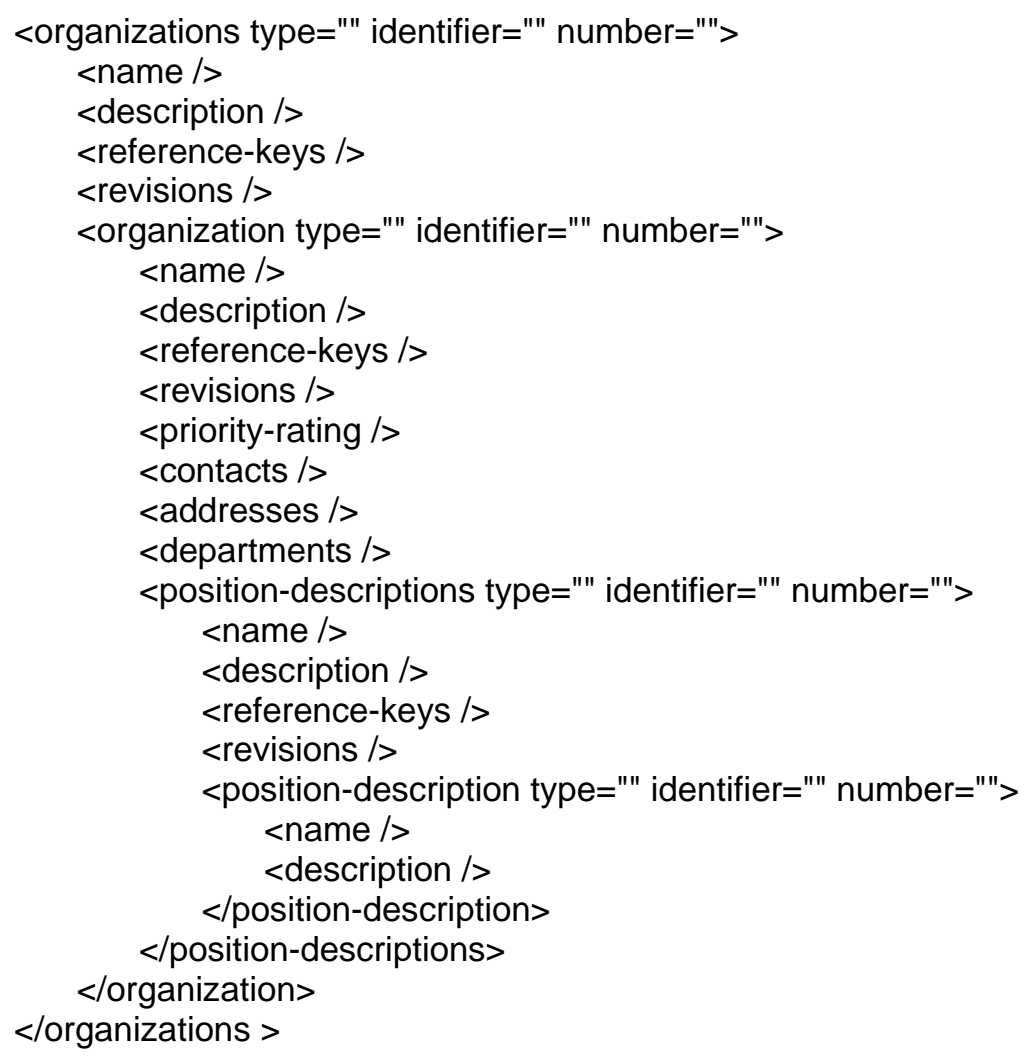


The unique data elements, data element keys, and common data elements introduced in this element are described below.

\section{a) Unique Data Elements}

departments: the departments that contained within an organization, see the departments element in Section 3.2. Use of the departments element is optional, since the departmental structure of external organizations may not be known or relevant.

position-description: a particular job position within the organization.

position-descriptions: a list of position descriptions for the organization.

organization: the organization that is being modeled and external organizations with which it interacts, e.g., customers and suppliers.

organizations: a collection of organizational information such as points of contact and addresses for internal or external organizations, e.g., suppliers, customers.

\section{b) Data Element Keys, Multi-keys, and Key Lists}

The following keys are used in this element: reference-keys. Elements within resources, parts, procurements, revisions, and work use the organization-key and contact-key to reference the data elements in the organizations element.

\section{c) Common Data Elements}

See Sections 2.2 and 2.3 for a discussion of these common data attributes and elements used by this element: addresses, contacts, description, identifier, name, number, priority-rating, revisions, and type.

\subsection{Departments}

departments defines the departments within the organization, the child departments of the department, the positions within the department, and the employees occupying those positions. The position elements within department is used to identify a position-description contained within position-descriptions. The departments element is illustrated below:

The UML information model for the departments element is shown below:

\begin{tabular}{|c|c|c|c|c|c|c|}
\hline \multirow[b]{2}{*}{ departments } & \multicolumn{2}{|r|}{ department } & & \multirow{5}{*}{ positions } & & position \\
\hline & & \multirow{7}{*}{$\begin{array}{l}\text {-type[0..1] } \\
\text {-identifier[1] } \\
\text {-number[1] } \\
\text {-name[0..1] } \\
\text {-level[0..1] } \\
\text {-CONTACTS[0..1] } \\
\text {-ADDRESSES[0..1] } \\
\text {-CALENDAR-MULTI-KEY[0..1] } \\
\text {-CHILD-DEPARTMENT-MULTI-KEYS[0..1] }\end{array}$} & & & & \multirow{7}{*}{$\begin{array}{l}\text {-type[0..1] } \\
\text {-identifier[1] } \\
\text {-number[1] } \\
\text {-name[0..1] } \\
\text {-hourly-rate[0..1] } \\
\text {-ADDRESSES[0..1] } \\
\text {-POSITION-DESCRIPTION-KEY[0..1] } \\
\text {-number-of-positions[0..1] } \\
\text {-EMPLOYEE-KEYS[0..1] }\end{array}$} \\
\hline \multirow{6}{*}{\begin{tabular}{|l|}
-type[0..1] \\
-identifier[1] \\
-number[1] \\
-name[0..1] \\
-description[0..1] \\
-priority-rating[0..1]
\end{tabular}} & & & & & & \\
\hline & & & & & & \\
\hline & \multirow{4}{*}{$11 . .^{*}$} & & & & & \\
\hline & & & $\perp 1 .$. & & $\perp 1 . .{ }^{n}$ & \\
\hline & & & & & & \\
\hline & & & & & & \\
\hline
\end{tabular}

The XML structure for the departments element is shown below:

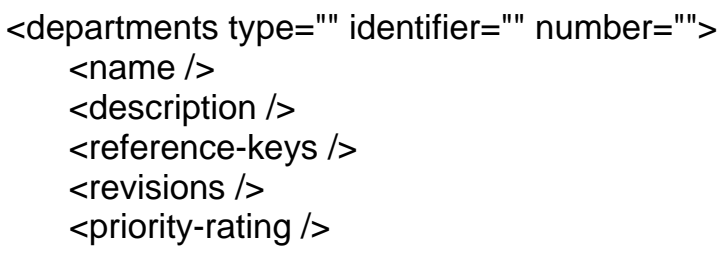




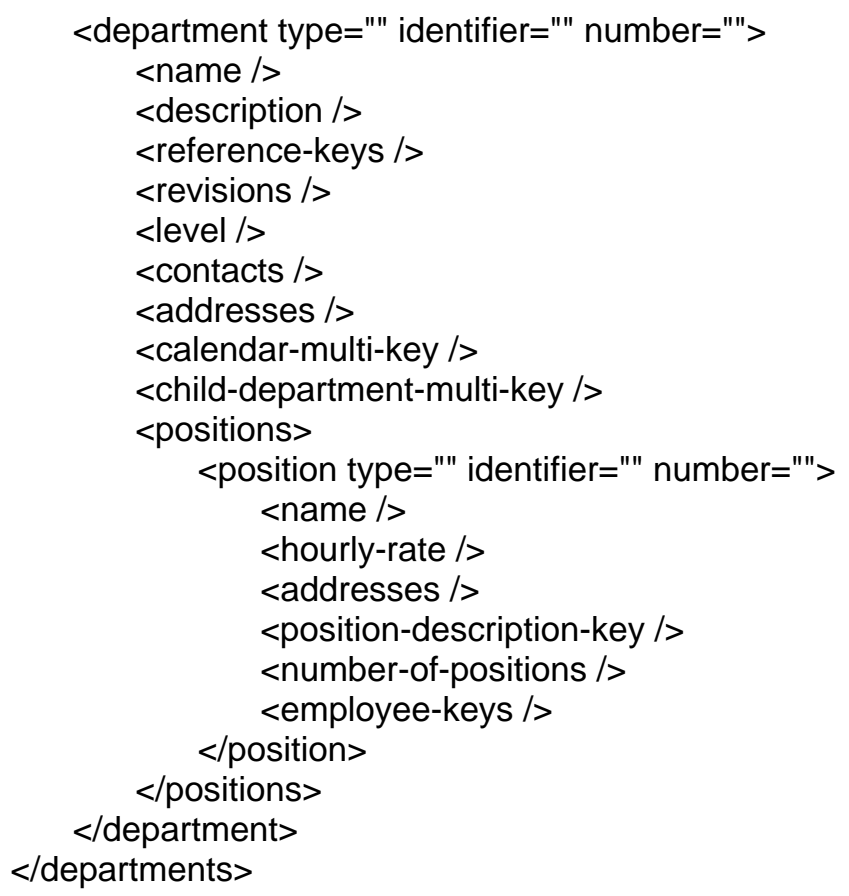

The unique data elements, data element keys, and common data elements introduced in this element are described below.

\section{a) Unique Data Elements}

department: an element that identifies a particular organizational element and its relationships to other organization elements, department-wide shift schedules used, the positions and employees in the department.

departments: a collection of individual departments.

level: the hierarchical level within the organization at which the department is resided. The convention is that the highest level in the organization is given the number " 1 ". Child departments are organized in a hierarchical tree structure and have increasingly higher level numbers. A child department does not necessarily have to be at the next sequentially higher number. For example, a level " 3 " department may be the child department of a level "1" department. (Note: Departmental level definitions and keys will be added in a later version of this specification.)

position: a specific departmental role held by an employee. An employee may hold multiple positions in a department, in different departments, and different organizations.

positions: a list of positions contained within a department. positions is defined by one or more position data elements.

\section{b) Data Element Keys, Multi-keys, and Key Lists}

calendar-multi-key, child-department-multi-key, employee-keys, and position-description-key are used in this element. calendar-multi-key is used to identify the effective shift schedule and non-working days associated with a particular department. child-department-multi-keys is used to specify a list of one or more departments that are subordinate to the specified department. The multi-key provides keys to identify both the organization and department elements for the child department. employee-keys is used to specify the list of one or more employee keys for the employees that occupy a position in the department. position- 
description-key is used to specify a specific position in a department. Elements employees and revisions use a department-key and position-multi-keys to reference the data elements in the departments.

\section{c) Common Data Elements}

See Sections 2.2 and 2.3 for a discussion of these common data attributes and elements used by this element: addresses, contacts, description, hourly-rate, identifier, name, number, number-of-positions, priority-rating, and type.

\subsection{Calendars}

calendars identifies the shift schedules that are in effect for a period of time, breaks, holidays. The calendars element is illustrated below:

The UML information model for the calendars element is shown below:
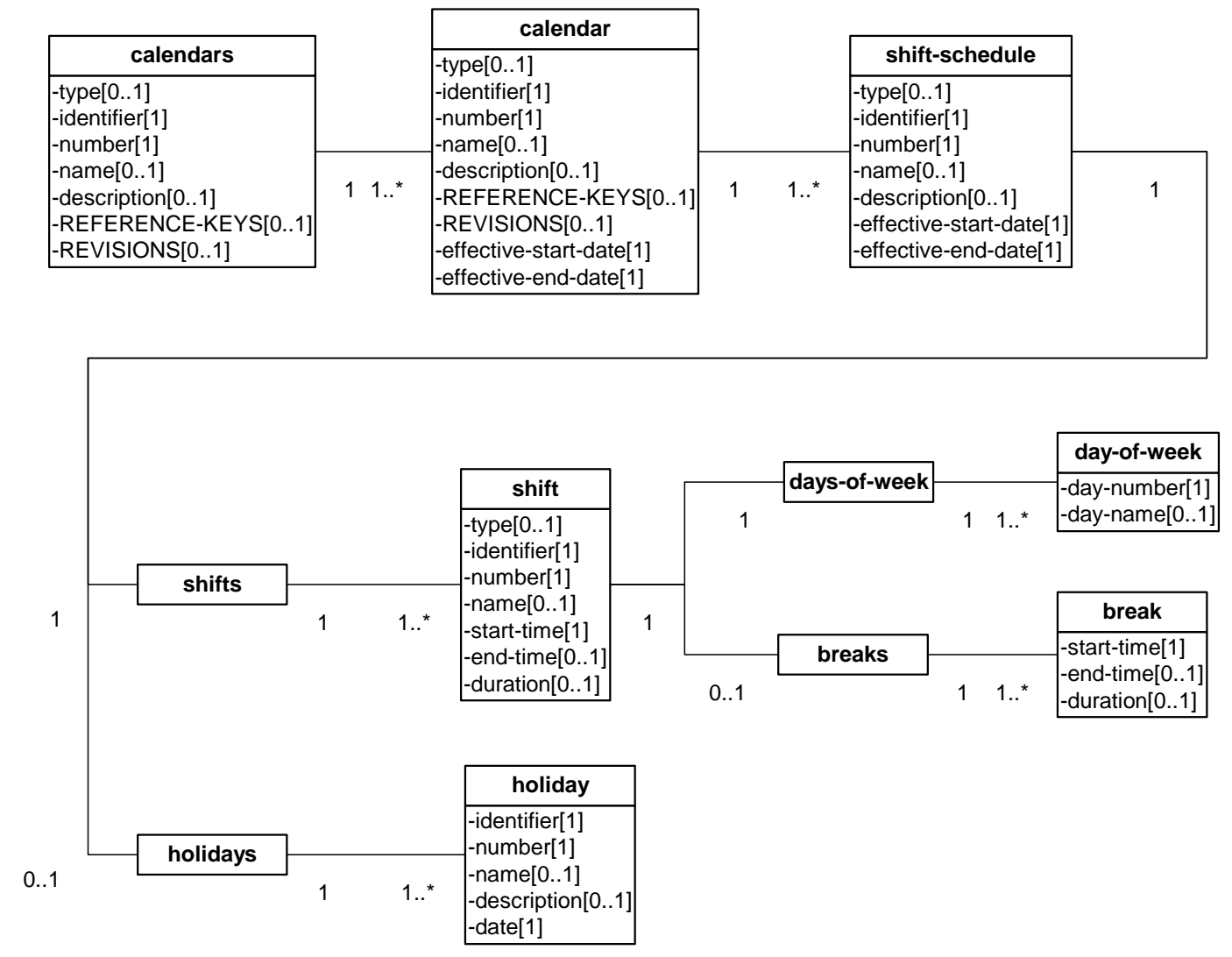

The XML structure for the calendars element is shown below:

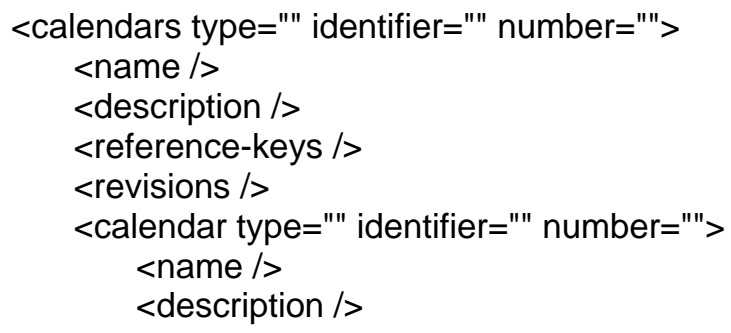




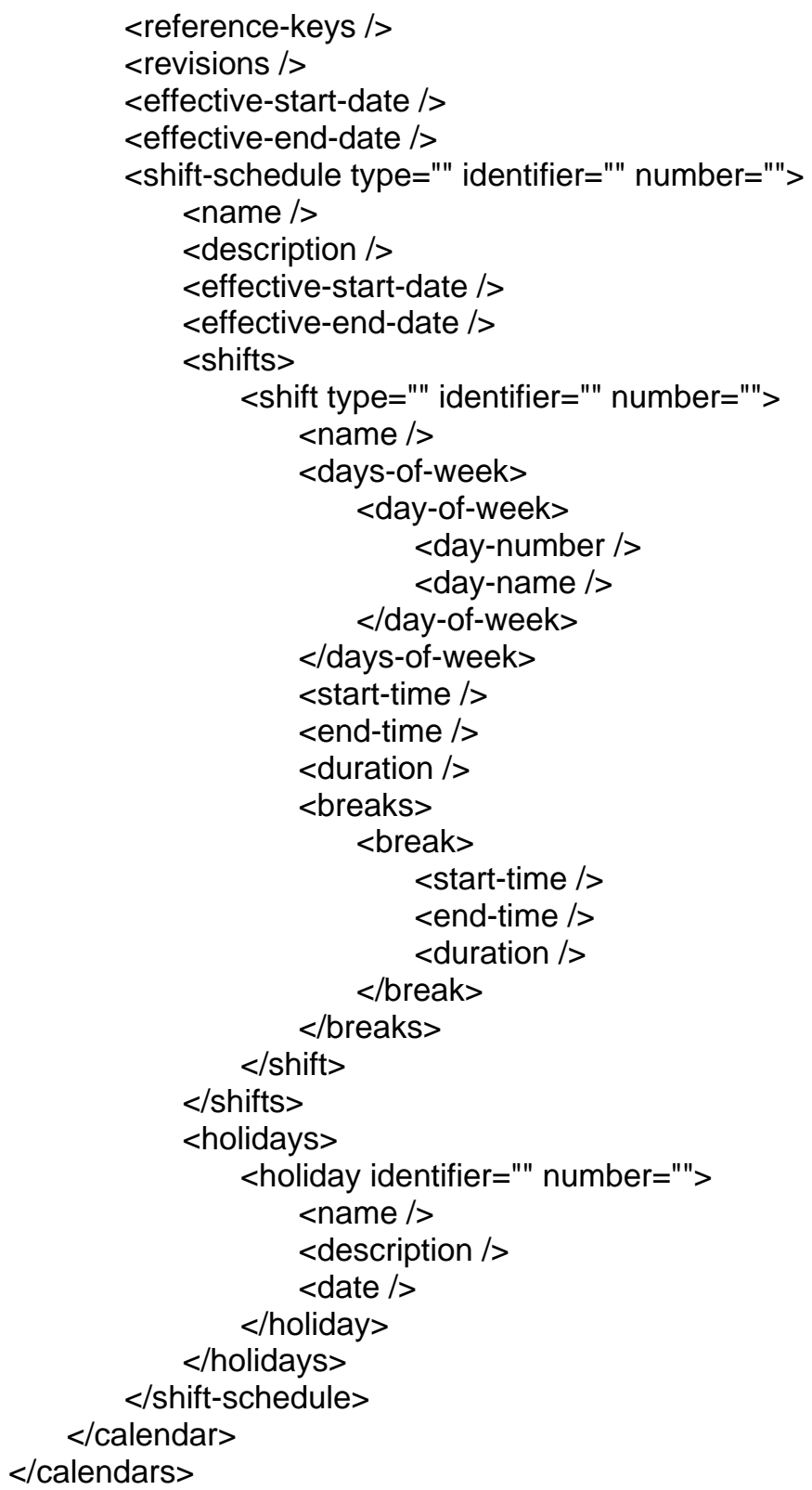

The unique data elements, data element keys, and common data elements introduced in this element are described below.

\section{a) Unique Data Elements}

break: a scheduled free time, i.e., non-working time, during a particular work shift.

breaks: a collection of individual break definitions.

calendar: information about the shift schedules that are in effect for a period of time, breaks, and holidays. calendars: a collection of individual calendar definitions.

day-name: Sunday, Monday, Tuesday, Wednesday, Thursday, Friday, or Saturday. 
day-number: 0, 1, 2, 3, 4, 5, or 6, (representing Sunday, Monday, Tuesday, Wednesday, Thursday, Friday, or Saturday.)

days-of-week: the working days within the week. days-of-week is defined by a set of day-number and dayname data elements.

holiday: a non-work day specified by the organization.

holidays: a collection of individual holidays.

shift: a mechanism for representing a particular work shift.

shifts: a list of one or more shift data elements.

shift-schedule: a mechanism for presenting all work shifts and holidays for a range of dates.

\section{b) Data Element Keys, Multi-keys, and Key Lists}

reference-keys are used in this element. Elements within resources and departments use the calendar-multikey to reference the data elements in the calendars element.

\section{c) Common Data Elements}

See Sections 2.2 and 2.3 for a discussion of these common data attributes and elements used by this element: date, description, duration, effective-end-date, effective-start-date, end-time, identifier, name, number, revisions, start-time, and type.

\subsection{Resources}

resources describes all the resources that may be assigned to tasks in the shop. The resource types available in the machine shop environment include: stations and machines, cranes, employees, tool and fixture catalog items.

The UML information model for the resources element is shown below:

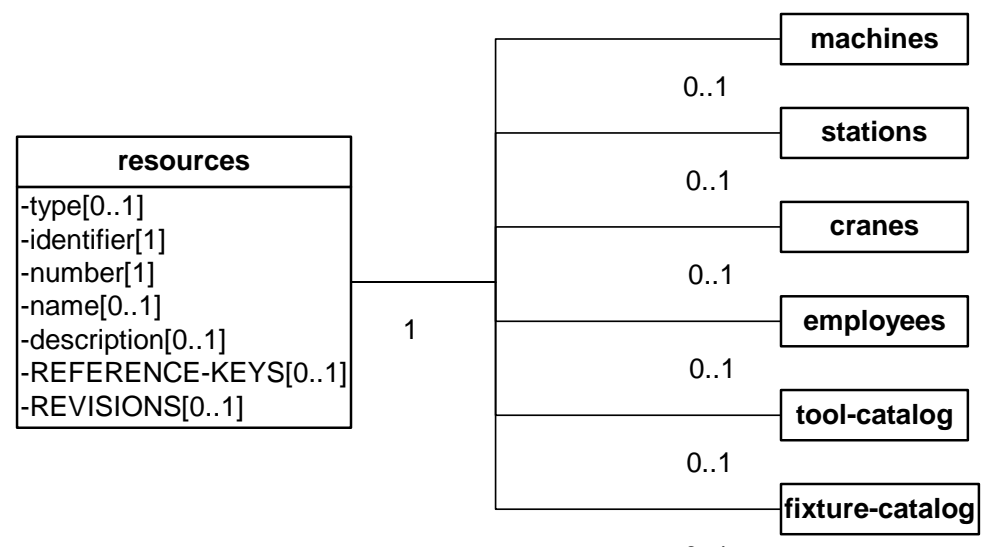

0.1

The XML structure for the resources element is shown below:

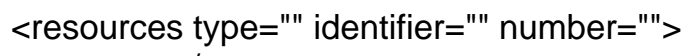




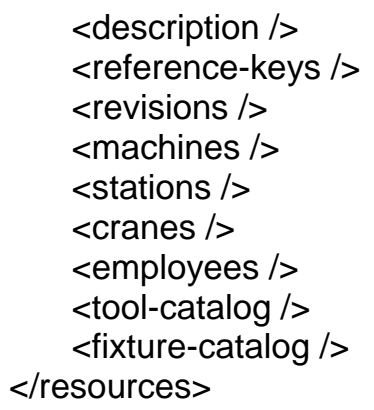

The unique data elements, data element keys, and common data elements introduced in this structure are described below.

\section{a) Unique Data Elements}

cranes: an element for specifying a collection of crane-type resources (refer to Section 3.7)

employees: an element for specifying a collection of employee-type resources (refer to Section 3.8)

machines: an element for specifying a collection of machine-type or machine-group-type resources (refer to Section 3.5)

fixture-catalog: an element for specifying a collection of fixture-type resources (refer to Section 3.10)

resources: a collection of shop resource records, e.g., employees, machines, and stations.

stations: an element for specifying a collection of station-type or station-group-type resources (refer to Section 3.6)

tool-catalog: an element for specifying a collection of tool-type resources (refer to Section 3.9)

\section{b) Data Element Keys, Multi-keys, and Key Lists}

reference-keys is used in this structure. Keys within resources-assigned, resources-required, and resources-used point at elements in this structure.

\section{c) Common Data Elements}

See Sections 2.2 and 2.3 for a discussion of these common data attributes and elements used by this element: description, identifier, name, number, revisions, and type.

\subsection{Machines}

machines lists each machine that exists within the shop. The machine element provides descriptive information, hourly rate, technical specifications, status, station associations, and reliability data for a machine.

The UML information model for the machines element is shown below: 


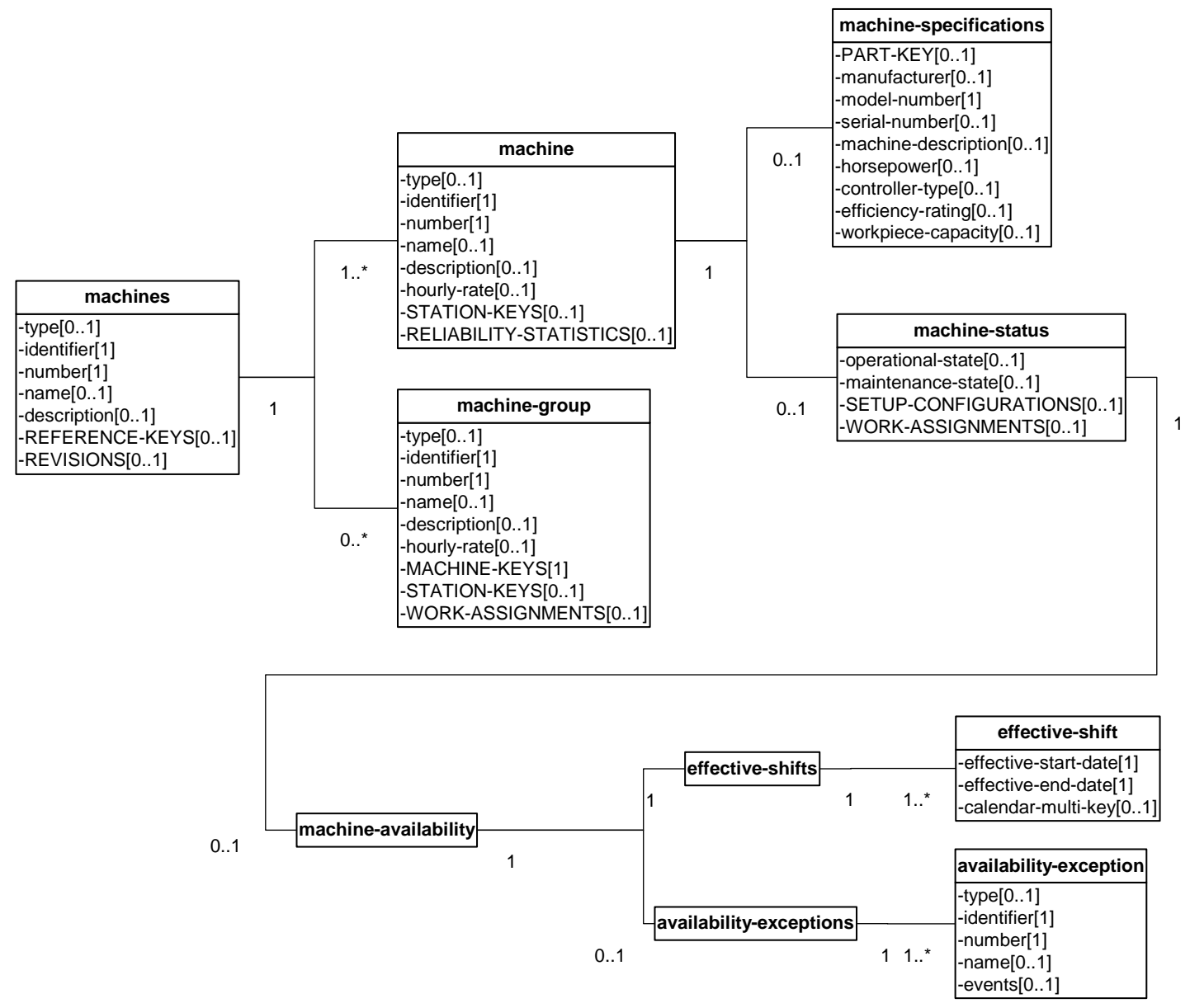

The XML structure for the machines element is shown below:

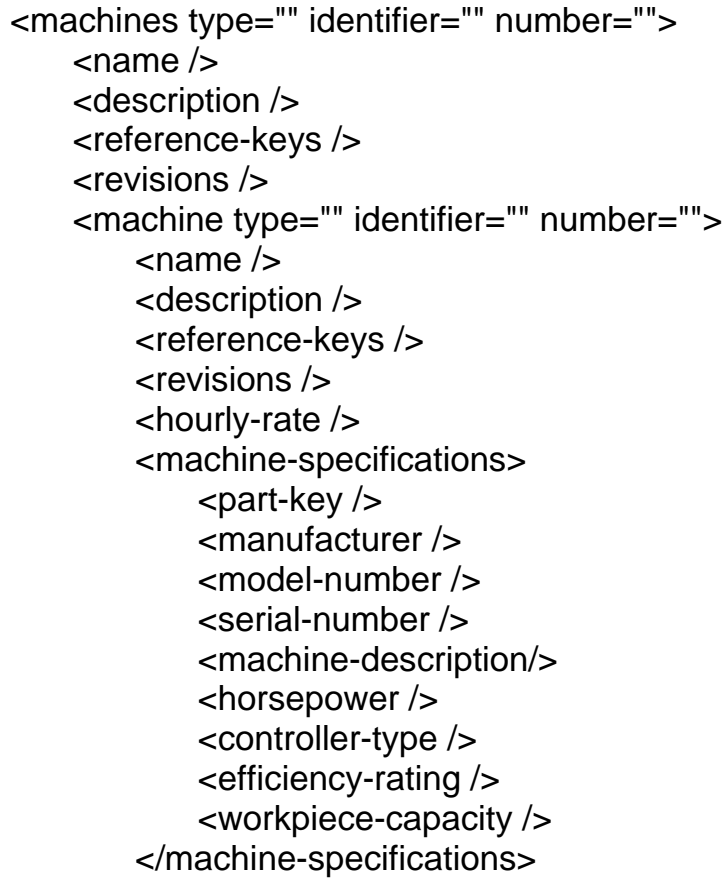




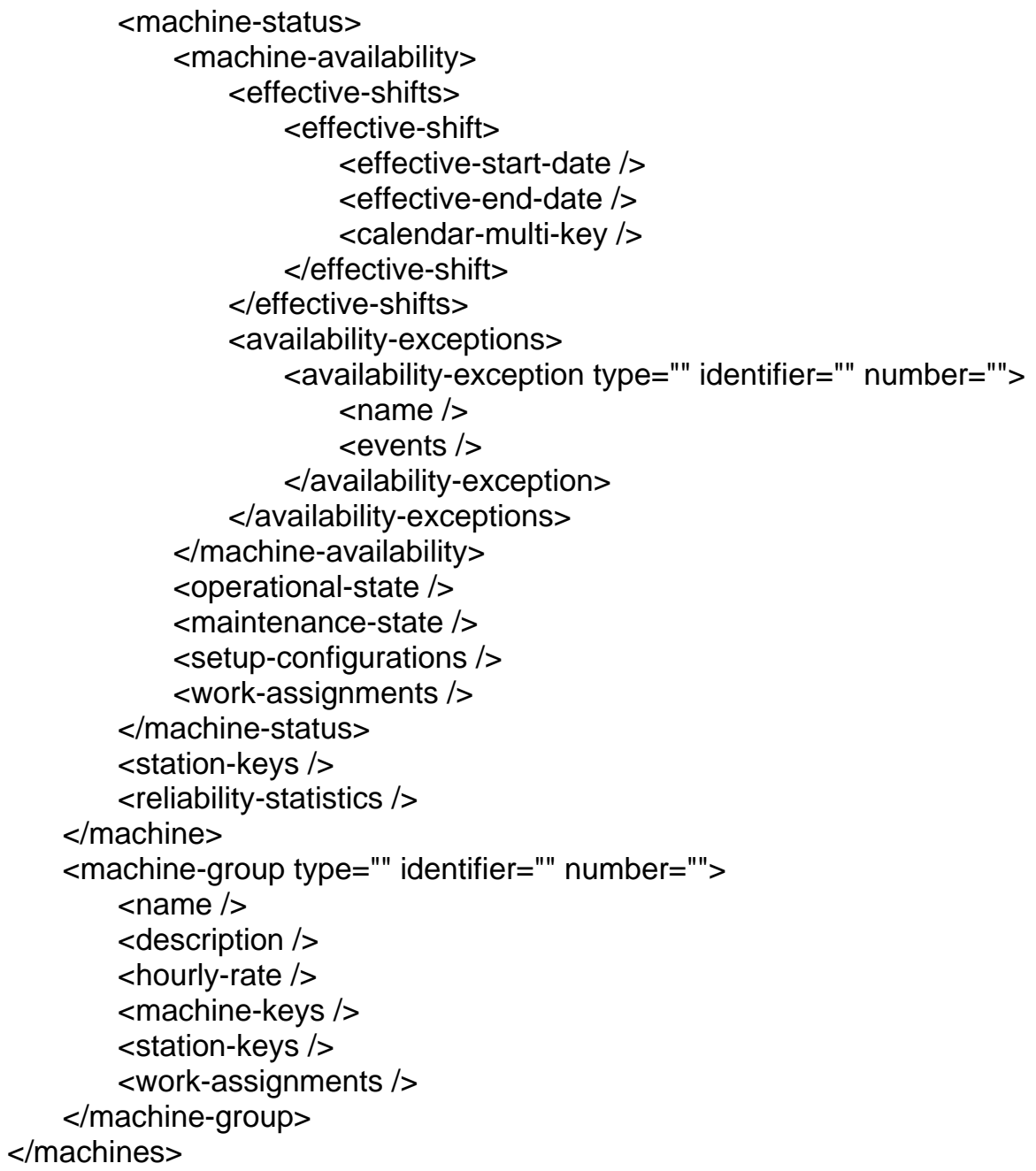

The unique data elements, data element keys, and common data elements introduced in this element are described below.

\section{a) Unique Data Elements}

controller-type: the type of controller on the machine.

efficiency-rating: the relative efficiency of a machine as compared to other machines capable of performing similar processes. The nominal efficiency rating is 1.0. A machine with an efficiency rating of 2.0 would be $\% 100$ more efficient. Presumably the machine with the rating 2.0 would perform the same process in half the time of a machine with an efficiency rating of 1.0 .

horsepower: the horsepower rating of the machine.

machine: information about a machine.

machines: a collection of individual machines.

machine-group: a group of machines that have similar characteristics for scheduling purposes. 
machine-specifications: information about the machine's specifications. It is represented by the following data elements: manufacturer, model-number, serial-number, description, horsepower, controller-type, and efficiency-rating.

machine-status: the operational state, maintenance state, current setup, and work assignments associated with a machine.

manufacturer: the name of the manufacturer of the machine.

workpiece-capacity: the maximum number of workpieces that can be processed by the machine at the same time.

\section{b) Data Element Keys, Multi-keys, and Key Lists}

The following keys are used in this element: machine-keys, part-key, reference-keys, and station-keys. machine-keys identifies a set of similar machines that are contained within a machine group. station-keys identifies one or more stations where employees may be assigned that are associated with a machine. Elements within machine-programs, resources-assigned, resources-required, resources-used, schedules, and stations use the machine-key to reference the data elements in the machines element.

\section{c) Common Data Elements}

See Sections 2.2 and 2.3 for a discussion of these common data attributes and elements used by this element: description, hourly-rate, identifier, maintenance-state, model-number, name, number, operational-state, reliability-statistics, revisions, serial-number, setup-configurations, type, and workassignments.

\subsection{Stations}

stations specifies all the places where employees may perform work in the shop. The element provides elements for indicating station status, associated machines, assigned employees and work assignments. station-group specifies a set of stations that have the same characteristics. station-keys are used to identify the stations that make up the group.

The UML information model for the stations element is shown below: 


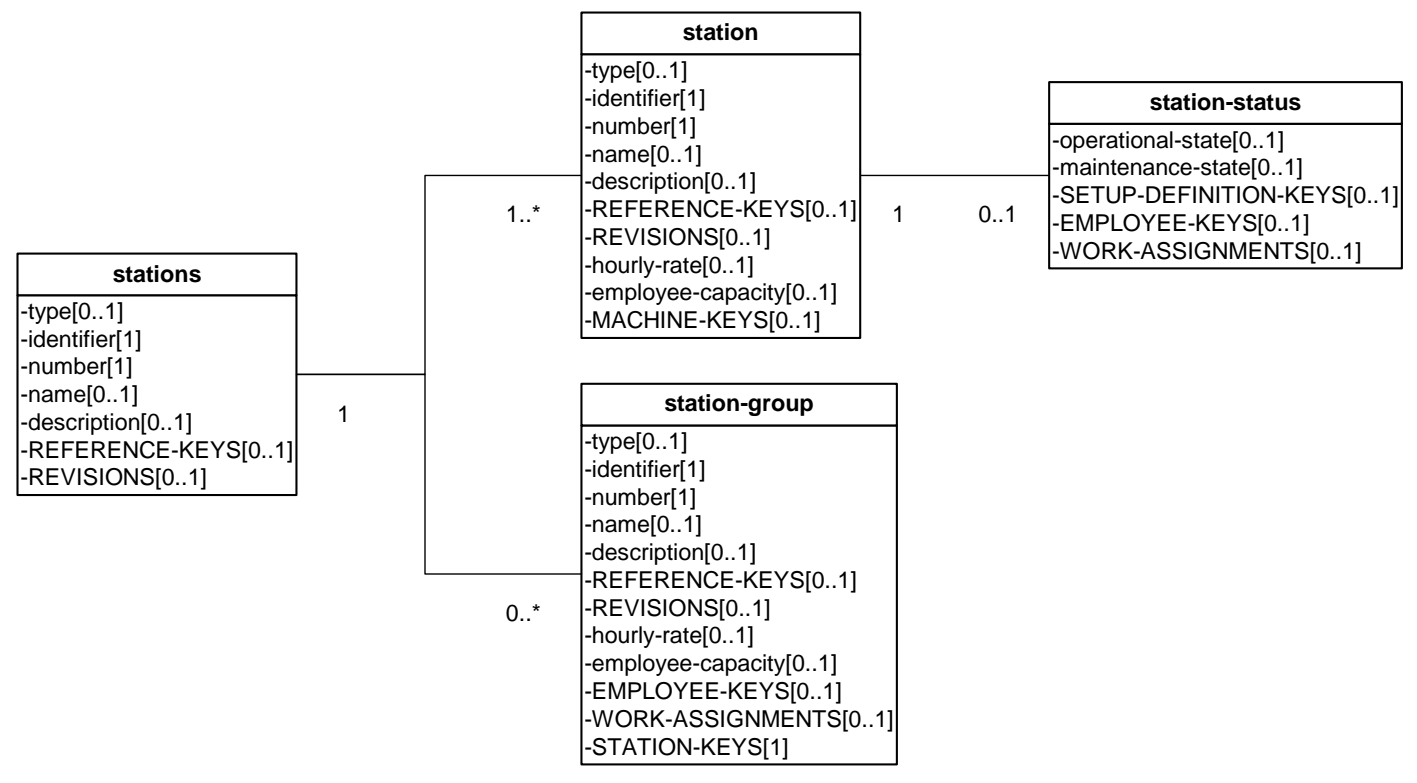

The XML structure for the stations element is shown below:

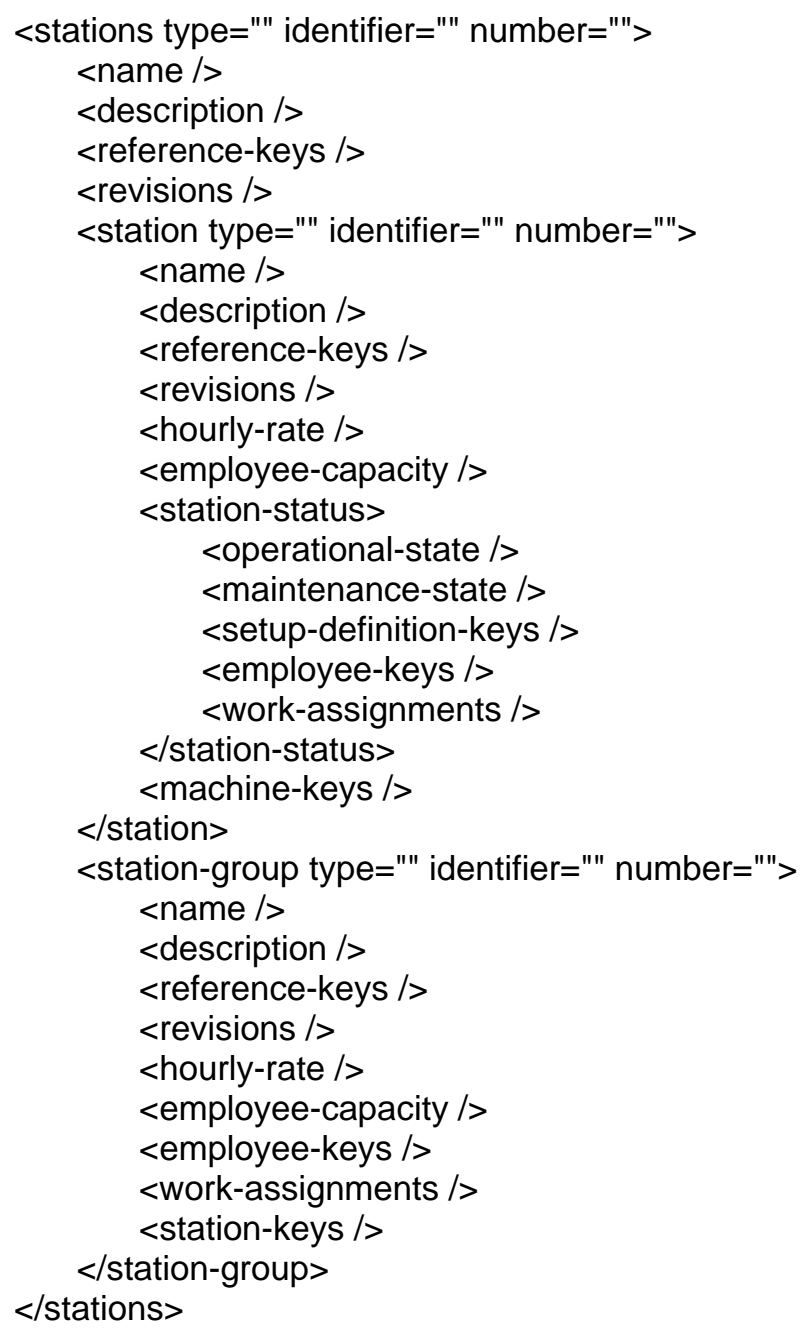


The unique data elements, data element keys, and common data elements introduced in this element are described below.

\section{a) Unique Data Elements}

employee-capacity: the maximum number of employees that can be assigned to this station at the same time.

station: information about a station, its status, machines, and work assignments.

station-group: a set of stations that have similar characteristics.

stations: a collection of individual stations.

station-status: information about the operational state, maintenance state, current setup, and work assignments of a station. Note that a machine associated with a station will normally identify the fixture and tool setups. Some stations, e.g., manual welding stations, may not be associated with any machine, hence the setup-definition-keys should be included at this level, if appropriate.

\section{b) Data Element Keys, Multi-keys, and Key Lists}

The following keys are used in this element: employee-keys, machine-keys, reference-keys, and setupdefinition-keys. Elements within cranes, machines, operation-definitions, resources-assigned, resourcesrequired, resources-used, and schedules use the station-group-key and station-key to reference the data elements in the stations element.

\section{c) Common Data Elements}

See Sections 2.2 and 2.3 for a discussion of these common data attributes and elements used by this element: description, hourly-rate, identifier, operational-state, maintenance-state, name, number, revisions, type, and work-assignments.

\subsection{Cranes}

cranes specifies all the cranes that may be assigned to work in the shop, their status, the stations served, machines served, and work assignments.

The UML information model for the cranes element is shown below:

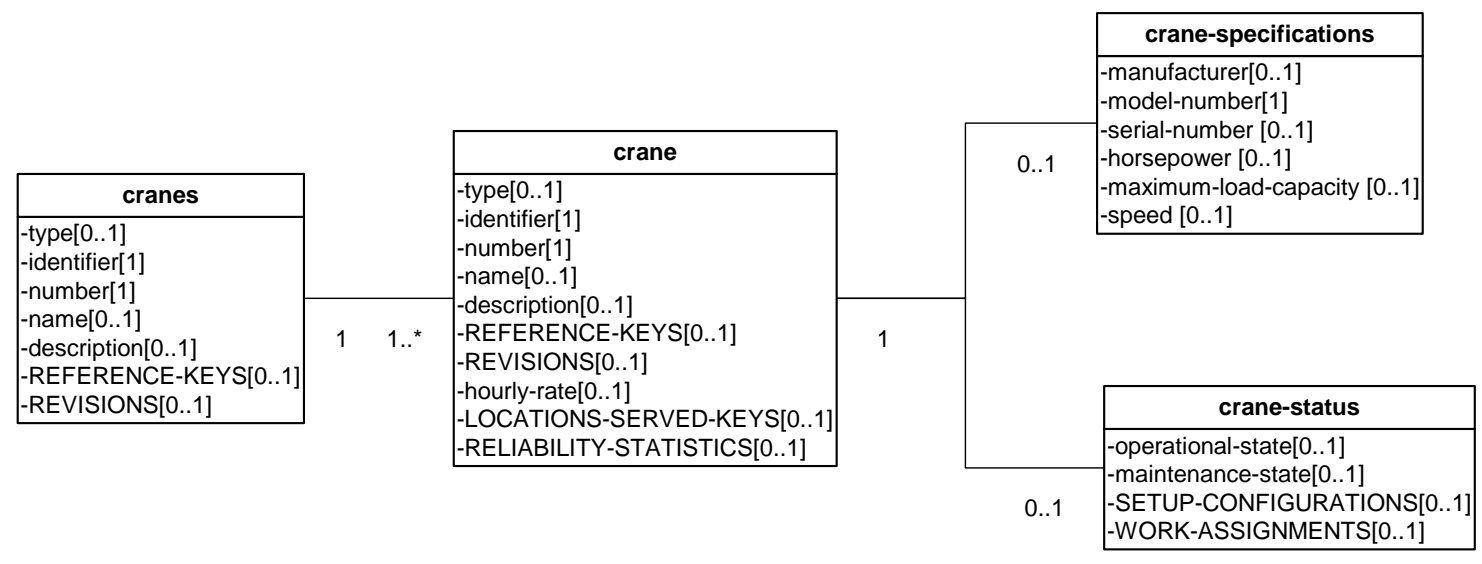


The XML structure for the cranes element is shown below:

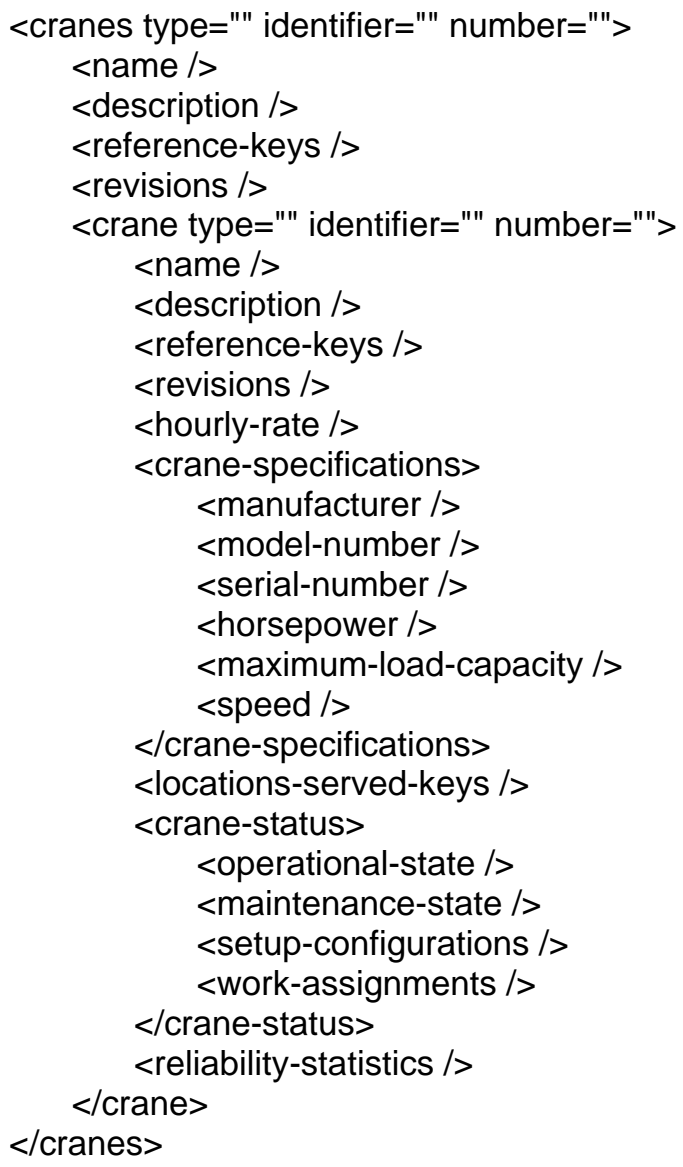

The unique data elements, data element keys, and common data elements introduced in this element are described below.

\section{a) Unique Data Elements}

crane: information about a crane.

cranes: a collection of individual cranes.

crane-specifications: information about the crane's technical specifications including the crane's manufacturer, model-number, serial-number, horsepower, maximum-load-capacity, and speed.

crane-status: information about the status of operation and maintenance, current setup, and work assignments of the crane.

horsepower: the horsepower rating of the crane

manufacturer: the name of the manufacturer of the machine

maximum-load-capacity: maximum carrying capacity of the crane in specified weight units.

speed: the speed at which a crane can move from one location served to the next. 


\section{b) Data Element Keys, Multi-keys, and Key Lists}

The following keys are used in this element: locations-served-keys and reference-keys. locations-servedkeys identifies the stations, machines, and storage buffers that are accessible to the crane. Elements within resources-assigned, resources-required, resources-used, and schedules use the crane-key to reference the data elements in the cranes element.

\section{c) Common Data Elements}

See Sections 2.2 and 2.3 for a discussion of these common data attributes and elements used by this element: description, hourly-rate, identifier, maintenance-state, model-number, name, number, operational-state, reliability-statistics, revisions, serial-number, setup-configurations, type, and workassignments.

\subsection{Employees}

employees specifies all the employees that may be assigned work in the shop, their status, and scheduled assignments to work items. Each employee's addresses, positions in the organization, skills, shift assignments, availability exceptions, pay and leave information, and work assignments are also defined.

The UML information model for the employees element is shown below:

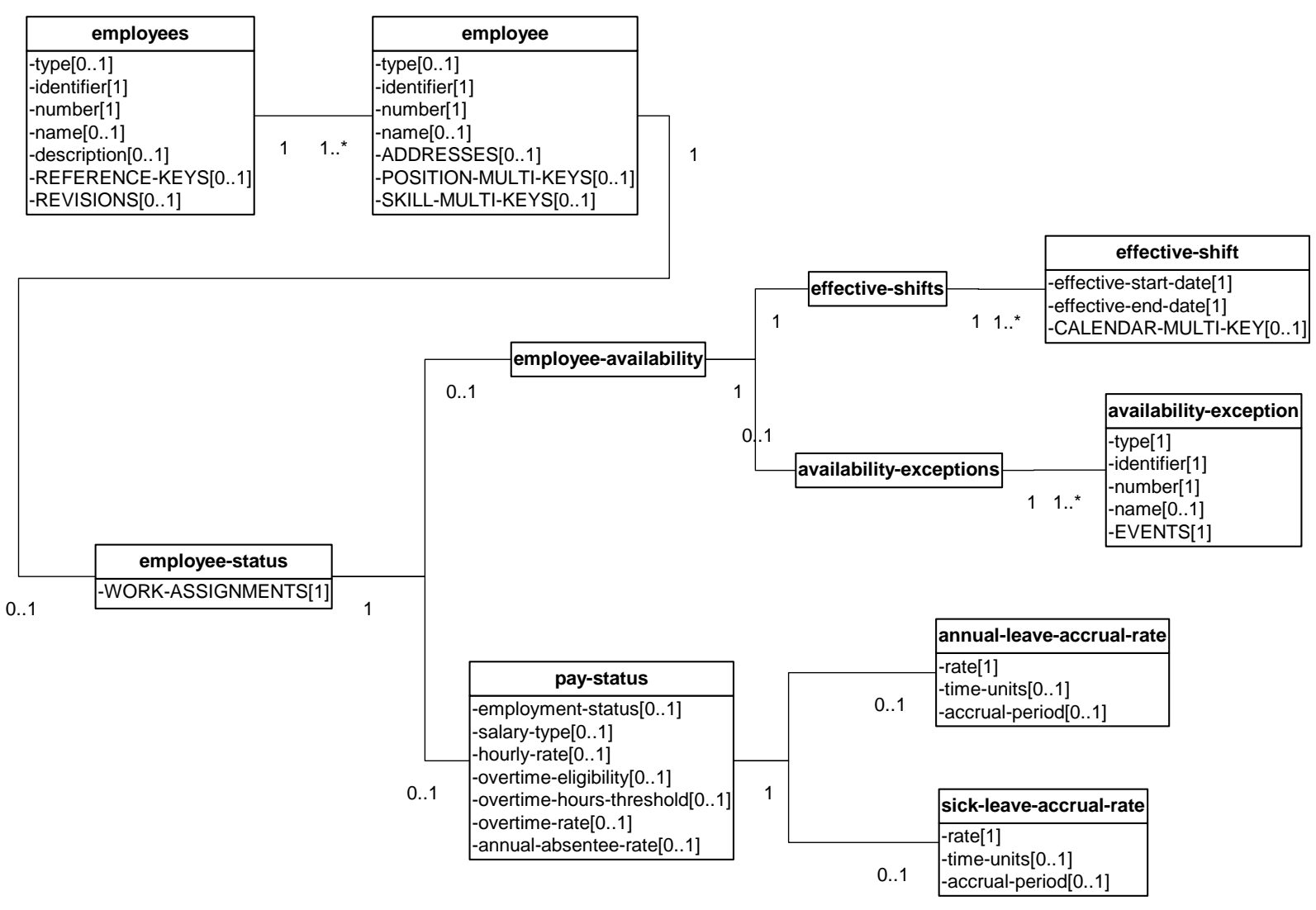

The XML structure for the employees element is shown below:

<employees type="'" identifier="'" number="'"> 


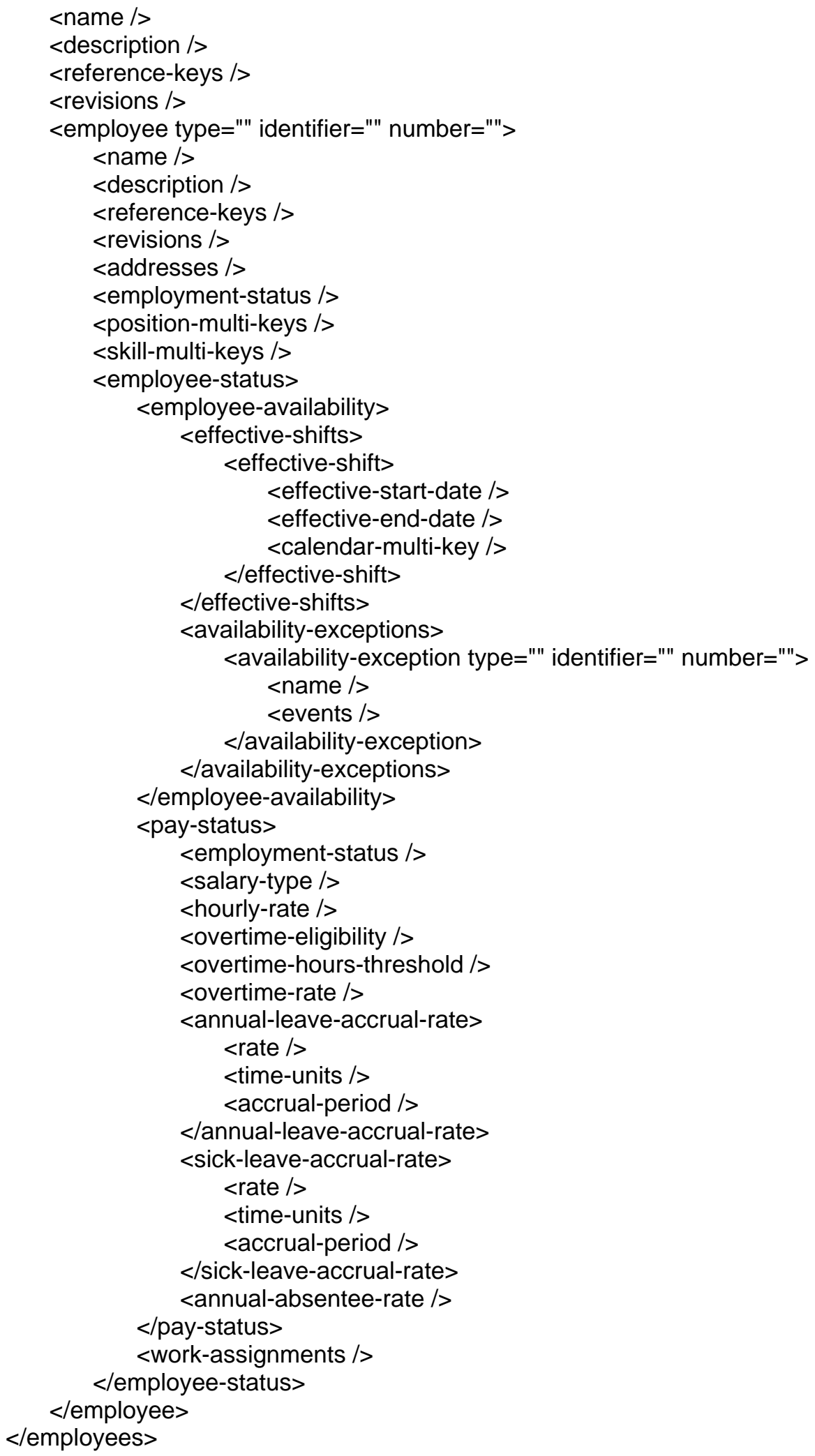

The unique data elements, data element keys, and common data elements introduced in this element are described below. 


\section{a) Unique Data Elements}

accrual-period: a period of time that used to accrue annual leave or sick leave for an individual employee. annual-level-accrual-rate: the number of annual leave hours accrued per pay period.

availability-exception: a period of time that the employee is unavailable to be scheduled for regular duties. availability-exceptions: a collection of availability exceptions for an individual employee.

effective-shift: a particular shift in which the employee has duty.

effective-shifts: a collection of shifts in which the employee has duty.

employee: information about the individual working for the organization.

employee-availability: information about an employee's shift assignments, and periods of time that they will not be available, i.e., availability exceptions.

employees: a collection of employee elements.

employee-status: a collection of status elements about an employee including shift assignments, availability exceptions, pay status, and work assignments.

employment-status: a code indicating employment status, e.g., part-time, full-time, and retired.

overtime-eligibility: the eligibility status to earn overtime.

overtime-hours-threshold: the number of hours at which employee goes into over-time status.

pay-status: a collection of elements regarding an employee’s pay status.

sick-leave-accrual-rate: the number of sick leave hours accrued per pay period.

\section{b) Data Element Keys, Multi-keys, and Key Lists}

The following keys are used in this element: calendar-multi-key, position-multi-keys, reference-keys, and skill-multi-keys. Elements within departments, resources-assigned, resources-required, resources-used, revisions, schedules, stations, and timesheets use the employee-key and skill-multi-keys to reference the data elements in the employees element.

\section{c) Common Data Elements}

See Sections 2.2 and 2.3 for a discussion of these common data attributes and elements used by this element: addresses, annual-absentee-rate, description, effective-end-date, effective-start-date, events, hourly-rate, identifier, name, number, overtime-rate, rate, revisions, salary-type, time-units, and type.

\subsection{Tool Catalog}

tool-catalog defines all the tools and toolsets that may be assigned to tasks in the shop. Bill of materials associated with the tools, and tools that included in each toolset are also defined.

The UML information model for the tool-catalog element is shown below: 


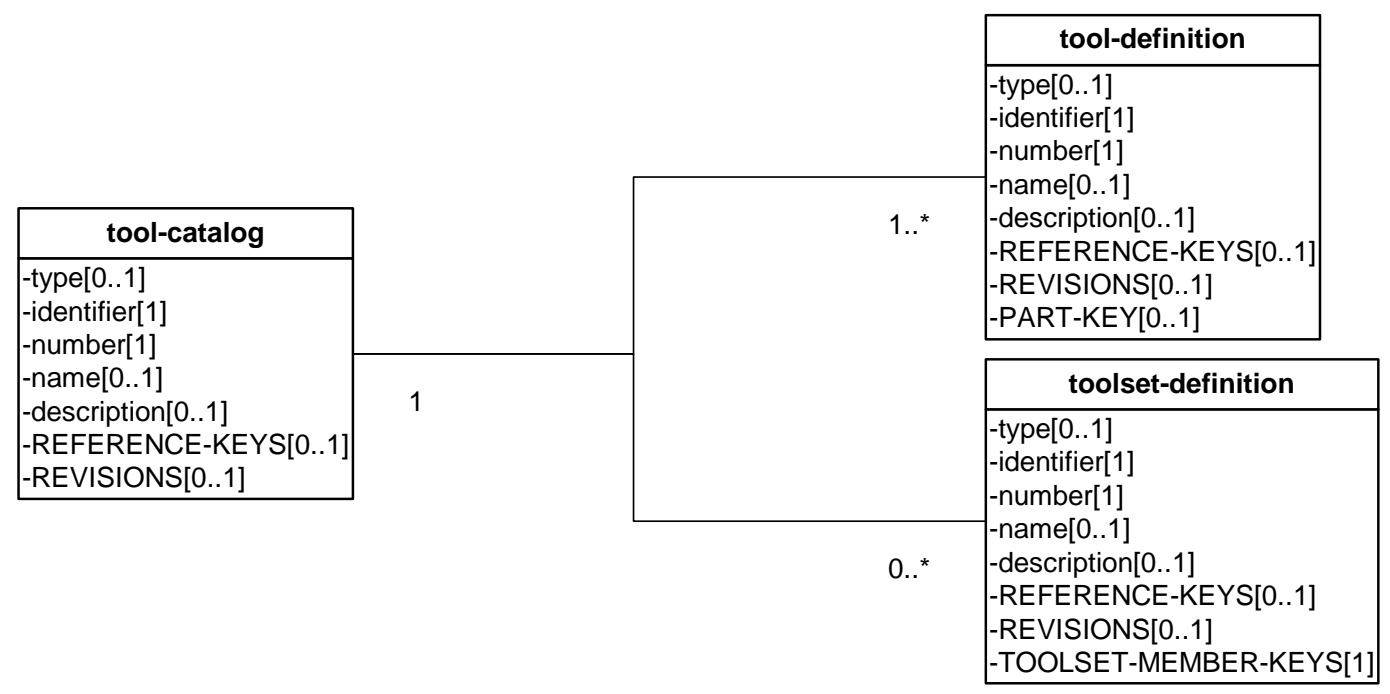

The XML structure for the tool-catalog element is shown below:

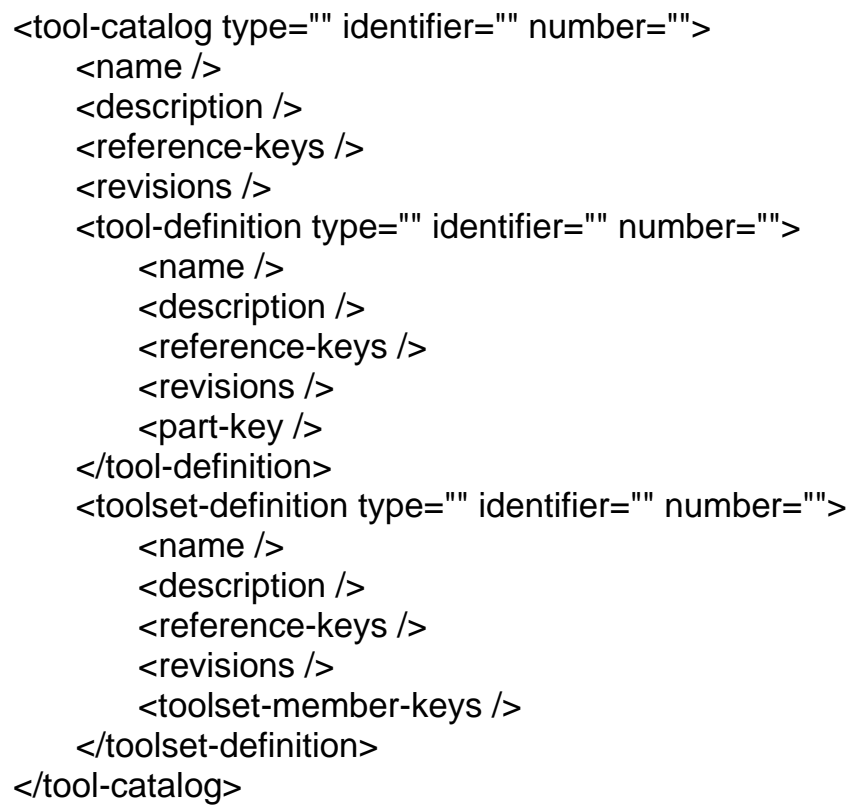

The unique data elements, data element keys, and common data elements introduced in this element are described below.

\section{a) Unique Data Elements}

tool-catalog: a collection of elements that define tools that are available in the shop tool crib.

tool-definition: information about the characteristics of a particular tool.

toolset-definition: information about the characteristics of a particular tool set or collection of tools.

b) Data Element Keys, Multi-keys, and Key Lists 
The following keys are used in this element: part-key, reference-keys, and toolset-member-keys. Elements within setup-components, tool-inventory, and tool-orders use the tool-definition-key, and toolset-definitionkey to reference the data elements in the tool-catalog element.

\section{c) Common Data Elements}

See Sections 2.2 and 2.3 for a discussion of these common data attributes and elements used by this element: description, identifier, name, number, revisions, and type.

\subsection{Fixture Catalog}

fixture-catalog defines all the fixtures and fixturesets that may be assigned to tasks in the shop. Bill of materials associated with the fixtures, and fixtures that included in each fixtureset are also defined.

The UML information model for the fixture-catalog element is shown below:

\begin{tabular}{|c|c|c|c|}
\hline & & & \\
\hline & & & fixture-definition \\
\hline & & & -type[0..1] \\
\hline & & & -number[1] \\
\hline & & & -name[0..1] \\
\hline fixture-catalog & & $1 . .^{\star}$ & -REFERENCE-KEYS[0..1] \\
\hline $\begin{array}{l}\text {-type[0..1] } \\
\text {-identifier[1] }\end{array}$ & & & $\begin{array}{l}\text {-REVISIONS[0..1] } \\
\text {-PART-KEY[0..1] }\end{array}$ \\
\hline -name[0..1] & & & fixtureset-definition \\
\hline -description[0..1] & 1 & & -type[0..1] \\
\hline -REFERENCE-KEYS[0..1] & & & -identifier[1] \\
\hline -REVISIONS[0..1] & & & -number[1] \\
\hline & & $0 . . *$ & 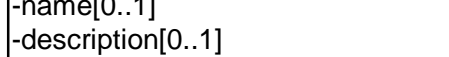 \\
\hline & & $0 .$. & -REFERENCE-KEYS[0..1] \\
\hline & & & -REVISIONS[0..1] \\
\hline & & & -FIXTURESET-MEMBER-KEYS[1] \\
\hline
\end{tabular}

The XML structure for the fixture-catalog element is shown below:

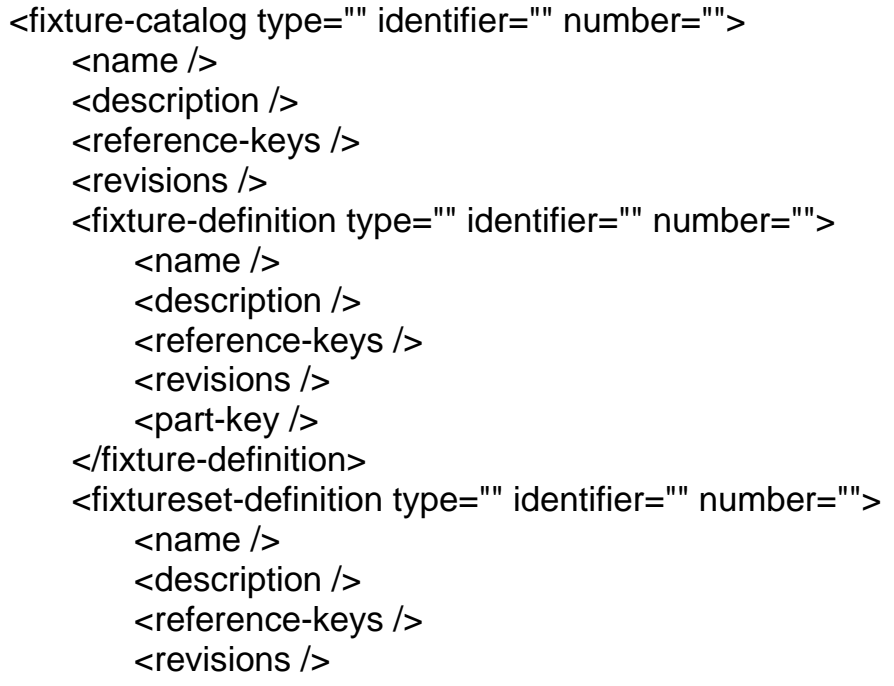




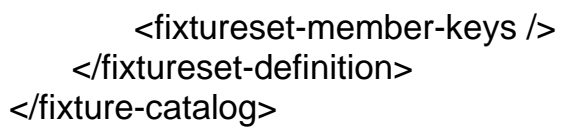

The unique data elements, data element keys, and common data elements introduced in this element are described below.

\section{a) Unique Data Elements}

fixture-catalog: a collection of fixtures that are available in the shop's fixture crib.

fixture-definition: information about the characteristics of a particular fixture.

fixtureset-definition: information about the characteristics of a particular fixture set.

\section{b) Data Element Keys, Multi-keys, and Key Lists}

The following keys are used in this element: part-key, reference-keys, and fixtureset-member-keys. Elements within fixture-inventory and setup-components use the fixture-definition-key, and fixturesetdefinition-key to reference the data elements in the fixture-catalog element.

\section{c) Common Data Elements}

See Sections 2.2 and 2.3 for a discussion of these common data attributes and elements used by this element: description, identifier, name, number, revisions, and type.

\subsection{Layout}

layout defines the location of reference points within the shop, area boundaries, paths, resource, and part objects. It contains reference pointers to external graphics files that use appropriate graphics standards to further define these elements.

The UML information model for the layout element is shown below: 


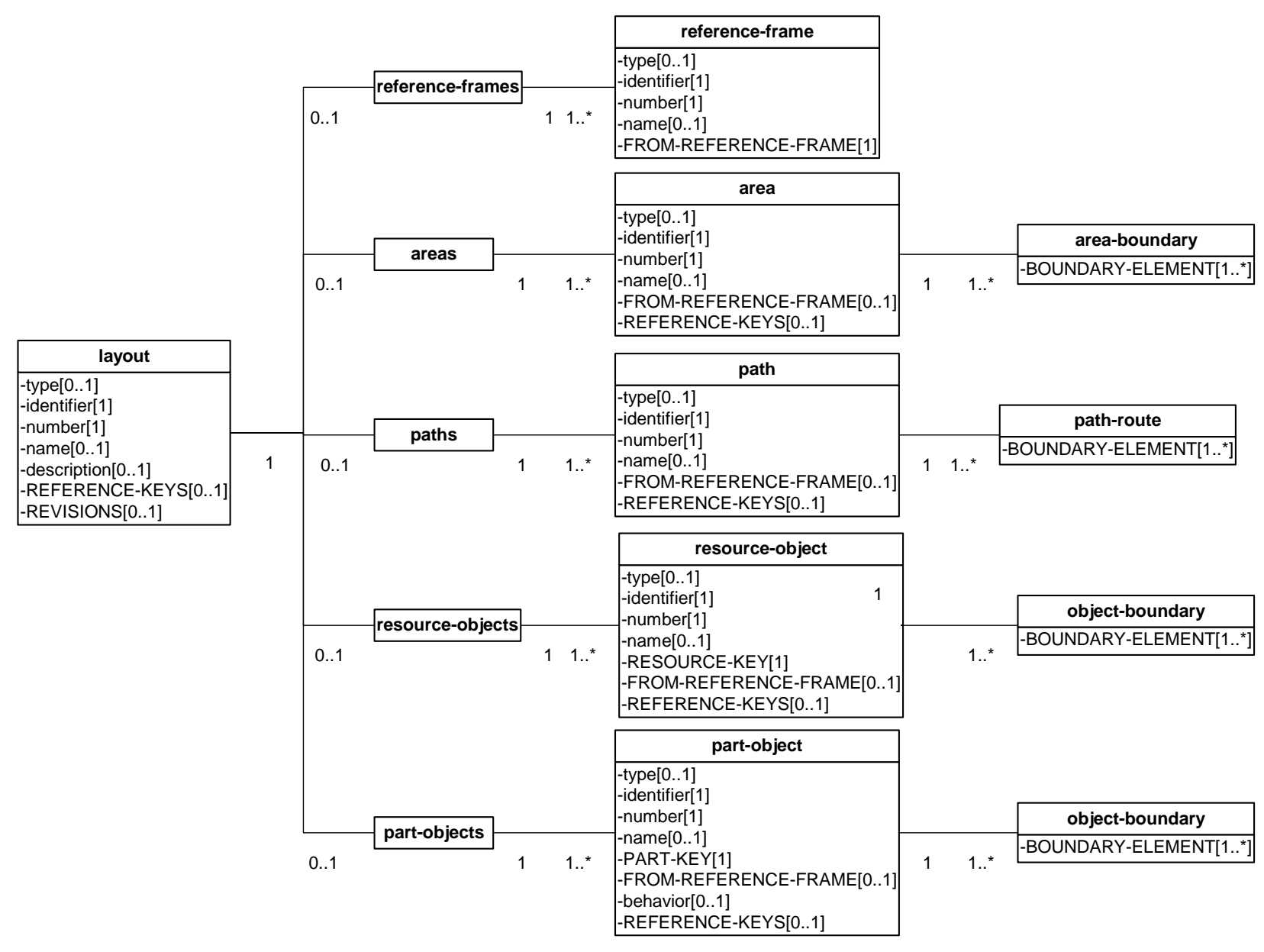


The XML structure for the layout element is shown below:

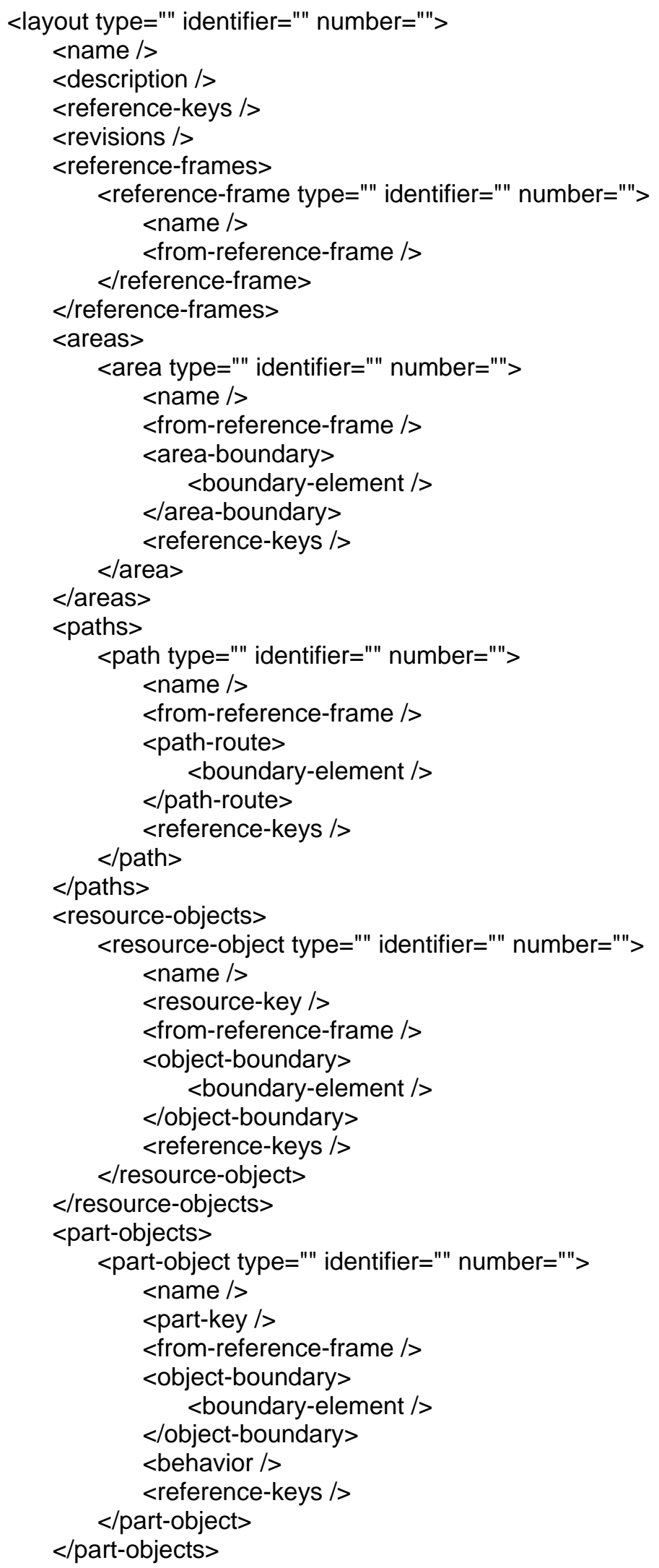


$</$ layout $>$

The unique data elements, data element keys, and common data elements introduced in this structure are described below.

\section{a) Unique Data Elements}

$<$ Note: Definitions of the following elements are not provided here due to these elements are still under development.>

area:

area-boundary:

areas:

behavior:

layout:

object-boundary:

part-object:

part-objects:

path:

path-route:

paths:

reference-frame:

reference-frames:

resource-object:

resource-objects:

\section{b) Data Element Keys, Multi-keys, and Key Lists}

The following keys are used in this element: part-key, reference-keys, and resource-key.

\section{c) Common Data Elements}

See Sections 2.2 and 2.3 for a discussion of these common data attributes and elements used by this element: boundary-element, description, from-reference-frame, identifier, name, number, revisions, and type.

\subsection{Skill Definitions}

skill-definitions lists the skills that an employee may possess and the levels of proficiency associated with those skills. skill-definitions are referenced in employee definitions to identify the skill types and levels each employee has. They are also referenced in employee resource requirements contained in processplans and work items. An example of a skill might be the ability to operate a particular type of machine. levels indicate the range of skill levels that an employee may possess.

The UML information model for the skill-definitions element is shown below:

\begin{tabular}{|c|c|c|c|c|c|c|c|c|c|}
\hline skill-definitions & & & & & & & & & \\
\hline -type[0..1] & & & skill-definition & & & & & & level-definition \\
\hline -identifier[1] & & & -type[0..1] & & & levels & & & -type[0..1] \\
\hline $\begin{array}{l}\text {-number[1] } \\
\text {-name[0..1] } \\
\text {-description[0..1] } \\
\text {-REFERENCE-KEYS[0..1] } \\
\text {-REVISIONS[0..1] }\end{array}$ & 1 & 1..* & $\begin{array}{l}\text {-identifier[1] } \\
\text {-number[1] } \\
\text {-name[0..1] } \\
\text {-description[0..1] }\end{array}$ & 1 & 0.1 & $\begin{array}{l}\text {-minimum-level-number[1] } \\
\text {-maximum-level-number[1] }\end{array}$ & 1 & 1..* & $\begin{array}{l}\text {-identifier[1] } \\
\text {-number[1] } \\
\text {-name[0..1] } \\
\text {-description[0..1] }\end{array}$ \\
\hline
\end{tabular}


The XML structure for the skill-definitions element is shown below:

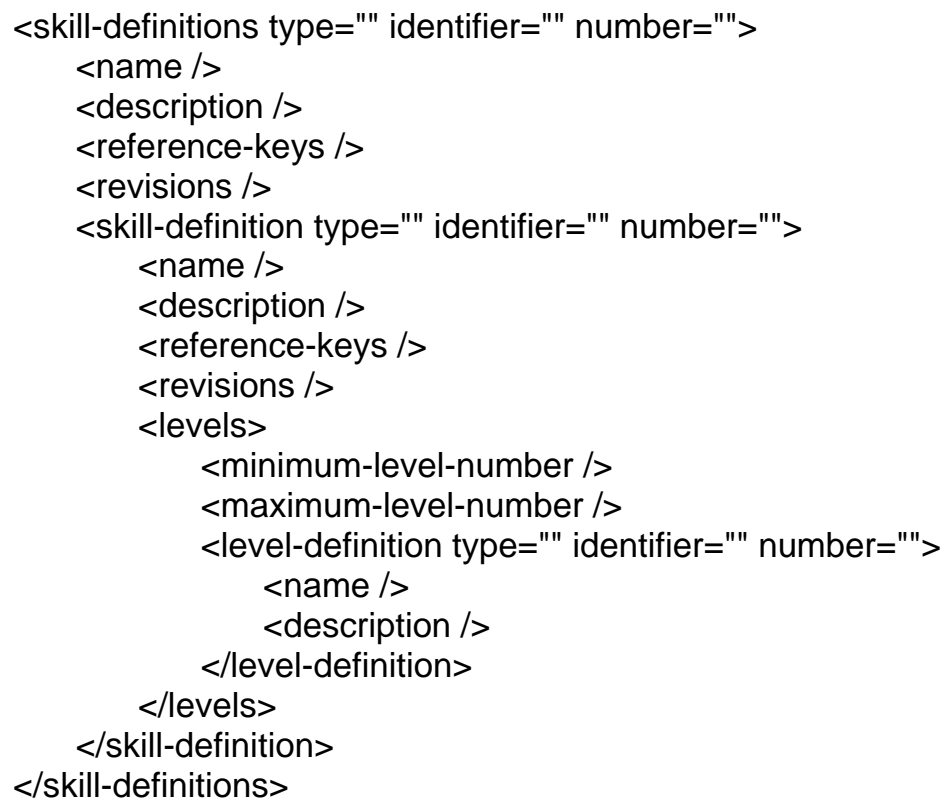

The unique data elements, data element keys, and common data elements introduced in this structure are described below.

\section{a) Unique Data Elements}

level-definition: a definition of a particular skill level. A level-definition is defined by a type, an identifier, a number, a name, and a description.

levels: An element that defines the levels associated with a particular skill. levels contains a minimum-levelnumber, a maximum-level-number, and one or more level-definition data elements.

skill-definition: an element for defining the allowable skills that employees may possess, and the levels of proficiency associated with each skill. A skill-definition contains a type attribute, an identifier attribute, a number attribute, a name element, a description element, and a levels complex element.

skill-definitions: a collection of individual skill definitions.

\section{b) Data Element Keys, Multi-keys, and Key Lists}

reference-keys is used in this structure. Elements within employees and resources-required use a skillmulti-keys to reference the data elements in the skill-definitions.

\section{c) Common Data Elements}

See Sections 2.2 and 2.3 for a discussion of these common data attributes and elements used by this element: description, identifier, maximum-level-number, minimum-level-number, name, number, revisions, and type.

\subsection{Setup Definitions}

setup-definitions typically specifies tool or fixture setups on a machine. Tool setups are typically the tools that are required in the tool magazine. Fixture setups are workholding devices mounted on the machine. Setups may also apply to cranes or stations. 
The UML information model for the setup-definitions element is shown below:

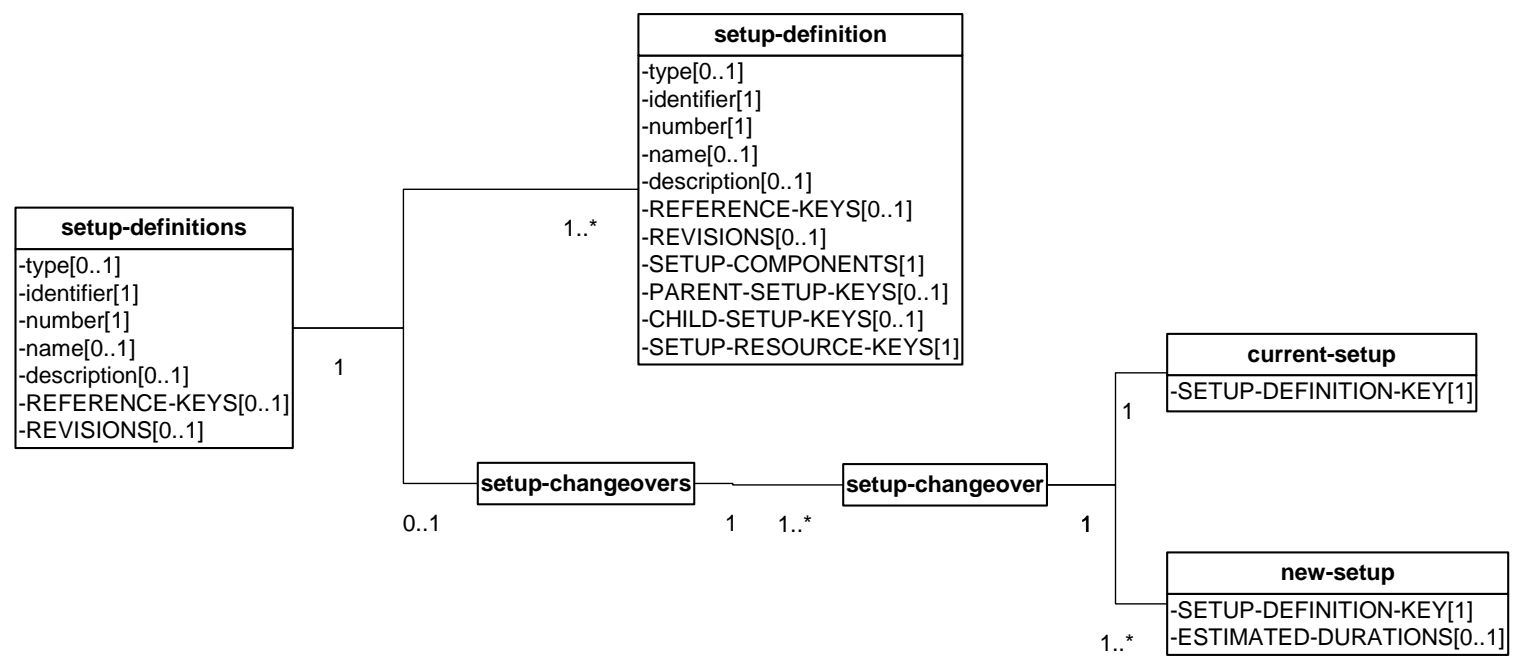

The XML structure for the setup-definitions element is shown below:

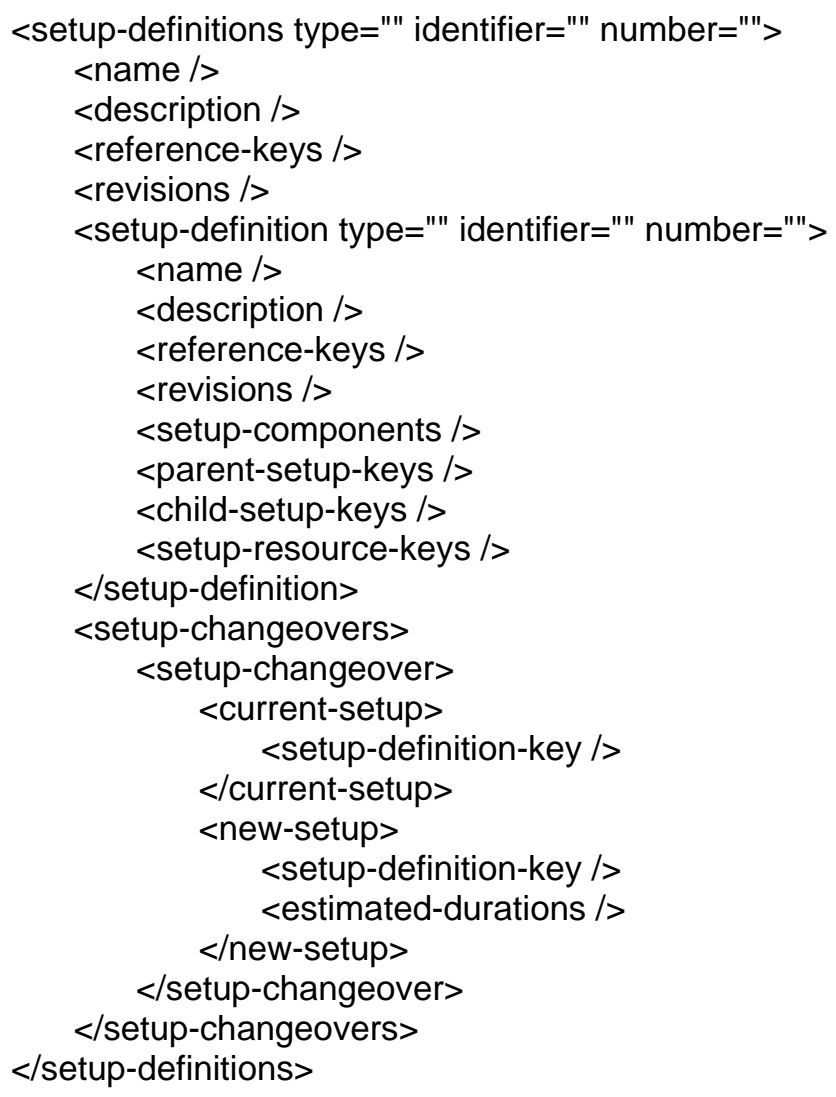

The unique data elements, data element keys, and common data elements introduced in this structure are described below.

\section{a) Unique Data Elements}


current-setup: an initial setup definition for which a changeover time is being specified.

new-setup: the new setup definition that a resource's setup is to be changed into.

setup-changeover: information about the machine or other resources changeover from one existing setup to any other setup configuration. It identifies the current setup and new setup by setup definition keys and the time requirement for doing the changeover.

setup-changeovers: a collection of individual setup changeovers that corresponds to a row in a changeover matrix. The row identifies one current configuration and all allowable new configurations.

setup-definition: a specification for a class of setup configuration for a resource, e.g., a machine, a station, or a crane.

setup-definitions: a collection of setup definitions.

\section{b) Data Element Keys, Multi-keys, and Key Lists}

child-setup-keys, parent-setup-keys, reference-keys, setup-definition-key, and setup-resource-keys are used in this structure. Elements within resources-assigned, resources-used, setup-configurations, stations, and work-assignments use a setup-definition-key to reference the data elements in the setup-definitions.

\section{c) Common Data Elements}

See Sections 2.2 and 2.3 for a discussion of these common data attributes and elements used by this element: description, estimated-durations, identifier, name, number, revisions, type, and setup-components.

\subsection{Operation Definitions}

operation-definitions lists all the definitions of the operations that may be performed at a particular station or group of stations in the shop.

The UML information model for the operation-definitions element is shown below:

\begin{tabular}{|c|c|c|c|}
\hline operation-definitions & & & \multirow{3}{*}{\begin{tabular}{|l}
\multicolumn{1}{|l}{ operation-definition } \\
-type[0..1] \\
-identifier[1] \\
-number[1] \\
-name[0..1] \\
-operation-type[1] \\
-operation-subtype[0..1] \\
-description[0..1] \\
-STATION-KEYS[0..1]
\end{tabular}} \\
\hline \multirow{2}{*}{$\begin{array}{l}\text {-type[0..1] } \\
\text {-identifier[1] } \\
\text {-number[1] } \\
\text {-name[0..1] } \\
\text {-description[0..1] } \\
\text {-REFERENCE-KEYS[0..1] } \\
\text {-REVISIONS[0..1] } \\
\end{array}$} & & & \\
\hline & 1 & 1..* & \\
\hline
\end{tabular}

The XML structure for the operation-definitions element is shown below:

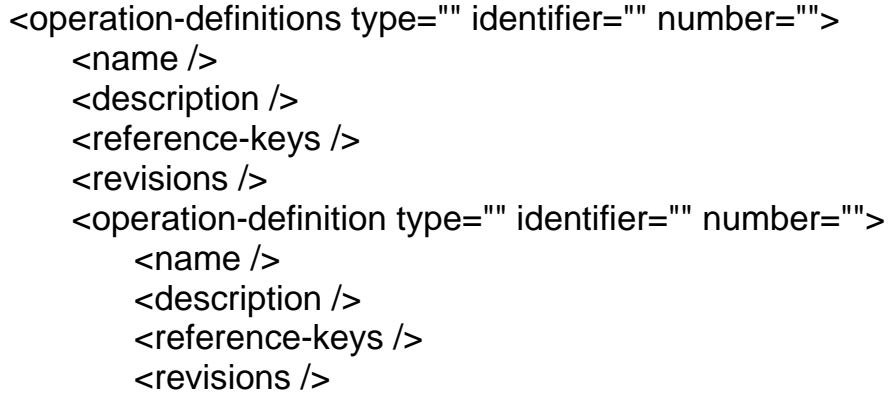




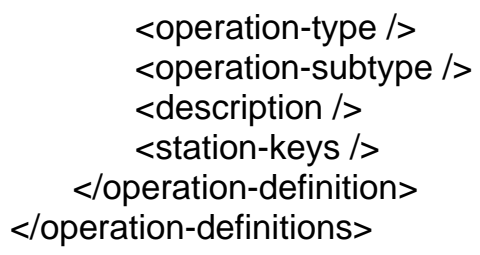

The unique data elements, data element keys, and common data elements introduced in this structure are described below.

\section{a) Unique Data Elements}

operation-definition: an element for specifying the particular operations that may be performed at a particular station or group of stations in the shop.

operation-definitions: a collection of operation definitions.

\section{b) Data Element Keys, Multi-keys, and Key Lists}

The reference-keys and station-keys elements are used in this structure. Elements within plan-definition use an operation-definition-key to reference the data elements in the operation-definitions.

\section{c) Common Data Elements}

See Sections 2.2 and 2.3 for a discussion of these common data attributes and elements used by this element: description, identifier, name, number, revisions, type, operation-subtype, and operation-type.

\subsection{Maintenance Definitions}

maintenance-definitions specifies preventive or corrective maintenance to be done on machines or other maintained resources.

The UML information model for the maintenance-definitions element is shown below:

\begin{tabular}{|c|c|c|c|}
\hline \multirow[b]{3}{*}{ maintenance-definitions } & & & \begin{tabular}{|c|} 
maintenance-definition \\
\end{tabular} \\
\hline & & & \multirow{10}{*}{$\begin{array}{l}\text {-type[0..1] } \\
\text {-identifier[1] } \\
\text {-number[1] } \\
\text {-name[0..1] } \\
\text {-description[0..1] } \\
\text {-periodicity[1] } \\
\text {-REFERENCE-KEYS[0..1] } \\
\text {-REVISIONS[0..1] } \\
\text {-PLAN-DEFINITION[0..1] } \\
\text {-ESTIMATED-DURATIONS[0..1] } \\
\text {-COST-SUMMARY[0..1] } \\
\text {-MAINTAINED-RESOURCE-KEYS[1] }\end{array}$} \\
\hline & & & \\
\hline \multirow{8}{*}{$\begin{array}{l}\text {-type[0..1] } \\
\text {-identifier[1] } \\
\text {-number[1] } \\
\text {-name[0..1] } \\
\text {-description[0..1] } \\
\text {-REFERENCE-KEYS[0..1] } \\
\text {-REVISIONS[0..1] }\end{array}$} & & & \\
\hline & & & \\
\hline & & & \\
\hline & & $1 . .^{*}$ & \\
\hline & & & \\
\hline & & & \\
\hline & & & \\
\hline & & & \\
\hline
\end{tabular}

The XML structure for the maintenance-definitions element is shown below:

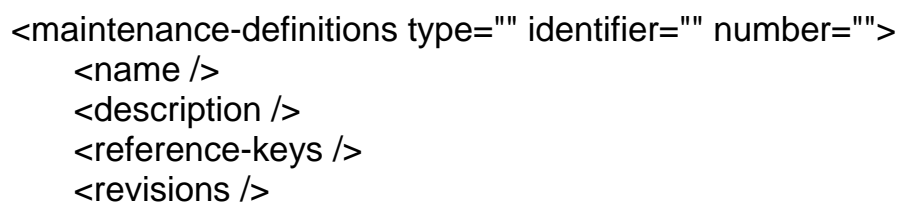




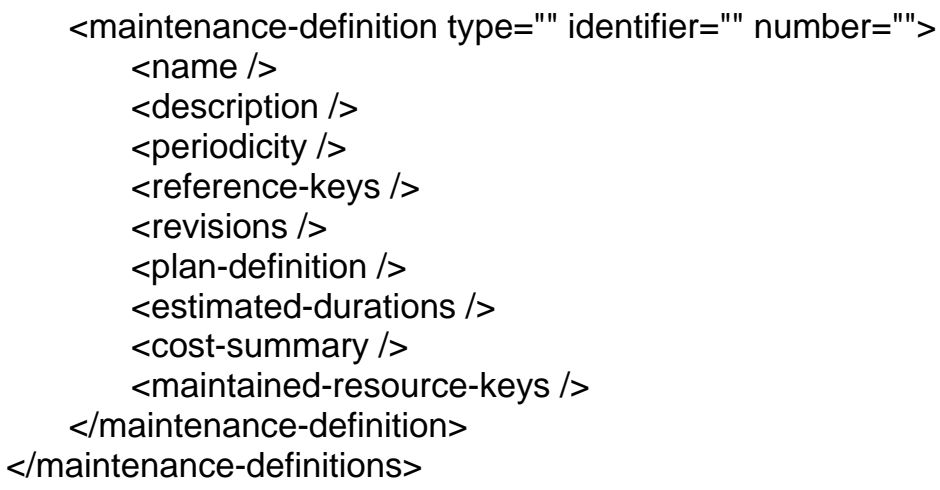

The unique data elements, data element keys, and common data elements introduced in this structure are described below.

\section{a) Unique Data Elements}

maintenance-definition: a specification for performing a particular maintenance action on a maintained resource.

maintenance-definitions: a collection of maintenance definitions for one or more maintained resources, for example a group of machines.

periodicity: the frequency at which this maintenance action should be performed.

\section{b) Data Element Keys, Multi-keys, and Key Lists}

The maintained-resource-keys and reference-keys elements are used in this structure. Elements within maintenance-orders use a maintenance-definition-key to reference the data elements in the maintenancedefinitions element.

\section{c) Common Data Elements}

See Sections 2.2 and 2.3 for a discussion of these common data attributes and elements used by this element: cost-summary, description, estimated-durations, identifier, name, number, plan-definition, revisions, and type.

\subsection{Parts}

parts provides elements for part specifications, group technology codes, customers, suppliers, as well as links to bill of materials, process plans, drawings, part models, and other references.

The UML information model for the parts element is shown below: 


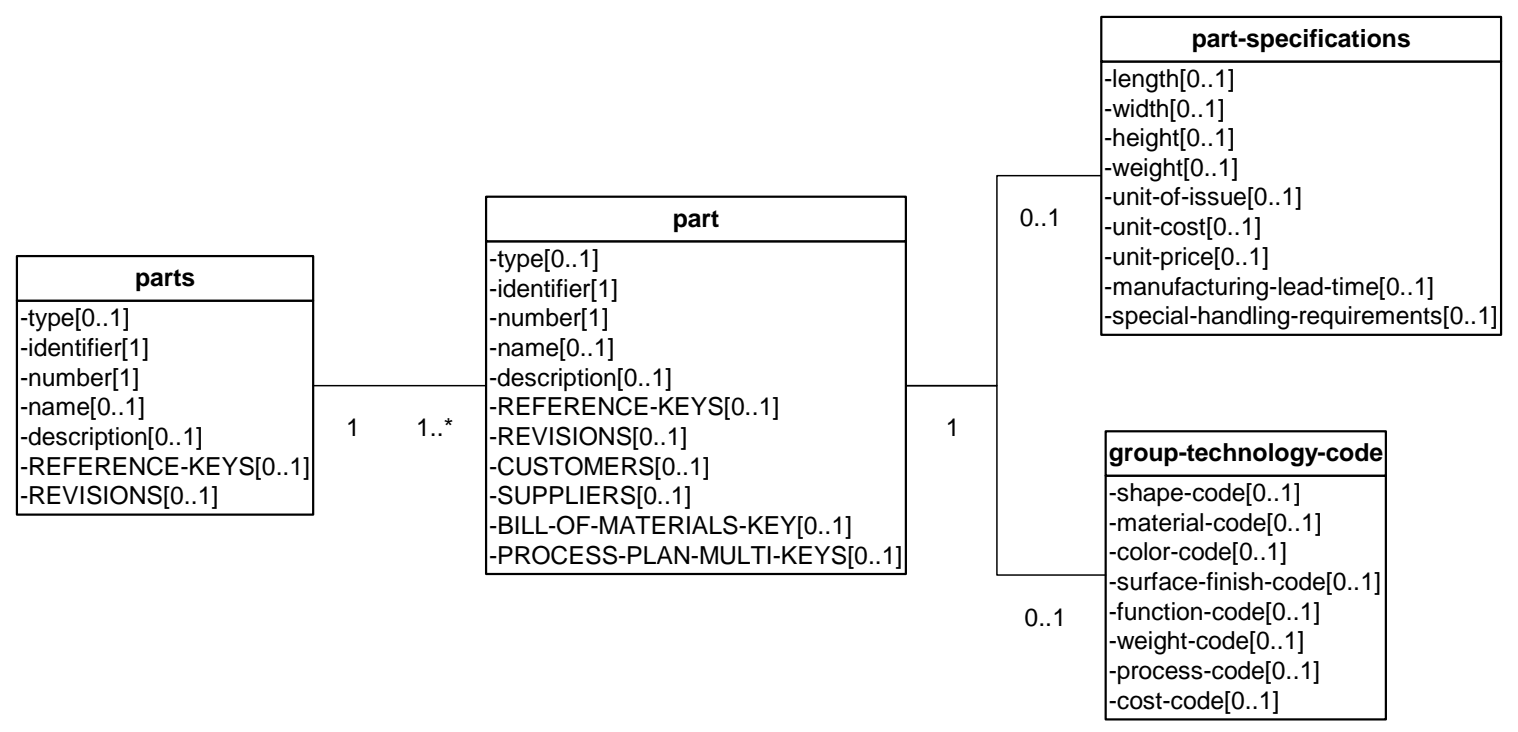

The XML structure for the parts element is shown below:

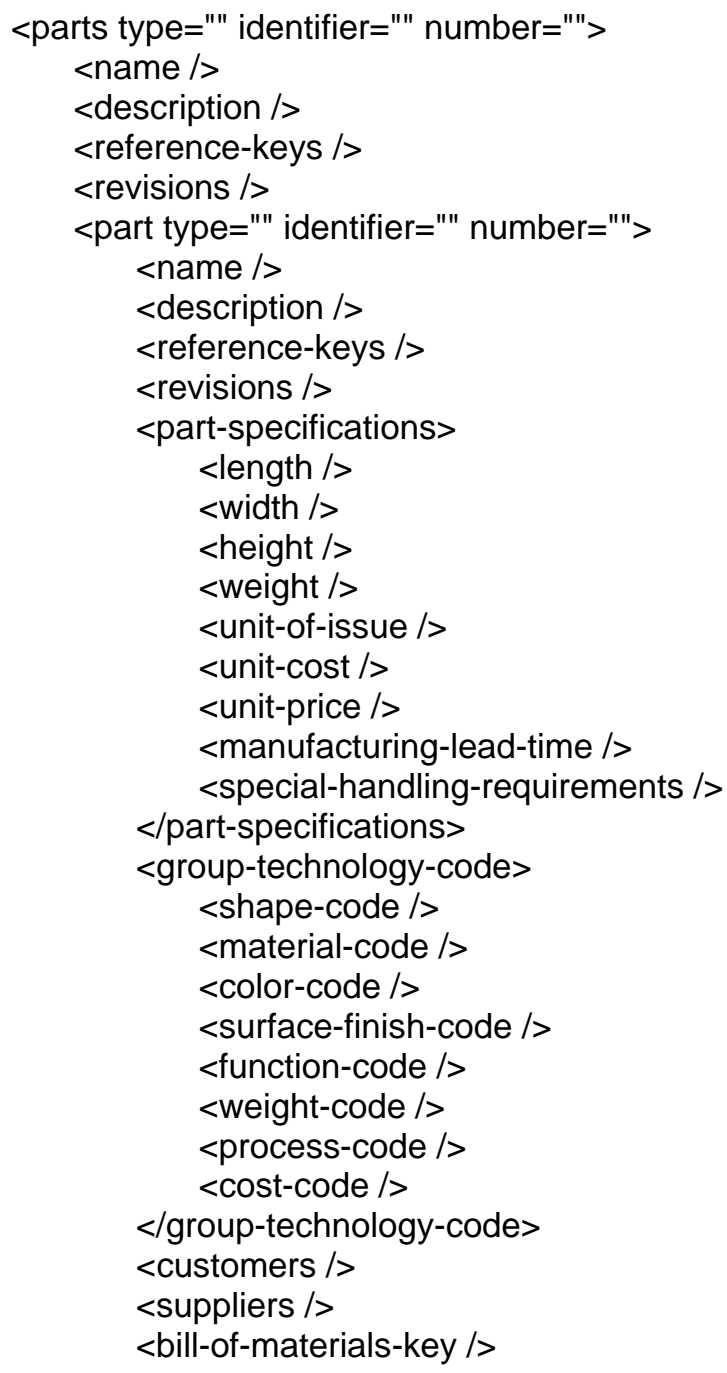




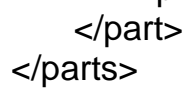

The unique data elements, data element keys, and common data elements introduced in this structure are described below.

\section{a) Unique Data Elements}

group-technology-code: a code system that defines a particular part. The system identifies the part's shape, material, color, surface finish, function, weight, process, and cost using a predefined set of codes.

height: a number indicating the height of the part in the specified units of measurement.

length: a number indicating the length of the part in the specified units of measurement.

manufacturing-lead-time: the manufacturing lead time for the part in days.

part: a record for a part that may be a component, work-in-process, or finished goods.

parts: a collection of part records.

part-specifications: a section of the part element containing part specifications.

special-handling-requirements: a note for any special handling that may be required because the part is fragile, contains hazardous materials, etc.

unit-cost: the cost to make or buy the part.

unit-price: the price at which the part is sold.

unit-of-issue: the unit type for which the part is issued, e.g., each, dozen, box.

weight: the weight of the part in the specified units of measurement.

width: the width of the part in the specified units of measurement.

\section{b) Data Element Keys, Multi-keys, and Key Lists}

The following keys are used in this structure: bill-of-materials-key, process-plan-multi-keys, and referencekeys. Elements within bill-of-materials, inventory, layout, process-plans, procurements, and work use the part-key to reference the data elements in the parts element.

\section{c) Common Data Elements}

See Sections 2.2 and 2.3 for a discussion of these common data attributes and elements used by this element: color-code, cost-code, customers, description, function-code, identifier, material-code, name, number, process-code, revisions, shape-code, suppliers, surface-finish-code, type, and weight-code.

\subsection{Bills-of-Materials}

bills-of-materials cross-references the parts and quantities required in a hierarchical bill-of-materials structure.

The UML information model for the bills-of-materials element is shown below: 


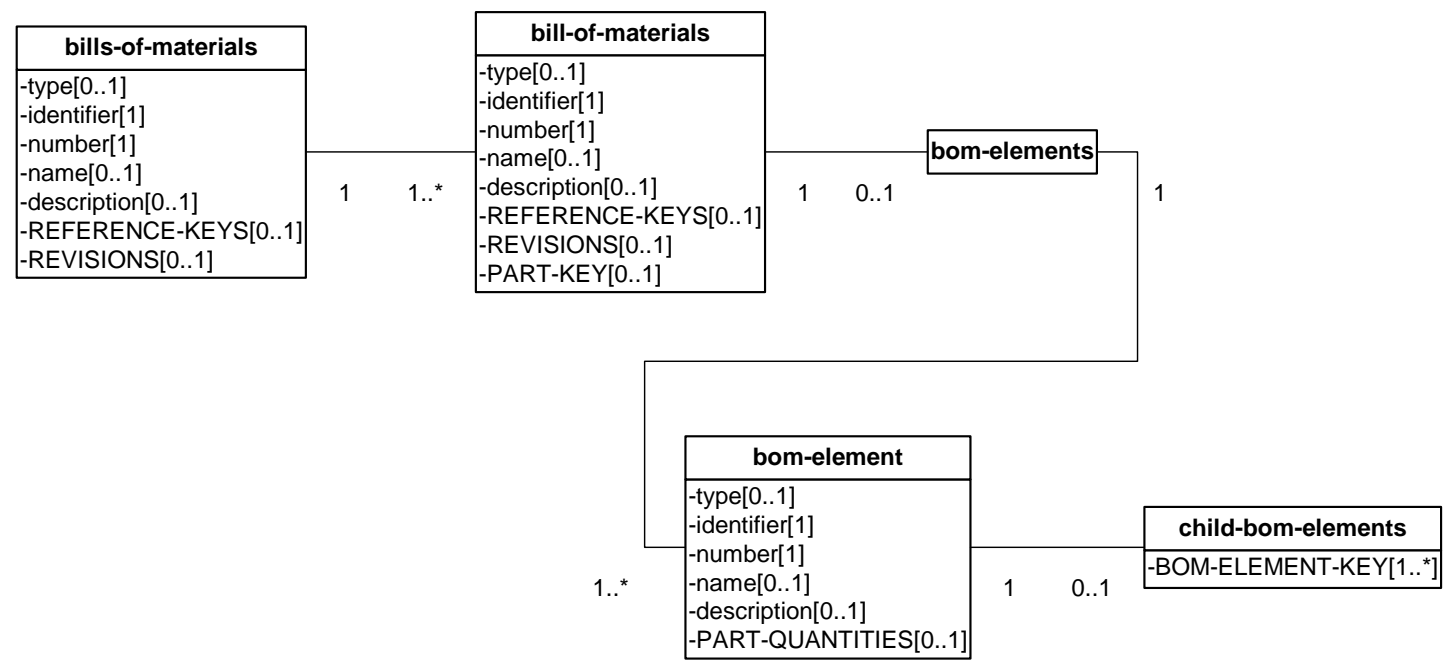

The XML structure for the bills-of-materials element is shown below:

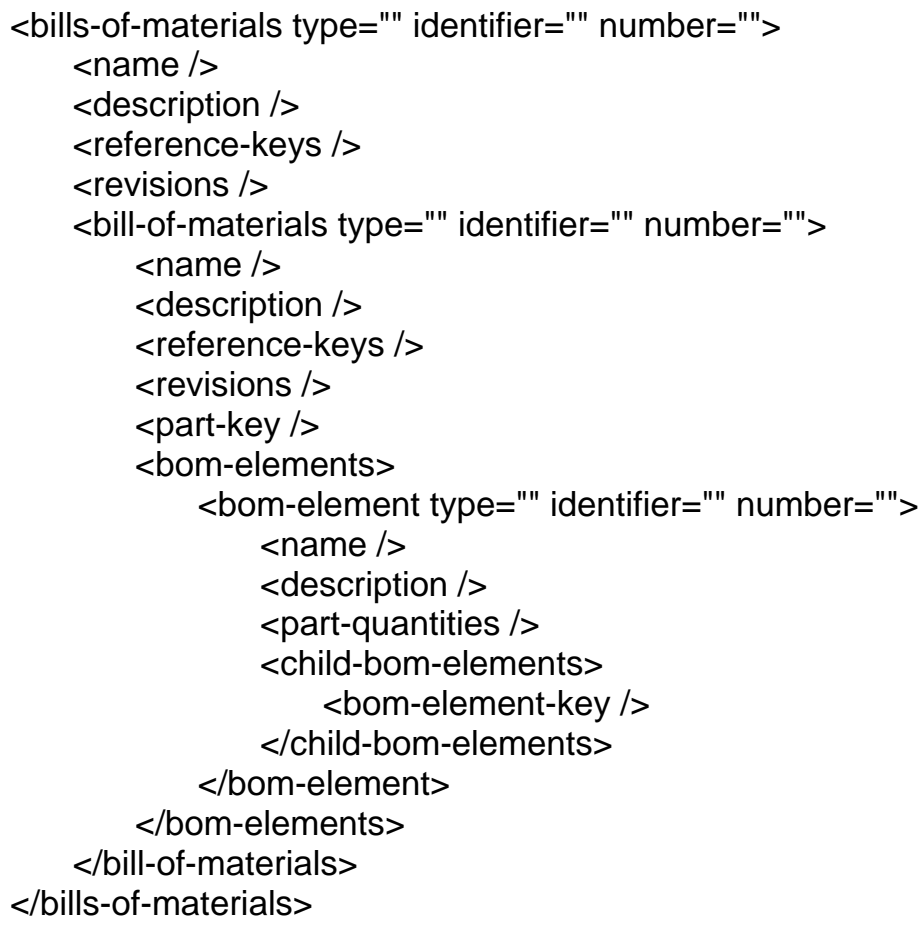

The unique data elements, data element keys, and common data elements introduced in this structure are described below.

\section{a) Unique Data Elements}

bill-of-materials: a bill-of-materials structure for one part.

bills-of-materials: a collection of bill-of-materials records for one or more different parts. 
bom-element: a component element in the bill-of-materials for one part, i.e., a bill-of-materials line item. bom-elements: a collection of component elements that makes up the bill-of-materials for a part.

child-bom-elements: a collection of keys for component elements of a single bill-of-materials element or line item.

\section{b) Data Element Keys, Multi-keys, and Key Lists}

The following keys are used in this structure: bom-element-key, part-key, and reference-keys. Elements within parts use the bill-of-materials-key to reference the data elements in the bills-of-materials element.

\section{c) Common Data Elements}

See Sections 2.2 and 2.3 for a discussion of these common data attributes and elements used by this element: description, identifier, name, number, part-quantities, revisions, and type.

\subsection{Inventory}

inventory identifies the instances and locations for part, materials, tool, and fixture inventory.

The UML information model for the inventory element is shown below:

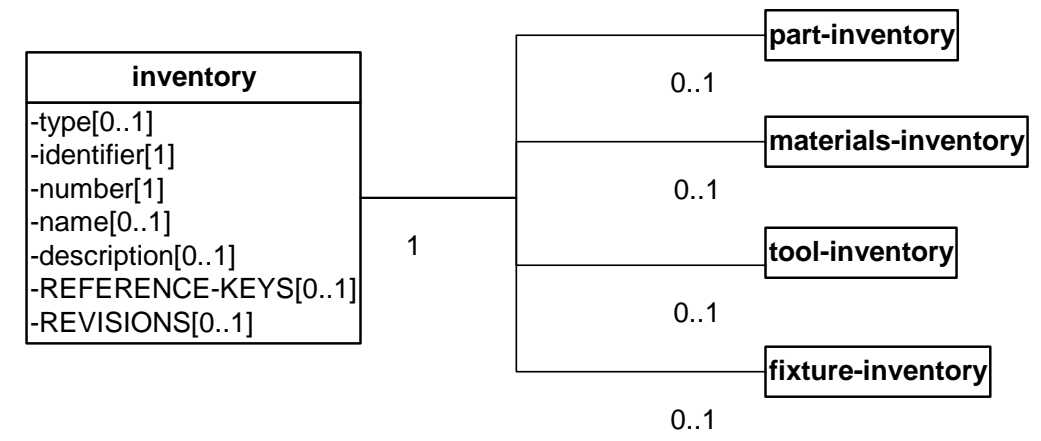

The XML structure for the inventory element is shown below:

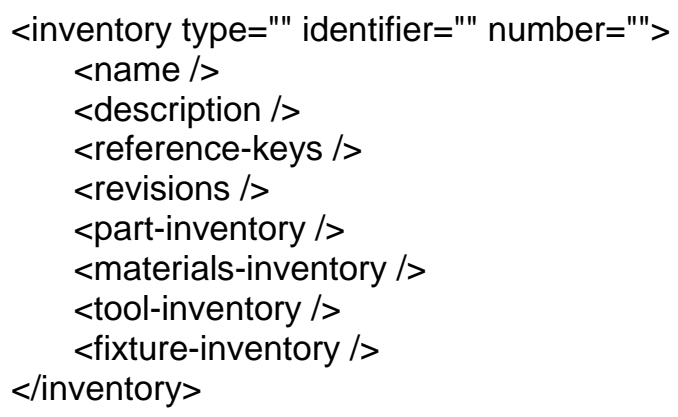

The unique data elements, data element keys, and common data elements introduced in this structure are described below.

\section{a) Unique Data Elements}

fixture-inventory: a collection of inventory records for fixtures and sets of fixture components. 
inventory: a collection of inventories for parts, materials, tools, and fixtures.

materials-inventory: a collection of inventory records for materials, i.e., goods that may be partiallyconsumed (bar stock, sheet stock, wire spools, etc.)

part-inventory: a collection of inventory records for component parts, work-in-process, and finished goods.

tool-inventory: a collection of inventory records for tools and sets of tools.

\section{b) Data Element Keys, Multi-keys, and Key Lists}

The reference-keys element is used in this element. Elements within layout, resources-assigned, resourcesused and setup-definitions use resource-key, part-instance-key, and setup-resource-keys to reference the data elements in the inventory element.

\section{c) Common Data Elements}

See Sections 2.2 and 2.3 for a discussion of these common data attributes and elements used by this element: description, identifier, name, number, revisions, and type.

\section{d) Example Part}

\subsection{Part Inventory}

part-inventory identifies the instances and locations for inventory of individual parts, such as components, work-in-process, and finished goods.

The UML information model for the part-inventory element is shown below:

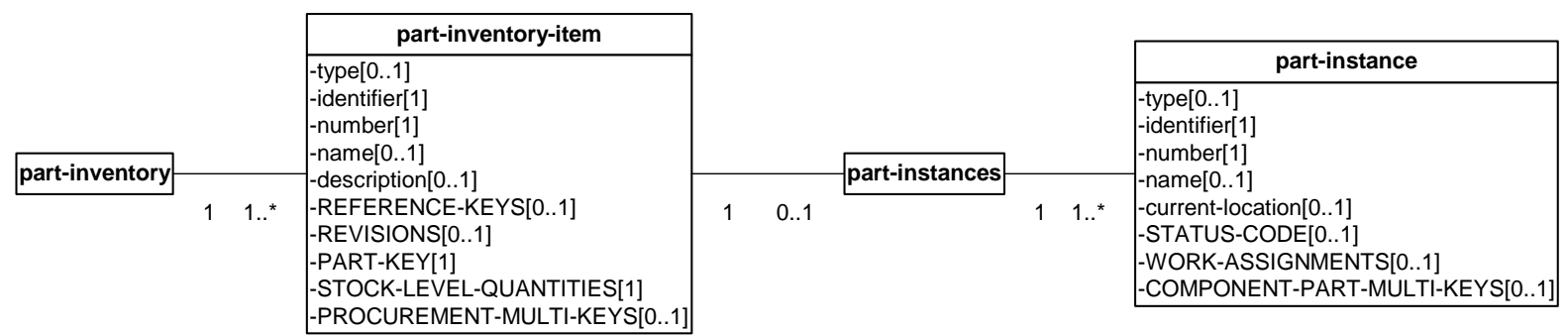

The XML structure for the part-inventory element is shown below:

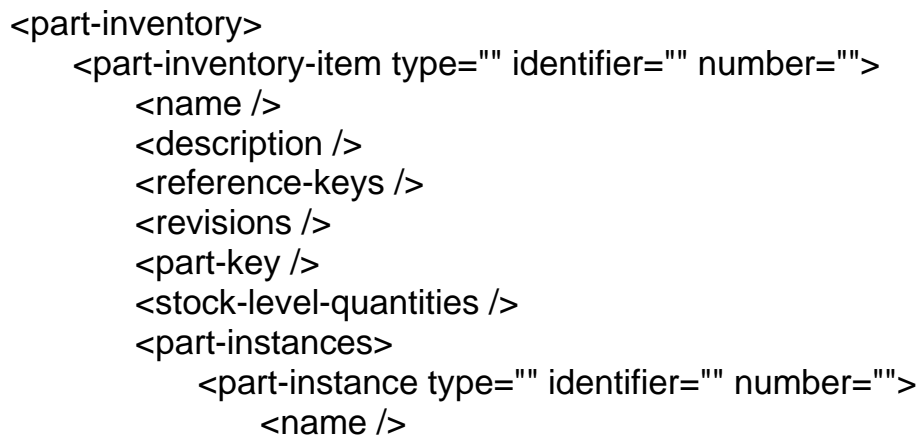




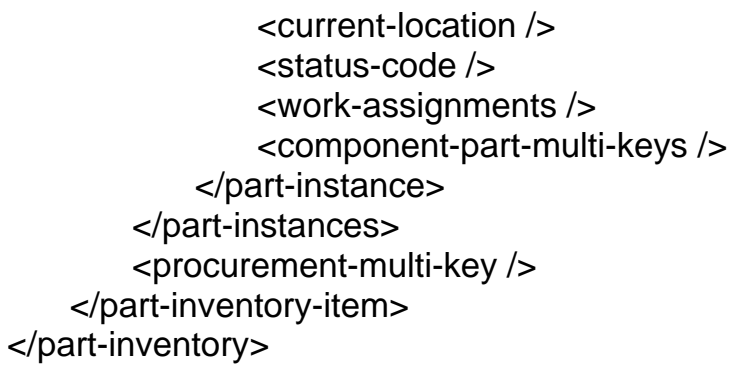

The unique data elements, data element keys, and common data elements introduced in this structure are described below.

\section{a) Unique Data Elements}

part-instance: an individual instance of a part number in inventory, each instance has a current location, a status code, possibly work assignments that is allocated to, and pointers to component part instances if it is an assembly.

part-instances: a collection of instances of a part number in inventory.

part-inventory: a collection of inventory records for one or more part numbers.

part-inventory-item: the record for one part number maintained in inventory.

\section{b) Data Element Keys, Multi-keys, and Key Lists}

The following keys are used in this structure: component-part-multi-key, part-key, procurement-multi-keys, and reference-keys. Elements within resources-assigned and resources-used use a part-instance-key to reference the data elements in the part-inventory element.

\section{c) Common Data Elements}

See Sections 2.2 and 2.3 for a discussion of these common data attributes and elements used by this element: current-location, description, identifier, name, number, revisions, status-code, stock-levelquantities, type, and work-assignments.

\subsection{Materials Inventory}

materials-inventory identifies the instances and locations for materials inventory. Materials are parts that may be partially consumed, e.g., sheet stock, bar stock, tubing, spools of wire.

The UML information model for the materials-inventory element is shown below: 


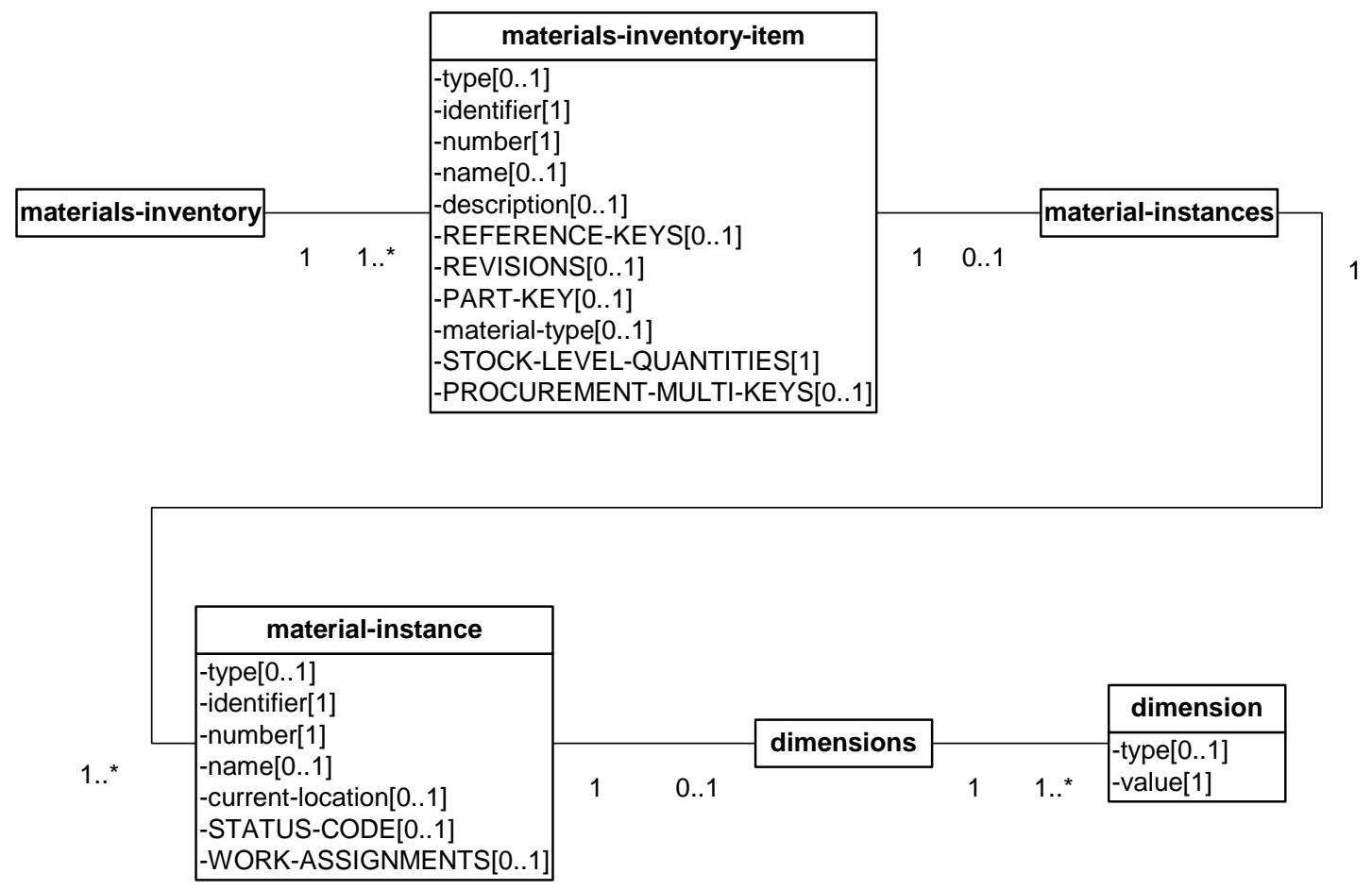

The XML structure for the materials-inventory element is shown below:

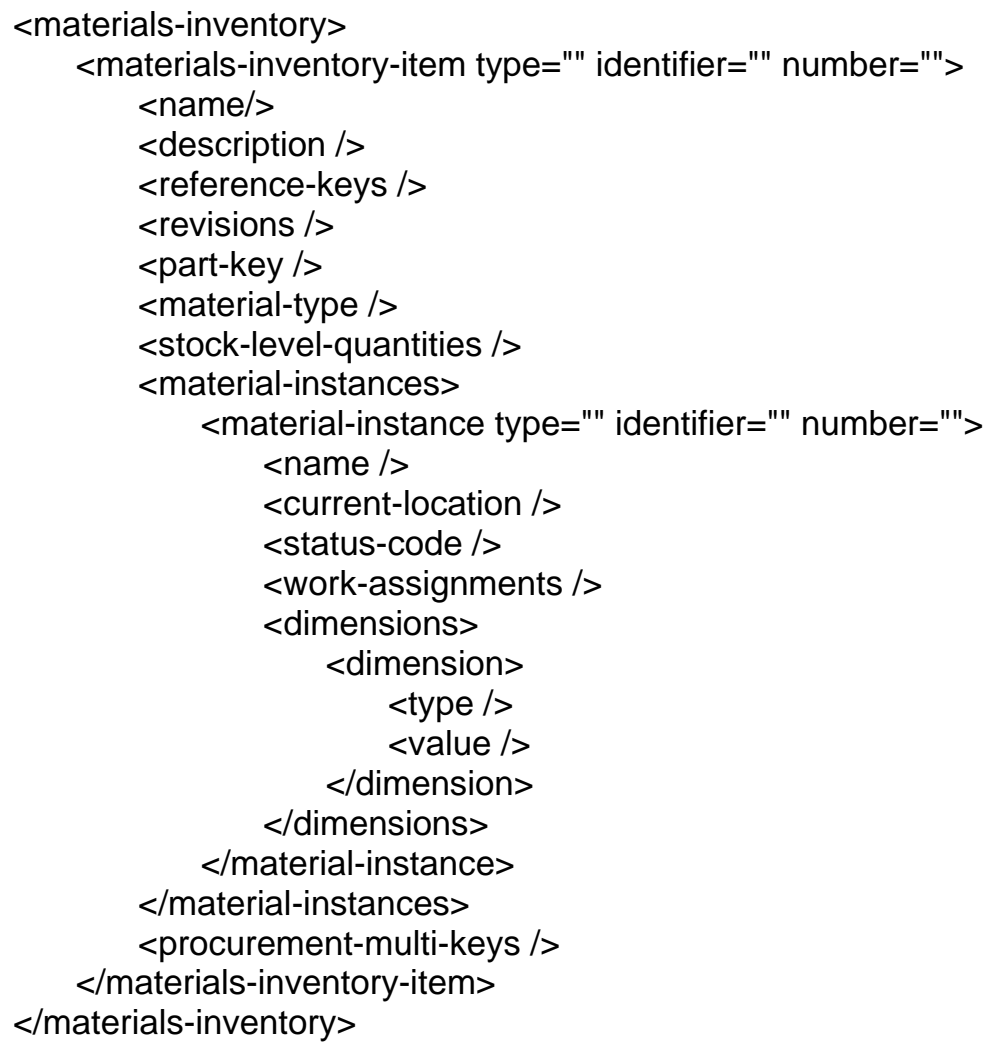


The unique data elements, data element keys, and common data elements introduced in this structure are described below.

\section{a) Unique Data Elements}

dimension: one dimension of piece of a materials-type part instance.

dimensions: a collection of dimensions of a piece of a materials-type part instance.

material-instance: an individual instance of a materials-type part number in inventory, each instance has a current location, a status code, possibly work assignments that is allocated to, and dimensions of the piece of materials.

material-instances: a collection of instances of a materials-type part number in inventory

materials-inventory: a collection of inventory records for one or more materials-type part numbers.

materials-inventory-item: the record for one materials-type part number maintained in inventory.

\section{b) Data Element Keys, Multi-keys, and Key Lists}

The following keys are used in this structure: part-key, procurement-multi-keys, and reference-keys.

\section{c) Common Data Elements}

See Sections 2.2 and 2.3 for a discussion of these common data attributes and elements used by this element: current-location, description, identifier, material-type, name, number, revisions, status-code, stock-level-quantities, type, value, and work-assignments.

\subsection{Tool Inventory}

tool-inventory identifies the instances and locations for tools and toolsets.

The UML information model for the tool-inventory element is shown below: 


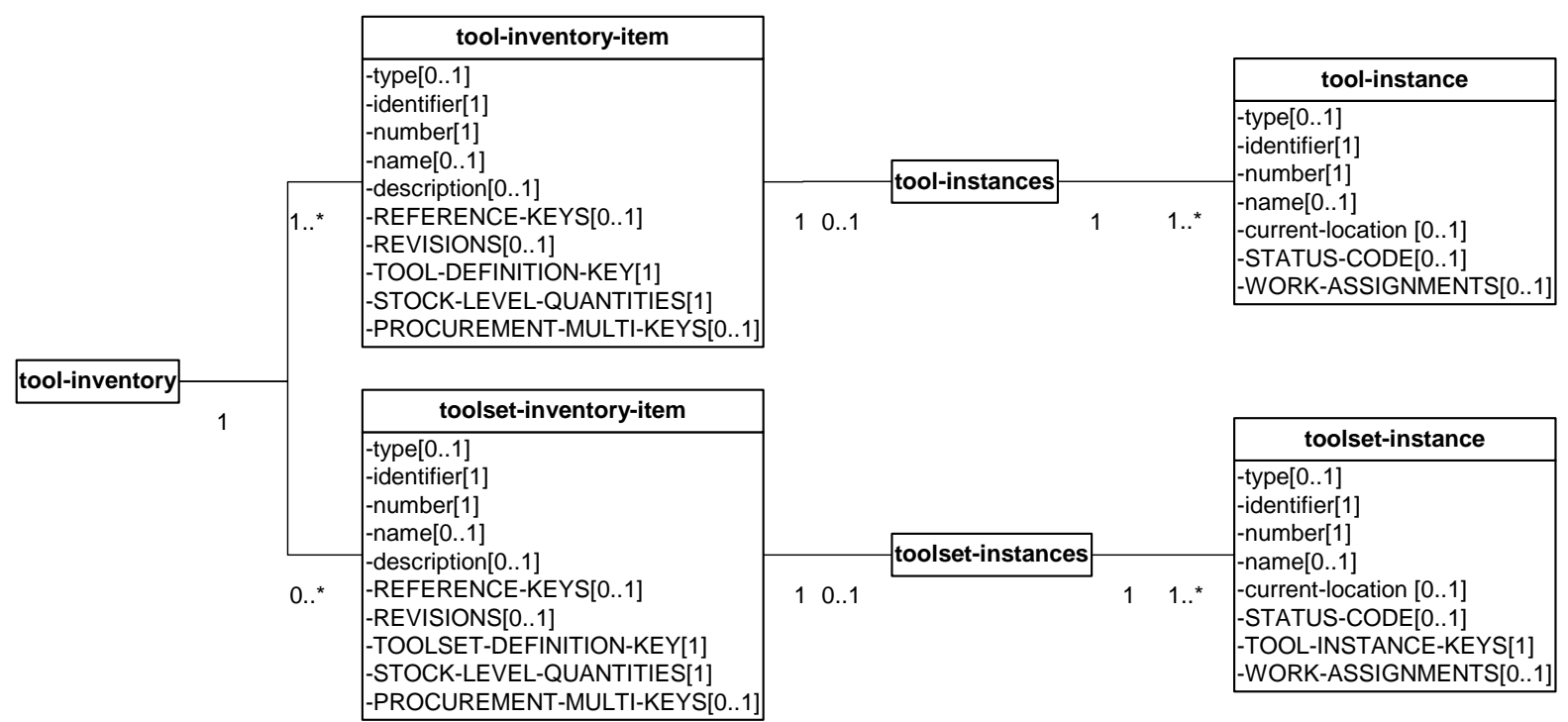

The XML structure for the tool-inventory element is shown below:

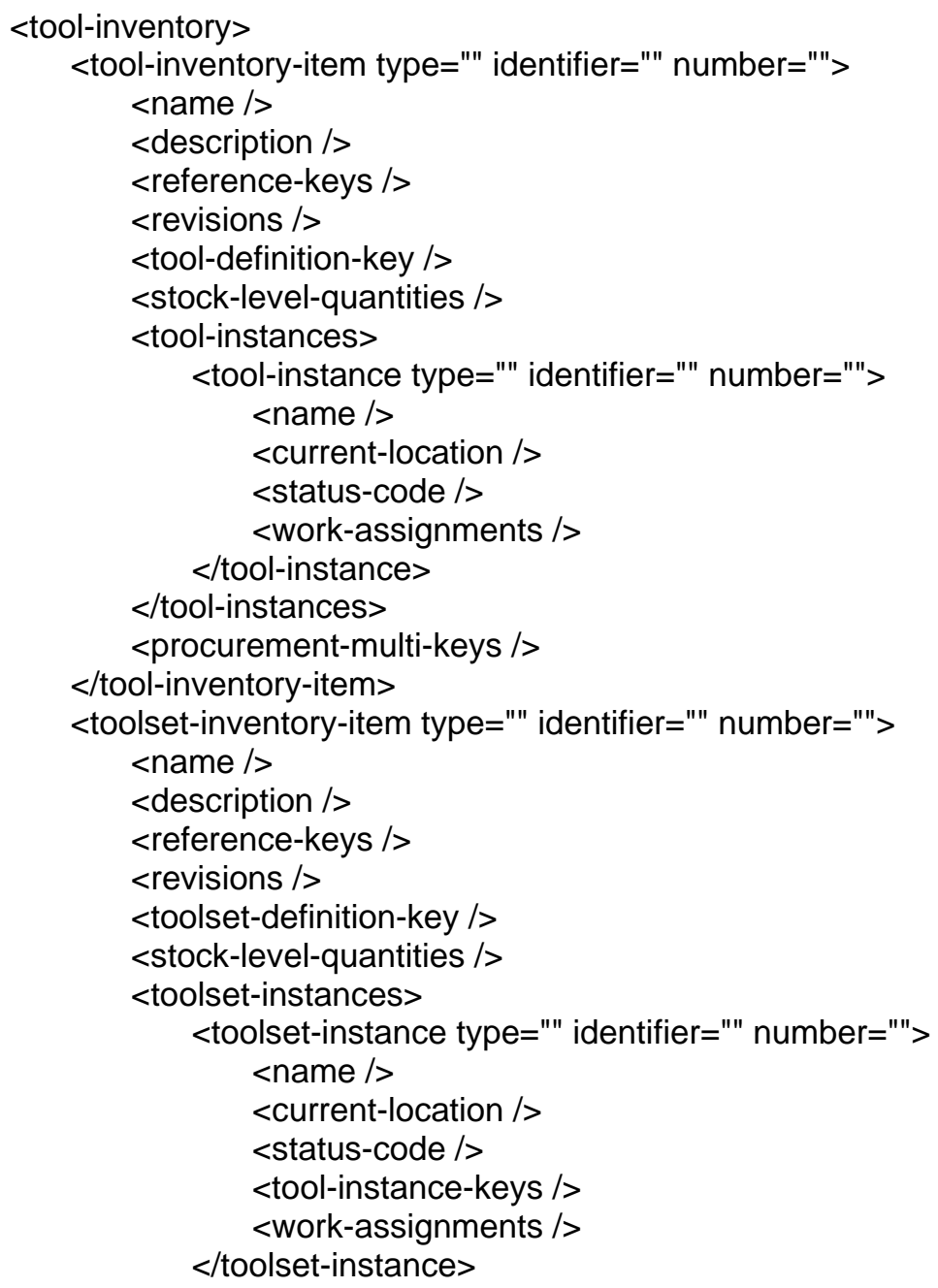




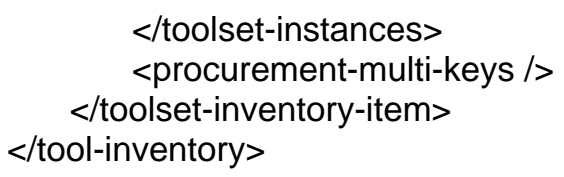

The unique data elements, data element keys, and common data elements introduced in this structure are described below.

\section{a) Unique Data Elements}

tool-instance: a specific instance of a tool, i.e., copy of a tool type that has a unique identifier and location. tool-instances: a collection of tool instances of a particular tool type.

tool-inventory: a collection of tool inventory item records.

tool-inventory-item: the inventory records for a particular type of tool, i.e., tool definition.

toolset-instance: a specific instance of a toolset, i.e., a group of tool that has a unique identifier and location.

toolset-instances: a collection of toolset instances of a particular toolset type.

toolset-inventory-item: the inventory records for a particular type of toolset, i.e., tool group configuration.

\section{b) Data Element Keys, Multi-keys, and Key Lists}

The following keys are used in this structure: procurement-multi-keys, reference-keys, tool-definition-key, tool-instance-keys, and toolset-definition-key.

\section{c) Common Data Elements}

See Sections 2.2 and 2.3 for a discussion of these common data attributes and elements used by this element: current-location, description, identifier, name, number, revisions, status-code, stock-levelquantities, type, and work-assignments.

\subsection{Fixture Inventory}

fixture-inventory identifies the instances and locations for workholding devices, i.e., fixtures and fixture sets.

The UML information model for the fixture-inventory element is shown below: 


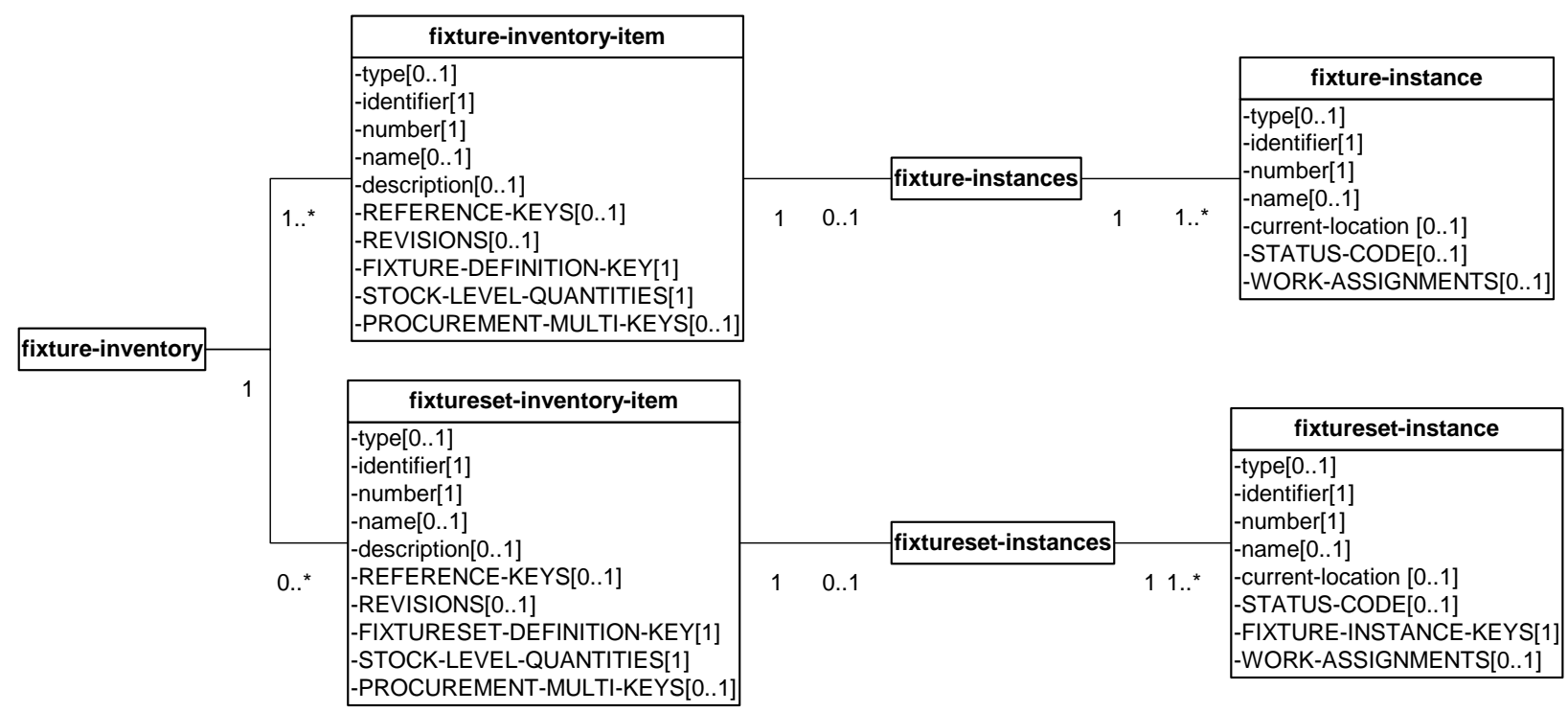

The XML structure for the fixture-inventory element is shown below:

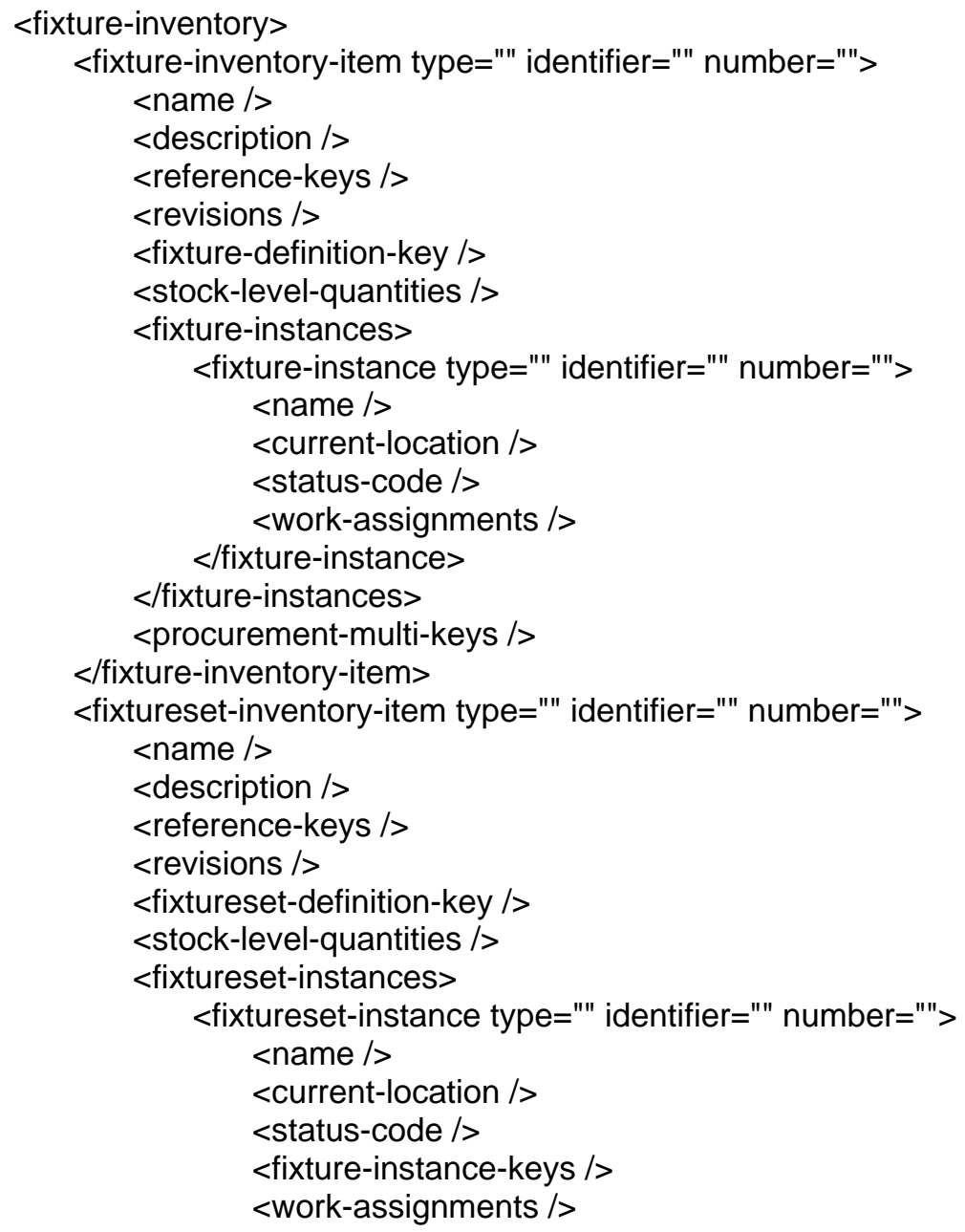




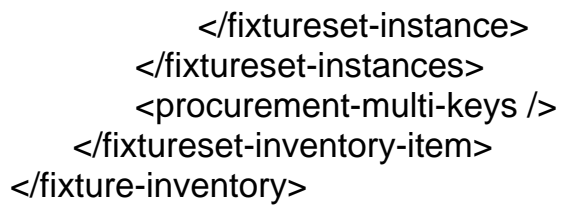

The unique data elements, data element keys, and common data elements introduced in this structure are described below.

\section{a) Unique Data Elements}

fixture-instance: a specific instance of a fixture, i.e., copy of a fixture type that has a unique identifier and location.

fixture-instances: a collection of fixture instances of a particular fixture type.

fixture-inventory: a collection of fixture inventory item records.

fixture-inventory-item: the inventory records for a particular type of fixture, i.e., fixture definition.

fixtureset-instance: a specific instance of a fixtureset, i.e., a group of fixture that has a unique identifier and location.

fixtureset-instances: a collection of fixtureset instances of a particular fixtureset type.

fixtureset-inventory-item: the inventory records for a particular type of fixtureset, i.e., fixture group configuration.

\section{b) Data Element Keys, Multi-keys, and Key Lists}

The following keys are used in this structure: fixture-definition-key, fixture-instance-keys, fixturesetdefinition-key, procurement-multi-keys, and reference-keys.

\section{c) Common Data Elements}

See Sections 2.2 and 2.3 for a discussion of these common data attributes and elements used by this element: current-location, description, identifier, name, number, revisions, status-code, stock-levelquantities, type, and work-assignments.

\subsection{Procurements}

procurements identifies the external purchases that have been created to satisfy part inventory and manufacturing requirements.

The UML information model for the procurements element is shown below: 

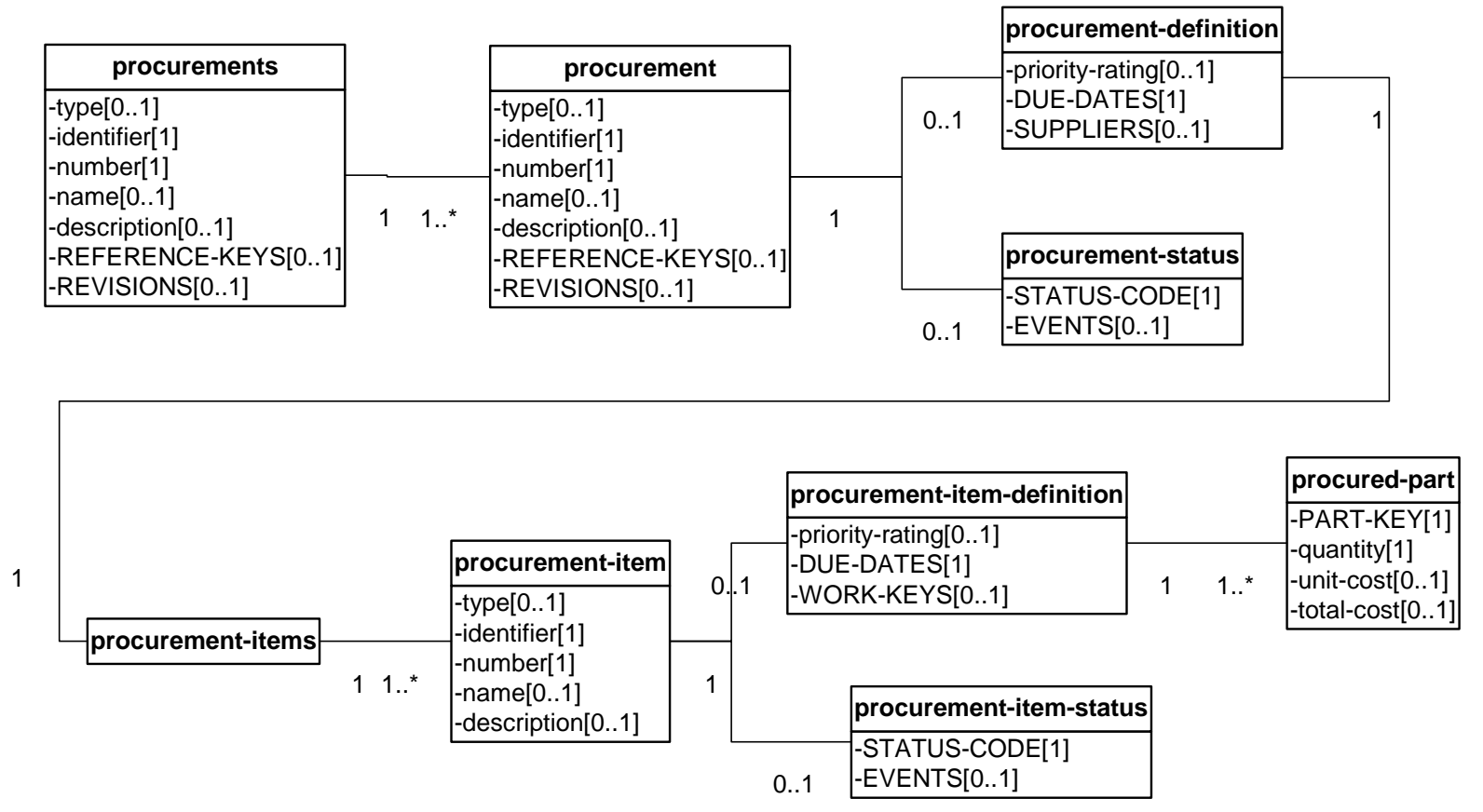

The XML structure for the procurements element is shown below:

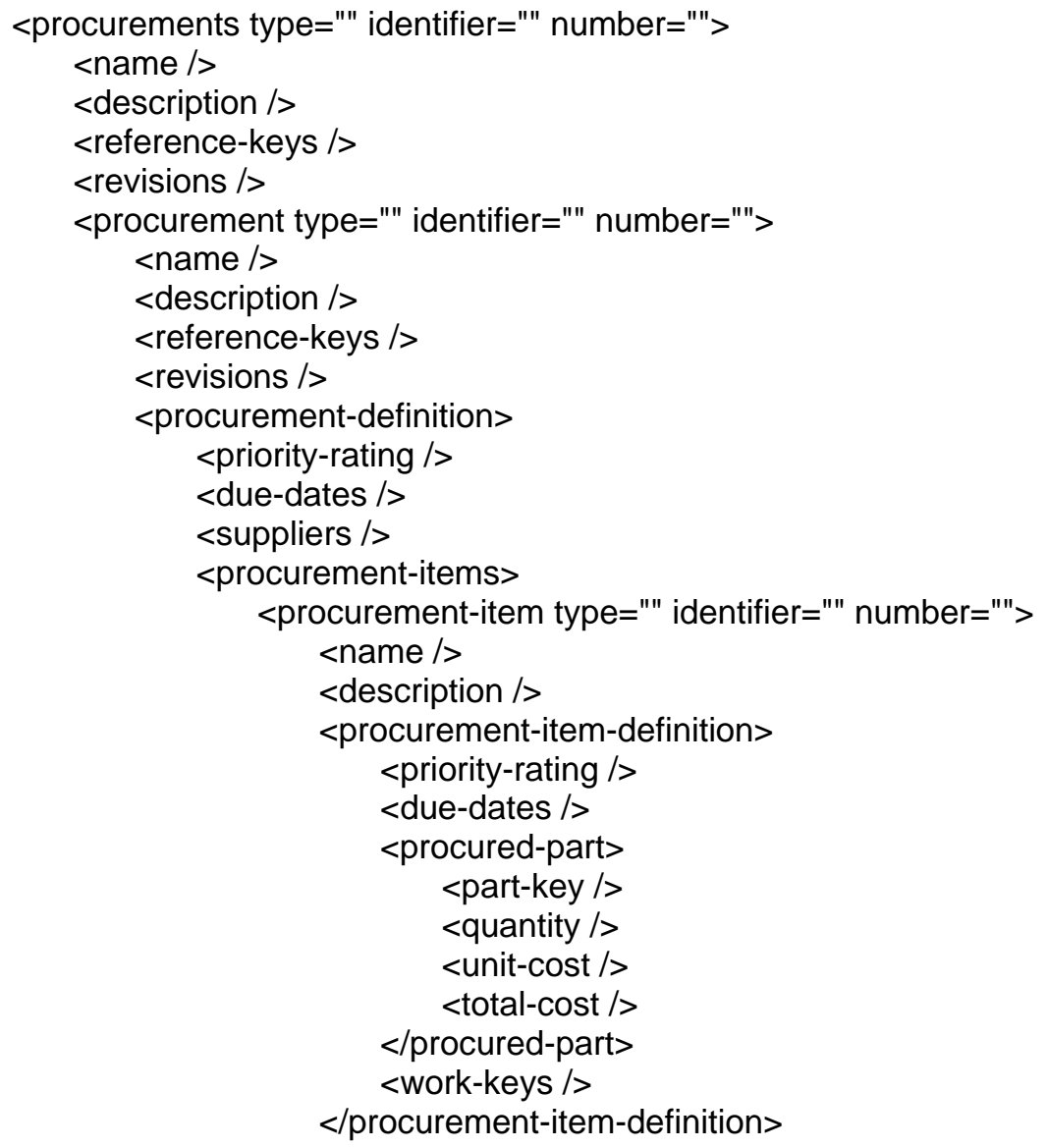




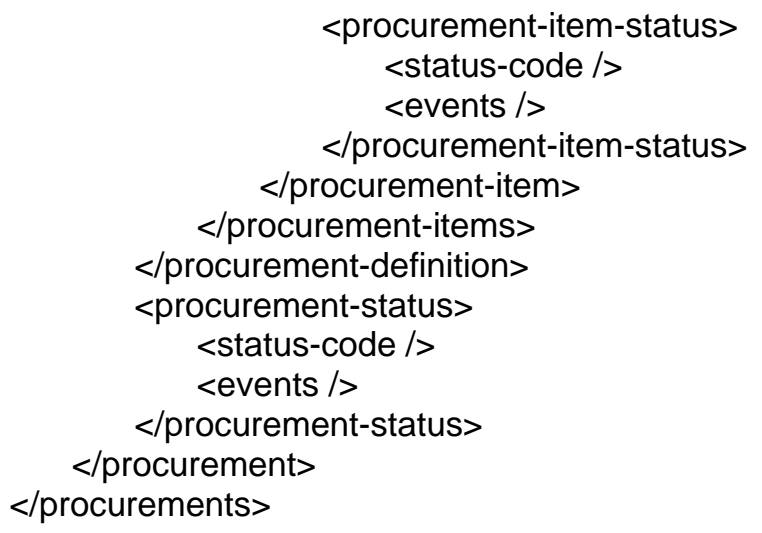

The unique data elements, data element keys, and common data elements introduced in this structure are described below.

\section{a) Unique Data Elements}

procured-part: a section of the procurement item definition that identifies the part key, quantities, unit and total cost information.

procurement: one procurement order to a supplier.

procurement-definition: a subsection of an individual procurement order that defines the items to be purchased, due dates, priorities, etc.

procurement-item: the section of a procurement that contains a line item for one item.

procurement-item-definition: the definition of the characteristics of one procurement item, e.g., the part key, due dates, priority.

procurement-items: a collection of procured items in a single procurement order.

procurement-item-status: the status of one procured item in a single procurement order.

procurements: a collection of one or more procurement orders.

procurement-status: the overall status of a single procurement order.

\section{b) Data Element Keys, Multi-keys, and Key Lists}

The following keys are used in this structure: part-key, reference-keys, and work-keys. Structures within inventory use the procurement-multi-keys to reference the data elements in the procurements structure.

\section{c) Common Data Elements}

See Sections 2.2 and 2.3 for a discussion of these common data attributes and elements used by this element: description, due-dates, events, identifier, name, number, priority-rating, quantity, revisions, status-code, suppliers, total-cost, type, and unit-cost.

\subsection{Process Plans}

process-plans specifies a set of process plans that are associated with production and support activities for a particular part or parts. A process plan has routings sheets and/or operation sheets that correspond to the job 
and/or task level in the work hierarchy. process-plan contains routing-sheets, operation-sheets, and machine-programs.

The UML information model for the process-plans element is shown below:

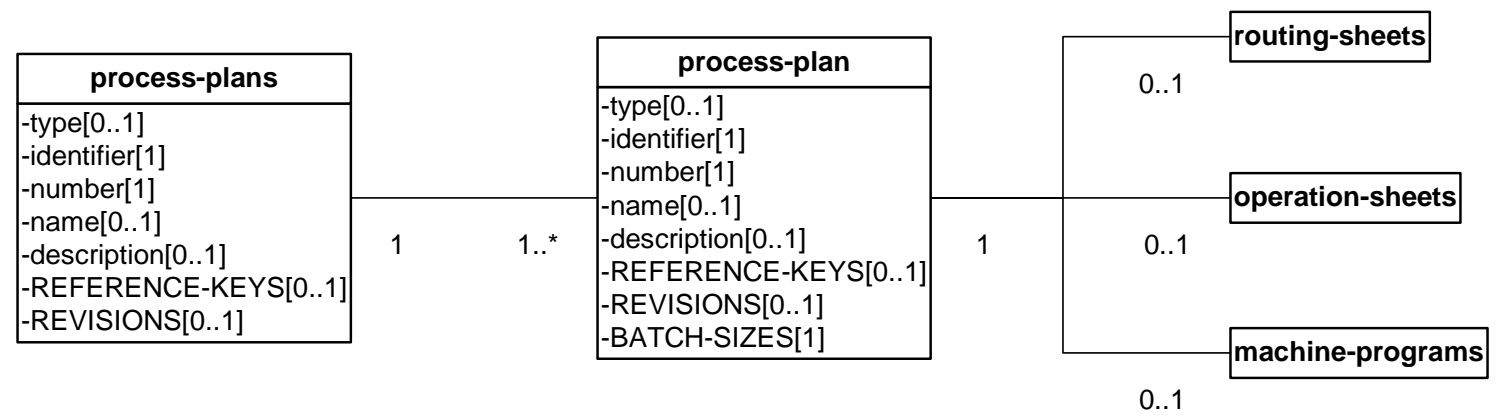

The XML structure for the process-plans element is shown below:

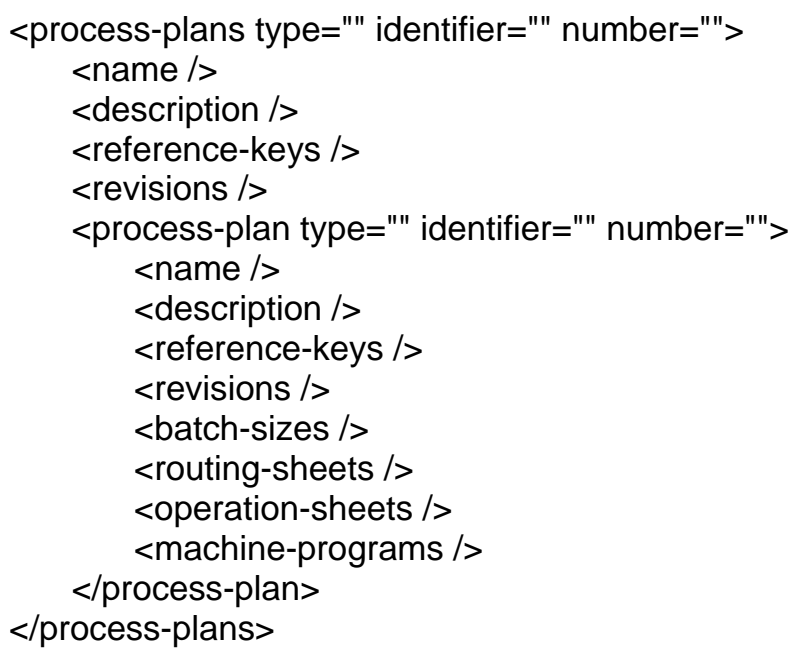

The unique data elements, data element keys, and common data elements introduced in this structure are described below.

\section{a) Unique Data Elements}

machine-programs: (refer to Section 3.27)

operation-sheets: (refer to Section 3.26)

process-plan: a group of documents that specifies the manufacturing processes for a particular part or parts. Documents include routing sheets for job level work, operation sheets for task level work, and machine programs.

process-plans: a collection of individual process plans, routing sheets, operation sheets, and machine programs.

routing-sheets: (refer to Section 3.25) 


\section{b) Data Element Keys, Multi-keys, and Key Lists}

The reference-keys element is used in this element. Elements within parts and works use a process-planmulti-key(s) to reference the data element in the process-plans element.

\section{c) Common Data Elements}

See Sections 2.2 and 2.3 for a discussion of these common data attributes and elements used by this element: batch-sizes, description, identifier, name, number, revisions, and type.

\subsection{Routing Sheets}

routing-sheets are complex process planning documents that specify production and support activities that may take place at different stations or work areas within the shop. Routing sheets correspond to the job level in the work hierarchy. A routing sheet defines the steps, precedence constraints between steps, and resources associated with the production of parts and performance of support activities. It may require one or more routing sheets to completely define a process plan. One routing sheet corresponds to one job. A job may contain one or more tasks. The steps of the routing sheet typically correspond to tasks that need to be created.

The UML information model for the routing-sheets element is shown below:

\begin{tabular}{|c|c|c|c|}
\hline \multirow{2}{*}{ routing-sheets } & & & \multirow{3}{*}{\begin{tabular}{|l}
\multicolumn{1}{|c}{ routing-sheet } \\
-type[0..1] \\
-identifier[1] \\
-number[1] \\
-name[0..1] \\
-description[0..1] \\
-REFERENCE-KEYS[0..1] \\
-REVISIONS[0.1] \\
-BATCH-SIZES[1] \\
-PLAN-DEFINITION[1]
\end{tabular}} \\
\hline & & & \\
\hline & 1 & $1 . .{ }^{*}$ & \\
\hline
\end{tabular}

The XML structure for the routing-sheets element is shown below:

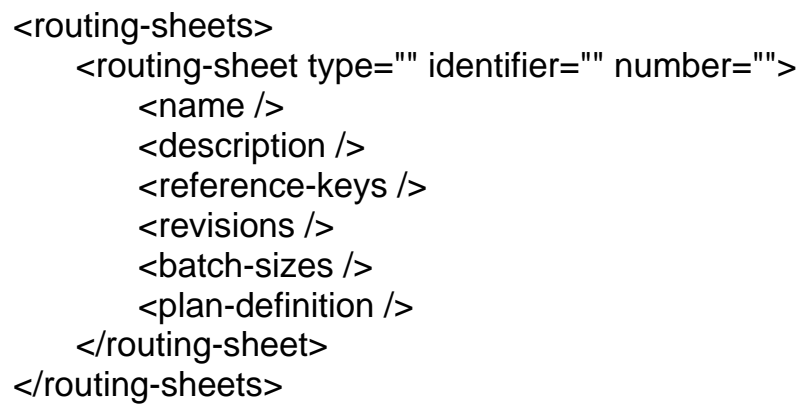

The unique data elements, data element keys, and common data elements introduced in this structure are described below.

\section{a) Unique Data Element}


routing-sheet: a document that specifies a complex plan for production that typically takes place at multiple stations or areas where work is performed. The routing sheet determines what tasks need to be created. Steps in the routing may correspond to a critical path network where many activities go on in parallel.

routing-sheets: a collection of individual routing sheets.

\section{b) Data Element Keys, Multi-keys, and Key Lists}

This element uses reference-keys. Elements within jobs and tasks use process-plan-multi-key to reference the data elements in the routing-sheets element.

\section{c) Common Data Elements}

See Sections 2.2 and 2.3 for a discussion of these common data attributes and elements used by this element: batch-sizes, description, identifier, name, number, plan-definition, revisions, and type.

\subsection{Operation Sheets}

operation-sheets specifies the operation sheets that are associated with production and support activities. Operation sheets correspond to the task level in the work hierarchy. A task normally performs on a workpiece at one given station. An operation sheet defines the steps, precedence constraints between steps, and resources associated with the production of parts and performance of support activities. One operation sheet supports one task, and it requires one or more operation sheets to completely define a process plan.

The UML information model for the operation-sheets element is shown below:

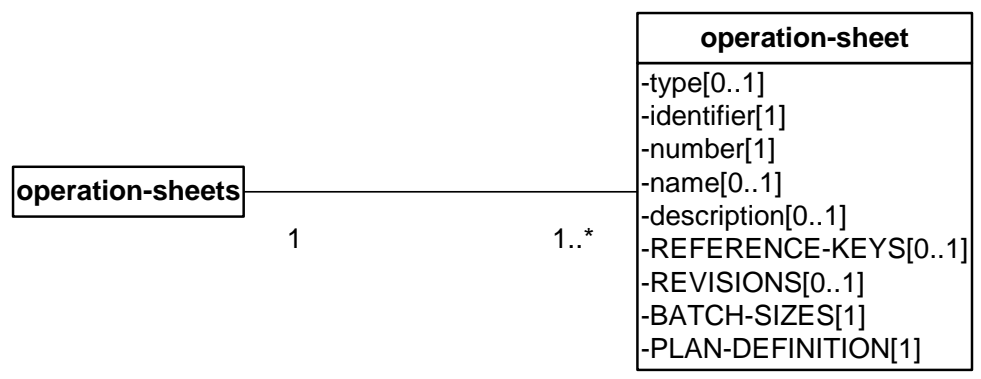

The XML structure for the operation-sheets element is shown below:

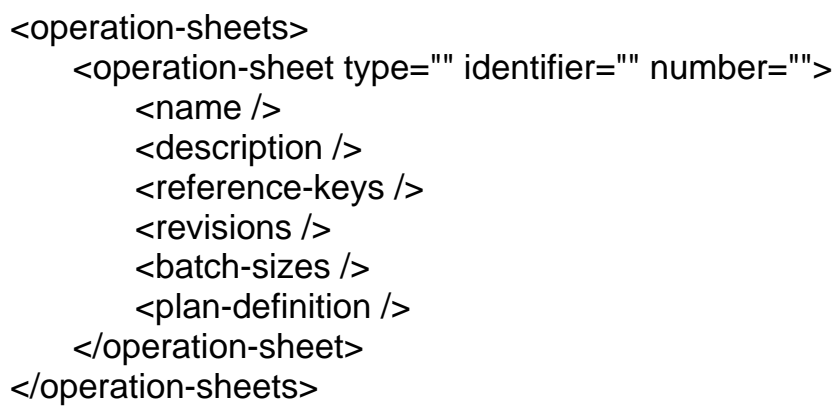

The unique data elements, data element keys, and common data elements introduced in this structure are described below.

\section{a) Unique Data Element}


operation-sheet: information about a set of operations or processes that are typically performed on a workpiece at a specific station and machine. The operation sheet specifies the detailed steps that are associated with carrying out a task. The task typically is associated with one step in a routing sheet level document within a process plan.

operation-sheets: a collection of individual operation sheets.

\section{b) Data Element Keys, Multi-keys, and Key Lists}

reference-keys are used in this element. reference-keys and tasks typically reference individual operation sheets using process-plan-multi-key.

\section{c) Common Data Elements}

See Sections 2.2 and 2.3 for a discussion of these common data attributes and elements used by this element: batch-sizes, description, identifier, name, number, plan-definition, revisions, and type.

\subsection{Machine Programs}

machine-programs specifies the machine programs that are used with the operation sheet. It also defines the target machine and program duration of support activities.

The UML information model for the machine-programs element is shown below:

\begin{tabular}{|c|c|c|c|c|c|c|}
\hline & & & machine-proqram & & & \\
\hline & & & \begin{tabular}{|l|}
-type[0..1] \\
-identifier[1] \\
-number[1]
\end{tabular} & & & torat mohing \\
\hline machine-programs & & & -name[0..1] & & & \\
\hline macnine-programs & 1 & 1..* & $\begin{array}{l}\text {-description[0..1] } \\
\text {-REFERENCE-KEYS[0..1] }\end{array}$ & 1 & $0 . .1$ & $\begin{array}{l}\text {-MACHINE-KEYS[1..*] } \\
\text {-controller-type[0..1] }\end{array}$ \\
\hline & & & -REVISIONS[0..1] & & & \\
\hline & & & -BATCH-SIZES[0..1] & & & \\
\hline & & & -ESTIMATED-DURATIONS[0..1] & & & \\
\hline
\end{tabular}

The XML structure for the machine-programs element is shown below:

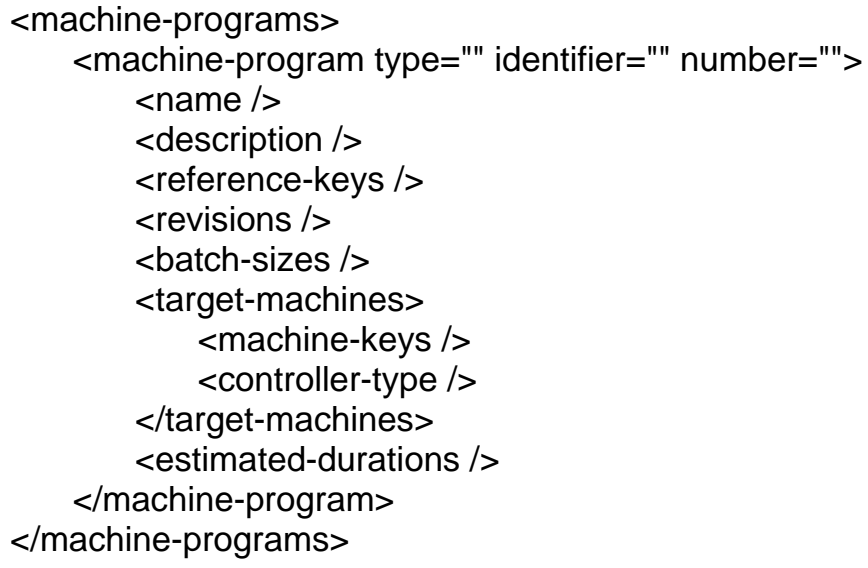


The unique data elements, data element keys, and common data elements introduced in this structure are described below.

\section{a) Unique Data Element}

controller-type: the type of controller the machine uses.

machine-program: the program used with the machine for a particular task and associated step or steps in an operation sheet.

machine-programs: a collection of machine programs.

target-machines: the machines and their controller type that the program was written to execute on.

\section{b) Data Element Keys, Multi-keys, and Key Lists}

This element uses machine-keys and reference-keys. tasks references machine-programs using processplan-multi-key.

\section{c) Common Data Elements}

See Sections 2.2 and 2.3 for a discussion of these common data attributes and elements used by this element: batch-sizes, description, estimated-durations, identifier, name, number, revisions, and type.

\subsection{Work}

The work section is used to specify a collection of a hierarchy of production orders, jobs, and tasks. It is also used to specify a collection of internal support orders for maintenance activities, inventory picking, and tool preparation. Standard header data is provided for the collection element: type, identifier, number, name, description, reference-keys, and revisions.

The UML information model for the work element is shown below:

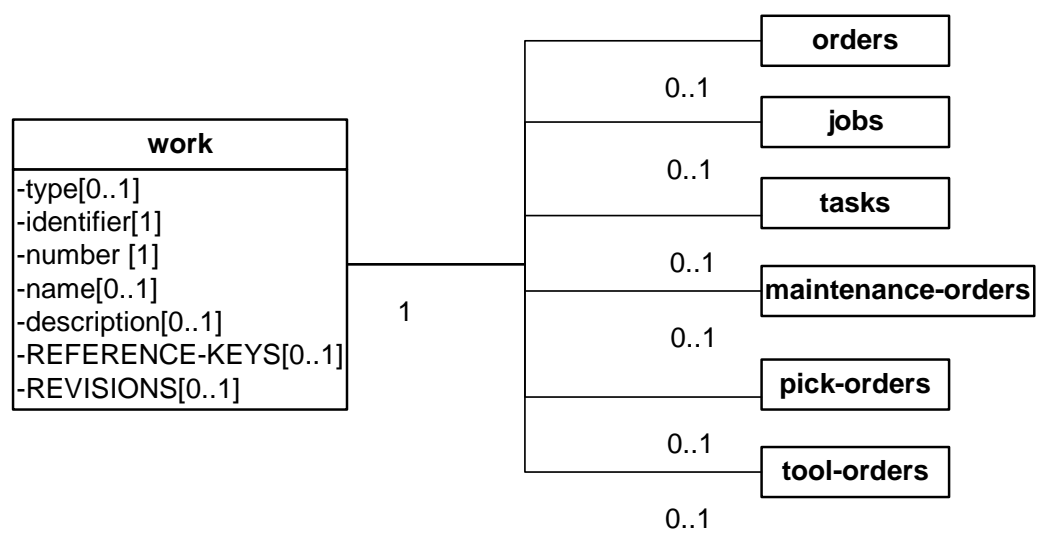


The XML structure for the work element is shown below:

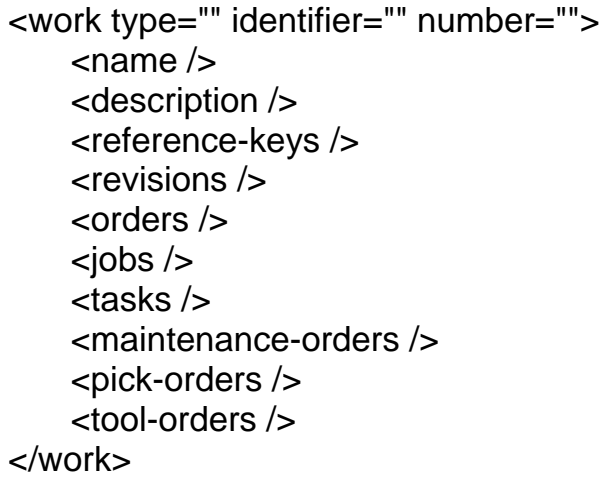

The unique data elements, data element keys, and common data elements introduced in this structure are described below.

\section{a) Unique Data Elements}

jobs: the high level internal production activities associated with an order to produce goods. A job typically has a routing sheet process plan that specifies the steps of production at multiple stations, resources, and lower level plans (operation sheets) required to complete the job. A job may be decomposed into other jobs or tasks (refer to Section 3.31).

maintenance-orders: maintenance actions on machine tools and other equipment (refer to Section 3.33).

orders: orders for goods to be delivered to internal and external customers. Goods may be drawn from stock or produced to meet order requirements (refer to Section 3.29).

pick-orders: orders to draw goods from inventory (refer to Section 3.34).

tasks: the low level production activities associated with one step of a job level routing sheet. A task takes place at one station and may have an operation sheet that specifies the individual steps to be performed and the resources required (refer to Section 3.32).

tool-orders: tooling orders typically for kitting and/or assembly of tool components and assemblies in the tool crib (refer to Section 3.35).

work: a collection of orders, jobs, tasks, maintenance orders, tool orders, and pick orders.

\section{b) Data Element Keys, Multi-keys, and Key Lists}

reference-keys are used in this element. Elements within child-work-items, precedent-constraints, and work-assignments use a work-keys to reference the data elements in the work element.

\section{c) Common Data Elements}

See Sections 2.2 and 2.3 for a discussion of these common data attributes and elements used by this element: description, identifier, name, number, revisions, and type.

\subsection{Orders}


orders specifies a collection of production work orders to be processed within the shop. Each order contains an order-definition and/or an order-status section. The order-definition contains attributes of the order including a list of order-items, i.e., a listing of individual parts. The same part may be listed in the order multiple times in different order items if each instance has unique attributes, e.g., different due dates.

The UML information model for the orders element is shown below:

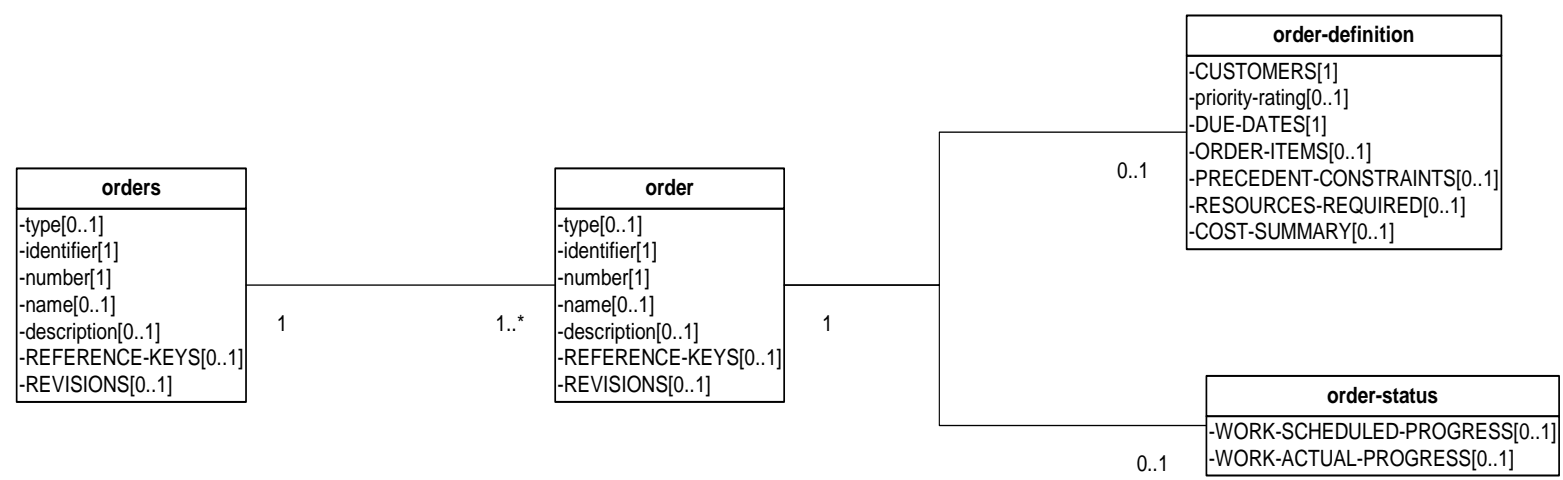

The XML structure for the orders element is shown below:

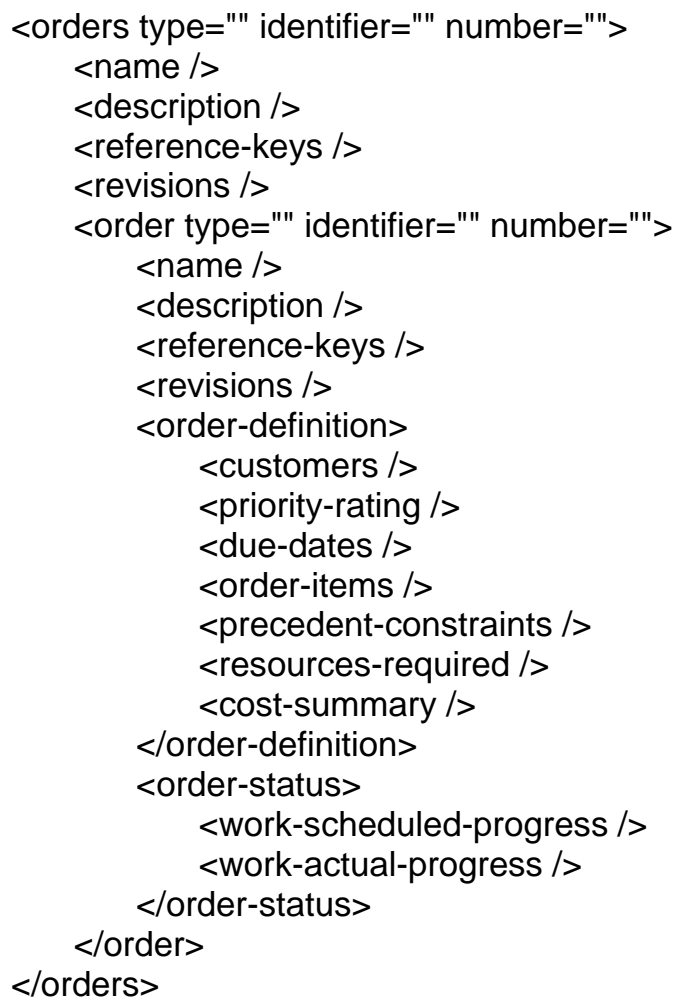


The unique data elements, data element keys, and common data elements introduced in this structure are described below.

\section{a) Unique Data Elements}

order: an instance of a production order.

order-definition: information that specifies who the order is for (customers), the relative priority of the order (priority-rating), critical due dates for the order (due-dates), what output products are required (order-items), resource requirements (resources-required), precedence relationships between order items (precedent-constraints), and summary of estimated and actual cost data (cost summary).

order-items: information on specific parts that make up the order (refer to Section 3.30)

orders: a collection of individual orders.

order-status: information about scheduled and actual progress towards completing the order. The workscheduled-progress and work-actual-progress common data elements are used to organize this information.

\section{b) Data Element Keys, Multi-keys, and Key Lists}

reference-keys are used in this element. Elements within schedules use an order-multi-key to reference the data elements in the orders element.

\section{c) Common Data Elements}

See Sections 2.2 and 2.3 for a discussion of these common data attributes and elements used by this element: cost-summary, customers, description, due-dates, identifier, name, number, precedent-constraints, priority-rating, resources-required, revisions, type, work-actual-progress, and work-scheduled-progress.

\subsection{Order Items}

order-items lists the individual parts that make up a particular order. Each order-item has an order-itemdefinition element that may specify a unique priority rating, due dates, part number, quantity needed, child work items (jobs), and summary cost information for a particular order item. The order-item also an orderstatus element that contains scheduled and actual progress towards completing the order item.

The UML information model for the order-items element is shown below: 


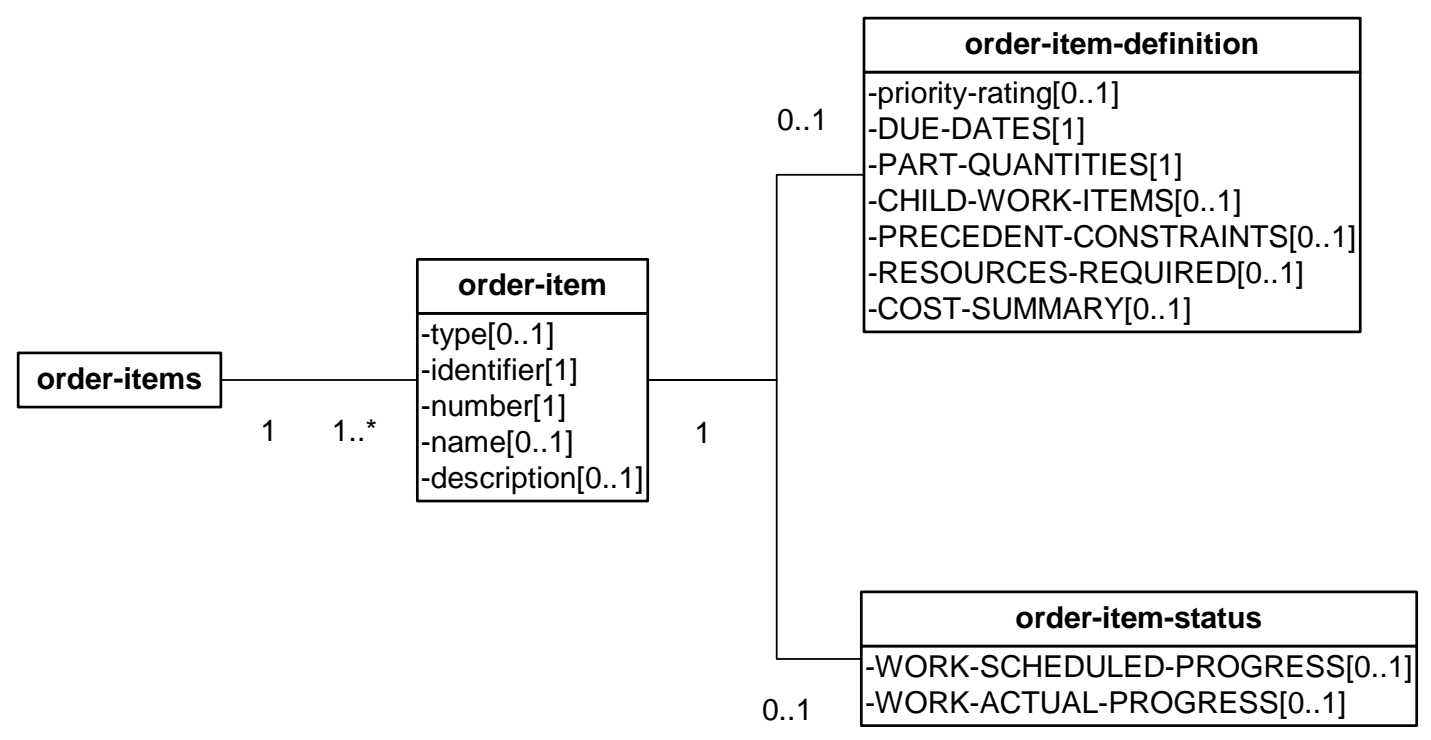

The XML structure for the order-items element is shown below:

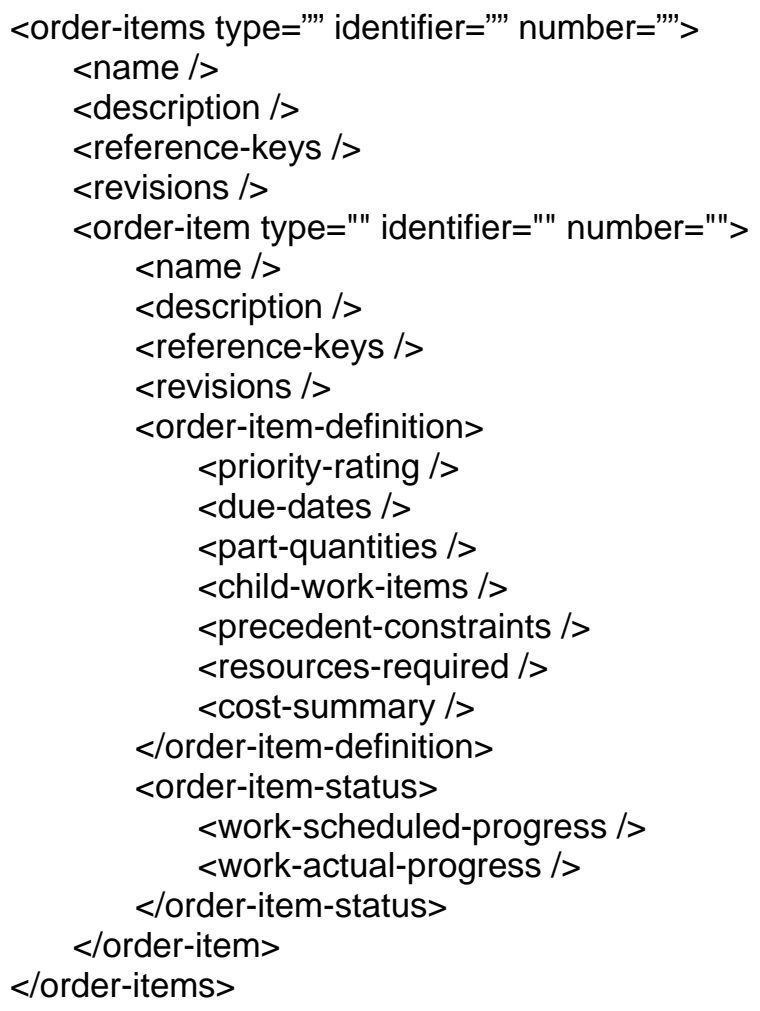


The unique data elements, data element keys, and common data elements introduced in this structure are described below.

\section{a) Unique Data Elements}

order-item: one type of part item in a production order.

order-item-definition: the relative priority of this order item within the order (priority-rating), critical due dates for the order item (due-dates), what products are required (part-quantities), resource requirements (resources-required), precedence relationships between order items (precedent-constraints), and summary of estimated and actual cost data (cost summary).

order-items: a collection of specific order items associated with individual parts that make up an order.

order-item-status: information about scheduled and actual progress towards completing the order. The work-scheduled-progress and work-actual-progress common data elements are used to organize this information.

\section{b) Data Element Keys, Multi-keys, and Key Lists}

No keys are used in this structure. Elements within schedules use an order-multi-key to reference the data elements in the order-items element.

\section{c) Common Data Elements}

See Sections 2.2 and 2.3 for a discussion of these common data attributes and elements used by this element: child-work-items, cost-summary, description, due-dates, identifier, name, number, part-quantities, precedent-constraints, priority-rating, resources-required, revisions, type, work-actual-progress, and workscheduled-progress.

\subsection{Jobs}

jobs specifies a collection of individual production jobs to be processed by the shop. Jobs are created to produce the parts called out in the order-items section of an order. Each job has a job-definition and a jobstatus section. The job-definition section specifies what needs to be done. The job-status section specifies planning progress and actual progress towards accomplishing the job. child-work-items are the subordinate work items that are created for a job, they may be either other jobs or tasks. 
The UML information model for the jobs element is shown below:

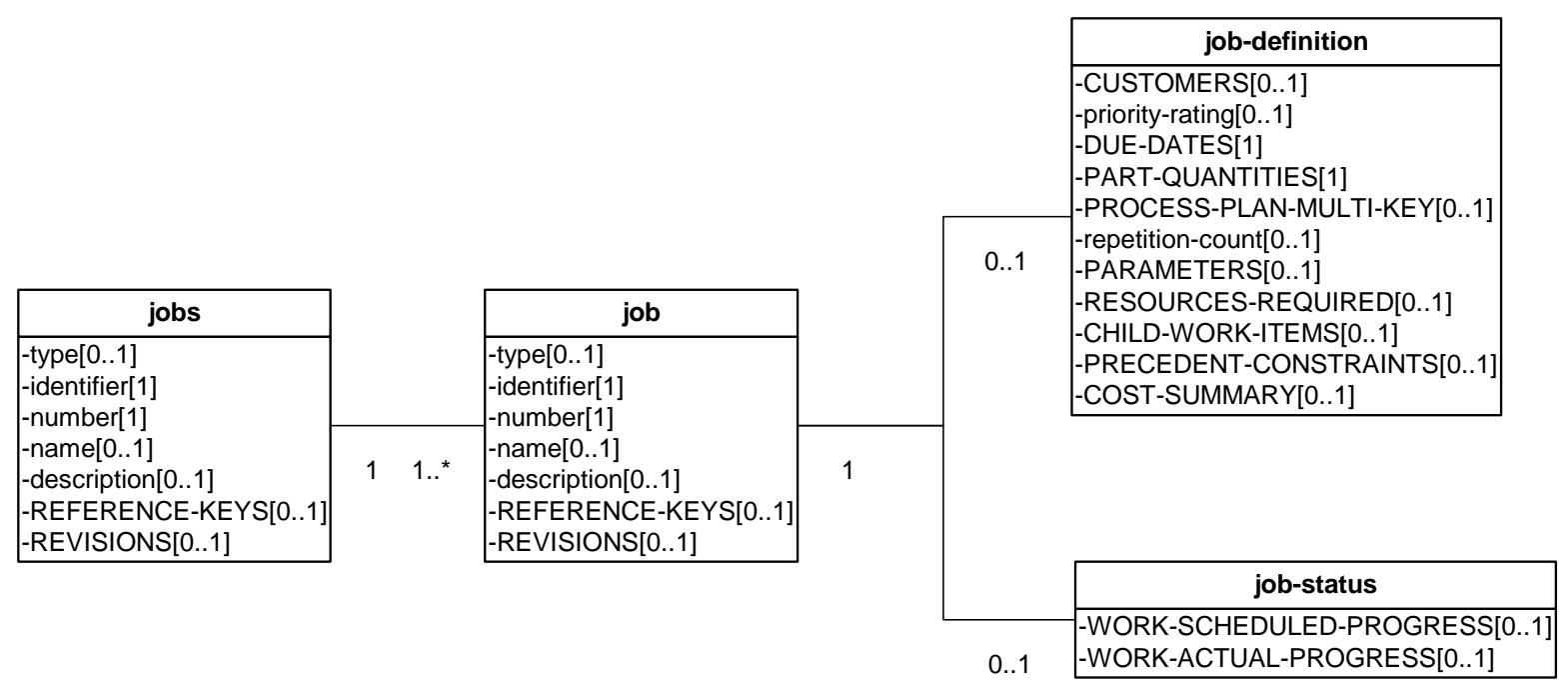

The XML structure for the jobs element is shown below:

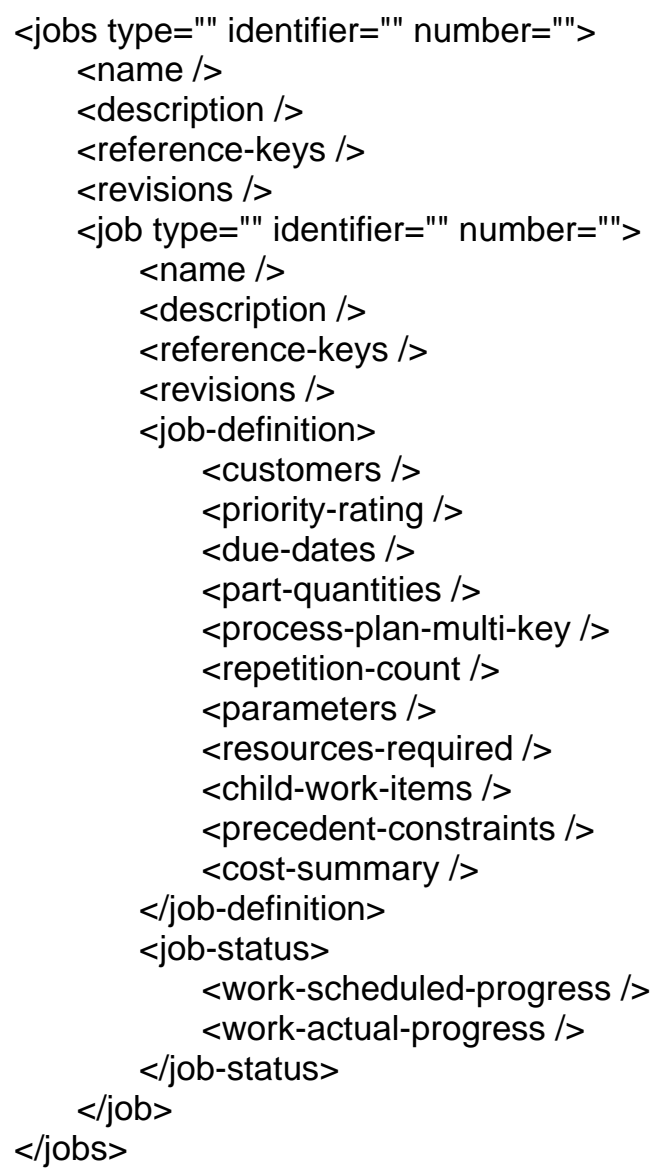

The unique data elements, data element keys, and common data elements introduced in this structure are described below. 


\section{a) Unique Data Elements}

job: a child work item of an order.

job-definition: the relative priority of this job (priority-rating), critical due dates for the job (due-dates), what products are required (part-quantities), resource requirements (resources-required), precedence relationships between child work items of this job (precedent-constraints), and summary of estimated and actual cost data (cost summary).

jobs: a collection of individual jobs.

job-status: information about scheduled and actual progress towards completing the job. The workscheduled-progress and work-actual-progress common data elements are used to organize this information.

\section{b) Data Element Keys, Multi-keys, and Key Lists}

The following key elements are used in this structure: process-plan-multi-key and references-keys. Elements within schedules use a job-key to reference the data elements in the jobs element.

\section{c) Common Data Elements}

See Sections 2.2 and 2.3 for a discussion of these common data attributes and elements used by this element: child-work-items, cost-summary, customers, description, due-dates, identifier, name, number, parameters, part-quantities, precedent-constraints, priority-rating, repetition-count, resources-required, revisions, type, work-actual-progress, and work-scheduled-progress.

\subsection{Tasks}

tasks specifies the hierarchy of task items to be processed within the shop. Precedence constraints defined in operation sheets are mapped to associated task items. Scheduling data and resource assignments for each task item are maintained in the structure, as well as other data. jobs and tasks are cross-referenced to each other as well as routing and operation sheets respectively.

The UML information model for the tasks element is shown below:

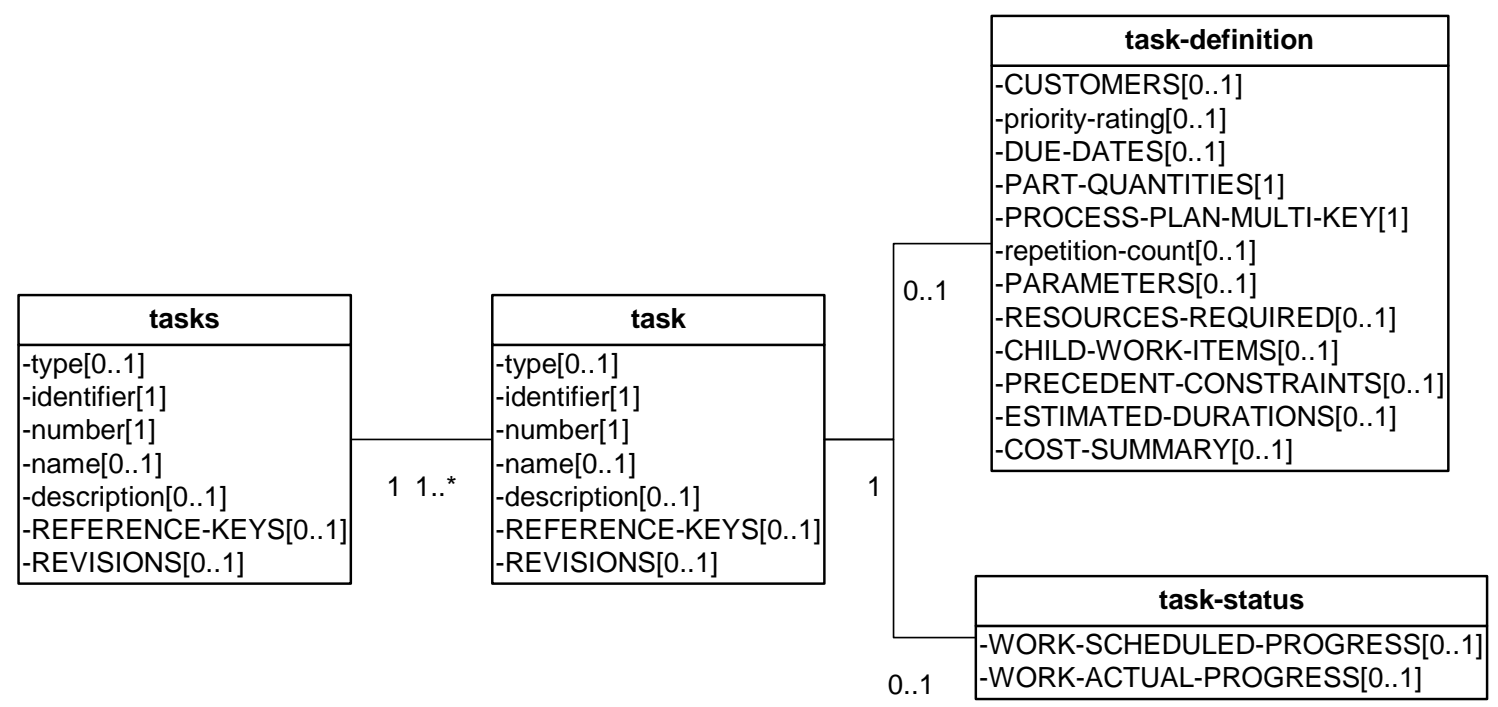

The XML structure for the tasks element is shown below: 


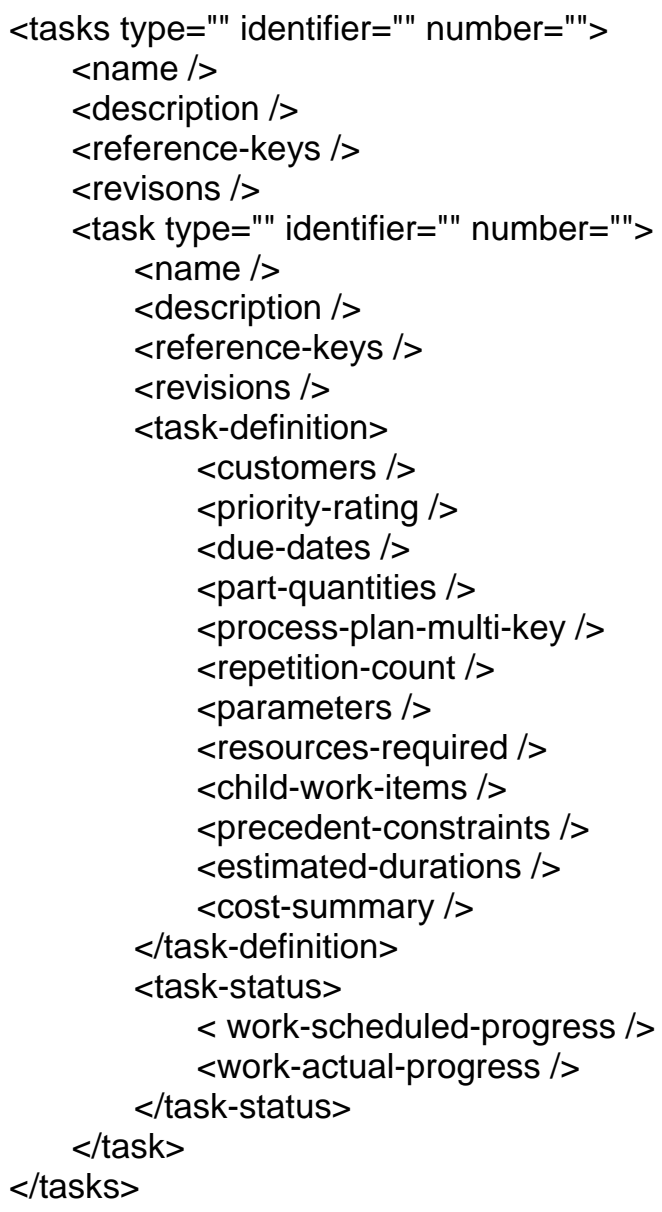

The unique data elements, data element keys, and common data elements introduced in this structure are described below.

\section{a) Unique Data Elements}

task: a child work item of a job.

task-definition: the relative priority of this task (priority-rating), critical due dates for the task (due-dates), what products are required (part-quantities), resource requirements (resources-required), precedence relationships between child work items (precedent-constraints), and summary of estimated and actual cost data (cost summary). Child work items for a task may be pick-orders or tool-orders.

tasks: a collection of individual tasks.

task-status: information about scheduled and actual progress towards completing the task. The workscheduled-progress and work-actual-progress common data elements are used to organize this information.

\section{b) Data Element Keys, Multi-keys, and Key Lists}

The following key elements are used in this structure: process-plan-multi-key and references-keys. Elements within schedules use a task-key to reference the data elements in the tasks element. 


\section{c) Common Data Elements}

See Sections 2.2 and 2.3 for a discussion of these common data attributes and elements used by this element: child-work-items, cost-summary, customers, description, due-dates, estimated-durations, identifier, name, number, parameters, part-quantities, precedent-constraints, priority-rating, repetitioncount, resources-required, revisions, type, work-actual-progress, and work-scheduled-progress.

\subsection{Maintenance Orders}

maintenance-orders specifies maintenance work to be done on machines or equipment within the shop. The UML information model for the maintenance-orders element is shown below:

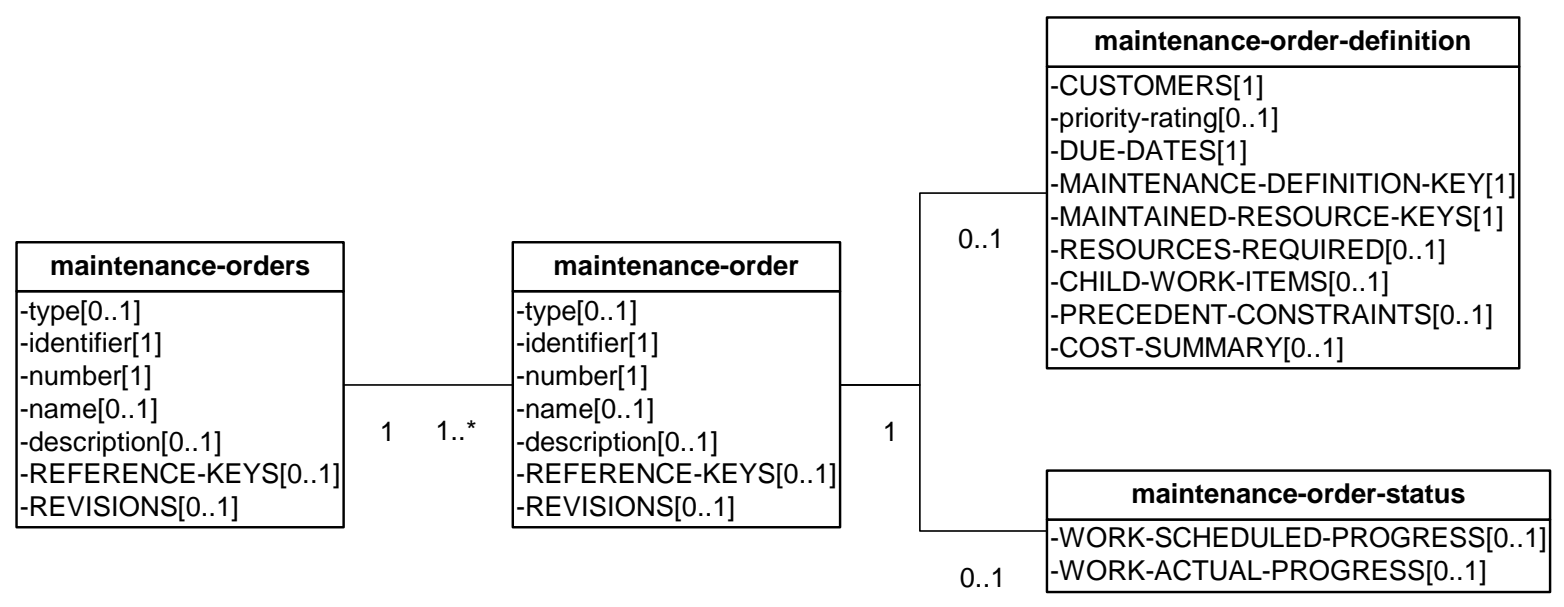

The XML structure for the maintenance-orders element is shown below:

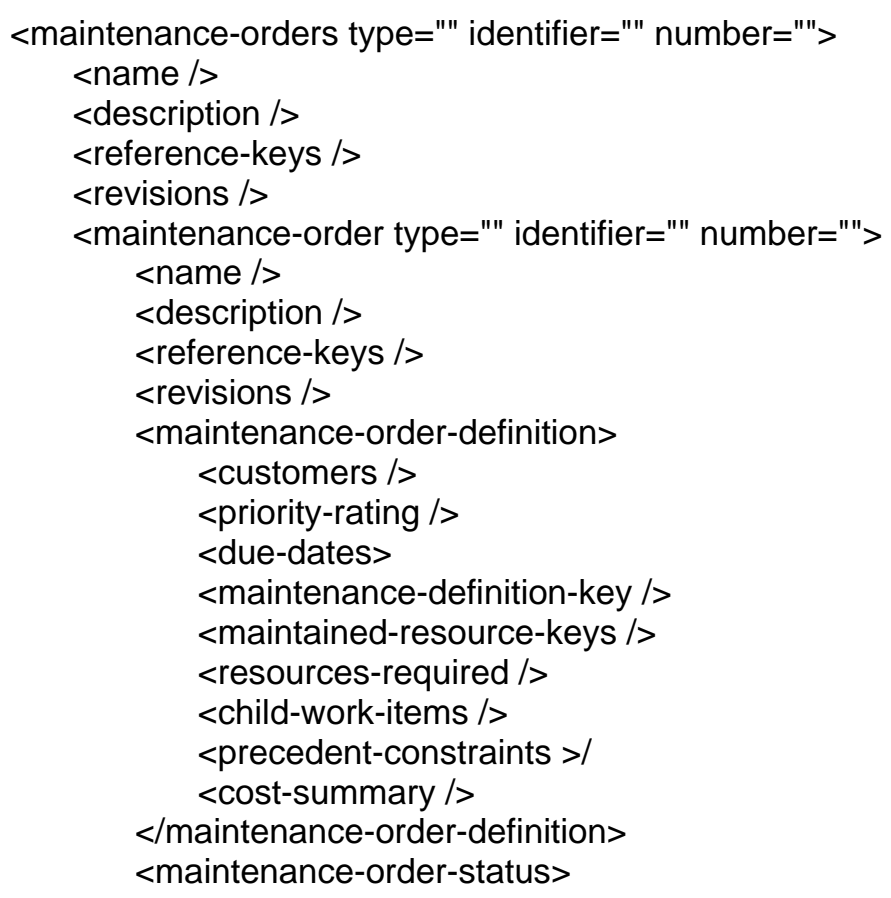




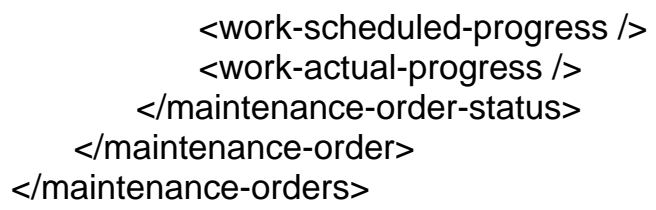

The unique data elements, data element keys, and common data elements introduced in this structure are described below.

\section{a) Unique Data Elements}

maintenance-order: an order to perform a maintenance action on one or more maintained resources.

maintenance-order-definition: a section of the maintenance order that identifies the customers, the resource to be maintained, a key to the definition of the maintenance action to be performed, resources required, child work items (typically subordinate maintenance orders), precedence relationships between child work items, and a cost summary.

maintenance-orders: a collection of maintenance orders.

maintenance-order-status: a section contained scheduled and actual progress towards completing the maintenance action.

\section{b) Data Element Keys, Multi-keys, and Key Lists}

The following keys are used in this structure: maintained-resource-keys, maintenance-definition-key, and reference-keys. Elements within schedules use a maintenance-order-key to reference the data elements in the maintenance-orders element.

\section{c) Common Data Elements}

See Sections 2.2 and 2.3 for a discussion of these common data attributes and elements used by this element: child-work-items, cost-summary, customers, description, due-dates, identifier, name, number, precedent-constraints, priority-rating, resources-required, revisions, type, work-actual-progress, and workscheduled-progress.

\subsection{Pick Orders}

pick-orders specifies orders to draw goods from inventory

The UML information model for the pick-orders element is shown below: 


\begin{tabular}{|l|}
\multicolumn{1}{|c|}{ pick-orders } \\
\hline -type[0..1] \\
-identifier[1] \\
-number[1] \\
-name[0..1] \\
-description[0..1] \\
-REFERENCE-KEYS[0..1] \\
-REVISIONS[0..1] \\
\cline { 2 - 2 }
\end{tabular}
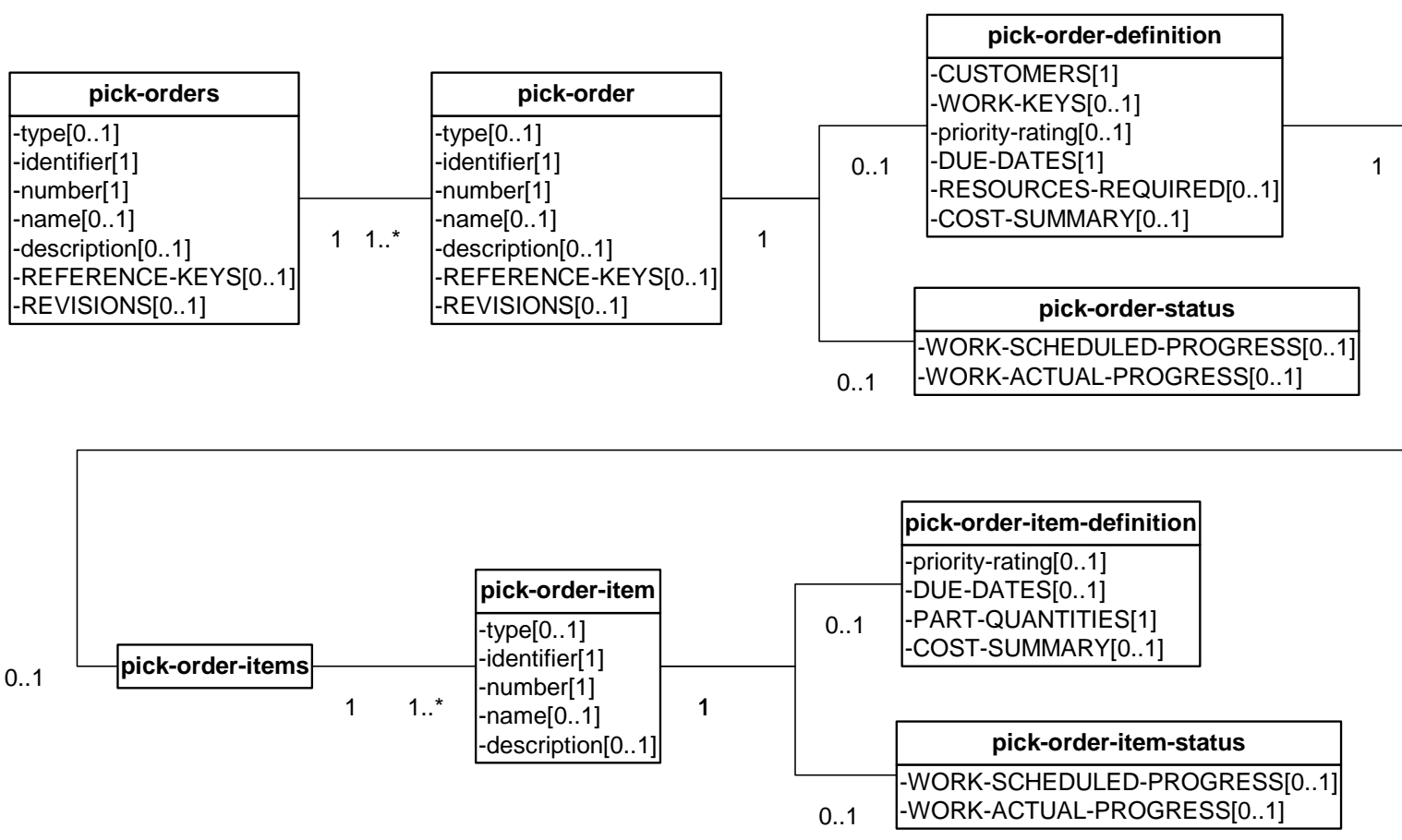

The XML structure for the pick-orders element is shown below:

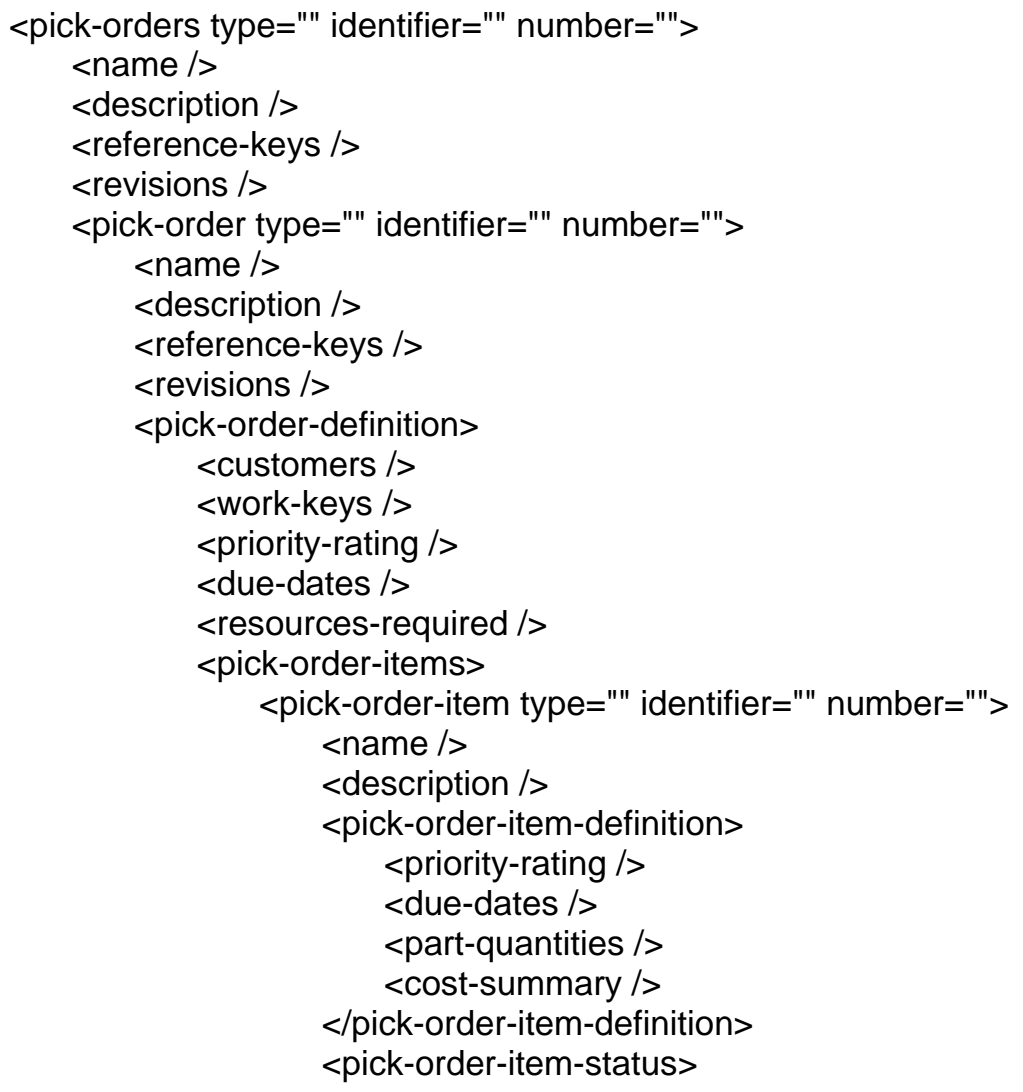




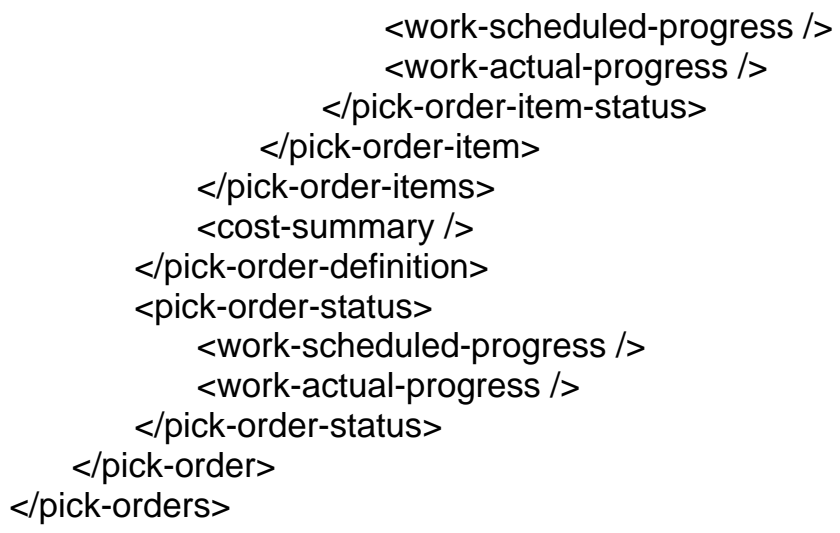

The unique data elements, data element keys, and common data elements introduced in this structure are described below.

\section{a) Unique Data Elements}

pick-order: an order to pull an item or a group of items from inventory.

pick-order-definition: a section of the pick order specifying the customer, priority rating, due dates, the work to be done, the work item that the pick order serves, the individual pick order items, resources required, etc.

pick-order-item: a specific item to be drawn from inventory.

pick-order-item-definition: specification of the details of one part item type and quantity to be drawn from inventory.

pick-order-items: a list of individual pick order items in a pick order definition.

pick-order-item-status: the status of one item to be picked in a pick order.

pick-order-status: the overall status of the pick order.

\section{b) Data Element Keys, Multi-keys, and Key Lists}

The following keys are used in this structure: reference-keys and work-keys. Elements within schedules use a pick-order-key to reference the data elements in the pick-orders element.

\section{c) Common Data Elements}

See Sections 2.2 and 2.3 for a discussion of these common data attributes and elements used by this element: cost-summary, customers, description, due-dates, identifier, name, number, part-quantities, priority-rating, resources-required, revisions, type, work-actual-progress, and work-scheduled-progress.

\subsection{Tool Orders}

tool-orders specifies orders for kitting and/or assembly of tool components and assemblies in the tool crib area.

The UML information model for the tool-orders element is shown below: 


\begin{tabular}{|c|c|c|c|c|c|c|}
\hline & & & & & & tool-order-definition \\
\hline & & & & & & \begin{tabular}{|l|}
-CUSTOMERS[0..1] \\
-priority-rating[0..1] \\
-DUE-DATES[1]
\end{tabular} \\
\hline tool-orders & & & tool-order & & & -TOOL-DEFINITION-KEY[0..*] \\
\hline $\begin{array}{l}\text {-type[0..1] } \\
\text {-identifier[1] } \\
\text {-number[1] }\end{array}$ & & & $\begin{array}{l}\text {-type[0..1] } \\
\text {-identifier[1] } \\
\text {-number[1] }\end{array}$ & & $0 . .1$ & $\begin{array}{l}\text {-RESOURCES-REQUIRED[0..1] } \\
\text {-WORK-KEYS[0..1] } \\
\text {-COST-SUMMARY[0..1] }\end{array}$ \\
\hline $\begin{array}{l}\text {-description[0..1] } \\
\text {-REFERENCE-KEYS[0..1] } \\
\text {-REVISIONS[0..1] }\end{array}$ & & 1..* & $\begin{array}{l}\text {-description[0..1] } \\
\text {-REFERENCE-KEYS[0..1] } \\
\text {-REVISIONS[0..1] }\end{array}$ & 1 & & \\
\hline & & & & & & tool-order-status \\
\hline & & & & & 0. & $\begin{array}{l}\text {-WORK-SCHEDULED-PROGRESS[0..1] } \\
\text {-WORK-ACTUAL-PROGRESS[0..1] }\end{array}$ \\
\hline
\end{tabular}

The XML structure for the tool-orders element is shown below:

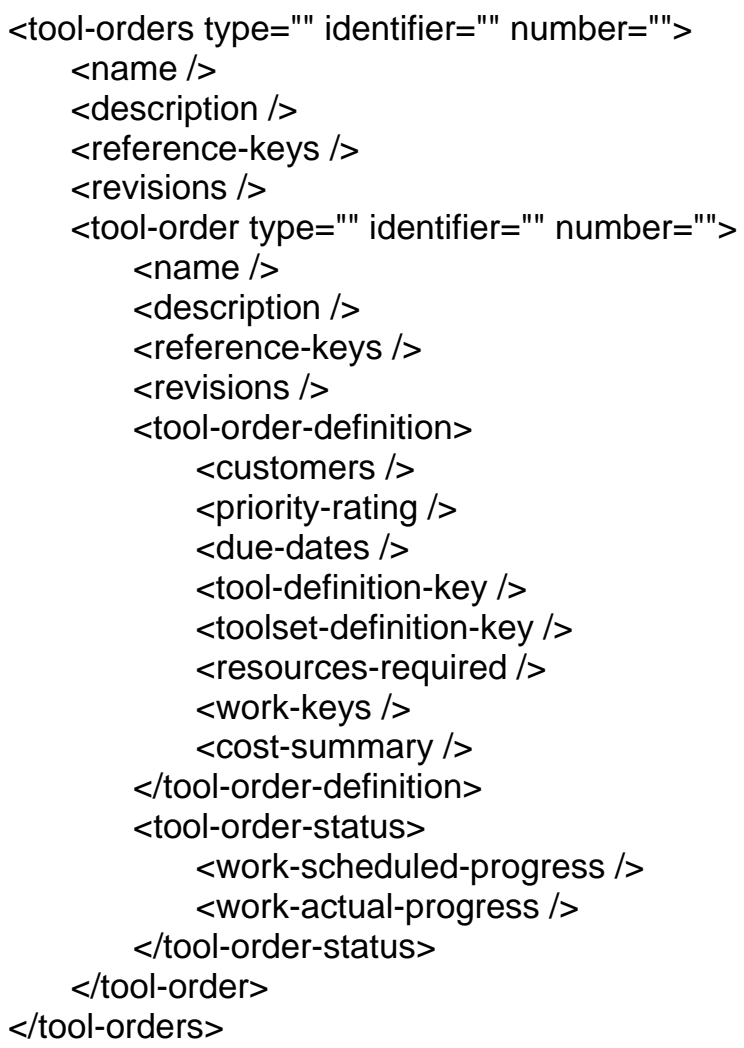

The unique data elements, data element keys, and common data elements introduced in this structure are described below. 


\section{a) Unique Data Elements}

tool-order: an order to provide a tool (tool-definition-key) or a set of tools (toolset-definition-key) from the tool crib to a specified work item (work-keys). The tool-definition-key and toolset-definition-key elements may be repeated to allow for the specification of multiple tools or tool sets in one tool order. Construction of a tool assembly may be involved. The definition of the tool or tool set in the tool catalog will identify its components.

tool-order-definition: a section of the tool order specifying the customer, priority rating, due dates, the work to be done, the work item that the tool order serves, the individual tools or tool sets ordered, resources required, etc.

tool-orders: a collection of individual tool orders.

tool-order-status: the overall status of the tool order.

\section{b) Data Element Keys, Multi-keys, and Key Lists}

The following keys are used in this structure: reference-keys, tool-definition-key, toolset-definition-key, and work-keys. Elements within schedules use a tool-order-key to reference the data elements in the tool-orders element.

\section{c) Common Data Elements}

See Sections 2.2 and 2.3 for a discussion of these common data attributes and elements used by this element: cost-summary, customers, description, due-dates, identifier, name, number, priority-rating, resources-required, revisions, type, work-actual-progress, and work-scheduled-progress.

\subsection{Schedules}

schedules lists planned assignment or mapping of work to resources (resources-section) and resources to work (work-section). In the resource-section, there are sections for each type of resource, e.g., machines, stations, employees. A schedule for a particular resource gives the key for the resource followed by a list of work assignments. In the work section, work is grouped by type, e.g., jobs, tasks, pick orders. A particular work schedule element lists the key for the work followed by a list of all resource assignments.

The high level UML information model for the schedules element is shown below:

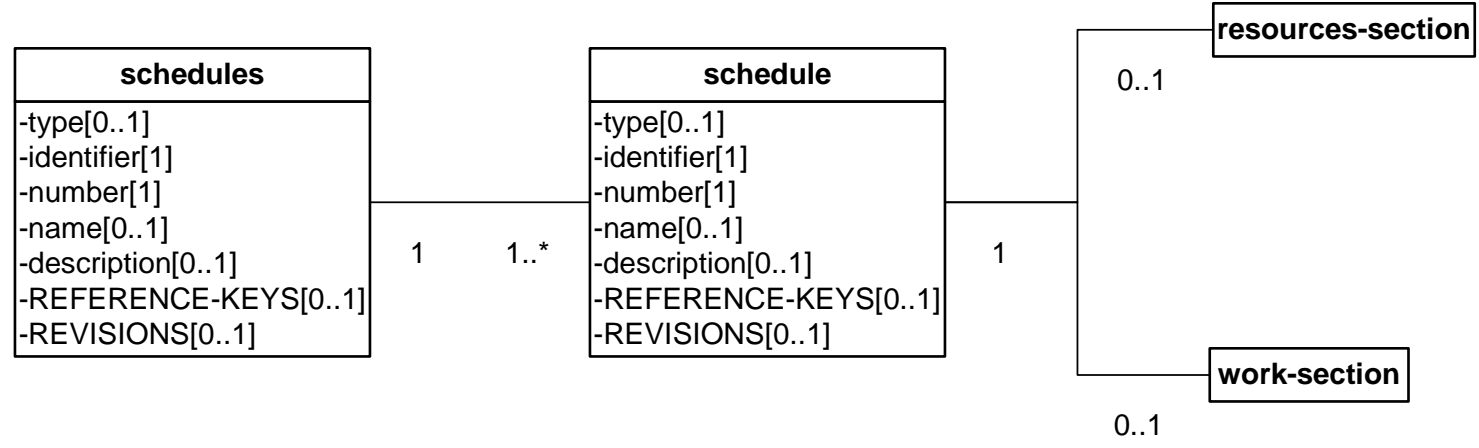

The UML information model for the resource-section of schedule element is shown below: 


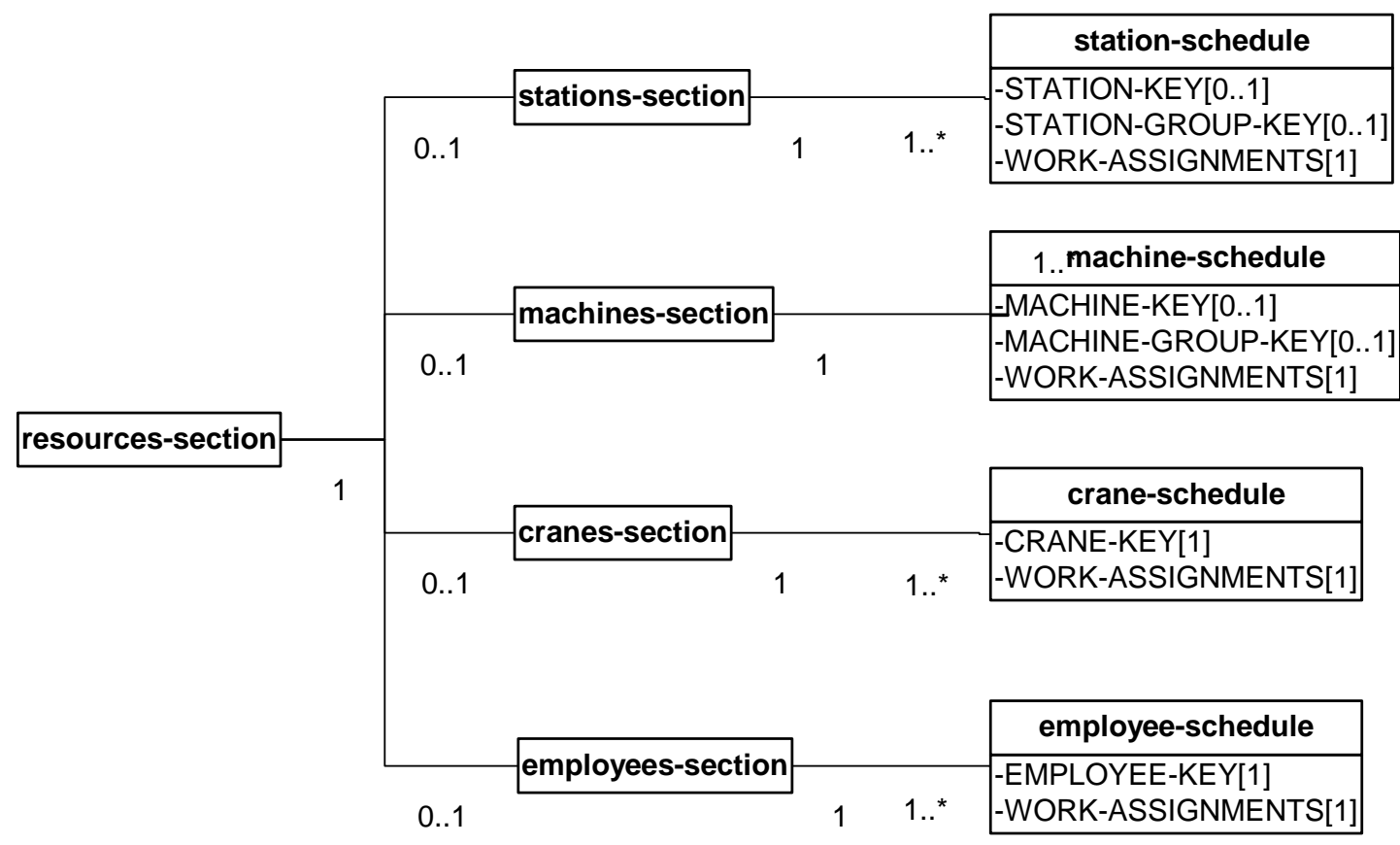

The UML information model for the work-section of schedule element is shown below:

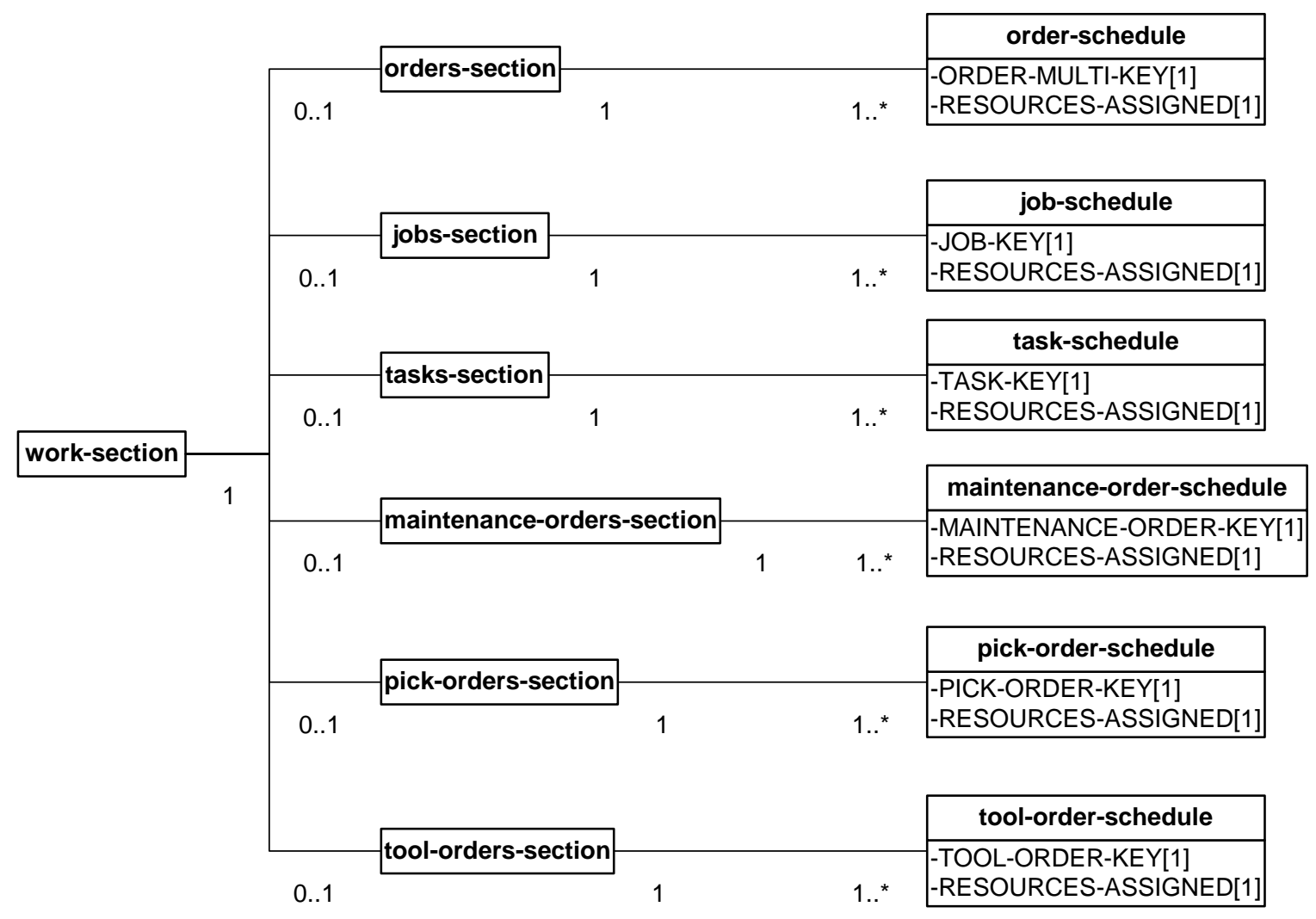


The XML structure for the schedules element is shown below:

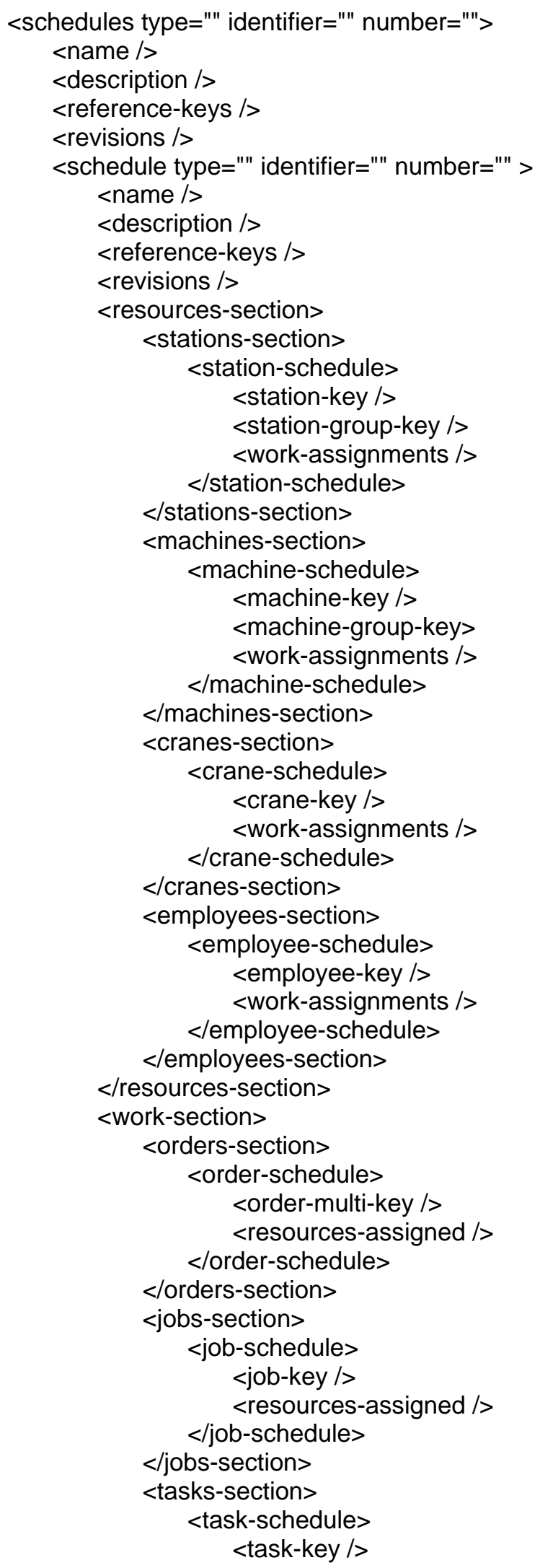




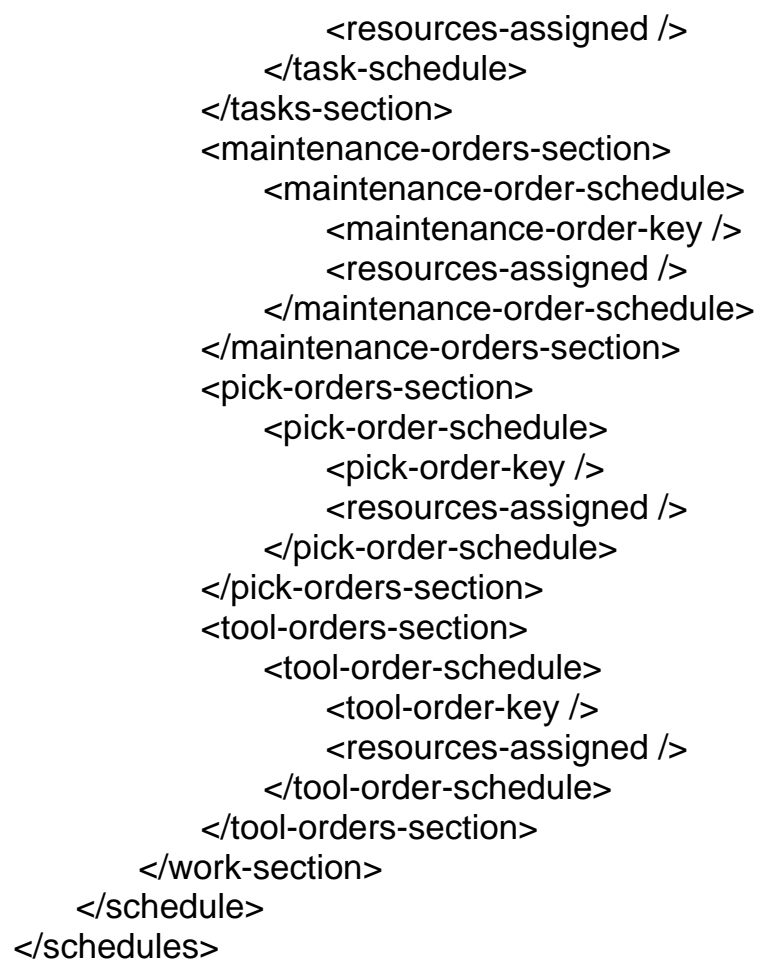

The unique data elements, data element keys, and common data elements introduced in this structure are described below.

\section{a) Unique Data Elements}

job-schedule: a schedule for an individual job that identifies the job by key and associated resource assignments.

jobs-section: the subsection of the work section where all job schedules are located.

crane-schedule: a schedule for an individual crane that identifies the crane by key and associated work assignments.

cranes-section: the subsection of the resources section where all crane schedules are located.

employee-schedule: a schedule for an individual employee that identifies the employee by key and associated work assignments.

employees-section: the subsection of the resources section where all employee schedules are located.

machine-schedule: a schedule for an individual machine that identifies the machine by key and associated work assignments.

machines-section: the subsection of the resources section where all machine schedules are located.

maintenance-order-schedule: a schedule for an individual maintenance order that identifies the maintenance order by key and associated resource assignments.

maintenance-orders-section: the subsection of the work section where all maintenance order schedules are located. 
order-schedule: a schedule for an individual order that identifies the order by key and associated resource assignments.

orders-section: the subsection of the work section where all production order schedules are located.

pick-order-schedule: a schedule for an individual pick order that identifies the pick order by key and associated resource assignments.

pick-orders-section: the subsection of the work section where all pick order schedules are located.

resources-section: the section of a schedule where all resource schedules are located, e.g., machine, station, employee, crane schedules.

schedule: an instance of a schedule containing a section for resource and work schedules.

schedules: a collection of resource and work schedules for the shop.

station-schedule: a schedule for an individual station that identifies the station or station group by key and associated work assignments.

stations-section: the subsection of the resources section where all station schedules are located.

task-schedule: a schedule for an individual task that identifies the task by key and associated resource assignments.

tasks-section: the subsection of the work section where all task schedules are located.

tool-order-schedule: a schedule for an individual tool order that identifies the tool order by key and associated resource assignments.

tool-orders-section: the subsection of the work section where all tool order schedules are located.

work-section: the section of a schedule where all work schedules are located, e.g., order, job, task, maintenance order, pick order, and tool order schedules.

\section{b) Data Element Keys, Multi-keys, and Key Lists}

The following keys are used in this structure: job-key, crane-key, employee-key, machine-key, maintenanceorder-key, order-multi-key, pick-order-key, reference-keys, station-key, station-group-key, task-key, and tool-order-key. Resource keys are used to identify the resource whose work assignments are being scheduled. Work keys are used to identify the order, job, task, etc. whose resource assignments are being scheduled.

\section{c) Common Data Elements}

See Sections 2.2 and 2.3 for a discussion of these common data attributes and elements used by this element: description, identifier, name, number, resources-assigned, revisions, type, and work-assignments.

\subsection{Time Sheets}

time-sheets provides a list of individual time sheet elements. A time-sheet is used to log the hours that employee works, the time employee takes off from work, and accrual of leave hours.

The UML information model for the time-sheets element is shown below: 


\begin{tabular}{|c|c|c|c|}
\hline & & & \\
\hline & & & time-sheet \\
\hline & & & \begin{tabular}{|l}
-type[0..1] \\
-identifier[1]
\end{tabular} \\
\hline time-sheets & & & -number[1] \\
\hline -type[0..1] & & & [-FMPI OY..1] \\
\hline -identifier[1] & & & -pay-period[1] \\
\hline -number[1] & & & -overtime-eligibility[0..1] \\
\hline -name[0..1] & & & -hours-regular-time $[0 . .1]$ \\
\hline -description[0..1] & 1 & 1...* & -hours-overtime[0..1] \\
\hline -REFERENCE-KEYS[0..1] & & & -hours-vacation[0..1] \\
\hline -REVISIONS[0..1] & & & -hours-sick-leave[0..1] \\
\hline & & & -hours-holiday[0..1] \\
\hline & & & -hours-unpaid[0..1] \\
\hline & & & $\begin{array}{l}\text {-total-hours }[0 . .1] \\
\text {-total-days-absent[0..1] }\end{array}$ \\
\hline
\end{tabular}

The XML structure for the time-sheets element is shown below:

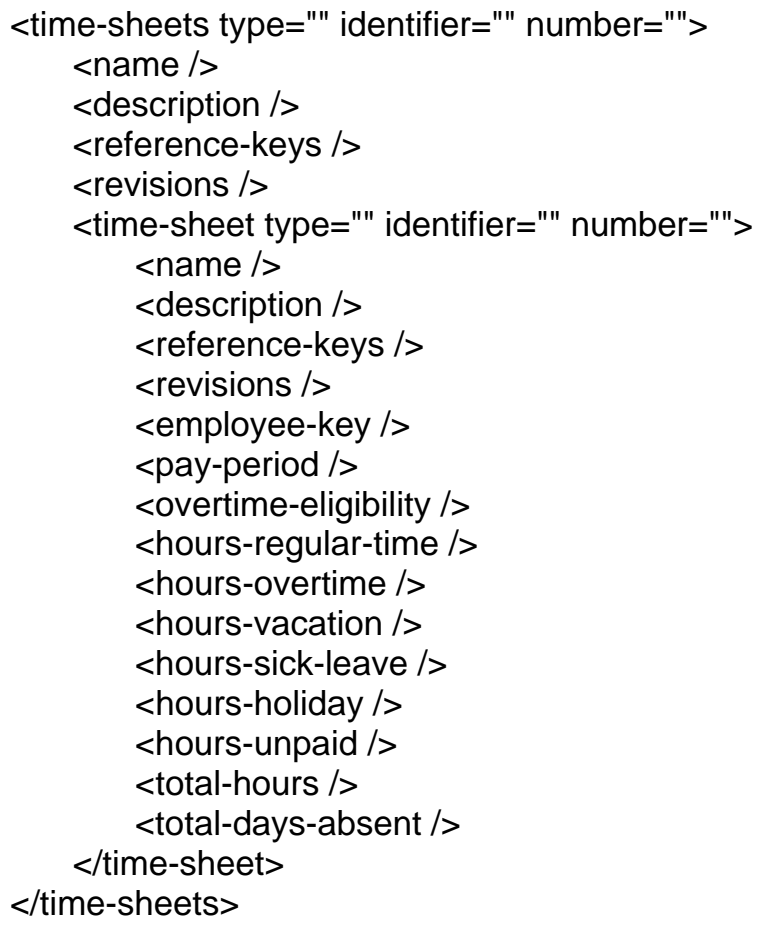

The unique data elements, data element keys, and common data elements introduced in this structure are described below.

\section{a) Unique Data Elements}

hours-holiday: hours of holiday time charged in this pay period.

hours-overtime: hours of overtime charged in this pay period.

hours-regular-time: hours of regular time charged in this pay period. 
hours-sick-leave: hours of sick leave time charged in this pay period.

hours-unpaid: hours of unpaid time recorded in this pay period.

hours-vacation: hours of vacation time charged in this pay period.

overtime-eligibility: eligibility for overtime pay.

pay-period: the number of the pay period in the current fiscal year.

time-sheet: a time sheet for an individual employee indicated by an employee key.

time-sheets: a collection of time sheets.

total-days-absent: total days absent for sick leave during the current fiscal year.

total-hours: total hours charged this pay period all work and leave categories.

\section{b) Data Element Keys, Multi-keys, and Key Lists}

The following keys are used in this structure: employee-key and reference-keys.

\section{c) Common Data Elements}

See Sections 2.2 and 2.3 for a discussion of these common data attributes and elements used by this element: description, identifier, name, number, revisions, and type.

\subsection{References}

references describes the information about the reference materials that support or further define the data elements contained within the shop data structure. A reference material may be in a digital or paper form. references is defined by a type, an identifier, a number, a name, a description, a revisions, and one or more reference data elements. The data associated with reference are the following: identifier, number, name, revisions, digital-files, and paper-document. digital-files specifies the reference that is stored in electronic form. paper-document specifies the reference that is stored in paper form.

The UML information model for the references element is shown below:

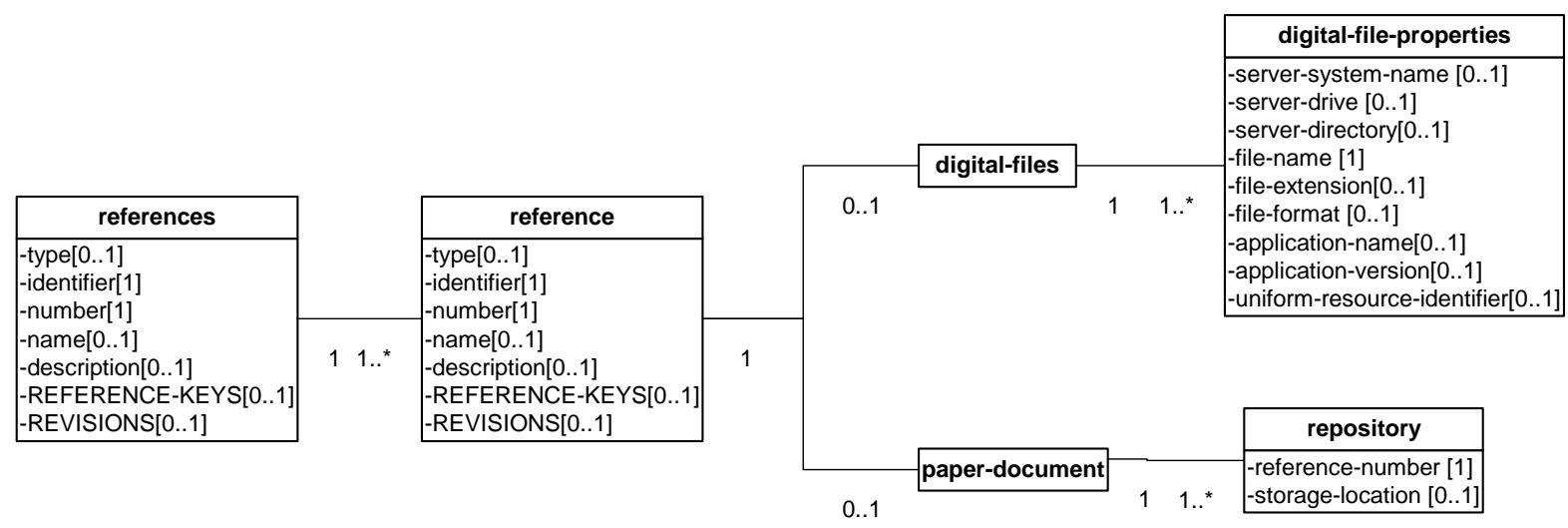


The XML structure for the references element is shown below:

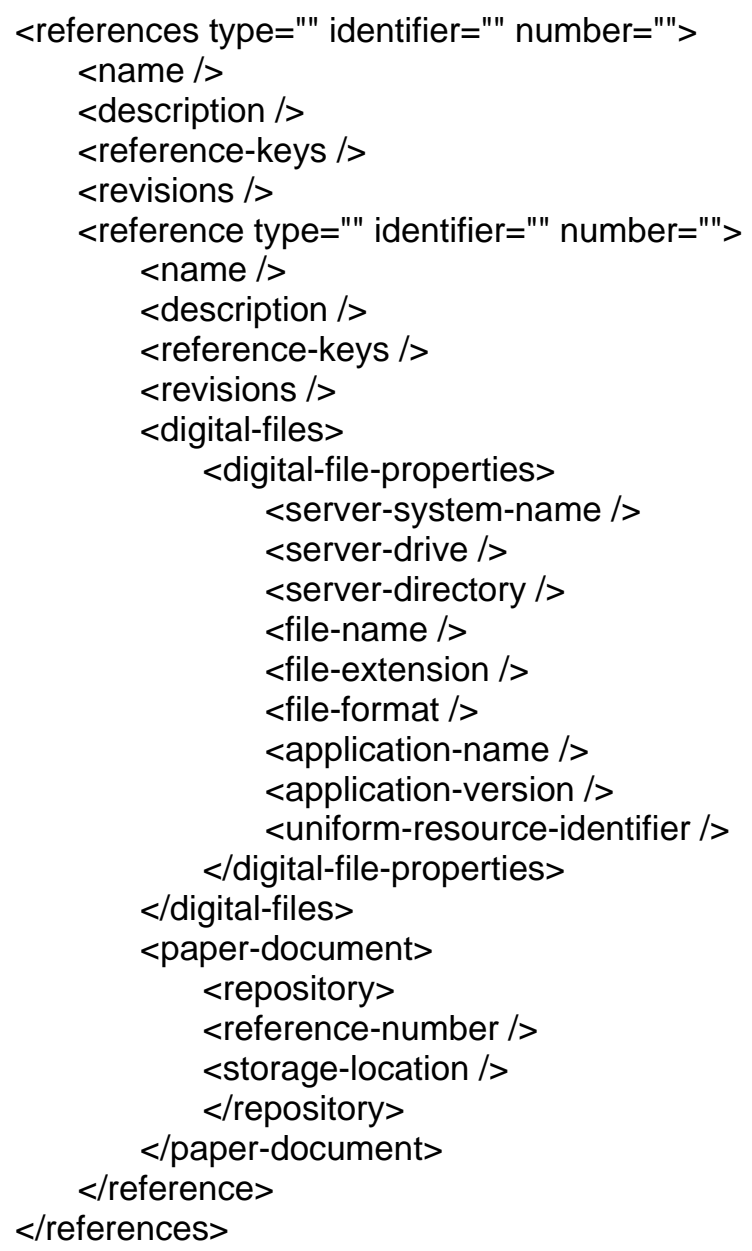

The unique data elements, data element keys, and common data elements introduced in this structure are described below.

\section{a) Unique Data Elements}

application-name: the name of the application system that used to save digital document.

application-version: the version of the application system that used to save digital document.

digital-file-properties: information describes how and where a digital file is stored.

digital-files: information about a reference that is stored in electronic form. It is presented by a repository data element.

file-extension: the file extension used by the digital document.

file-format: the file format used by the digital document.

file-name: the file name that the digital document stores.

paper-document: information about a reference that is stored in paper form. It is presented by a repository data element 
reference-number: the reference number that used to keep track the paper document.

references: a collection of one or more references.

repository: a mechanism that gathers information about the resource, format, or location of a reference. It is represented by the following data elements: server-system-name, server-drive, server-directory, filename, file-format, application-name, application-version, and uniform-resource-indicator if the reference is a digital document, or the following data elements: reference-number, and storage-location if the reference is a paper document.

server-directory: the name of the server directory that the digital document stores.

server-drive: digital-document: the server drive that the digital document stores.

server-system-name: the name of the server system that the digital document stores.

storage-location: the paper document's storage location.

uniform-resource-identifier: the uniform resource indicator (URI) that the digital document resides.

\section{b) Data Element Keys, Multi-keys, and Key Lists}

The reference-keys element is used in this structure.

\section{c) Common Data Elements}

See Sections 2.2 and 2.3 for a discussion of these common data attributes and elements used by this element: identifier, type, number, name, description, and revisions.

\subsection{Probability Distributions}

probability-distributions specifies distributions that are used to vary processing times, breakdown and repair times, availability of resources, etc. Distributions may be referenced from elsewhere using the keystructure, or may be specified within the structure by providing the distribution coefficient values.

It is represented by the following data elements: type, identifier, number, name, description, and probability-distribution-set.

The UML information model for the probability-distributions element is shown below:

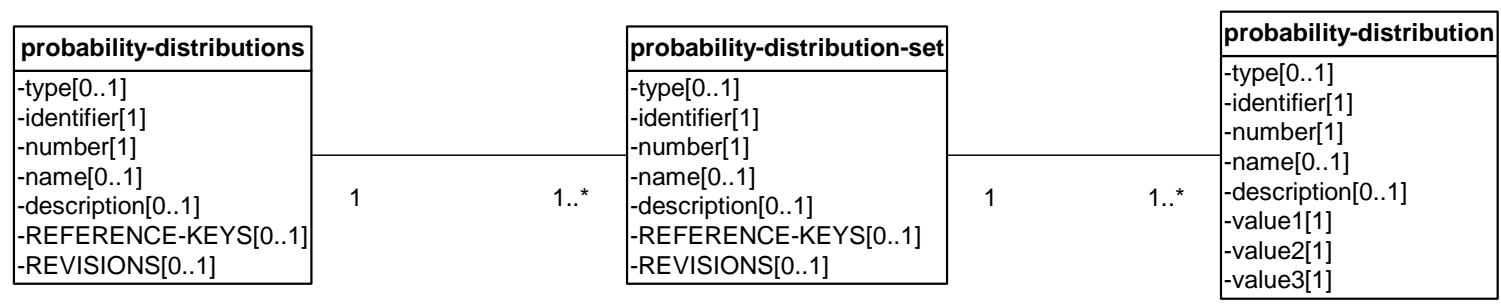

The XML structure for the probability-distributions element is shown below:

<probability-distributions type="'" identifier="'" number="'"> 


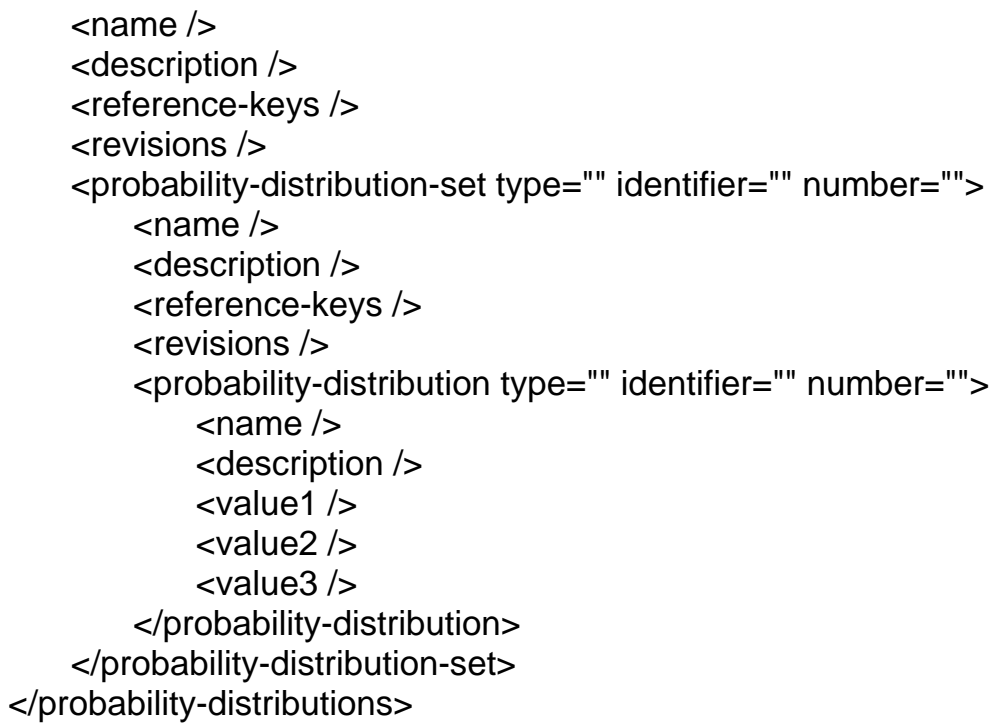

The unique data elements, data element keys, and common data elements introduced in this structure are described below.

\section{a) Unique Data Elements}

probability-distribution: a distribution that is used to vary processing times, breakdown and repair times, availability of resources, etc. It is represented by the following data elements: type, identifier, number, name, description, value1, value2, and value3; value1, value2 and value3 are distribution coefficients.

probability-distributions: a collection of one or more probability distributions.

probability-distribution-set: a collection of probability-distribution data elements. It is represented by the following data elements: type, identifier, number, name, description, probability-distribution, and reference-keys.

\section{b) Data Element Keys, Multi-keys, and Key Lists}

The reference-keys element is used in this structure. Elements within estimated-durations, through the duration-distributions element, use a probability-distribution-key to reference the data elements in the probability-distributions element.

\section{c) Common Data Elements}

See Sections 2.2 and 2.3 for a discussion of these common data attributes and elements used by this element: type, identifier, number, name, description, revisions, type, value1, value2, and value3. 
[ISO 1994] "ISO 10303-1, Part 1: Overview and Fundamental Principles. Industrial Automation Systems and Integration - Product Data Representation and Exchange,” ISO 10303, International Organization for Standardization, Geneva, Switzerland, 1994.

[Kemmerer 1997] Kemmerer, Sharon, and Fowler, James E., "Initial Manufacturing Exchange Specification (IMES), IMES Concept Document For Manufacturing Systems Integration,” NISTIR 5978, National Institute of Standards and Technology, Gaithersburg, MD, 1997.

[NIST 2003] National Institute of Standards and Technology (NIST), Systems Integration for Manufacturing Applications, 2003, Available online via http://www.mel.nist.gov/msid/sima/sima.htm

[OMG 2003] Object Management Group (OMG), Unified Modeling Language, 2003, Available online via http://www.omg.org/uml/

[SISO 2005] Simulation Interoperability Standards Organization (SISO), Simulation Interoperability Standards Organization, 2005, Available online via http://www.sisostds.org/

[W3C 2000] World Wide Web Consortium (W3C), Extensible Markup Language (XML) 1.0 (second edition), 2000, Available online via http://www.w3.org/TR/REC-xml.html 
APPENDIX A - DATA ELEMENT ENUMERATIONS

\begin{tabular}{|c|c|c|}
\hline Data Element & Source & Enumeration Items \\
\hline behavior & layout & TBD \\
\hline controller-type & machine-program, machines & TBD \\
\hline day-name & calendars & [SUN, MON, TUE, WED, THR, FRI, SAT] \\
\hline day-number & calendars & {$[0,1,2,3,4,5,6]$} \\
\hline efficiency-rating & machines & TBD \\
\hline employment-status & employees & $\begin{array}{l}\text { [FULL-TIME, PART-TIME, } \\
\text { CONTRACTOR, LAID-OFF, FORMER- } \\
\text { EMPLOYEE] }\end{array}$ \\
\hline file-format & references & [WORD, TEXT, ....] \\
\hline logical-relationship & $\begin{array}{l}\text { child-work-items, plan- } \\
\text { definition, precedent- } \\
\text { constraints }\end{array}$ & [TRUE, FALSE, UNKNOWN] \\
\hline maintenance-state & cranes, machines, stations & $\begin{array}{l}\text { [COMPLETED, UNDER-REPAIR, TO-BE- } \\
\text { REPAIR, UNKNOWN] }\end{array}$ \\
\hline material-type & materials-inventory & \\
\hline operational-state & cranes, machines, stations & $\begin{array}{l}\text { [BUSY, IDLE, RESERVED, OUT-OF- } \\
\text { ORDER] }\end{array}$ \\
\hline operation-subtype & operation-definitions & TBD \\
\hline operation-type & operation-definitions & TBD \\
\hline overtime-eligibility & employees, time-sheets & [YES, NO] \\
\hline priority-rating & departments, organizations & {$[1,2,3,4,5]$} \\
\hline priority-rating & procurements & [REGULAR, URGENT] \\
\hline priority-rating & work & [HOT, HOT-HOT, REGULAR] \\
\hline salary-type & employees & TBD \\
\hline status-code & $\begin{array}{l}\text { inventory, work-actual- } \\
\text { progress, work-scheduled- } \\
\text { progress }\end{array}$ & $\begin{array}{l}\text { [EXISTING, NOT-EXISTING, IN-ORDER, } \\
\text { PENDING, ACCEPTED, RELEASED, IN- } \\
\text { PROCESS, COMPLETE, CANCELLED] }\end{array}$ \\
\hline units (angular-units) & units-of-measurement & [DEGREE, RADIAN] \\
\hline units (currency-units) & units-of-measurement & [DOLLARS, EUROS, YENS] \\
\hline units (distance-units) & units-of-measurement & $\begin{array}{l}\text { [MILE, FOOT, INCH, KILOMETER, } \\
\text { METER, CENTIMETER, YARD] }\end{array}$ \\
\hline units (length-units) & units-of-measurement & $\begin{array}{l}\text { [MILE, FOOT, INCH, KILOMETER, } \\
\text { METER, CENTIMETER] }\end{array}$ \\
\hline units (mass-units) & units-of-measurement & $\begin{array}{l}\text { [TON, POUND, OUNCE, KILOGRAM, } \\
\text { GRAM] }\end{array}$ \\
\hline units (speed-units) & units-of-measurement & [MILES/HOUR, KILOMETERS/HOUR] \\
\hline $\begin{array}{l}\text { units (time-duration- } \\
\text { units) }\end{array}$ & units-of-measurement & $\begin{array}{l}\text { [YEARS, WEEKS, DAYS, HOURS, } \\
\text { MINUTES, SECONDS] }\end{array}$ \\
\hline units (volume-units) & units-of-measurement & $\begin{array}{l}\text { [OUNCE, MILLILITER, LITER, } \\
\text { GALLON, CUBICFEET, CUBICMETER, } \\
\text { CUBICINCH, CUBICCENTIMETER] }\end{array}$ \\
\hline
\end{tabular}


APPENDIX B - DATA ELEMENT FORMATS

\begin{tabular}{ll}
\hline Data Element & Format \\
\hline capacity & REAL \\
coefficient & REAL \\
cost & REAL /dddddddd.cc (refer to units-of-measurements) \\
date & yyyy-mm-dd \\
duration & REAL/ ddd.cc (refer to units-of-measurements) \\
horsepower & REAL \\
periodicity & REAL \\
time & hh:mm:ss \\
value (of parameter) & REAL \\
\hline
\end{tabular}

